Aus der Klinik für Hämatologie und Medizinische Onkologie

(Prof. Dr. med. L. Trümper)

der Medizinischen Fakultät der Universität Göttingen

\title{
Wnt-Signalwegsanalysen während der Metastasierung von Mamma-Karzinomen
}

\author{
INAUGURAL-DISSERTATION \\ zur Erlangung des Doktorgrades \\ der Medizinischen Fakultät der \\ Georg-August-Universität zu Göttingen \\ vorgelegt von \\ Antonia Schubert \\ aus Dresden
}

Göttingen 2016 
Dekan:

1. Berichterstatter:

2. Berichterstatter:

3. Berichterstatter:

Tag der mündlichen Prüfung:
Prof. Dr. rer. nat. H. K. Kroemer

Prof. Dr. med. T. Pukrop

Prof. Dr. rer. nat. H. Bastians

Prof. Dr. med. dent. R. Mausberg

21. November 2016 



\section{Inhaltsverzeichnis}

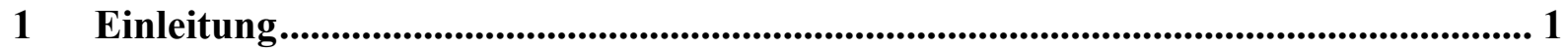

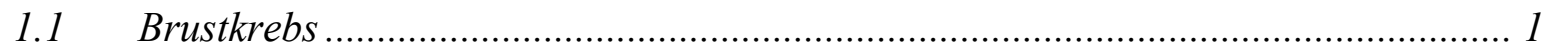

1.2 Tumorprogression, Metastasierung und Tumormikroenvironement ....................... 2

1.3 Epithelial-mesenchymale Transition (EMT) ........................................................ 4

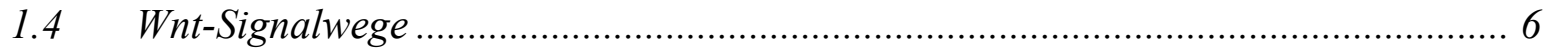

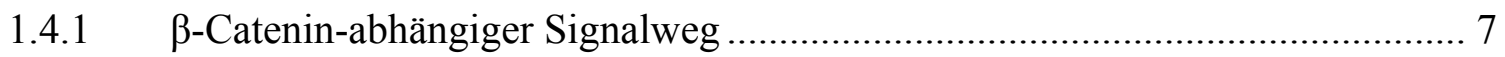

1.4.2 $\beta$-Catenin-unabhängige Wnt-Signalwege ................................................ 9

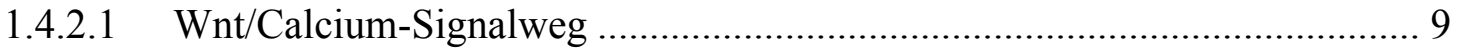

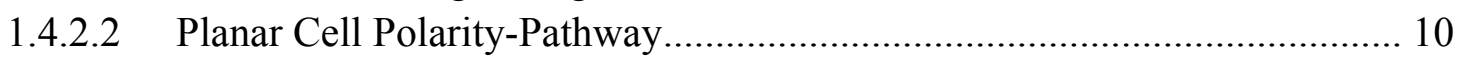

1.4.2.3 $\beta$-Catenin-unabhängige Signalwege über ROR ...................................... 12

1.5 Dishevelled als Schaltprotein kanonischer und nicht-kanonischer Signalwege...... 16

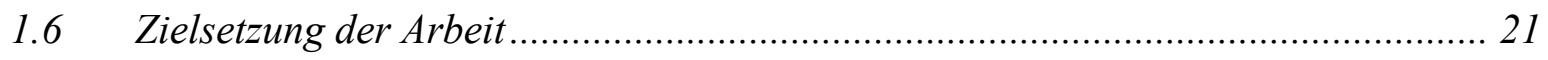

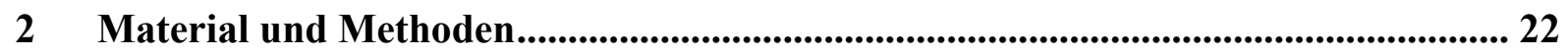

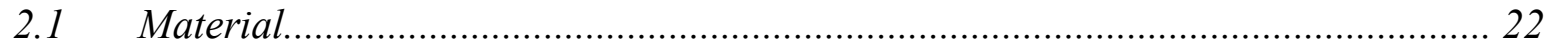

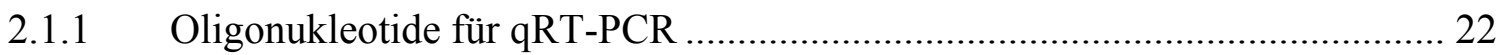

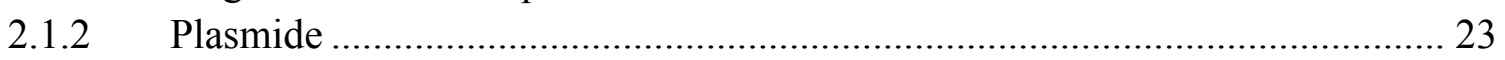

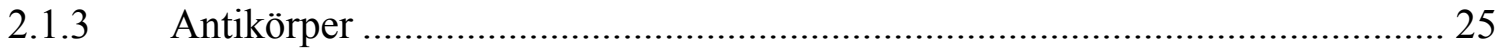

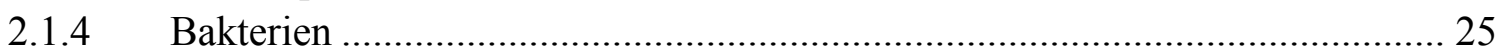

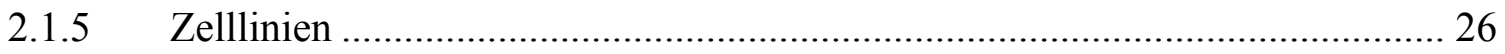

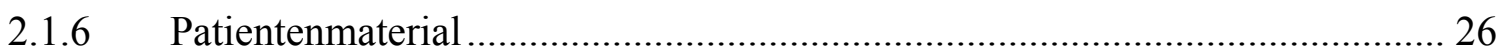

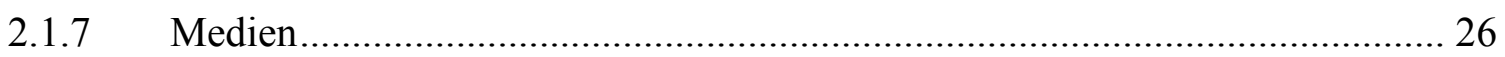

2.1.7.1 Medien für die Bakterienkultur .......................................................... 26

2.1.7.2 Medien für die eukaryontische Zellkultur ................................................. 27

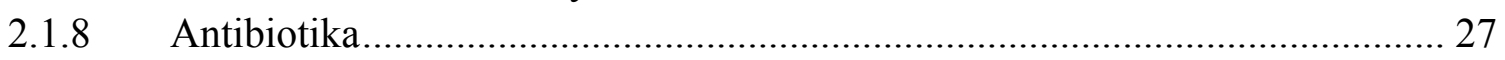

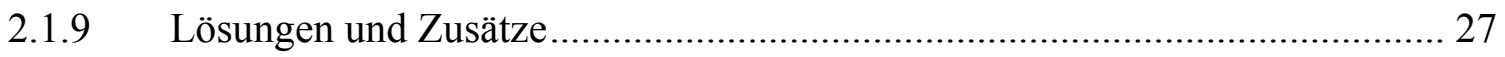

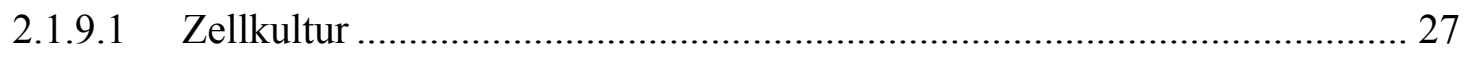

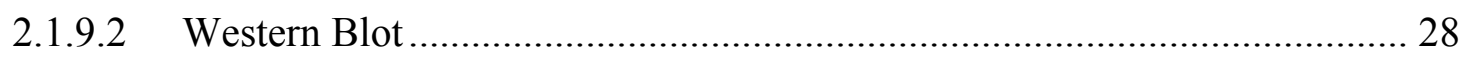

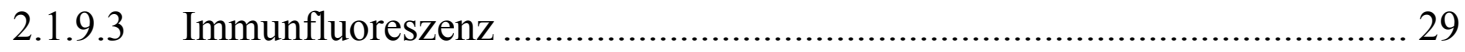

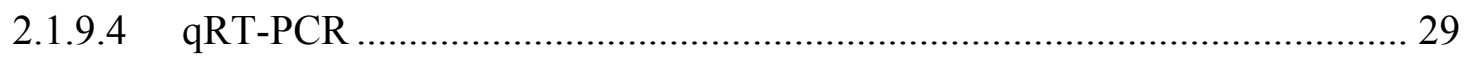

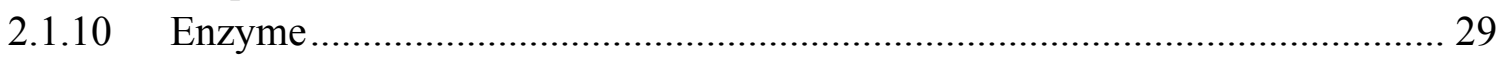

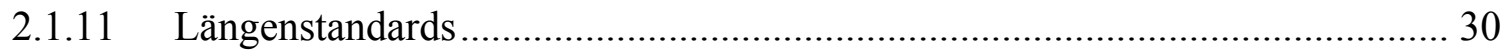

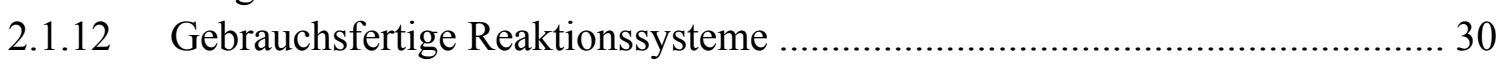

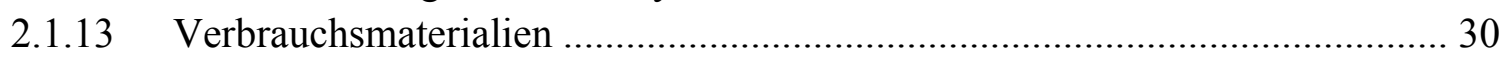

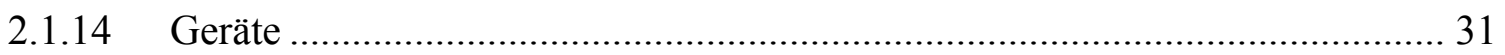

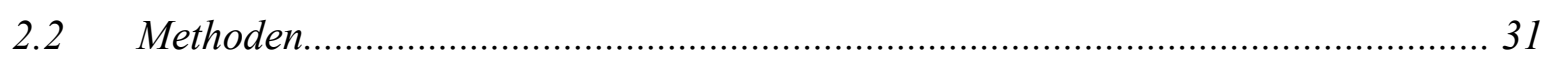

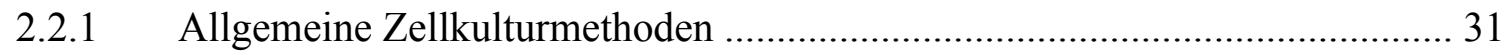

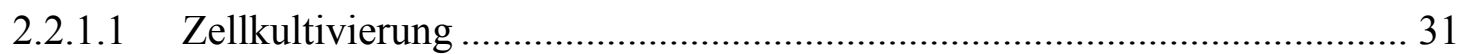

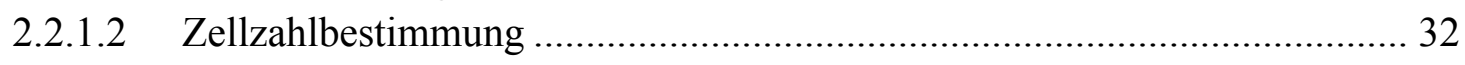

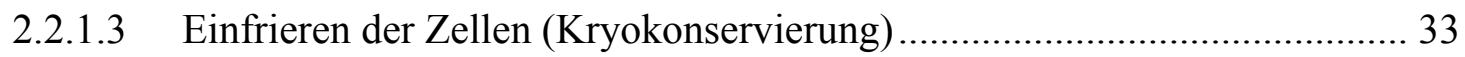




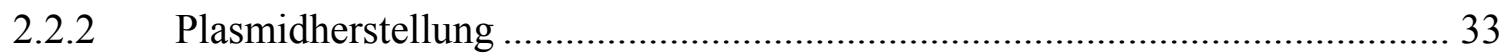

2.2.2.1 Transformation von kompetenten Bakterien .............................................. 33

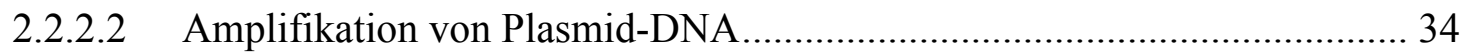

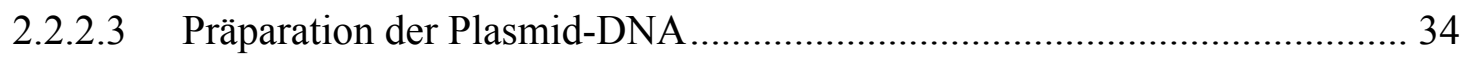

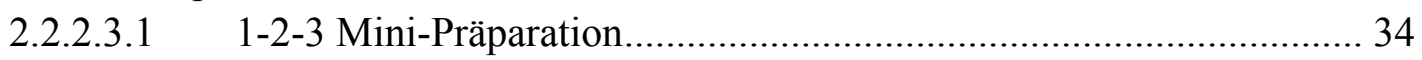

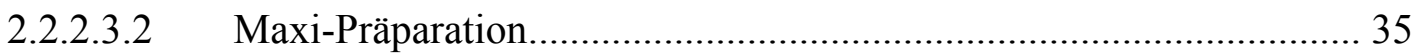

2.2.2.4 Bestimmung der DNA-Konzentration durch die NanoDrop ${ }^{\text {TM-Methode ... } 36}$

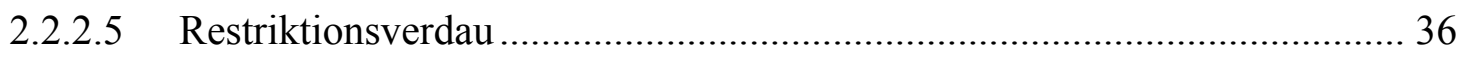

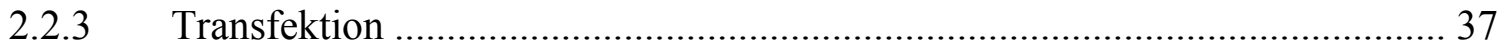

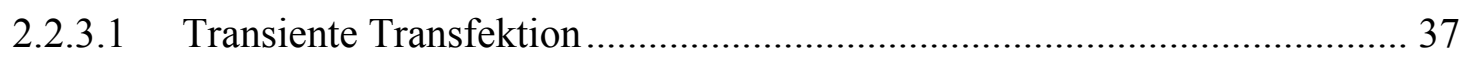

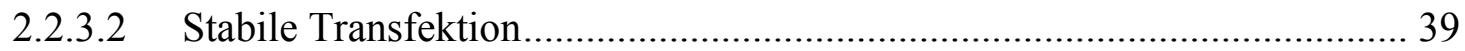

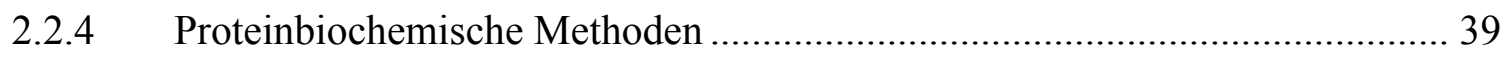

2.2.4.1 Herstellung von Zelllysaten für den Western Blot ..................................... 39

2.2.4.2 Zellauftrennung: Zytosol/Zellkerne/Membran ........................................... 40

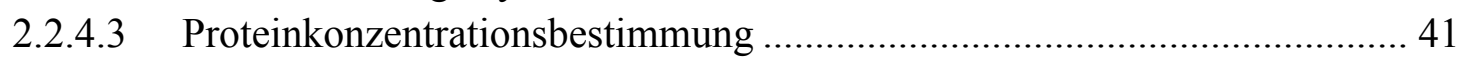

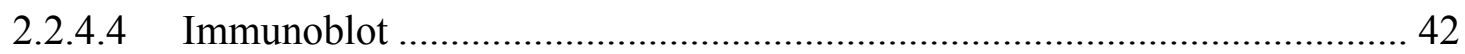

2.2.4.5 Diskontinuierliche Proteinelektrophorese im SDS-Polyacrylamidgel ........ 43

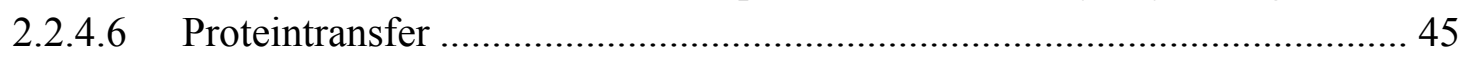

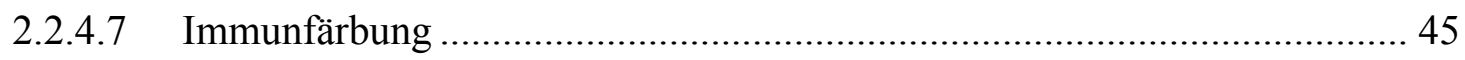

2.2.5 Quantitative Echtzeit-Polymerase-Kettenreaktion (RT-qPCR) ...................... 46

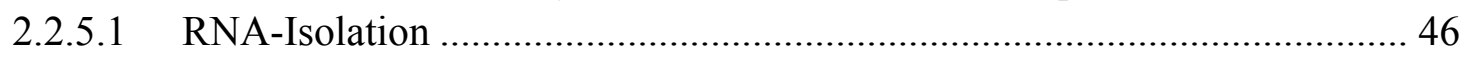

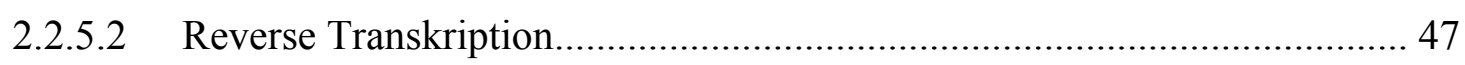

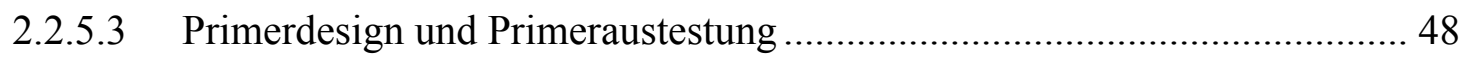

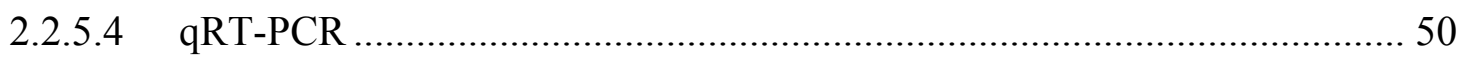

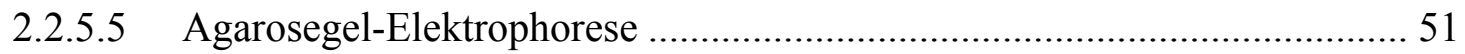

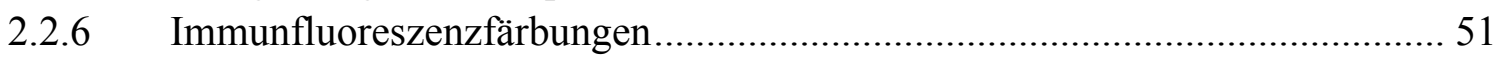

2.2.6.1 Indirekte Einfach-Immunfluoreszenzfärbung ........................................ 51

2.2.6.2 Morphologie der Zellen im Konfrontationsassay ....................................... 52

2.2.6.2.1 Aussaat der Zellen.................................................................. 53

2.2.6.2.2 Kleben der Konfrontation im 2-Loch-Kammerobjektträger .............. 53

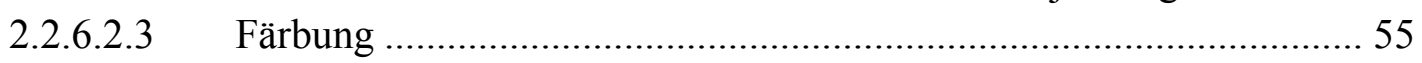

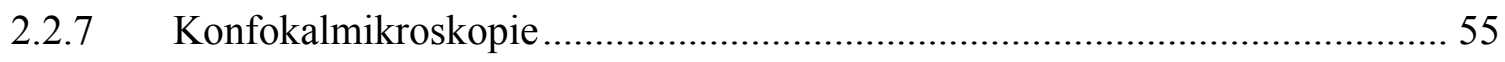

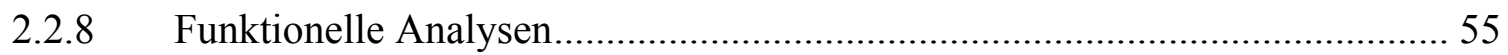

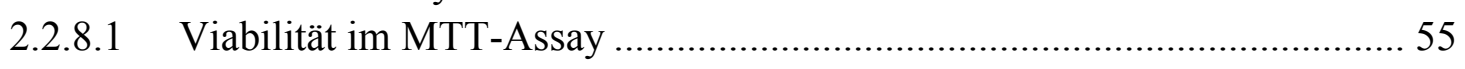

2.2.8.2 Wanderungsgeschwindigkeit im Migrationsassay ................................... 56

2.2.8.3 Proliferation und Cell Index im $x$ CELLigence ${ }^{\circledR}$........................................ 57

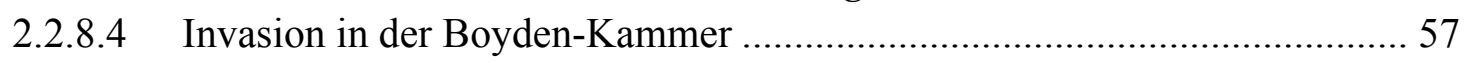

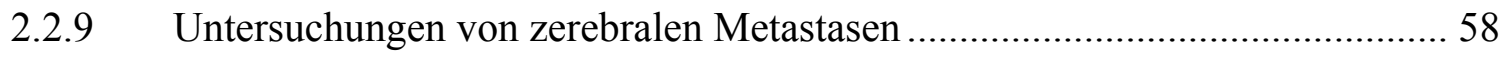

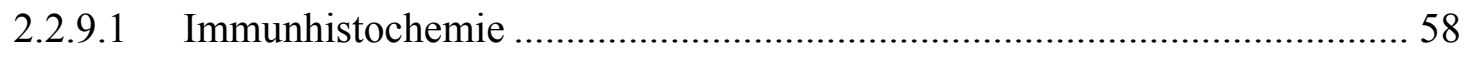

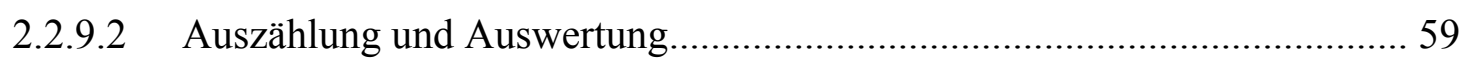

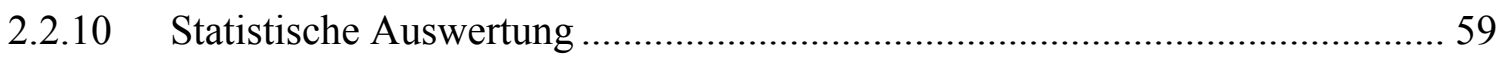


3.1 Charakterisierung der Brustkrebslinien hTERT-HME1, MCF-7, SkBr3 und MDA$M B 231$.

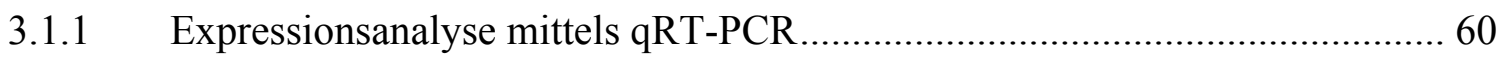

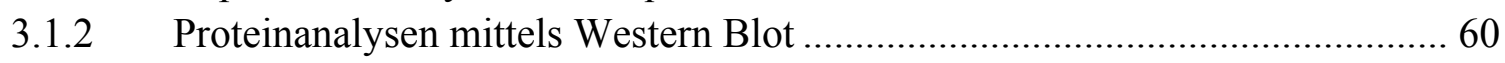

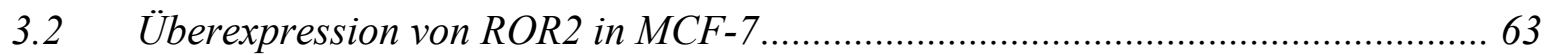

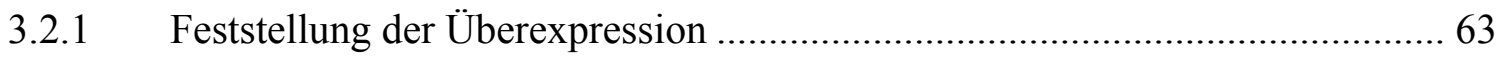

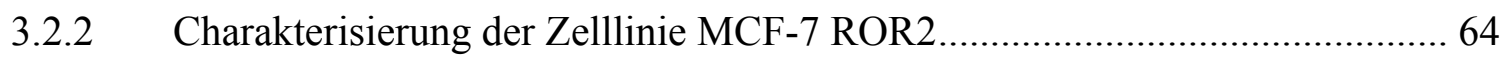

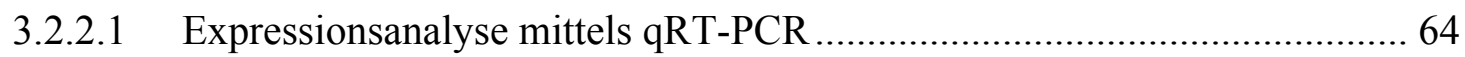

3.2.2.1.1 Die Überexpression von ROR2 führt zu einem Anstieg des $m R N A$ Gehalts für ROR1 in der qRT-PCR ................................................. 65

3.2.2.1.2 $\quad m R N A$-Konzentrationen der EMT-Marker Vimentin und Snail1 reduzierten sich in der qRT-PCR statistisch signifikant ................... 65

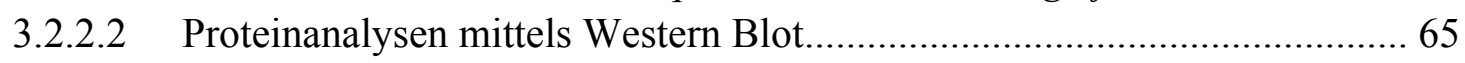

3.2.2.2.1 Zunahme des Signals für DVL3 im Western Blot .............................. 65

3.2.2.2.2 ROR2 hat allenfalls leichten inhibitorischen Einfluss auf die Aktivierung von $\beta$-Catenin ............................................................. 65

3.2.2.2.3 ROR2-Überexpression führt zur Akkumulation von p-JNK und c-

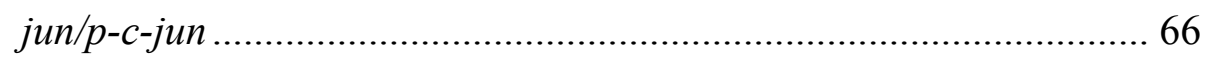

3.2.3 Funktionelle Untersuchung der Zelllinie MCF-7 ROR2 ............................... 67

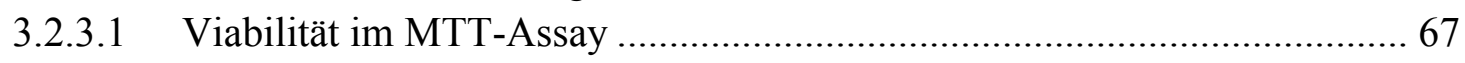

3.2.3.1.1 Die Viabilität der Zellen wird durch eine Überexpression von ROR2

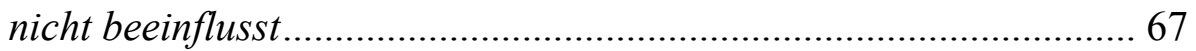

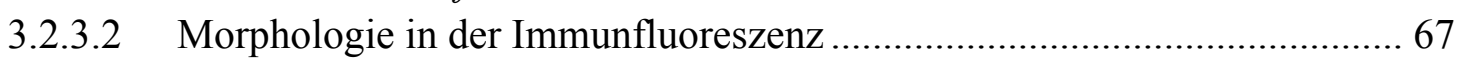

3.2.3.2.1 Die Überexpression von ROR2 bewirkt morphologische

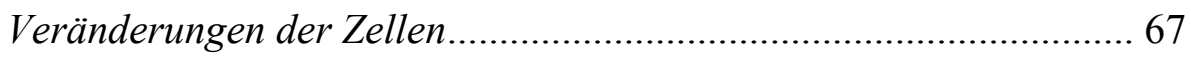

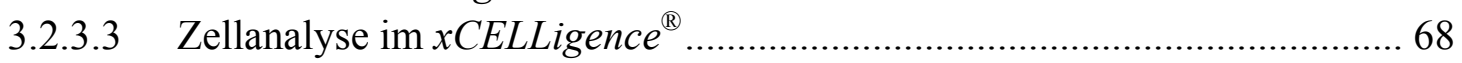

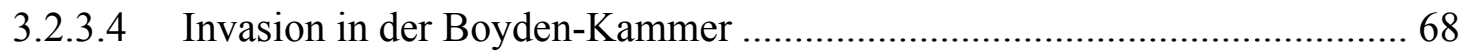

3.2.3.4.1 ROR2 steigert die Invasivität der Zellen signifikant .......................... 68

3.2.3.4.2 Durch Inhibition von JNK wird der Invasivitätsanstieg unterbunden 68

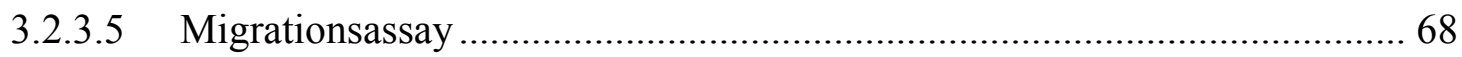

3.3 Überexpression von DVL3 wt und verschiedenen DVL3-Konstrukten in MCF-7-

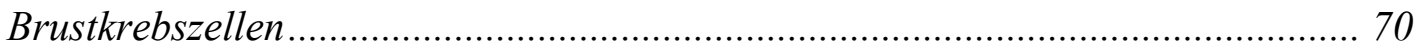

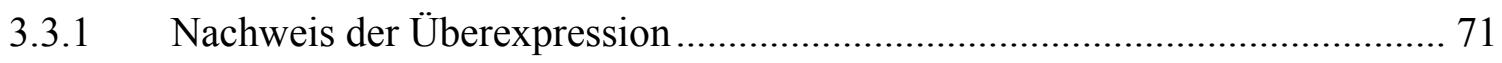

3.3.2 Charakterisierung der stabil in MCF-7 transfizierten DVL3-Konstrukte ........ 71

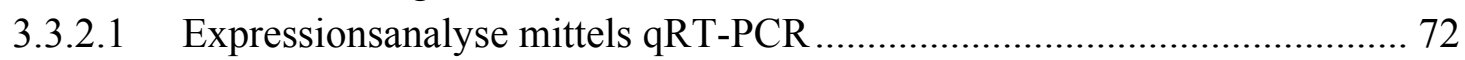

3.3.2.1.1 Das Konstrukt $\triangle D I X \triangle P D Z \triangle D E P$ führt zum Anstieg der mRNA für

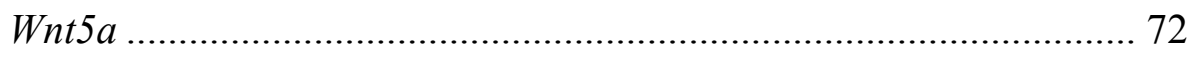

3.3.2.1.2 DVL3-Überexpression führt zu einem Anstieg der ROR-mRNA in Abhängigkeit von den Domänen PDZ und DEP .............................. 72

3.3.2.1.3 DVL3 wt-Überexpression führt zur verminderten $m R N A$-Expression von DVL2; DVL1 mRNA wird nicht beeinflusst............................. 72

3.3.2.1.4 DVL3-Überexpression hat geringen Einfluss auf die hier untersuchten EMT-Marker ........................................................................... 72

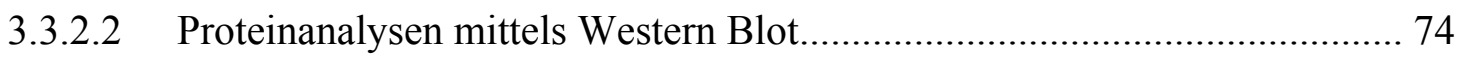


3.3.2.2.1 Die Überexpression von DVL3 wt führt zu keiner Akkumulation von $\beta$ Catenin 74

3.3.2.2.2 Das Konstrukt DVL3 $\triangle D I X$ inhibiert die Akkumulation von $\beta$-Catenin in Zytosol- und Kernfraktion ohne Einfluss auf die $\beta$-Catenin-

Gesamtproteinmenge.

3.3.2.2.3 Die Überexpression von DVL3 wt führt allenfalls zu einer diskreten Zunahme der Phosphorylierung von JNK.

3.3.3 Funktionelle Untersuchung der stabil in MCF-7 transfizierten DVL3-

Konstrukte 75

3.3.3.1 Morphologie in der Immunfluoreszenz ..................................................... 75

3.3.3.1.1 Durch Überexpression der DVL3-Konstrukte kam es zu keiner in der Immunfluoreszenz sichtbaren morphologischen Veränderung der

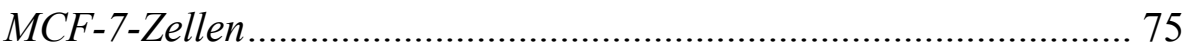

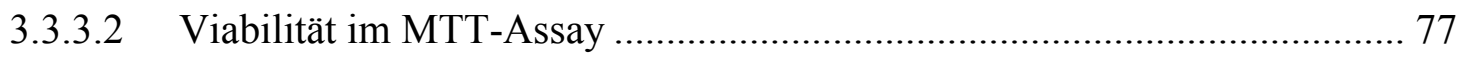

3.3.3.2.1 Die Viabilität der Zellen wird durch eine Überexpression der DVL3-

Konstrukte nicht beeinflusst ............................................................... 77

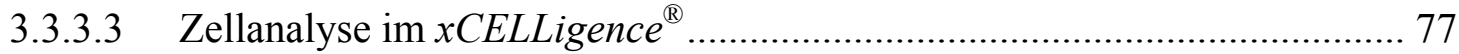

3.3.3.3.1 DVL3 wt zeigt einen verminderten Cell Index im $x$ CELLigence ${ }^{\circledR}-$

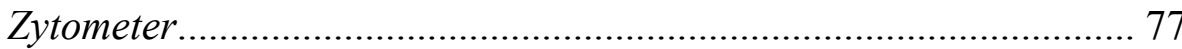

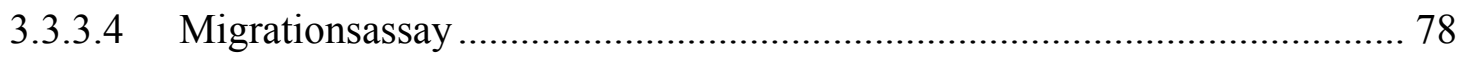

3.3.3.4.1 DVL3 wt reduziert die Migrationsgeschwindigkeit der Zellen in der Ebene unabhängig vom hochkonservierten C-Terminus .................. 78

3.3.3.5 Invasion in der Boyden-Kammer .......................................................... 78

3.3.3.5.1 DVL3 steigert die Invasivität der Zellen in der Boyden-Kammer...... 78

3.3.4 Untersuchung intrazellulärer Aggregate ..................................................... 80

3.3.4.1.1 DVL3 bildet dynamische Aggregate in Abhängigkeit vom

Vorhandensein der DIX-Domäne .................................................... 80

3.4 DVL3 in zerebralen Mamma-Karzinommetastasen ......................................... 82

3.4.1 Untersuchungen von Zytoplasma und Nukleus auf DVL3 …......................... 82

3.4.1.1 Zytoplasmatisches DVL3 ist in einem Großteil der Hirnmetastasen nachweisbar .............................................................................. 82

3.4.1.2 Die Patientenproben unterscheiden sich sowohl in der Anzahl wie auch der Intensität der Anfärbbarkeit des Zytoplasmas auf DVL3 .......................... 83

3.4.1.3 DVL3 ist nukleär nachweisbar, jedoch nicht in allen Proben gleichermaßen

3.4.1.4 Korrelation von zytoplasmatischem und nukleärem DVL3-Gehalt............. 83

4.1 Die Aussagekraft einzelner Spieler der Wnt-Signalwege über den Malignitätsgrad kultivierter Zelllinien ......................................................................................... 86

4.2 ROR2 beeinflusst die Morphologie hin zu einem mesenchymalen Phänotyp .......... 87

4.3 Die Überexpression von ROR2 in Brustkrebszellen führt zu keiner Steigerung der Tumorzellmigration ohne Exposition mit exogenem Wnt5a 
4.4 Die Überexpression von ROR2 in Brustkrebszellen steigert die Invasivität unabhängig von $\beta$-Catenin über die Aktivierung von JNK und c-jun.

4.5 Die Überexpression von ROR2 führt zu einer Akkumulation von DVL3 in Zytosol und Kern.

4.6 Auswirkung der DVL3-Überexpression auf die Aktivierung von $\beta$-Catenin ........... 92

4.7 DVL3 steigert $\beta$-Catenin-unabhängig die Invasivität der Brustkrebszellen............ 94

4.8 Die Überexpression von DVL3 inhibiert die Tumorzellmigration ohne Exposition mit exogenem Wnt5a.

4.9 DVL3 bildet dynamische Aggregate in Abhängigkeit vom Vorhandensein der DIXDomäne......

4.10 Die Lokalisation der DVL3-Konstrukte in Zytoplasma und Nukleus ................... 102

4.11 Aufgaben von DVL abseits der Rezeptor-abhängigen Funktionen........................ 104

4.12 Signalwege über DVL und ROR2 -mehr gemeinsame Schnittmeng-en als bisher angenommen?

4.13 Wnt-Signalwege als komplexes Netzwerk von Signalkaskaden ........................... 106

4.14 Bedeutung von EMT in Brustkrebs ..................................................................... 108

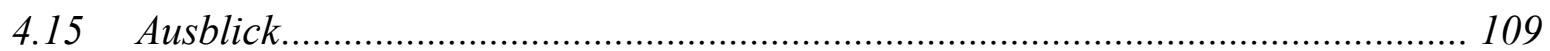

4.15.1 ROR2 als ein potentieller Angriffspunkt einer spezifizierten, personalisierten Tumortherapie des Brustkrebs. 109

4.15.2 Die DEP-Domäne von DVL3 ist ein potentieller therapeutischer Angriffspunkt für Patientinnen mit Tumoren und Metastasen mit DVL3-Überexpression .. 110

4.15.3 Die DIX-Domäne von DVL3 ist ein potentieller therapeutischer Angriffspunkt in Tumoren, in denen eine Aktivierung von $\beta$-Catenin für die Tumorprogression von Bedeutung ist

6 Literaturverzeichnis

7 Anhang.

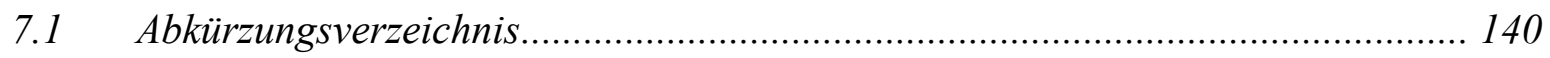

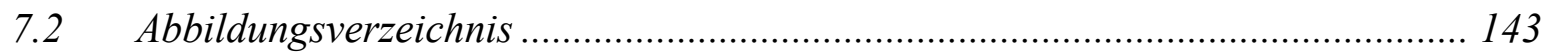

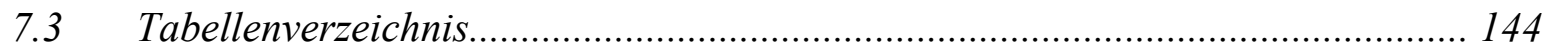

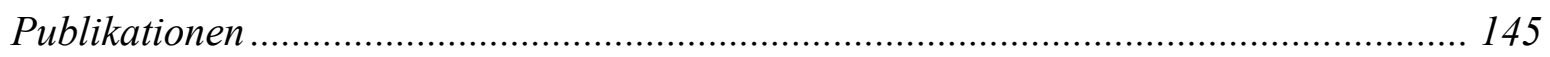

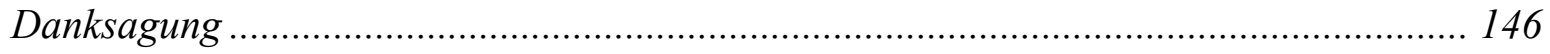

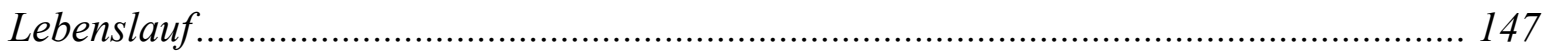




\section{$1 \quad$ Einleitung}

\subsection{Brustkrebs}

Das Mamma-Karzinom ist in der westlichen Welt der häufigste bösartige Tumor bei Frauen. Und trotz der Verbesserung der Früherkennungsprogramme und der Therapiestrategien bei Operation, Strahlen-, Chemo- und eventuell Hormontherapie sterben immer noch mehr Frauen an Brustkrebs als an einer anderen malignen Erkrankung.

Nach Angaben des Robert Koch-Instituts (RKI) lag die Neuerkrankungsrate in Deutschland im Jahr 2010 bei 70.340 Patientinnen'; 17.466 Frauen erlagen 2010 ihrer Erkrankung oder verstarben an deren Folgen. Für das Jahr 2014 wurden sogar 75.200 Diagnosestellungen prognostiziert. Die relative 5-Jahres-Überlebensrate des Mamma-Karzinoms liegt bei $87 \%$. Dies ist vor allem von schwerwiegender Bedeutung, da etwa jede vierte Patientin bereits vor dem 55. Lebensjahr erkrankt, jede zehnte Patientin sogar bereits vor dem 45. Lebensjahr (Krebs in Deutschland 2013).

Als positive Entwicklung ist anzuführen, dass trotz Zunahme der Neuerkrankungen heutzutage weniger Frauen an Brustkrebs versterben, als noch vor 20 Jahren. Nicht nur die Therapiefortschritte sind hierfür ein wesentlicher Faktor (Early Breast Cancer Trialists' Collaborative Group 2012), von neuen Früherkennungsprogrammen -wie der jährlichen Tastuntersuchung der Brust für Frauen ab 30 oder dem seit 2008 eingeführten Mammographie-Screening, zu dem alle Frauen zwischen dem 50. und 69. Lebensjahr alle 24 Monate eingeladen werden- wird im allgemeinen eine weitere Senkung der Mortalität erwartet.

Heutzutage wird der Brustkrebs früher erkannt als je zuvor, Therapiestrategien wurden und werden optimiert und mehr Frauen leben nach abgeschlossener Primärtherapie zum Teil über Jahrzehnte krankheitsfrei (Krebs in Deutschland 2013).

2007 klassifizierte die in St. Gallen tagende Konsensuskonferenz Risikogruppen für Brustkrebsrezidive, um anhand dieser die adjuvante Therapie zu optimieren und zielgerecht einzusetzen. Sie wiesen dem Vorhandensein von Lymphknotenmetastasen, besonders wenn diese die Anzal von drei überschreiten, ein erhöhtes Risiko zu (Goldhirsch et al. 2007).

\footnotetext{
${ }^{1}$ Nur ein Prozent der Neuerkrankungen betreffen Männer (Backe 2002). Auf Grund dieser Rarität wird in der vorliegenden Arbeit auf das Mamma-Karzinom der Frau fokussiert.
} 
Lokale Rezidive, regionale und Fernmetastasen treffen die dann zum Teil als „geheilt“ bezeichneten Patientinnen besonders schwerwiegend, denn bei Fernmetastasen sinkt die relative 5-Jahres-Überlebensrate auf circa $10 \%$ und die meisten Patientinnen versterben am metastasierten Brustkrebs (Chevallier et al. 1995, Khayat und Antoine 1997).

Folglich ist es von größter Bedeutung, Metastasierungsprozesse des Mamma-Karzinoms besser $\mathrm{zu}$ verstehen und zielgerichtete Therapien $\mathrm{zu}$ entwickeln, die nicht nur den Primärtumor bekämpfen, sondern auch Absiedelungen der Zellen in andere Organe minimieren, wenn nicht sogar zu verhindern versuchen.

\subsection{Tumorprogression, Metastasierung und Tumormikroenvironement}

Die Kolonisation und das Auswachsen von Mamma-Karzinomzellen in fernliegenden Organen wird als Metastasierung bezeichnet.

Im Metastasierungsprozess lösen sich Karzinomzellen vom primären Tumor in der Brust und wandern über die Lymphe, Blut oder die Oberflächenauskleidung von Körperhöhlen in entfernte Organe (Stacker et al. 2002). Hierfür bedarf die Zelle verschiedener Funktionen, die sie im Laufe ihrer genetischen und epigenetischen Entartung neu hinzu- oder wiedergewinnt. Dieser Prozess wird auch als Tumorprogression bezeichnet und ist Voraussetzung für die Metastasierung. Stellt man diesen hoch komplexen -und zum Teil noch wenig verstandenenProzess der Tumorprogression in einem stark vereinfachten Schema dar, so besteht er aus mehreren Stufen: der Tumorinitiation (im Deutschen heute häufig bezeichnet als Karzinogenese), der Progression im Primarius und der Metastasierung (zum Vergleich siehe Bacac und Stamenkovic 2008, Hanahan und Weinberg 2000 und 2011). Während im ersten Stadium vor allem schnell eintretende, irreversible genetische Modifikationen zur Unabhängigkeit von physiologischen, wachstumsfördernen und -hemmenden Signalen führen und der programmierte Zelltod (Apoptose) ausgeschaltet wird, findet in der langsam eintretenden Promotion kein weiterer direkter DNA-Schaden statt. Hier verändert sich vor allem die biologische Potenz der Zellen, die so zunehmend anfällig werden für die Wirkung weiterer pro-onkogener, das heißt tumorfördernder Faktoren. Es findet zudem eine uneingeschränkte Replikation (klonale Expansion) mit atypischer Differenzierung zur präkanzerösen Läsion statt. Mit jedem Vermehrungszyklus steigt in dieser Phase das Risiko weiterer genetischer Alterationen. Während der malignen Transformation finden weitere Entartungsschritte statt: die Zellen erlangen die Fähigkeit, ihre genetische Instabilitiät und das unkontrollierte Wachstum auch an ihre Tochterzellen weiterzugeben; diesen ersten Schritt 
nennt man Tumorinitiation. Das Stadium der Tumorprogression im primären Tumor stellt bereits den ersten Schritt der eigentlichen Metastasierung dar. Neben einer klonalen Expansion werden die Zellen zunehmend heterogen und erlangen die Fähigkeit, Gefäßneubildung zu induziieren (Neoangiogenese). Sie lockern sich von den benachbarten Zellen des Primarius und invadieren das umliegende Gewebe. Die Neoangiogenese sichert hierbei sowohl das Überleben der Zellen des sogenannten Primarius als auch der in diesem Stadium entstehenden ersten Metastasen (nach Hanahan und Weinberg 2000). Onkogene als pro-kanzerogene Faktoren stehen in diesem Stadium in einem Ungleichgewicht $\mathrm{zu}$ Tumorsuppressorgenen, Apoptosegenen, DNA-Reparaturfunktionen und Telomerasegenen (Weber 2008).

Im weiteren Prozess der Metastasierung (nach Bacac und Stamenkovic 2008, siehe auch Gupta und Massagué 2006, ) dringen die ersten sich absiedelnden Tumorzellen in die Lymphund Blutzirkulation des Körpers ein (Intravasation). Um im jeweiligen Gefäßsystem zu überleben, müssen diese zirkulierenden Tumorzellen (circulating tumor cells, CTC) der körpereigenen Immunantwort entgehen sowie verschiedenste physikalische Barrieren überwinden. In einem entfernten Organ müssen sie ein weiteres Mal die Gefäßwand durchdringen (Extravasation) und sich den neuen Umgebungsbedingungen anpassen bzw. diese $\mathrm{zu}$ ihren Gunsten modulieren (Kolonisation). Die ersten Zellen werden auch als Mikrometastase (Durchmesser $\leq 2 \mathrm{~mm}$ ) bezeichnet. Durch Tumorzell-, Gefäß- und Bindegewebsproliferation nehmen die Absiedelungen weiter an Größe zu und wachsen zu einer Makrometastase aus.

Nur 0,01\% der CTC sind bei der Etablierung einer Fernmetastase erfolgreich (Fidler 1970, Langley und Fidler 2011). Lee beschrieb 1983 eine vornehmliche Absiedelung von zirkulierenden Brustkrebszellen in Leber, Lunge, Knochen und Gehirn. Aus solchen Beobachtungen heraus entstand die Frage, warum bestimmte Krebsarten Metastasen in präferierten Geweben bildeten.

Stephen Paget sprach bereits im Jahr 1889 von den Krebszellen als „Samen“ (seeds), welche nur auf dem „Boden“ eines spezifischen Organes (soil) wüchsen und suggerierte schon damals eine Interaktion zwischen den CTC und dem Mikroenvironment des befallenen Organs (Seed-and-Soil-Hypothese) (Fidler 2002).

Während zunächst die oben angeführten intrinsischen Faktoren der Zellfunktion (die Samen: seeds) im Fokus der Forschung standen, waren seit den 1980-er Jahren zunehmend die 
extrinsischen Faktoren des Tumormikroenvironements (der Boden: soil) von Interesse (Joyce und Pollard 2009, Hanahan und Weinberg 2011).

Dieses besteht sowohl aus Zellen und der extrazellulären Matrix des umliegenden Gewebes als auch aus löslichen Faktoren, Signalmolekülen und den physikalischen Eigenschaften, welche die Transformation, das Zellwachstum und die Invasion unterstützen können. Gleichzeitig kann es die Zellen vor dem eigenen Immunsystem schützen und therapeutische Resistenz fördern (Nikolaou et al. 2013).

Von den zellulären Faktoren sind bisher die Eigenschaften der krebsassoziierten Fibroblasten (cancer associated fibroblasts, CAF) und die tumorassoziierten Makrophagen (tumor associated macrophages, TAM) im Primärtumor am umfassendsten erforscht. Sie sind an der Ausbildung einer Art chronischen Entzündung beteiligt, die, anders als die akute, eine Tumorprogression sogar fördern kann (Bernhard 2011, Stasinopoulos et al. 2011). Leek et al. konnten 1996 durch immunhistochemische Färbungen eine Korrelation zwischen Anreicherungen von TAM und sowohl einer vermehrten Gefäßzahl als auch einem kürzeren Überleben herstellen.

Die chronische Inflammation wird getragen von verschiedensten Molekülen wie Histamin, Leukotrienen, Serotonin, Prostaglandin, Bradykinin, Substanz P und Zytokinen, die über zahlreiche Signalkaskaden Kontakt zwischen Tumorzellen und Umgebung vermitteln (Bernhard 2011).

Unter anderem konnten 2006 Pukrop et al. nicht-kanonische Wnt-Signalwege über Wnt5a als einen wichtigen Signalweg in Tumorzellen und in der Interaktion mit den tumorassoziierten Makrophagen in Brustkrebs identifizieren.

\subsection{Epithelial-mesenchymale Transition (EMT)}

Die epithelial-mesenchymale Umwandlung ist ein ursprünglich aus der Entwicklungsbiologie bekannter Prozess, der die Umwandlung von Epithelzellen in mesenchymale Zellen beschreibt. Sie verändern hierbei sowohl ihren Phänotyp als auch ihre Funktion (Thiery et al. 2009).

Epitheliale Zellen stehen über ein stark ausgeprägtes Netzwerk von Verbindungskontakten wie Tight junctions, Gap junctions und Zonulae adherentes miteinander in Verbindung. Gleichzeitig erfahren sie eine apikal-basale Polarisierung durch ihr Zytoskelett und ein Konzentrationsgefälle verschiedener Signalmoleküle und löslicher Stoffe. Ihr Verband ist in einer Basallamina verankert. Mesenchymale Zellen dahingegen sind deutlich weniger 
miteinander vernetzt, deutlich geringer polarisiert und morphologisch auffällig durch ein spindelförmiges Äußeres (Thiery und Sleeman 2006).

EMT ist embryonal beispielsweise unersätzlich in der Bildung des Neuralrohrs oder der Entwicklung des Mesoderms (Typ I EMT: Entwicklung). Im adulten Organismus soll sie unter anderem in der Wundheilung, in der bindegewebigen Umwandlung verschiedener Organe (Fibrosierung) (Typ II EMT: Fibrose und Wundheilung) und der Initiation von Metastasierungsprozessen von Bedeutung sein (Typ III EMT: Krebs) (Kalluri und Weinberg 2009).

Selbstverständlich kann auch Mesenchym in Epithel umgewandelt werden. Dieser zur EMT reverse Prozess wird auch als MET, mesenchymal-epitheliale Transition, bezeichnet (Kalluri und Weinberg 2009) und ist im finalen Schritt der Metastasierung -nach Verlassen des Blutstroms und der Bildung von Mikrometastasen von Karzinomen- von besonderer Bedeutung (Chaffer und Weinberg 2011).

Zur Charakterisierung dieser Prozesse bestimmt man verschiedene Marker, die für beide Zellarten typisch sind. So ist beispielweise E-Cadherin eine charakteristische Komponente von Epithelzellen. N-Cadherin, Fibronectin und Vimentin definieren Mesenchymzellen. Gleichzeitig können Transkriptionsfaktoren bestimmt werden, welche die Expression von ECadherin unterdrücken und so indirekt EMT bilden. Hierzu zählen beispielsweise das Zinc finger-Protein (Snail1, auch bekannt als SNAI1) und Zinc finger E-box-binding homebox 1 und 2 (ZEB1 und 2) (Peinado et al. 2007, Yang und Weinberg 2008).

Die Initiierung von EMT ist für verschiedene Signalwege beschrieben, unter anderem auch für den $\beta$-Catenin-abhängigen Wnt-Weg (Savagner 2001, Micalizzi et al. 2010).

In Brustkrebszellen ist durch die Aktivierung von Wnt die Regulierung des Transkriptionsfaktors Snail1 und mesenchymaler Marker wie Vimentin beschrieben, gleichzeitig in Bezug auf die Knochenmetastasierung die Aktivierung von EMT, durch einen weiteren Signalweg über den Transforming Growth Factor- $\beta$ (TGF- $\beta$ ), ein lokales Zytokin mit ähnlichen Zuständigkeitsgebieten wie Wnt (Kang et al. 2005).

Die Tatsache, dass p53, ein bedeutender Tumorsuppressor, EMT durch die Expression verschiedener ZEB und Snail-hemmender microRNAs unterdrückt, betont die Bedeutung dieses Prozesses für die Tumorprogression ein weiteres Mal (Chang et al. 2011).

Mani et al. zeigten 2008, dass die Induktion von EMT in immortalisierten humanen Brustdrüsenepithelzellen (HMLEs) nicht nur einen mesenchymalen Phänotyp hervorrief, sondern die Zellen gleichzeitig auch verschiedene Stammzellmarker neu exprimierten. 
Aufgrund ihrer Ergebnisse postulierten sie einen Zusammenhang zwischen EMT und dem Gewinn epithelialer Stammzelleigenschaften.

\subsection{Wnt-Signalwege}

Wnt-Proteine sind Cystein-reiche Glykoproteine, die, nach parakriner oder autokriner Sekretion, lokal, durch Bindung an einen extrazellulären Rezeptor, intrazellulär einen von vielen möglichen Signaltransduktionswegen der Zellen auslösen können. Die Bezeichnung Wnt (wingless type MMTV integration site) stammt aus der Zeit der Entdeckung des Signalwegs in der Fliegenspezies Drosophila melanogaster. Das wingless (wg)-Gen wurde 1980 von Nüsslein-Volhard und Wieschaus als entscheidend für die Segmentpolarisierung in der Embryogenese beschrieben. 1987 konnten Rijsewijk und Kollegen die Integration des Onkogens Int-1 (Intracellular protein transport protein USO1) am mouse mammary tumor virus (MMTV), einem der wg-Homologa, aufzeigen. Aus beidem entstand die heutige Bezeichnung.

Insgesamt sind 19 verschiedene Wnt-Proteine mit einer durchschnittlichen Länge von 350400 Aminosäuren bekannt. Die hydrophoben Glykoproteine können über spezifische Proteoglykane Extrazellulärmatrix binden und so essenzielle Aufgaben in der Entwicklung verschiedenster Organismen übernehmen. (Mikels und Nusse 2006a).

Sie induzieren zum einen die Proliferation, Differenzierung und Migration von Zellen, sind zusätzlich aber auch für die Ausrichtung und Polarität der Zellen im Gewebe und die Angiogenese von Bedeutung. Durch Reaktivierung dieser entwicklungsgeschichtlich bedeutsamen Vorgänge im Kontext von degenerativen Erkrankungen und Krebs erlangen entartete Zellen höchste maligne Potenz (Logan und Nusse 2004).

Die funktionelle Vielfalt und Komplexität der verschiedenen Wnt-Proteine zeigt sich auch in den verschiedenen Signalwegen, an denen die Vertreter beteiligt sind. Hierbei werden Signalwege über den Kotranskriptionsfaktor $\beta$-Catenin als „kanonische Signalwege“ von den $\beta$ Catenin-unabhängigen „nicht-kanonischen“ Signalwegen abgegrenzt. Letztere sind äußerst vielseitig, allerdings deutlich schlechter erforscht. Das Netzwerk der nicht-kanonischen Signalwege verzweigt sich stetig, während mehr und mehr Informationen über sie in Erfahrung gebracht werden. $\mathrm{Zu}$ folgenden drei Signalwegen liegen nach jetzigem Forschungsstand die meisten Informationen vor: der $\mathrm{Wnt} / \mathrm{Ca}^{2+}{ }_{-}$Signalweg, der planar cell polarity pathway (PCP-Signalweg) und ein dritter über Rezeptoren der Tyrosinkinasenähnlichen Orphan-Rezeptor (ROR)-Familie (vgl. hierzu Abb. 1.1). 


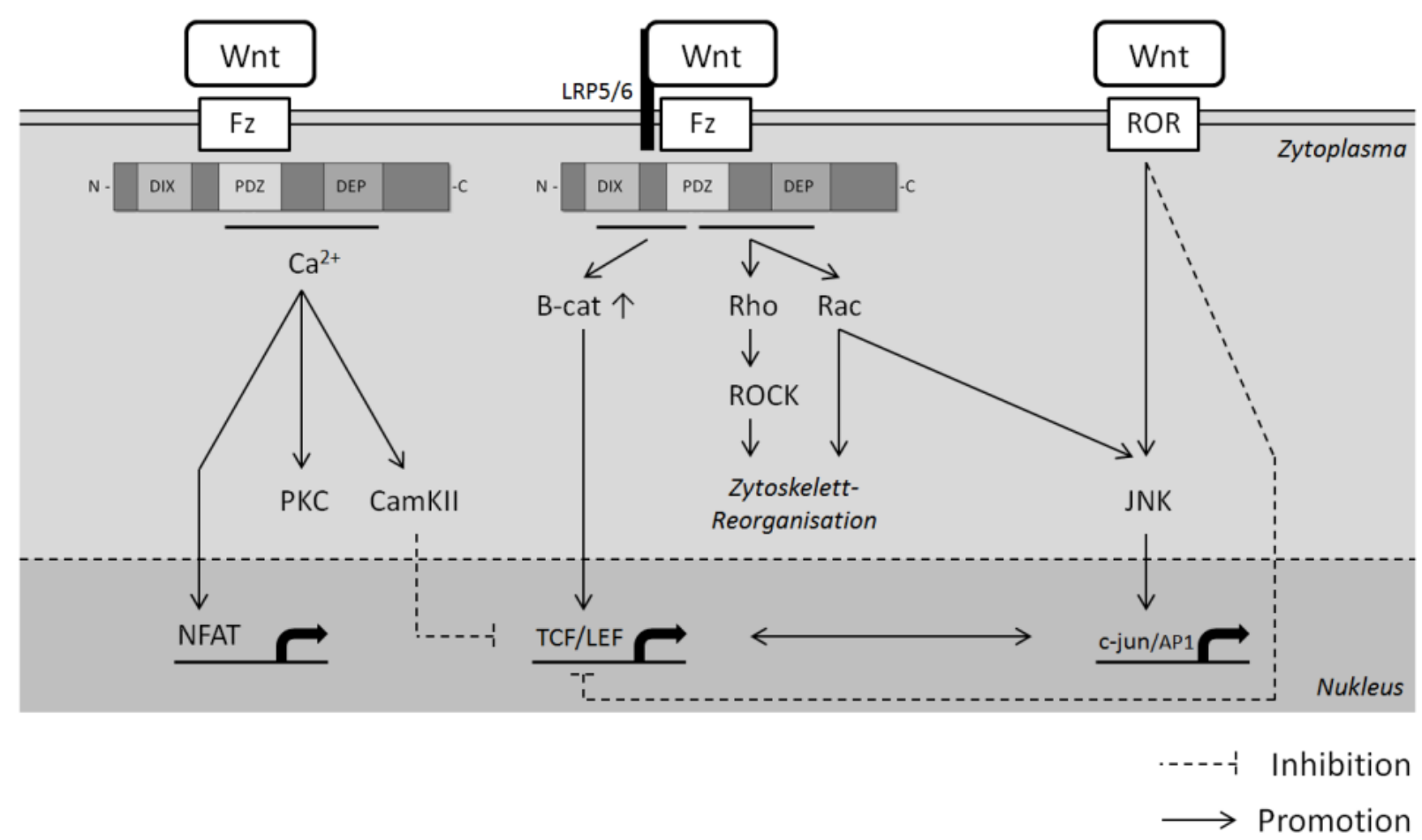

Abbildung 1.1 Übersicht über die Wnt-induzierten Signalwege und ihre Abhängigkeit von DVL und seinen Domänen. Wnt/Calcium-Signalweg (DVL PDZ und DEP), $\beta$-Catenin-abhängiger Signalweg (DVL DIX und PDZ), PCP-Pathway und (DVL PDZ und DEP) der Wnt-Signalweg über ROR. Für Details siehe Text. Modifiziert nach Pukrop und Binder (2008) und Wallingford und Habas (2005).

\subsection{1 $\quad \beta$-Catenin-abhängiger Signalweg}

Der kanonische Wnt-Signalweg wirkt über den Membranrezeptor Frizzled (Fz), den KoRezeptor Lipoprotein-Rezeptor-Related Protein 5/6 (LRP 5/6) (Nusse 2005, Clevers 2006) und das Signalmolekül Dishevelled (DVL) (Wallingford und Habas 2005) (Vgl. hierzu Abb. $1.2)$.

Über den kanonischen Wnt-Signalweg wird die intrazelluläre Menge an $\beta$-Catenin im Zytoplasma und Nukleus reguliert. Bindet eines der klassisches Wnts, beispielsweise Wnt1, 3 oder 8, an die extrazelluläre N-terminale, Cystein-reiche Domäne des Membranrezeptors Fz, so wird DVL phosphoryliert und aktiviert. Das aktivierte DVL inhibiert über seine Domänen Dishevelled and Axin (DIX) und PSD-95 Disc-large und ZO-1-Proteine (PDZ) den sogenannten $\beta$-Catenin-Destruction-Complex, der sich unter anderem aus dem Adenomatosis-Polyposis-Coli-Protein (APC), axis inhibition protein (Axin), der Casein-Kinase la

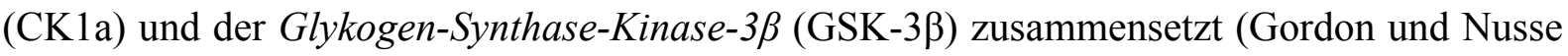
2006). In Abwesenheit von Wnt wird $\beta$-Catenin ubiquitiniert, also für den Abbau im Proteosomen markiert und dann durch dieses degradiert. In Anwesenheit der klassischen Wnts wird 
dieser Komplex inhibiert, so dass sich $\beta$-Catenin im Zytosol anreichern und anschließend in den Nukleus translozieren kann, wo es über Transkriptionsfaktoren der T-cell specific transcription factor/Lymphoid enhancer-binding factor (TCF/LEF)-Familie die Synthese von distinkten Zielgenen induziert. Hierzu gehören unter anderem das Proto-Onkogen $c$-myc (He et al. 1998), das im Verlauf über die Aktivierung weiterer Gene wirkt sowie Cyclin D1, das an der Zellzyklusregulation mitwirkt. Des Weiteren die Matrixmetalloprotease-7 (MMP-7) (Brabletz et al. 1999, Westermarck und Kahari 1999), ein Extrazellulärmatrix abbauendes Enzym, und Fibronectin (Gradl et al. 1999), das unter anderem Kollagen, Fibrin und Proteoglykane binden kann und somit bei der Metastasierung von Krebszellen eine bedeutende Rolle spielt.

Grigoryan et al. beschrieben 2008 die Bedeutung des $\beta$-Catenin-abhängigen Signalwegs für die Regulation der Aufrechterhaltung eines Stammzell- bzw. Vorläuferpools, Expansion und Spezifizierung in embryonalen, wie auch adulten Geweben.

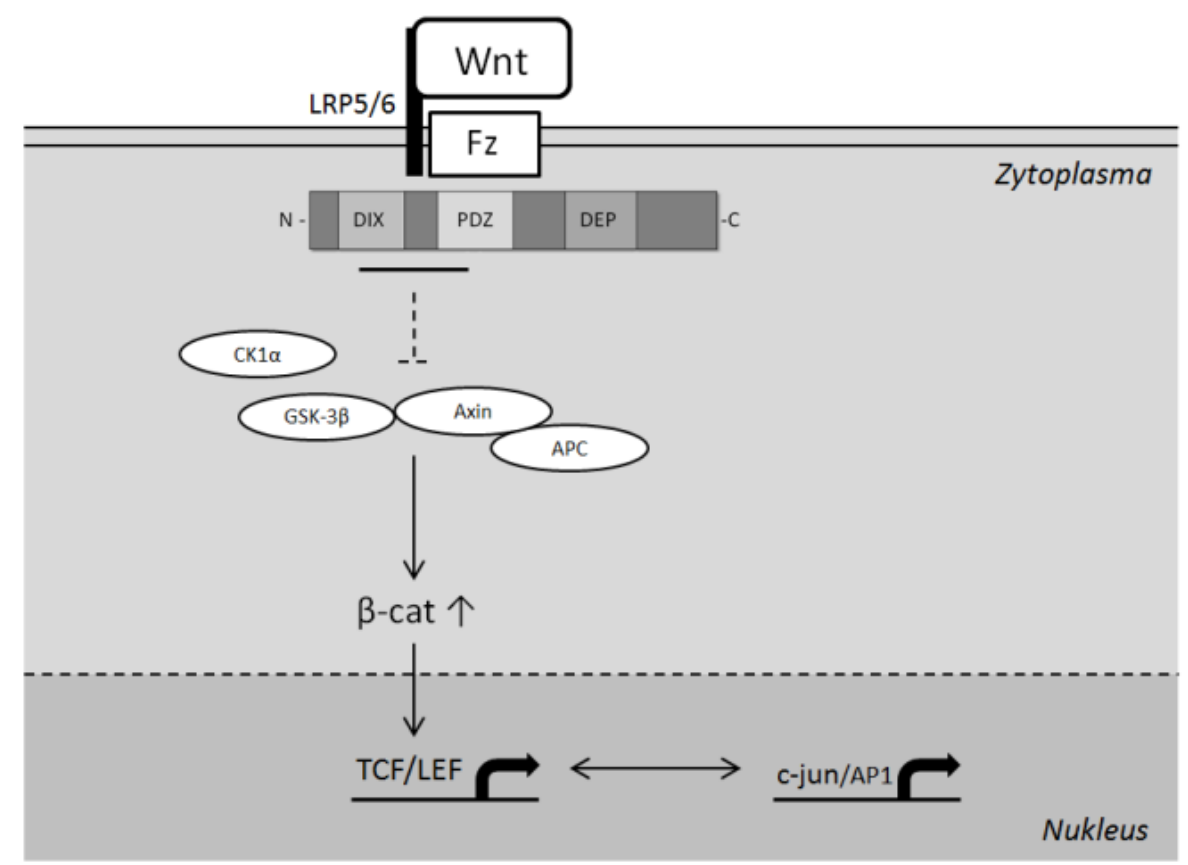

\begin{abstract}
Abbildung 1.2 $\beta$-Catenin-abhängiger Signalweg in Anwesenheit von Wnt. Durch ein kanonisches Wnt wird die Signalkaskade über den Rezeptor Fz und die DVL-Domänen DIX und PDZ aktiviert. Dadurch wird der $\beta$ Catenin-Destruction-Complex inhibiert und nicht phosphoryliertes $\beta$-Catenin kumuliert im Zytoplasma. Nach der Translokation in den Zellkern interagiert $\beta$-Catenin unter anderem mit den Transkriptionsfaktoren LEF/TCF. Für Details siehe Text. Modifiziert nach Pukrop und Binder (2008), Wallingford und Habas (2005) und Gordon und Nusse (2006).
\end{abstract}




\subsection{2 $\beta$-Catenin-unabhängige Wnt-Signalwege}

Für einen Überblick über die weiteren nicht-kanonischen Signalwege siehe auch Semenov et al. 2007.

\subsubsection{Wnt/Calcium-Signalweg}

In diesem Signalweg verursacht die Bindung von nicht klassischen Wnts, z.B. Wnt5a, die intrazelluläre Freisetzung von $\mathrm{Ca}^{2+}$ (vgl. hierzu Abb. 1.3). Nachdem der Ligand gebunden hat, wird beispielsweise über den 7-Transmembranrezeptor Frizzled 2 (Fz2) und intrazellulär DVL mit seinen Dömänen PDZ und Dishevelled, Egl-10 and Pleckstrin domain (DEP) (Sheldahl et al. 2003) ein heterotrimäres Guaninnucleotid-bindendes Protein (G-Protein) aktiviert, das in eine $\mathrm{G} \alpha$ - und eine G $\beta \gamma$-Untereinheit dissoziiert. G $\alpha$ aktiviert eine Phosphodiesterase, die zyklisches Guanosinmonophosphat (cGMP) umbaut. Dadurch wird die hiervon abhängige Proteinkinase G (PKG) gehemmt (Ahumada et al. 2002, Ma und Wang 2006). Über die G $\beta \gamma$-Untereinheit wird des Weiteren die Phospholipase C (PLC) aktiviert, welche die gut erforschte Signalkaskade der Spaltung von Phosphatidylinositol-4,5-bisphosphat $\left(\mathrm{PIP}_{2}\right) \mathrm{zu}$ Inositol-1,4,5-trisphosphat ( $\left.\mathrm{IP}_{3}\right)$ und Diacylglycerin (DAG) in Gang setzt (Slusarski et al. 1997a, Slusarski und Pelegri 2007).

Während $\mathrm{IP}_{3}$ durch Bindung am Endoplasmatischen Retikulum eine Ausschüttung von Calcium aus diesem endogenen Speicher hervorruft, aktiviert DAG, unterstützt durch erhöhte $\mathrm{Ca}^{2+}$-Level, die Proteinkinase C (PKC) (Slusarski et al. 1997b, Sheldahl et al. 1999). Das im Überfluss vorhandene Calcium bindet das regulatorische Protein Calmodulin (CaM) und aktiviert daraufhin zum einen die Phosphatase Calcineurin, die über den nuclear factor of $T$ celles (NFAT) als Transkriptionsfaktor die Genexpression beeinflussen kann, zum anderen auch die $\mathrm{Ca}^{2+}$-abhängige Proteinkinase II (CamKII) und somit die Initiation verschiedener Effektormoleküle des Wnt/Calcium-Signalwegs (Kuhl et al. 2000a; Kuhl et al. 2000b).

Dem Wnt/Calcium-Signalweg wird eine bedeutende Rolle in der Entwicklung und Tumorentstehung zugeschrieben (Kohn und Moon 2005). So lenkt Wnt5a beispielsweise die Metastasierung von Malignen Melanomen durch Induktion einer epithelial-mesenchymalen Transition (EMT) über den PKC-Weg (Dissanayake et al. 2007). 


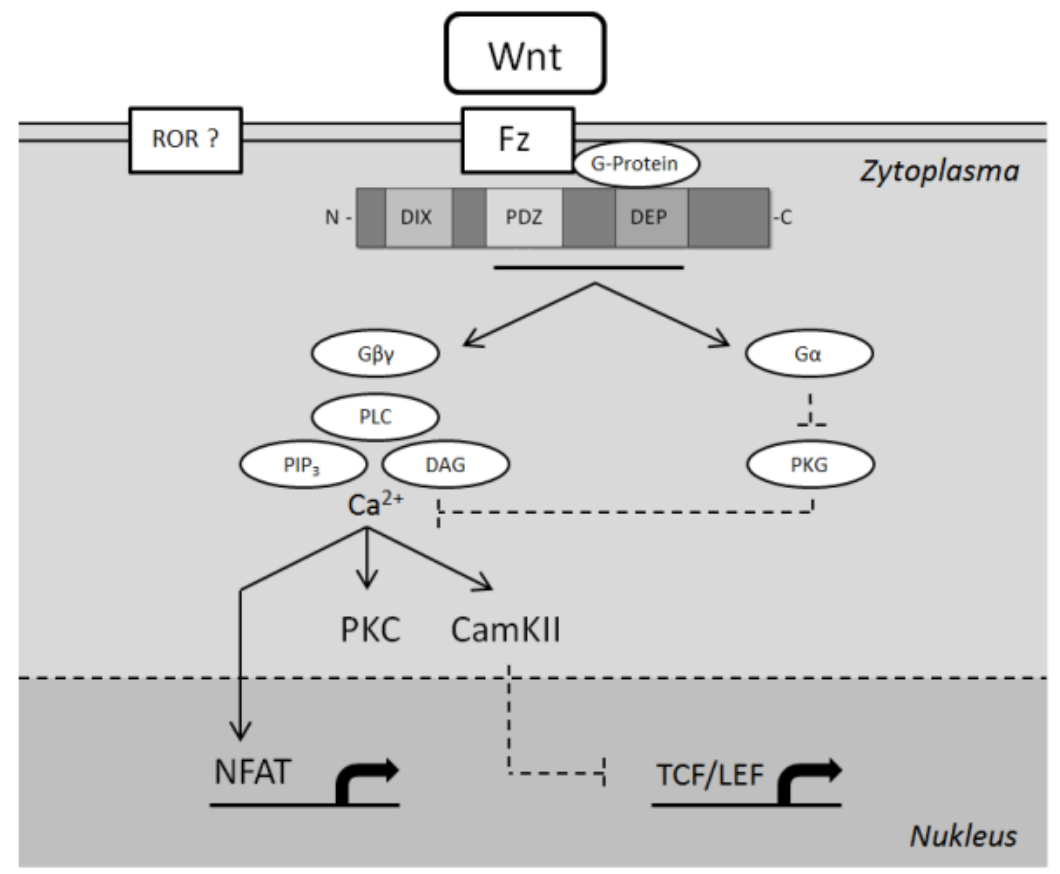

Abbildung 1.3 Wnt/Calcium-Signalweg. Wnt bindet an den Rezeptor Fz und reguliert so über die DVLDomänen PDZ und DEP und die Aktivierung von G-Proteinen die Aktivierung der Phospholipase C. Diese vermittelt eine Freisetzung von Calcium aus den endogenen Speichern der Zelle, was zu einer Aktivierung der Proteinkinase C und der Calmodulin-abhängigen Kinase führt. Diese phosphorylieren weitere Substrate und nehmen so unter anderem Einfluss auf die Gentranskription. Für Details siehe Text. Modifiziert nach Pukrop und Binder (2008), Wallingford und Habas (2005), Kikuchi et al. (2012).

\subsubsection{Planar Cell Polarity-Pathway}

Der Begriff „planare Zellpolarität“ entstammt aus der Erforschung der Gewebspolarität in Drosophila-Fliegen. Er beschreibt die Ausrichtung des Epithels längs der apikal-basalen Achse (Nubler-Jung 1987) und wurde später auch in Wirbel- und Säugetieren, wie zum Beispiel bei der Gastrulation, Axonausrichtung und Anordnung der Cilien im Respirationstrakt nachgewiesen (Goodrich 2008).

Der Planar Cell Polarity-Signalweg ist für die Strukturierung des Zytoskeletts von Bedeutung und reguliert die Bewegung von Zellen in epithelialen Verbänden (Seifert und Mlodzik 2007, Jones und Chen 2007), vgl. hierzu Abb. 1.4..

Wnt5a, aber auch Wnt4 und Wnt11, binden an Fz und seine Ko-Rezeptoren. Unter anderem werden ROR2 und Ryk als solche diskutiert (Medina et al. 2000, Nishita et al. 2010a, Habu et al. 2014). Dies führt zur Rekrutierung des Proteins Dishevelled über seine Domänen PDZ und DEP an die Plasmamembran. Dishevelled-associated activator of morphogenesis 1 (DAAM1) bindet am C-terminalen Ende und Ras homolog gene family, member A (RhoA) am N- 
terminalen von DVL, wodurch es zur Zusammenlagerung des DVL-RhoA-Komplexes kommt, welcher dann die Rho-assoziierte Kinase ROCK aktiviert, einen der Hauptregulatoren der Zytoskelettbildung der Zelle (Winter et al. 2001). Mit DAAM1 interagiert auch Profilin und initiiert so die Bildung von Aktin-Stressfasern. DVL und das Ras-related C3 botulinum toxin substrate 1 (Rac1) aktivieren die c-jun N-terminale Kinase (JNK) (Moriguchi et al. 1999, Wallingford und Habas 2005). Die aktivierte JNK phosphoryliert c-jun (Weber et al. 2000) und so den dimeren Transkriptionsfaktor activator protein-1 (AP-1), wodurch auch dieser Weg der Wnt-Signalkaskade Einfluss auf die Genexpression der Zelle nehmen kann.

Moduliert und reguliert wird der PCP-Signalweg auf unterschiedlichen Ebenen: schon auf Rezeptorebene interagiert Fz mit dem 4-Transmembranprotein Van Gogh-like (Vangl), das wiederum die Interaktion mit DVL und der dies aktivierenden Proteinkinase PKC $\delta$ vermittelt. Dieser Vorgang wird moduliert vom 7-Transmembranprotocadherin Celsr (cadherin EGF $L A G$ seven-pass G-type receptor), indem es die asymmetrische Lokalisation von Fz und Vangl garantiert und so die Stabilisierung des PCP-Wegs gewährleistet. Vangl wiederum rekrutiert das zytoplasmatische PCP-inhibierende Protein Prickle, den direkten Gegenspieler von DVL zur Plasmamembran. Sprouty, ebenfalls ein zytoplasmatischer Mitspieler, inhibiert die Aktivierung der PKCס, kann jedoch selbst wieder durch das Protocadherin PAPC gebunden und blockiert werden (Wallingford und Habas 2005, Wang 2009, Kikuchi et al. 2012).

Das sezernierte Glykoprotein collagen triple helix repeat containing 1 (Cthrc1) unterstützt das Wnt-PCP-Signal über Komplexbildung und Stabilisierung der eingegangenen Bindung von Wnt und Fz. EphrinB1 als Transmembranligand für Eph bindet über seinen zytoplasmatischen Anteil DVL und aktiviert RhoA (Wang 2009).

Über die Bedeutung des PCP-Signalwegs im Rahmen der Karzinogenese liegen unterschiedliche und zum Teil gegensätzliche Forschungsergebnisse vor.

Wnt5a als einer der bedeutenden Auslöser der Signalkaskade kann bereits, in Abhängigkeit vom Kontext, sowohl als Tumorsuppressor, als auch als Oncogen fungieren. So fördert es im Bustkrebs (Pukrop et al. 2006), aber auch in Melanomen (Weeraratna et al. 2002) und Magenkarzinomen (Kurayoshi et al. 2006) die Metastasierung. Es kann durch Antagonisierung anderer Wnts, beispielsweise auf Rezeptorebene, in solchen Tumoren als Suppressor wirken, in denen $\beta$-Catenin-abhängig Tumorpromotion stattfindet (Veeman et al. 2003). Gleichzeitig besitzt auch Wnt5a das Potential, den kanonischen Signalweg zu aktivieren, in Abhängigkeit vom Rezeptorkontext (Mikels und Nusse 2006b). 
Forschung an Zellen verschiedener Brustkrebsstadien (Invasives Karzinom, Atypische duktale Hyperplasie und duktales Carcinoma in situ (DCIS)) zeigten stark variierende Expression von Wnt5a und unterschiedliche Reaktionen auf Exposition mit dem Liganden. So induzierte Wnt5a sowohl in den Zellen der atypischen Hyperplasie als auch in denen des DCIS Zellmigration, förderte die Invasion jedoch nur in den DCIS-Zellen. Deshalb gehen MacMillan und Kollegen aktuell von einer kontextabhängigen Funktionsweise des PCPSignalwegs in der Brustkrebsprogression aus (2014).

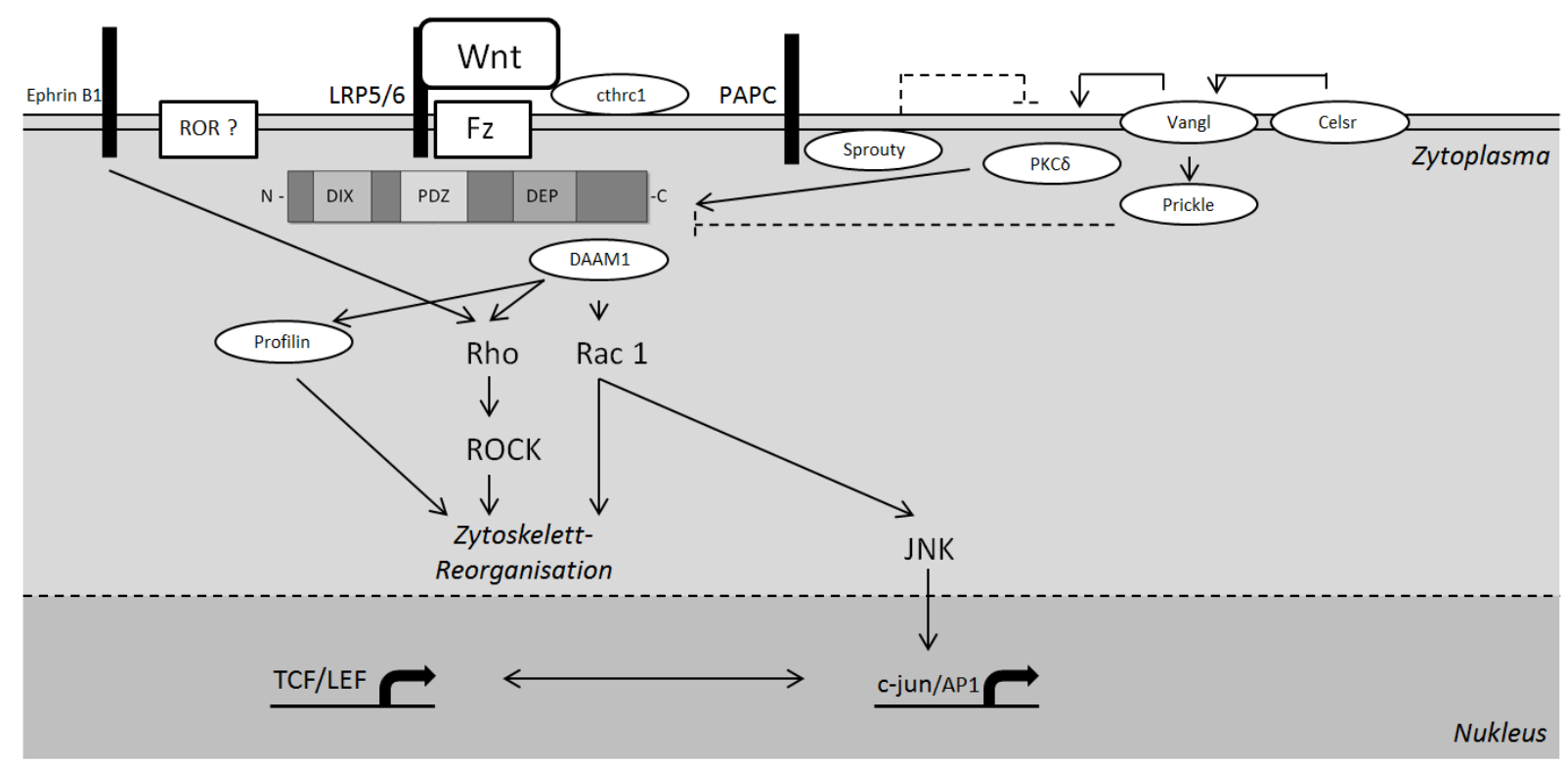

Abbildung 1.4 PCP-Signalweg. Durch Bindung an Fz aktiviert ein entsprechendes Wnt über die PDZ- und DEP-Domäne DVLs den PCP-Signalweg. Die ROCK wird vermittelt durch die kleine GTPase Rho und DAAM1 aktiviert. Gleichzeitig initiiert DAAM1durch Profilin die Bildung von Aktin-Stressfaser und somit die Zytoskelettorganisation. Ohne Aktivierung von DAAM1 moduliert DVL über die kleine GTPase Rac die JNK und nimmt somit Einfluss auf die Transkription. Modulatoren des PCP-Signalwegs sind die PKC $\delta$ (reguliert unter anderem durch Vangl/Celsr, Sprouty/PAPC), Prickle, Cthrc1 und EphrinB1. Für Details siehe Text. Modifiziert nach Pukrop und Binder (2008), Wallingford und Habas (2005), Wang (2009) und Kikuchi et al.(2012).

\subsubsection{3 $\beta$-Catenin-unabhängige Signalwege über ROR}

Als ein weiterer Rezeptortyp nicht-kanonischer Wnt-Moleküle gelten auch die Transmembranrezeptoren receptor tyrosine kinase-like orphan receptors 1 und 2 (ROR1/ ROR2) (Grumolato et al. 2010, Yamamoto et al. 2007), welche zur Familie der Rezeptortyrosinkinasen (RTK) gehören (vgl. hierzu Abb. 1.5.).

ROR-Rezeptoren sind kodiert auf den Chromosomen 1 und 9, als Protein etwa 104 kDa groß und nehmen essenzielle Rollen in der Morphogenese verschiedener Organismen ein. Hierfür 
bestehen die ROR-Rezeptoren extrazellulär aus einem Immunoglobulin-ähnlichen Motiv, einer Cystein-reichen frizzled und einer kringle-Domäne. Intrazellulär schließen sich eine Tyrosinkinase-ähnliche und eine Prolin-reiche Domäne an, die gesäumt werden von ebenfalls hochkonservierten Serin-Threonin-reichen Bereichen (vgl. hierzu Rebagay et al. 2012).

Während ROR1 physiologisch vor allem eine bedeutende Rolle in der Entwicklung des Zentralen Nervensystems spielt (Reddy et al. 1996), wird ROR2 eine Funktion in der Entwicklung von Chondrozyten sowie der Entwicklung von Knorpeln und der Wachstumsplatte zugeschrieben (Yamagata et al. 2012). Neben der Wiederaufnahme der ROR-Aktivität während der Metastasierungsprozesse (Zhang et al. 2012), in denen über diese Zellpolarität, Migration und Krebszellinvasion moduliert werden sollen (Enomoto et al. 2009, He et al. 2008), wird ihnen eine Bedeutung im Zusammenhang mit der Resistenzentwicklung gegen den selektiven Östrogenrezeptormodulator Tamoxifen (Loh et al. 2013) zugeschrieben. In vitro hergestellte Tamoxifen-resistente MCF-7 Zellen zeigten hier nicht nur eine Hochregulierung von ROR2 und jun, sondern auch von Markern des $\beta$-Catenin-abhängigen Signalwegs (z.B. myc) und eine vermehrte EMT (z.B. Vimentin).

Während für ROR1 bisher kein eindeutiger Ligand beschrieben wurde, bindet beispielsweise Wnt5a an die Cystein-reiche, extrazelluläre Domäne von ROR2 und aktiviert die c-jun Nterminale Kinase (JNK) (Oishi et al 2003, Nomachi et al. 2008).

Wie die Weiterleitung des Wnt-Signals jedoch stattfindet ist im Allgemeinen stark umstritten. Während sowohl die Arbeitskreise um Liu (2008) und Mikels (2009) eine Phosphorylierung an einem Tyrosinrest beschrieben und Yamamoto 2007 von einer Phsophorylierung an Serin/Threonin ausging, herrschte Konsens bezüglich der gemeinsamen Endstrecke über Klusterbildung sowie Trans- und Autophosphorylierung (Schlessinger 2000).

2010 wurde von Grumolato et al. auch eine Phosphorylierung von Ser 864 durch die Glykogensynthase-Kinase 3 (GSK3) als Antwort auf ein Wnt5a-Signal, analog der von LRP6 auf Wnt3a, beschrieben und als gemeinsamer Ko-Rezeptor für beide Signale Fz vermutet. Diese Phosphorylierung sei nicht nur essenziell für die Rezeptoraktivität in nicht-kanonischen Signalwegen, sondern auch übertragbar auf die Rezeptoreigenschaften von ROR1 (Grumolato et al. 2010).

Es wird angenommen, dass dieser ROR-Signalweg unabhängig von DVL oder den kleinen Guaninnucleotid-bindenden Proteinen (G-Proteine oder GTPasen) Rac und Rho stattfindet. Die aktivierte JNK kann -wie auch im Signalweg der planaren Zellpolarität- c-jun und das activator protein 1 (AP-1) aktivieren und so die Transskription verschiedener Zielgene 
modulieren (Schambony und Wedlich 2007, Liu et al. 2008). So wird unter anderem eine Zunahme von Markern der epithelial-mesenchymalen Transition über ROR1 angenommen (Cui et al. 2013).

Immer wieder wird auch eine Ko-Rezeptoraktivität von ROR2 in den Signalwegen über Fz diskutiert (Green et al. 2008, Nishita et al. 2010a). Wnt5a, Fz und ROR2 können über eine Frizzled-ähnliche Cystein-reiche Domäne einen ternären Komplex bilden (Oishi et al. 2003, Yamamoto et al. 2008, Nishita et al. 2010b). Gleichzeitig ähnelten Wnt5a-knockout-Mäuse phänotypisch jenen, denen ROR2 oder Fz fehlte (Oishi et al. 2003). Daraus schlussfolgerten Kikuchi et al. 2012 eine womöglich stärkere Involvierung von ROR2 in Wnt5a-abhängige Signalkaskaden, als bisher angenommen. Gleichzeitig vermuteten sie, dass auch ROR1 ein potentieller Rezeptor für Wnt5a sein könnte, da dieses sowohl binden als auch seine Phosphorylierung induzieren könne (Fukuda et al. 2008, Grumolato et al. 2010).

Des Weiteren wird inhibitorisches Potential des ROR-Zweiges auf dem $\beta$-Catenin-abhängigen TCF-Signalweg unter anderem von Mikels und Nusse (2006b) beschrieben.

Eine Übersicht über den Nachweis von ROR1 und ROR2 in humanen Geweben, ihre Wirkweise und Liganden ist in der Tabelle 1 aufgeführt (modifiziert nach Rebagay et al. 2012, Lee et al. 2012 und Loh et al. 2013).

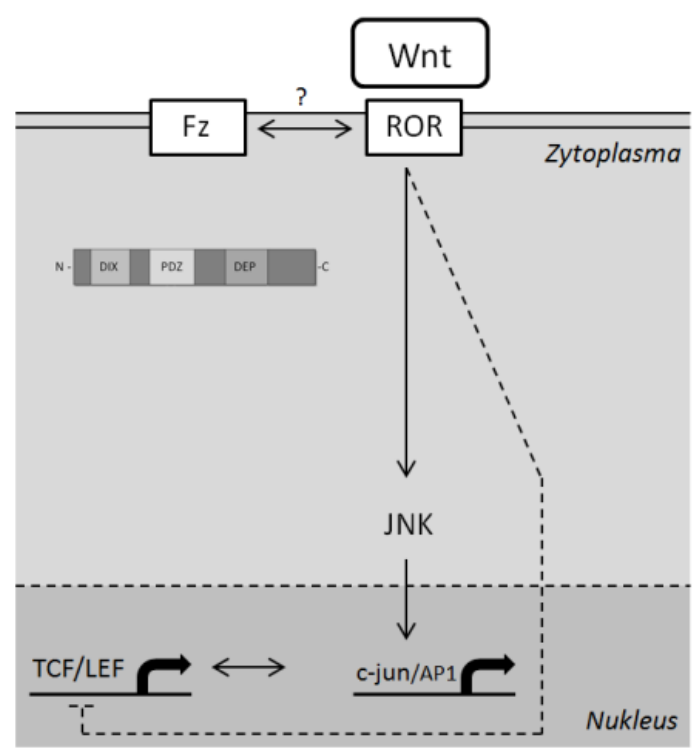

Abbildung 1.5 $\beta$-Catenin-unabhängige Signalwege über ROR. Wnt bindet an den Rezeptor ROR und reguliert so unabhängig von DVL die Aktivierung von JNK. Über diese regulieren c-jun und AP-1 die Transkription verschiedener Zielgene. Inhibition des $\beta$-Catenin-abhängigen TCF-Signalwegs durch ROR. Eine mögliche Ko-Rezeptoraktivität von ROR1/2 in den Fz-abhängigen Signalwegen wird diskutiert. Für Details siehe Text. Modifiziert nach Pukrop und Binder (2008), Kikuchi et al. (2012). 


\begin{tabular}{|c|c|c|c|}
\hline Eigenschaften & ROR1 & ROR2 & Referenz \\
\hline Größe & $104 \mathrm{kDa}$ & $105 \mathrm{kDa}$ & $\begin{array}{c}\text { Abcam, Cambridge, Vereinigtes } \\
\text { Königreich }\end{array}$ \\
\hline Lokalisation & 1p32-p31 & $9 q 22$ & $\begin{array}{l}\text { http://www.ncbi.nlm.nih.gov/gene } \\
(01.10 .2013)\end{array}$ \\
\hline Expression in adultem Gewebe & Fettgewebe $^{\mathrm{a}}$ & $\begin{array}{l}\text { Schilddrüse und } \\
\text { Magen }^{\mathrm{b}}\end{array}$ & $\begin{array}{l}\text { Baskar et al. 2008, Morioka et al. } \\
2009\end{array}$ \\
\hline $\begin{array}{l}\text { Genetische Erkrankungen durch } \\
\text { Mutation }\end{array}$ & nicht bekannt & $\begin{array}{c}\text { Brachydaktylie Typ B, } \\
\text { Robinow Syndrom }\end{array}$ & $\begin{array}{c}\text { Schwabe et al. 2000, } \\
\text { van Bokhoven et al. } 2000\end{array}$ \\
\hline Ligand & Wnt5a? & Wnt5a & $\begin{array}{l}\text { Liu et al. 2008, } \\
\text { Maeda et al. } 2012\end{array}$ \\
\hline Tyrosinkinaseaktivität & Pseudokinase & ja & $\begin{array}{l}\text { Gentile et al. 2011, } \\
\text { Liu et al. 2008, } \\
\text { Kani et al. 2004, } \\
\text { Yamamoto et al. } 2007\end{array}$ \\
\hline $\begin{array}{l}\text { Krebsarten mit Überexpression } \\
\text { oder Funktionen im Sinne eines } \\
\text { Oncogenes }\end{array}$ & $\begin{array}{c}\text { B-CLL, ALL, } \\
\text { Neuroblastom, } \\
\text { Mamma-Karzinom, } \\
\text { Nierenzellkarzinom }\end{array}$ & $\begin{array}{c}\text { Osteosarkom, } \\
\text { Melanom, } \\
\text { Nierenzellkarzinom, } \\
\text { Leiomyosarkome, } \\
\text { gastrointestinaler } \\
\text { Stromatumor, orale } \\
\text { Karzinome }\end{array}$ & $\begin{array}{c}\text { Baskar et al. 2008, } \\
\text { Shabani et al. 2008, } \\
\text { Asgharzadeh et al. 2006, } \\
\text { Zhang et al. 2012, } \\
\text { Rabbani et al. 2010, } \\
\text { Morioka et al. 2009, } \\
\text { O’Connell et al. 2010, } \\
\text { Wright et al. 2009, } \\
\text { Edris et al. 2012, } \\
\text { Kobayashi et al. 2009 }\end{array}$ \\
\hline $\begin{array}{l}\text { Krebsarten mit Überexpression } \\
\text { und Funktionen im Sinne eines } \\
\text { Onco-Supressors }\end{array}$ & nicht bekannt & Medulloblastoma & Lee et al. 2012 \\
\hline $\begin{array}{l}\text { Inhibierung der } \\
\text { Proliferation/Invasion mittels } \\
\text { siRNA }\end{array}$ & ja & ja & $\begin{array}{l}\text { Choudhury et al. 2010, } \\
\text { Wright et al. 2009, } \\
\text { O'Connell et al. } 2010\end{array}$ \\
\hline $\begin{array}{l}\text { in-vivo-Inhibierung des } \\
\text { Tumorzellwachstums/der } \\
\text { Invasion durch siRNA/mAb }\end{array}$ & ja & ja & $\begin{array}{l}\text { Cui et al. 2011, } \\
\text { Gentile et al. 2011, } \\
\text { Zhang et al. 2012, } \\
\text { Wright et al. 2009, } \\
\text { O'Connell et al. 2010 }\end{array}$ \\
\hline $\begin{array}{l}\text { Hochreguliert bei in-vitro- } \\
\text { Tamoxifen-Resistenz }\end{array}$ & nicht bekannt & ja & Loh et al. 2013 \\
\hline
\end{tabular}

\footnotetext{
${ }^{a}$ Proteinexpressionsanalysen lediglich durch Western Blot und nur oberflächliches ROR1 untersucht. Es bleibt daher möglich, dass oberflächliches ROR1 auch auf sehr niedrigem Niveau in Hoden, Uterus, Lunge, Blase und Kolon vorhanden ist.

${ }^{\mathrm{b}}$ mRNA-Gehalt geprüft durch Northern Blot. Sehr schwache Expressionssignale wurden in der Schilddrüse und dem Magen nachgewiesen.
}

Tabelle 1 Charakterisierung der Tyrosinkinase-ähnlichen Rezeptoren ROR1 und ROR2. Modifiziert nach Rebagay et al. 2012, Lee et al. 2012 und Loh et al. 2013, Fukuda et al. 2008. 


\subsection{Dishevelled als Schaltprotein kanonischer und nicht-kanonischer Signalwege}

Im Jahr 1998 erklärten sowohl Boutros und Kollegen als auch die Forscher um Axelrod Dishevelled zum Schaltprotein der Wnt-Signalwege. Es ist nicht nur an allen Wnt-Wegen, außer dem über ROR2, beteiligt, sondern übernimmt unterhalb von Frizzled auch zentrale Regulatorfunktionen. So steuert es spezifische biologische Prozesse wie Zellpolarität und Zellspezifizierung bis hin zu Sozialverhalten (Wallingford und Habas 2005).

Während die Art und Weise, wie es über die Weiterleitung in die verschiedenen Wnt-Zweige entscheidet, noch nicht vollständig verstanden ist, gibt es zahlreiche Untersuchungen über die Funktion des Proteins und der einzelnen Domänen, insbesondere aus der Entwicklungsbiologie. Teilweise widersprechen sich die Ergebnisse, wie im folgenden Abschnitt erläutert wird.

Mutationsanalysen der DVL-Domänen ergaben, dass die einzelnen hochkonservierten Domänen für die Rekrutierung von DVL an die Zellmembran von Bedeutung sind (Axelrod et al. 1998). Hieraus folgte die Schlussfolgerung, dass DVL durch eine differenzierte Bindung an die Zellmembran die verschiedenen Wnt- Signalwege induziere. Habas und Dawid beschrieben 2005 eine Rolle der Lokalisation, der relativen Verteilung des Proteins in verschiedenen Zellkompartimenten, als entscheidend für seine Funktion. Des Weiteren wurde eine spezifische Zuteilung der verschiedenen Aufgaben DVLs an die verschiedenen Subtypen angenommen (Schlange et al. 2007).

Erstmals wurde das Protein von Fahmy und Fahmy 1959 im Kontext einer Fliegenmutante beschrieben. Die Fliegenmutanten fielen durch abnormale Haar- und Borstenpolarität im Bereich von Kopf und Flügeln auf. Sie nannten es deswegen Dishevelled, was übersetzbar ist mit „,zerzaust“, ,zerrauft"oder ,ungekämmt“.

Trotz dieser auffälligen Modifikation wurde diesem Protein, bis in den 1980er Jahren weitere Funktionen entdeckt wurden, wenig Aufmerksamkeit geschenkt. 1987 zeigten Perrimon und Mahowald eine Schlüsselrolle Dishevelleds in der Entwicklung der Segmentpolarität in der frühen Embryonalzeit, was eine Welle weiterer Forschungsarbeit auf diesem Gebiet, vor allem in Fliegen, nach sich zog. Hier benutzt man bis heute Dsh als offizielle Abkürzung; für die Wirbeltierhomologe wurde später die Abkürzung DVL eingeführt.

Während Dsh erst dem kanonischen Wingless/Wnt-Signalweg zugeordnet wurde (Riggleman et al. 1990, Couso et al. 1994, Noordermeer et al. 1994, Siegfried et al. 1994), konnte später auch eine Rolle im PCP-Weg bewiesen werden (Krasnow et al. 1995, Theisen et al. 1994). 
Gleichzeitig wurden nicht nur Dishevelled-Homologe in Mäusen (DVL1,2,3), XenopusFröschen (xDsh) und drei humane Subtypen entdeckt (Sussman et al. 1994, Sokol et al. 1995, Klingensmith et al. 1996, Pizzuti et al. 1996, Tsang et al. 1996, Semenov und Snyder 1997), sondern auch ihre hochkonservierte Funktionsweise festgestellt (Rothbächer et al. 1995, Klingensmith et al. 1996).

Humane Homologe von Dsh, auch bezeichnet als dishevelled segment polarity proteins, sind zytoplasmatische Phosphoproteine, bestehend aus je circa 500 bis 716 Aminosäuren, und besitzen in circa 40 \% der Aminosäuresequenz Übereinstimmung mit Dsh. Das genetisch als $90 \mathrm{kDa}$ großes Protein kodierte DVL wird posttranslational phosphoryliert und erreicht so seine Endgröße von etwa $95 \mathrm{kDa}$ (Internet-Quelle: Gendatenbank des National Center for Biotechnology Information (NCBI): http://www.ncbi.nlm.nih.gov/gene, 28.07.2013).

Zum Teil sind für die drei humanen Subtypen spezifische Funktionen beschrieben worden.

DVL1 (NCBI-Gene ID: 1855), kodiert auf Chromosom 1p36, reguliert Zellproliferation und transduziert auf molekularer Ebene Entwicklungsprozesse wie beispielsweise Segmentierung und Neuroblastspezifizierung. Pathologische Beteiligungen sind für neuroblastomatöse Umwandlungsprozesse, das Schwartz-Jampel-Syndrom (myotone Chondrodystrophie) und die Charcot-Marie-Tooth-Krankheit (Hereditäre motorisch-sensible Neuropathie) vom Typ 2A beschrieben. DVL1 interagiert mit DVL3 (Kishida et al. 1999), Epidermal growth factor receptor kinase substrate 8 (EPS8) (Inobe et al. 1999), AXIN1 (Li et al. 1999, Kim et al. 2008) und Mothers against decapentaplegic homolog 3 (SMAD family member 3 oder SMAD3) (Warner et al. 2003). Zhao et al. zeigten 2010, dass in nicht-kleinzelligem Lungenkrebs DVL1-Überexpression Auswirkungen auf $\beta$-Catenin-abhängige Signalmoleküle hat, während JNK, die p38-mitogenaktivierte Proteinkinase (p38) und Extracellular-signal Regulated Kinase (ERK) nicht beeinflusst wurden.

Die genetische Information zur Synthese von DVL2 (NCBI-Gene ID: 1856) liegt auf Chromosom 17q21. Interaktionen wurden gezeigt für Zinc finger protein 165 (Rual et al. 2005), Disabled homolog 2 (DAB2) (Hocevar et al. 2003) und Arrestin beta 1 (Chen et al. 2001).

Das DVL3-Gen (NCBI-Gene ID: 1857) liegt auf Chromosom 3q27. Bisher wurden Kontakte mit DAB2 (Hocevar et al. 2003), DVL1 (Kishida et al. 1999) und U4/U6 small nuclear ribonucleoprotein Prp3 (PRPF3) gezeigt (Rual et al. 2005). Rekurrierend auf die Forschungsergebnisse an nicht-kleinzelligen Bronchialkarzinomen konnte Zhao mit seinem Arbeitskreis einen Zusammenhang von DVL3 und nicht-kanonischen Effektormolekülen wie 
JNK und p38 offenlegen. Andererseits zeigten Kwan und Kollegen 2013 eine Bedeutung DVL3s für $\beta$-Catenin-abhängige Signalwege in Zervixkarzinomen.

Alle DVL-Unterformen besitzen drei hochkonservierte Domänen, von N-terminal nach Cterminal bezeichnet als DIX, PDZ und DEP. Eine Übersicht stellt Abbildung 1.6 dar; zum Vergleich siehe auch Abbildung 1.1.

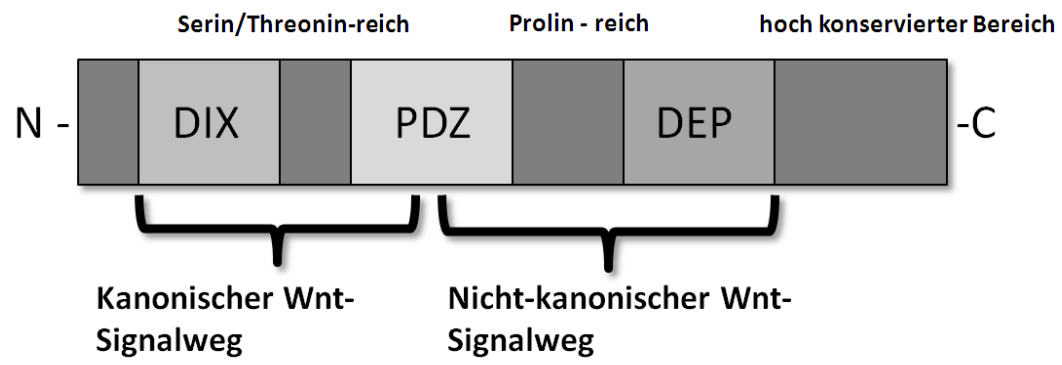

Abbildung 1.6 Hochkonservierte Domänen von DVL und ihre Funktionen in den Wnt-Signalwegen. Die am N-Terminus DVLs lokalisierte DIX-Domäne soll vor allem für die Weiteleitung kanonischer Signale über $\beta$ Catenin von Bedeutung sein. PDZ und DEP für die Regulation des Wnt/Ca2+-Signalwegs und den PCPSignalwegs. Für Details siehe Text. Modifiziert nach Wallingford und Habas 2005.

Die DIX-Domäne ist eine große $\alpha$-helikale Struktur, die auch in Axin ähnlich vorhanden ist und die Interaktion dieser beiden Signalmodulatoren vermitteln soll (Hsu et al. 1999). Gleichzeitig soll diese Domäne unersetzlich für die Informationsweiterleitung in den $\beta$ Catenin-abhängigen Wnt-Signalweg sein (Axelrod et al. 1998; Wallingford und Habas 2005, Capelluto et al. 2002).

PDZ wird gebildet von sechs $\beta$-Faltblatt-Strukturen, die zwei $\alpha$-Helices einhüllen und so eine hydrophobe Spalte bilden, welche die Bindung anderer Proteine erleichtert. Ähnliche Bereiche werden in einer Vielzahl verschiedener Signalmoleküle von Eumetazoa gefunden, oft angeordnet in sogenannten ,tandem arrangements “, das heißt vornehmlich hintereinander, in die selbe Richtung ausgerichtet. Ihr wird Bedeutung für spezifische Protein-ProteinInteraktionen zugeschrieben. Bindungen dieser Domäne sind sowohl an verschiedene Polypeptide als auch verschiedene Lipide beschrieben. PDZ soll für alle DVL-abhängigen Signalkaskaden unersetzlich sein. So soll über PDZ die Bindung an den C-terminalen Bereich des Rezeptors Fz ermöglicht werden (Cheyette et al. 2002, Wong et al. 2003).

DEP, bestehend aus drei $\alpha$-Helices, ist in verschiedenen DVL-ähnlichen Proteinen vorhanden. All diese nehemen Schlüsselrollen in der Übertragung des Wnt-Signals von der Zellmembran 
zum Kern ein. DEP soll hierin besonders für die Übertragung der nicht-kanonischen Wege PCP und Wnt/Ca ${ }^{2+}$ zuständig sein (Wong et al. 2000).

Zusätzlich zu diesen Domänen bestehen weitere stark erhaltene Abschnitte wie beispielsweise eine basische, Serin/Threonin-reiche Region zwischen DIX und PDZ, eine Prolinangereicherte zwischen PDZ und DEP, wie auch der C-terminale Bereich (Wallingford und Habas 2005).

\begin{tabular}{|c|c|c|c|}
\hline Komponente & Dsh Bindung & $\begin{array}{l}\text { Zelluläre Lo- } \\
\text { kalisation }\end{array}$ & Referenz \\
\hline Dishevelled & DIX & $\begin{array}{l}\text { Zytoplasma } \\
\text { Membran } \\
\text { Kern }\end{array}$ & Kishida et al. 1999, Rothbächer et al. 2000 \\
\hline $\begin{array}{l}\text { Serin/Threonin- } \\
\text { Proteinkinase PAK1 }\end{array}$ & DIX & $\begin{array}{l}\text { Zytoplasma } \\
\text { Membran }\end{array}$ & Luo et al. 2002 \\
\hline Axin & $\begin{array}{l}\text { DIX } \\
\text { PDZ }\end{array}$ & $\begin{array}{l}\text { Zytoplasma } \\
\text { Membran } \\
\text { Kern }\end{array}$ & $\begin{array}{l}\text { Itoh et al. 2000, Julius et al. 2000, Kishida et al. } \\
\text { 1999, Zeng et al. } 1997\end{array}$ \\
\hline Frizzled & PDZ & Membran & Cong et al. 2004, Wong et al. 2003 \\
\hline Casein-Kinase 1 & PDZ & $\begin{array}{l}\text { Zytoplasma } \\
\text { Kern }\end{array}$ & Peters et al. 1999, Sakanaka et al. 1999 \\
\hline Casein-Kinase 2 & PDZ & $\begin{array}{l}\text { Zytoplasma } \\
\text { Kern }\end{array}$ & Willert et al. 1997 \\
\hline $\begin{array}{l}\text { GSK3-binding pro- } \\
\text { tein/FRAT }\end{array}$ & PDZ & Zytoplasma & Li et al. 1999, Yost et al. 1998 \\
\hline Frodo & PDZ & Unbekannt & Gloy et al. 2002 \\
\hline Dapper & PDZ & $\begin{array}{l}\text { Zytoplasma } \\
\text { Kern? }\end{array}$ & Cheyette et al. 2002 \\
\hline $\begin{array}{l}\text { Inhibition of the Dvl } \\
\text { and Axin complex, } \\
\text { IDAX }\end{array}$ & PDZ & Zytoplasma & Hino et al. 2001 \\
\hline Naked Cuticle & PDZ & Zytoplasma & Rousset et al. 2001, Wharton et al. 2001 \\
\hline Strabismus & PDZ & Membran & $\begin{array}{l}\text { Bastock et al. 2003, Jessen et al. 2002, Park und } \\
\text { Moon 2002, Wolff und Rubin } 1998\end{array}$ \\
\hline $\begin{array}{l}\text { Prader- } \\
\text { Willi/Angelman regi- } \\
\text { on-1, PAR1 }\end{array}$ & PDZ & Zytoplasma? & Ossipova et al. 2005, Sun et al. 2001 \\
\hline Diego/Diversin & PDZ & Zytoplasma & Jenny et al. 2005 \\
\hline $\begin{array}{l}\text { Protein Phosphatase } \\
2 \mathrm{C}\end{array}$ & PDZ & Zytoplasma & $\begin{array}{l}\text { Ratcliffe et al. 2000, Strovel et al. 2000, Yang et al. } \\
2003\end{array}$ \\
\hline Notch & PDZ & Unbekannt & Axelrod et al. 1996 \\
\hline $\begin{array}{l}\text { Epidermal growth fac- } \\
\text { tor receptor kinase } \\
\text { substrate } 8 \text {, EPS8 }\end{array}$ & PDZ & Zytoplasma? & Inobe et al. 1999 \\
\hline Daple & PDZ & Unbekannt & Oshita et al. 2003 \\
\hline $\begin{array}{l}\text { Disheveled-associated } \\
\text { activator of morpho- } \\
\text { genesis 1, DAAM1 }\end{array}$ & $\begin{array}{l}\text { PDZ } \\
\text { DEP }\end{array}$ & $\begin{array}{l}\text { Zytoplasma } \\
\text { Membran }\end{array}$ & Habas, unpublished \\
\hline Prickle & DEP & $\begin{array}{l}\text { Zytoplasma } \\
\text { Membran }\end{array}$ & Jenny et al. 2005, Tree et al. 2002 \\
\hline
\end{tabular}




\begin{tabular}{|c|c|c|c|}
\hline $\begin{array}{l}\text { Muscle-Specific Ki- } \\
\text { nase, MuSK }\end{array}$ & DEP & $\begin{array}{l}\text { Zytoplasma } \\
\text { Membran }\end{array}$ & Luo et al. 2002 \\
\hline Disabled 2 & DEP & Membran & Hocevar et al. 2003 \\
\hline EphrinB1 & Full length & Membran & Tanaka et al. 2003 \\
\hline $\begin{array}{l}\text { Proteinkinase } \mathrm{C} \delta \text {, } \\
\mathrm{PKC} \delta\end{array}$ & Full length & Zytoplasma & Kinoshita et al. 2003 \\
\hline $\begin{array}{l}\text { Neuroepithelial cell- } \\
\text { transforming gene } 1 \\
\text { protein, NET1 }\end{array}$ & Full length & $\begin{array}{l}\text { Membran } \\
\text { Zytoplasma }\end{array}$ & Miyakoshi et al. 2004 \\
\hline$\beta$-Arrestin & Full length & Zytoplasma & Chen et al. 2003 \\
\hline
\end{tabular}

Tabelle 2 Bindungspartner von Dsh. Modifiziert nach Wallingford und Habas 2005. FRAT=Frequently Rearranged in Advanced T-Cell Lymphomas ist das Säugetierhomolog des GSK3-bindenden Proteins. PAR1 $=$ Protease-activated receptor $1 . \mathrm{EPS} 8=$ Epidermal growth factor receptor kinase substrate $8 . \mathrm{MuSK}=$ Muscle-Specific Kinase. NET1= Neuroepithelial cell-transforming gene 1 Protein.

Im Zuge der Wnt-induzierten Signaltransduktion transloziert DVL an die Plasmamebran. Es wird aktiviert, höchstwahrscheinlich durch Phosphorylierung. Prinzipiell kommen hierfür zahlreiche Proteinkinasen in Betracht. Bisher am besten beschrieben sind die Casein-Kinasen

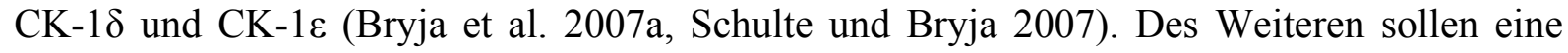
weitere CK-Unterform (CK-2), aber auch PAR1 und $\beta$-Arrestin DVL hyperphosphorylieren und damit aktivieren (Kafka et al. 2014).

Ob nun vor allem die Tatsache, welcher DVL-Subtyp zur Membran rekrutiert wird oder welche Domäne daraufhin aktiviert wird, über die Einleitung der verschiedenen Signalkaskaden entscheidet, ist im Moment noch unklar.

Eine weitere Theorie beschreibt die Bedeutung der Verteilung des DVLs an die apikale bzw. basolaterale Membran. Laut Wu et al. (2004) soll die Rekrutierung zur an der Spitze gelegenen Membran den PCP-Ast aktivieren, während $\beta$-Catenin über die basalen und seitli-chen Anteile dephosphoryliert wird.

Es bleibt unklar, welche Bedeutung eine immer wieder beschriebene nukläre Lokalisation (Torres und Nelson 2000, Itoh et al. 2005) des eigentlich zytosolischen, Fz-bezogenen DVLs hat, beziehungsweise welche Funktionen DVL im Kern übernimmt. 2008 vermuteten Gan et al. zwar eine Bedeutung DVLs in der Vermittlung des TCF-/ $\beta$-Catenin-Komplexes mit dem Transkriptionsfaktor c-jun, genauere Mechanismen oder eine Bedeutung im Rahmen $\beta$ Catenin-unabhängiger Signalwege sind jedoch nicht eruiert.

Negative Regulierung soll DVL durch Polyubiquitinierung erfahren. Hier sind unter anderem KLHL12 (Kelch-like protein 12), NEDL1 (NEDD4-like ubiquitin-protein ligase 1), Dapper1, Prickle1 und Inversin als Modulatoren beschrieben. Die Proteinphosphatase 2A (PP2A) soll 
DVL sowohl positiv als auch negativ regulieren können in Abhängigkeit von der bindenden regulatorischen Untereinheit (Kafka et al. 2014). Deubiquitinierung wird beispielsweise durch das Enzym Usp14 (Ubiquitin carboxyl-terminal hydrolase 14) gewährleistet (Jung et al. 2013).

\subsection{Zielsetzung der Arbeit}

Die Bedeutung $\beta$-Catenin-abhängiger Wnt-Signalwege für die Tumorprogression ist für verschiedene Tumorentitäten in der Vergangenheit ausführlich beschrieben worden.

Aus Vorarbeiten der Arbeitsgruppe ist bekannt, dass es im Zuge der Brustkrebsmetastasierung zur Überexpression von Wnt5a und damit verbunden zur Aktivierung $\beta$-Catenin-unabhängiger Signalkaskaden kommt (Pukrop et al. 2006, Pukrop et al. 2010, Klemm et al. 2011, Bleckmann et al. 2013).

Ziel meiner Promotion sollte es sein, mehr über die zellulären Vorgänge in Mammakarzinomen und der Brustkrebsmetastasierung in Erfahrung zu bringen und die Bedeutung der $\beta$-Catenin-unabhängigen Signalwege in diesem Kontext zu eruieren.

Vorerst wollte ich das Spektrum der bisher durch die Arbeitsgruppe auf nicht-kanonische Marker untersuchten Brustkrebslinien erweitern und analysierte hierfür die Zelllinien hTERTHME1, MCF-7, SkBr3 und MDA-MB 231 auf mRNA und Proteinebene.

Da wie bei Klemm et al. 2011 beschrieben, der Transmembranrezeptor ROR2 in den Hirnmetastasen der Brustkrebspatientinnen hoch exprimiert wurde, war ein Schwerpunkt der Arbeit ROR2 in der Östrogenrezeptor-positiven, luminal A klassifizierten Brustkrebszelle MCF-7 überzuexprimieren und diese Zellen vergleichend hinsichtlich funktioneller und morphologischer Eigenschaften zu charakterisieren.

Da die ROR-Rezeptoren, v.a. jedoch ROR2 zunehmend als Ko-Rezeptor von Fz in den DVLabhängigen Signalwegen beschrieben werden, führte ich ähnliche Untersuchungen auch mit MCF-7 Zellen durch, in welche ich verschiedene FLAG-markierte DVL3-Konstrukte stabil eingebracht hatte. Hierbei erhoffte ich mir auch weitere Informationen über DVL3 als Schaltprotein zwischen $\beta$-Catenin-abhängigen und -unabhängigen Wnt-Signalwegen zu gewinnen.

Nachdem ich die pro-invasive Wirkung von DVL3 in vitro nachweisen konnte, war von Interesse, inwieweit zerebrale Mamma-Karzinommetastasen eine Expression, eventuell sogar eine Überexpression von DVL3 zeigten, um so eine potentielle Bedeutung meiner Analysen in vivo abwägen zu können. 


\section{Material und Methoden}

\subsection{Material}

\subsubsection{Oligonukleotide für qRT-PCR}

Für die Echtzeit Polymerase-Kettenreaktion wurden Primer wie unter 2.2.5.3 beschrieben synthetisiert und getestet. Die Sequenzen sind hier tabellarisch aufgeführt.

\begin{tabular}{|c|c|c|c|}
\hline Gen & Primer & Sequenz & Quelle \\
\hline DVL1 & $\begin{array}{l}\text { hsDVL1_88 fwd } \\
\text { hsDVL1_88 rev }\end{array}$ & $\begin{array}{l}\text { TCAACATGGAAAGACATCAC } \\
\text { ATGGAGCCAATGTAGATGC }\end{array}$ & selbst entwickelt \\
\hline DVL2 & $\begin{array}{l}\text { hsDVL2_103 fwd } \\
\text { hsDVL2_103 rev }\end{array}$ & $\begin{array}{l}\text { TCAACAAGATCACCTTCTCTG } \\
\text { CCATCGTTGTCATTGAGAG }\end{array}$ & selbst entwickelt \\
\hline DVL3 & $\begin{array}{l}\text { hsDVL3_238 fwd } \\
\text { hsDVL3_238 rev }\end{array}$ & $\begin{array}{l}\text { CTTCTGTGCTGATAACCCA } \\
\text { GTCTCTGTGTCATTGTCCA }\end{array}$ & selbst entwickelt \\
\hline ROR1 & $\begin{array}{l}\text { hsROR1Ex5fw/Ex6rv115 fwd } \\
\text { hsROR1Ex5fw/Ex6rv115 rev }\end{array}$ & $\begin{array}{l}\text { CGTCTATATGGAGTCTTTGCAC } \\
\text { GAATGGCGAACTGAGAACAC }\end{array}$ & selbst entwickelt \\
\hline ROR2 & $\begin{array}{l}\text { hsROR2 fwd } \\
\text { hsROR2 rev }\end{array}$ & $\begin{array}{l}\text { TTсттстTGGTTTGCATGTG } \\
\text { CTGATCTCTTTGAGTTTGGC }\end{array}$ & selbst entwickelt \\
\hline Snaill & $\begin{array}{l}\text { hsSNAI1 (60) } f w d \\
\text { hsSNAI1 (60) rev }\end{array}$ & $\begin{array}{l}\text { CAATCGGAAGCCTAACTACAG } \\
\text { СTGCTGGAAGGTAAACTCTG }\end{array}$ & selbst entwickelt \\
\hline Vimentin & $\begin{array}{l}\text { hsVimentin (106) fwd } \\
\text { hsVimentin (106) rev }\end{array}$ & $\begin{array}{l}\text { CCTTGAACGCAAAGTGGAATC } \\
\text { GACATGCTGTTCCTGAATCTGAG }\end{array}$ & selbst entwickelt \\
\hline Wnt5a & hs Wnt5a Ex4 fw/Ex5 rv fwd & AGG GCT CCT ACG AGA GTG CT & $\begin{array}{l}\text { Weeraratna et } \\
\text { al. (2002) }\end{array}$ \\
\hline & hs Wnt5a Ex4 fw/Ex5 rv rev & GAC ACC CCA TGG CAC TTG & \\
\hline Wnt5b & $\begin{array}{l}\text { hs Wnt5b Ex4 fw/Ex5 rv fwd } \\
\text { hs Wnt5b Ex4 fw/Ex5 rv rev }\end{array}$ & $\begin{array}{l}\text { AGA AGA ACT TTG CCA AAG GA } \\
\text { CTA CGT CTG CCA TCT TAT ACA C }\end{array}$ & selbst entwickelt \\
\hline ZEB 1 & $\begin{array}{l}\text { hsZEB1 fwd } \\
\text { hsZEB1 rev }\end{array}$ & $\begin{array}{l}\text { ACAACAAGACACTGCTGTCA } \\
\text { TGGACAGGTGAGTAATTGTGAA }\end{array}$ & selbst entwickelt \\
\hline ZEB2 & $\begin{array}{l}\text { hsZEB2 fwd } \\
\text { hsZEB2 rev }\end{array}$ & $\begin{array}{l}\text { TTCCTGGGCTACGACCATAC } \\
\text { TGTGCTCCATCAAGCAATTC }\end{array}$ & $\begin{array}{l}\text { Mani et al. } \\
\text { (2008) }\end{array}$ \\
\hline
\end{tabular}

Fwd für forward entspricht $5^{\prime} \rightarrow 3^{\text {' }}$

Rev für reverse entspricht $3^{\prime} \rightarrow 5^{\circ}$ 
Die qRT-PCR-Primer wurden mit Hilfe des Programms PerlPrimer ausgewählt und durch die Firma Iba in Göttingen synthetisiert (http://perlprimer.sourceforge.net).

\subsubsection{Plasmide}

\begin{tabular}{|c|c|c|}
\hline Plasmid & Resistenzen & Referenz. \\
\hline pcDNA 3.1/Zeo $(+)$ & $\begin{array}{l}\text { Leervektor mit Zeocin }{ }^{\mathrm{TM}} \text { und Ampicillin- } \\
\text { Resistenzkasetten }\end{array}$ & $\begin{array}{c}\text { Invitrogen Life } \\
\text { Technologies, Paisley, UK }\end{array}$ \\
\hline DVL3 Wildtyp & $\begin{array}{l}\text { Full length DVL3 plus FLAG-Markierung, } \\
\text { Zeocin }^{\mathrm{TM}} \text { und Ampicillin-Resistenzkasetten }\end{array}$ & $\begin{array}{l}\text { Randall T. Moon, } \\
\text { Washington D.C., USA }\end{array}$ \\
\hline DVL3 $\Delta \mathrm{DIX}$ & Zeocin $^{\mathrm{TM}}$ und Ampicillin-Resistenzkasetten & $\begin{array}{l}\text { Randall T. Moon, } \\
\text { Washington D.C., USA }\end{array}$ \\
\hline DVL3 $\Delta$ DIX $\Delta$ PDZ & Zeocin $^{\mathrm{TM}}$ und Ampicillin-Resistenzkasetten & $\begin{array}{l}\text { Randall T. Moon, } \\
\text { Washington D.C., USA }\end{array}$ \\
\hline DVL3 $\triangle$ DIX $\triangle \mathrm{PDZ} \triangle \mathrm{DEP}$ & Zeocin $^{\mathrm{TM}}$ und Ampicillin-Resistenzkasetten & $\begin{array}{c}\text { Randall T. Moon, } \\
\text { Washington D.C., USA }\end{array}$ \\
\hline DVL3 $\triangle \mathrm{PDZ} \triangle \mathrm{DEP}$ & Zeocin $^{\mathrm{TM}}$ und Ampicillin-Resistenzkasetten & $\begin{array}{l}\text { Randall T. Moon, } \\
\text { Washington D.C., USA }\end{array}$ \\
\hline DVL3 $\triangle \mathrm{DEP}$ & Zeocin $^{\mathrm{TM}}$ und Ampicillin-Resistenzkasetten & $\begin{array}{l}\text { Randall T. Moon, } \\
\text { Washington D.C., USA }\end{array}$ \\
\hline DVL3 $\Delta \mathrm{C}$ term & Zeocin $^{\mathrm{TM}}$ und Ampicillin-Resistenzkasetten & $\begin{array}{l}\text { Randall T. Moon, } \\
\text { Washington D.C., USA }\end{array}$ \\
\hline hsROR2 & $\begin{array}{l}\text { Neomycin }{ }^{\mathrm{TM}} / \mathrm{G}-418 \text { und Ampicillin- } \\
\text { Resistenzkasetten }\end{array}$ & $\begin{array}{l}\text { Alexandra Schambony, } \\
\text { Erlangen, Deutschland }\end{array}$ \\
\hline
\end{tabular}

Da die verwendeten Plasmide nicht selbst synthetisiert, sondern von Randall T. Moon, Washington D.C., USA, bezogen wurden, erfolgte die detaillierte Charakterisierung der Schnittstellen zwischen den Domänen mittels Alignment. Hierfür wurde die bekanntgegebene Plasmidsequenz von DVL3 wt bzw. dem Leervektor, mit derer des zu untersuchenden Knockouts verglichen. Hierzu wurde die Basic Local Alignment Search Tool (BLAST)-Funktion der Homepage des National Center for Biotechnology Information (NCBI) eingesetzt (http://blast.ncbi.nlm.nih.gov/Blast.cgi). 


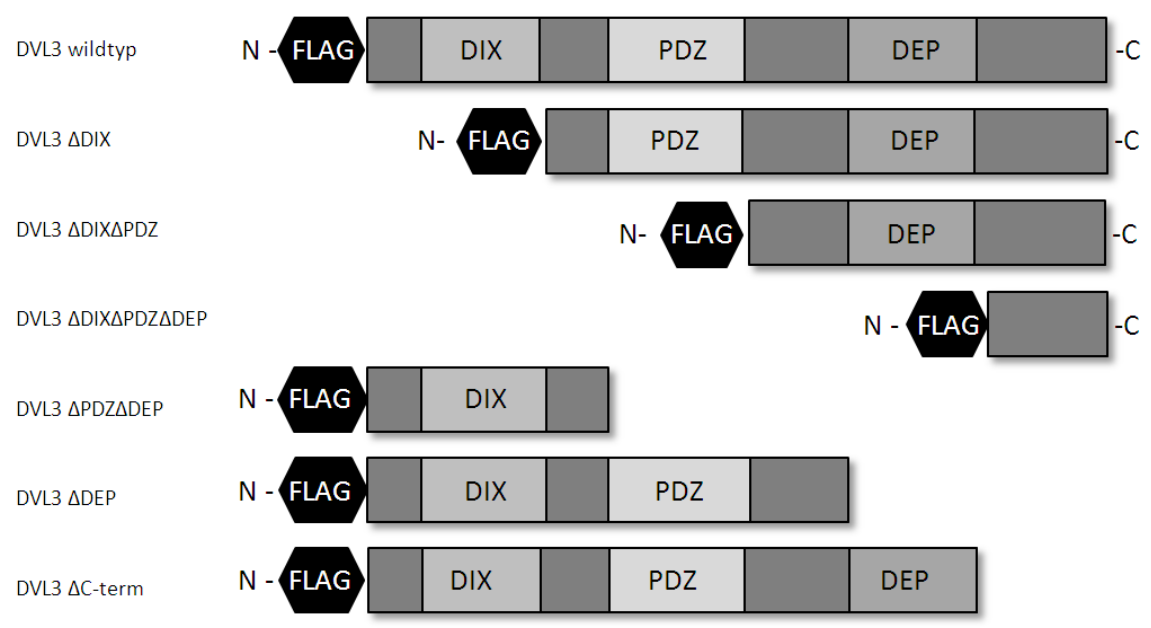

Abbildung 2.1 Übersicht über die verwendeten DVL3-Konstrukte. Modifiziert nach Randall T. Moon, Washington D.C., USA; zum Vergleich siehe auch Angers et al. 2006.

\begin{tabular}{|c|c|c|c|}
\hline Konstrukt & $\begin{array}{c}\text { Offizielle Bezeichnung durch } \\
\text { Randall T. Moon }\end{array}$ & $\begin{array}{l}\text { Schnittstellen } \\
\text { auf Plasmid }\end{array}$ & $\begin{array}{c}\text { Länge } \\
\text { Konstrukt }\end{array}$ \\
\hline DVL3 Wildtyp-FLAG & XE251 pCDNA3.1(zeo)-hDsh3 & $141-2292 \mathrm{bp}$ & $2151 \mathrm{bp}$ \\
\hline DVL3 $\triangle \mathrm{DIX}$ & XE253 pCDNA3.1(zeo)-hDsh3-82-716 & $387-2293 \mathrm{bp}$ & 1906 bp \\
\hline DVL3 $\Delta$ DIX $\Delta$ PDZ & XE252 pCDNA3.1(zeo)-hDsh3-333-716 & $1137-2293 \mathrm{bp}$ & $1156 \mathrm{bp}$ \\
\hline DVL3 $\Delta$ DIX $\triangle$ PDZ $\triangle \mathrm{DEP}$ & XE254 pCDNA3.1(zeo)-hDsh3-497-716 & $1629-2293 \mathrm{bp}$ & $664 \mathrm{bp}$ \\
\hline DVL3 $\triangle \mathrm{PDZ} \triangle \mathrm{DEP}$ & $\begin{array}{c}\mathrm{XE} 255 \text { pCDNA3.1(zeo)-hDsh3- } \\
\text { truncPDZ }\end{array}$ & $141-881 \mathrm{bp}$ & $740 \mathrm{bp}$ \\
\hline DVL3 $\triangle \mathrm{DEP}$ & $\begin{array}{l}\mathrm{XE} 257 \mathrm{pCDNA3.1(zeo)-hDsh3-} \\
\text { truncDEP }\end{array}$ & $141-1406 \mathrm{bp}$ & $1265 \mathrm{bp}$ \\
\hline DVL3 $\Delta \mathrm{C}$ term & $\begin{array}{c}\text { XE256 pCDNA3.1(zeo)-hDsh3- } \\
\text { deltaCTER }\end{array}$ & $141-1625 \mathrm{bp}$ & $1484 \mathrm{bp}$ \\
\hline
\end{tabular}

Daraus ergeben sich zwei Unterschiede in den Konstrukt-Längen:

- Die Schnittstelle des Wildtyp-Konstrukts ist Basenpaar 2292. Die Schnittstelle der mit dem C-Terminus abschließenden anderen Konstrukte ist jedoch Basenpaar 2293

- Die Schnittstellen der Konstrukte DVL3 $\triangle \mathrm{DIX} \Delta \mathrm{PDZ} \triangle \mathrm{DEP}$ und $\Delta \mathrm{C}$-term sind nicht kongruent, sondern variieren um 4 bp (1 Aminosäure) 


\subsubsection{Antikörper}

\begin{tabular}{|c|c|c|}
\hline Primärer Antikörper & Verdünnung & Firma/Bezugsquelle \\
\hline Active $\beta$-catenin & $1: 1.000$ & \# 05-665, Millipore (Schwalbach) \\
\hline$\beta$-catenin $(\mathrm{E}-5)$ & $1: 1.000$ & sc-7963, Santa Cruz (Heidelberg) \\
\hline c-Jun (60A8) & $1: 1.000$ & \# 9165, Cell Signaling (Frankfurt a. M.) \\
\hline DVL3 & $1: 1.000$ & \# 3218, Cell Signaling (Frankfurt a. M.) \\
\hline FLAG & $\begin{array}{l}\text { WB: } 1: 6.000 \\
\text { IF: } 1: 100\end{array}$ & F-4042, Sigma-Aldrich (München) \\
\hline HDAC1 & $1: 1.000$ & \# 2062, Cell Signaling (Frankfurt a. M.) \\
\hline JNK $1 / 3(c-17)$ & $1: 1.000$ & sc-474, Santa Cruz (Heidelberg) \\
\hline phospho-c-Jun (Ser63) II & $1: 1.000$ & \# 9261, Cell Signaling (Frankfurt a. M.) \\
\hline phospho-JNK (Thr183/Tyr185) & $1: 1.000$ & \# 9251, Cell Signaling (Frankfurt a. M.) \\
\hline ROR2 & $\begin{array}{l}\text { WB: } 1: 50 \\
\text { IF: } 1: 2\end{array}$ & $\begin{array}{c}\text { monoklonal, Maus, Hybridoma- } \\
\text { Supernatant Alexandra Schambony } \\
\text { (Erlangen) }\end{array}$ \\
\hline Wnt5a & $1: 1.000$ & $\begin{array}{c}\text { \# MAB645, R \& D Systems (Wiesbaden- } \\
\text { Nordenstadt) }\end{array}$ \\
\hline
\end{tabular}

\begin{tabular}{l|cc}
\hline \multicolumn{1}{c|}{$\begin{array}{c}\text { Sekundärer Antikörper } \\
\text { Western Blot }\end{array}$} & Verdünnung & Firma/Bezugsquelle \\
\hline goat anti-mouse IgG-HRP & $1: 6.000$ & sc-2005, Santa Cruz (Heidelberg) \\
goat-anti-rabbit IgG-HRP & $1: 6.000$ & sc-2004, Santa Cruz (Heidelberg) \\
goat-anti-rat IgG-HRP & $1: 6.000$ & sc-2006, Santa Cruz (Heidelberg) \\
\hline
\end{tabular}

\begin{tabular}{l|cc}
\hline \multicolumn{1}{c|}{$\begin{array}{c}\text { Sekundärer Antikörper } \\
\text { Immunfluoreszenz/weitere Zusätze }\end{array}$} & Verdünnung & Firma/Bezugsquelle \\
\hline Donkey anti-rabbit IgG-FITC & $1: 500$ & $\# 406403$, BioLegend \\
Goat anti-mouse IgG-FITC & $1: 500$ & sc-2010, Santa Cruz (Heidelberg) \\
\hline
\end{tabular}

\subsubsection{Bakterien}

Für die Plasmidamplifikation wurde der kompetente Escherichia coli (E. coli)-Stamm Top 10 der Firma Invitrogen Europe in Paisly, Großbritannien verwendet. 


\subsubsection{Zelllinien}

Die humanen Karzinomzelllinien wurden wie folgt bezogen:

\begin{tabular}{|c|c|c|c|c|c|}
\hline Name & Ursprung & Merkmale & Klass. & Herkunft & Referenz \\
\hline $\begin{array}{l}\text { hTERT- } \\
\text { HME1 }\end{array}$ & $\begin{array}{l}\text { Brustdrüsenepithel- } \\
\text { gewebe }\end{array}$ & $\begin{array}{l}\text { Benignes Drüsen- } \\
\text { ausgangsgewebe, } \\
\text { immortalisiert mit } \\
\text { hTERT }\end{array}$ & & $\begin{array}{l}\text { BD Bioscience } \\
\text { Clontech, Heidel- } \\
\text { berg }\end{array}$ & \\
\hline MCF-7 & $\begin{array}{l}\text { Humane Adenokar- } \\
\text { zinom-Zelllinie der } \\
\text { Brust }\end{array}$ & ER positiv & Luminal A & $\begin{array}{l}\text { Deutsche Samm- } \\
\text { lung von Mikro- } \\
\text { organismen und } \\
\text { Zellkulturen } \\
\text { (DSMZ, Braun- } \\
\text { schweig, Deutsch- } \\
\text { land) }\end{array}$ & $\begin{array}{l}\text { Soule et al. } \\
1973\end{array}$ \\
\hline $\begin{array}{l}\text { MDA-MB } \\
231\end{array}$ & $\begin{array}{l}\text { Humane Adenokar- } \\
\text { zinom-Zelllinie der } \\
\text { Brust }\end{array}$ & $\begin{array}{l}\text { ER negative, } \\
\text { PR negative, } \\
\text { Her2 negativ }\end{array}$ & Claudin-low & $\begin{array}{l}\text { Americal Type } \\
\text { Culture Collec- } \\
\text { tion (ATCC), } \\
\text { Wesel }\end{array}$ & $\begin{array}{l}\text { Cailleau et } \\
\text { al. } 1974\end{array}$ \\
\hline SkBr3 & $\begin{array}{l}\text { Humane Adenokar- } \\
\text { zinom-Zelllinie der } \\
\text { Brust }\end{array}$ & Her2 positiv & Her2 & ATCC, Wesel & $\begin{array}{l}\text { Trempe } \\
1976\end{array}$ \\
\hline
\end{tabular}

Alle Zelllinien wurden entsprechend den Herstellerangaben bei $37{ }^{\circ} \mathrm{C}$ und $95 \%$ Luftfeuchtigkeit mit einem $\mathrm{CO}_{2}$-Gehalt von $5 \%$ inkubiert. Die langfristige Lagerung erfolgte in fetalem Kälberserum mit $10 \%$ (v/v) DMSO bei $-150{ }^{\circ} \mathrm{C}$.

\subsubsection{Patientenmaterial}

Die Gewebsproben der Hirnmetastasen der Mamma-Karzinom-Patientinnen wurden nach Vorlage der erforderlichen Genehmigungen durch den Ethikausschuss der Universitätsklinik Göttingen nach der neurochirurgischen Resektion konserviert, archiviert und bis zur weiteren Verarbeitung aufbewahrt.

\subsubsection{Medien}

\subsubsection{Medien für die Bakterienkultur}

Das Bakterienmedium wurde mit bidestilliertem Wasser angesetzt, im Anschluss 20 Minuten bei $121{ }^{\circ} \mathrm{C}$ und 2 bar autoklaviert und bei $4{ }^{\circ} \mathrm{C}$ gelagert. Zur Herstellung der Bakterienkultur- 
platten wurde dieser Grundsubstanz vor dem Autoklavieren 1,5\%(w/v) Agar, wie unter 2.2.2.1 beschrieben zugesetzt.

\section{Luria Bertani (LB)-Medium:}

$\begin{array}{ll}\text { Pepton } & 10 \mathrm{~g} \\ \mathrm{Hefeextrakt} & 5 \mathrm{~g} \\ \mathrm{NaCl} & 10 \mathrm{~g} \\ \mathrm{H}_{2} \mathrm{O} & 11\end{array}$

\subsubsection{Medien für die eukaryontische Zellkultur}

Die Zelllinien MCF-7, MDA-MB 231 und SkBr3 wurden in RPMI 1640 (PAA, Cölbe) mit 10 $\%$ (v/v) fetalem Kälberserum (FKS) versetzt kultiviert.

Die immortalisierte hTERT-HME1 Zelllinie wurde in Serum-freiem, volldefiniertem Mammary Epithelial Cell Growth (MECG) Medium der Firma PromoCell (Heidelberg) kultiviert.

\subsubsection{Antibiotika}

Zur Selektion der transformierten Bakterienstämme wurde das Antibiotikum Ampicillin in einer Konzentration von $100 \mu \mathrm{g} / \mathrm{ml}$ dem abgekühlten Medium kurz vor Gebrauch zugesetzt.

Die transfizierten eukaryontischen Zellen wurden zur Selektion je nach Resistenzkasette mit Zeocin $^{\mathrm{TM}}$ (Invitrogen Europe, Paisly, UK) in einer Konzentration von $100 \mu \mathrm{g} / \mathrm{ml}$ Zellkulturmedium bzw. Neomycin ${ }^{\mathrm{TM}} / \mathrm{G}-418$ (Roche, Mannheim, Deutschland) in einer Konzentration von $750 \mu \mathrm{g} / \mathrm{ml}$ versetzt.

\subsubsection{Lösungen und Zusätze}

\subsubsection{Zellkultur}

\begin{tabular}{l|lll}
\hline \multicolumn{1}{c|}{ Abkürzung } & \multicolumn{1}{|c}{ Name } & \multicolumn{1}{c}{ Firma } & \multicolumn{1}{c}{ sonstiges } \\
\hline DMSO & Dimethylsulfidoxid & Sigma, München & \\
FCS & Fetales Kälberserum & Sigma, München & \\
Trypsin & & Biochrom, Berlin & \\
MTT-Reagenz & 3-(4,5-Dimethylthiazol-2-yl )2,5- & Sigma, München & $5 \mathrm{mg} / \mathrm{ml}$ in RPMI 1640 \\
& Diphenytetrazoliumbromid- & & \\
& Reagenz & & \\
MTT- & 3-(4,5-Dimethylthiazol-2-yl )2,5- & & \\
Lysepuffer & Diphenytetrazoliumbromid- & & \\
& Lysepuffer & & \\
\hline
\end{tabular}




\begin{tabular}{|c|c|c|c|}
\hline PBS & & $\begin{array}{l}\text { PAN Biotech } \\
\text { GmbH, Aidenbach }\end{array}$ & \\
\hline rhWnt5a & Rekombinantes Wnt5a & $\begin{array}{l}\text { R \& D Systems, } \\
\text { Wiesbaden }\end{array}$ & \\
\hline RIPA-Puffer & Radioimmunoprecipitation assay & & $\begin{array}{l}150 \mathrm{mM} \mathrm{NaCl} \\
1 \%(\mathrm{w} / \mathrm{v}) \text { TritonX } \\
0,5 \%(\mathrm{w} / \mathrm{v}) \\
\text { Natriumdesoxychelat } \\
0,1 \%(\mathrm{w} / \mathrm{v}) \mathrm{SDS} \\
50 \mathrm{mM} \mathrm{Tris} \\
\text { Auf } \mathrm{pH} 8 \text { einstellen }\end{array}$ \\
\hline Protease- & & Roche, Diagnostics & $10 \%(\mathrm{v} / \mathrm{v})$ \\
\hline Inhibitor & & GmbH, Mannhein & \\
\hline Phospho-Stop & Phosphatase-Inhibitor & $\begin{array}{l}\text { Roche, Diagnostics } \\
\text { GmbH, Mannhein }\end{array}$ & $1 \%(\mathrm{v} / \mathrm{v})$ \\
\hline NP-40 & & Sigma, München & \\
\hline
\end{tabular}

\subsubsection{Western Blot}

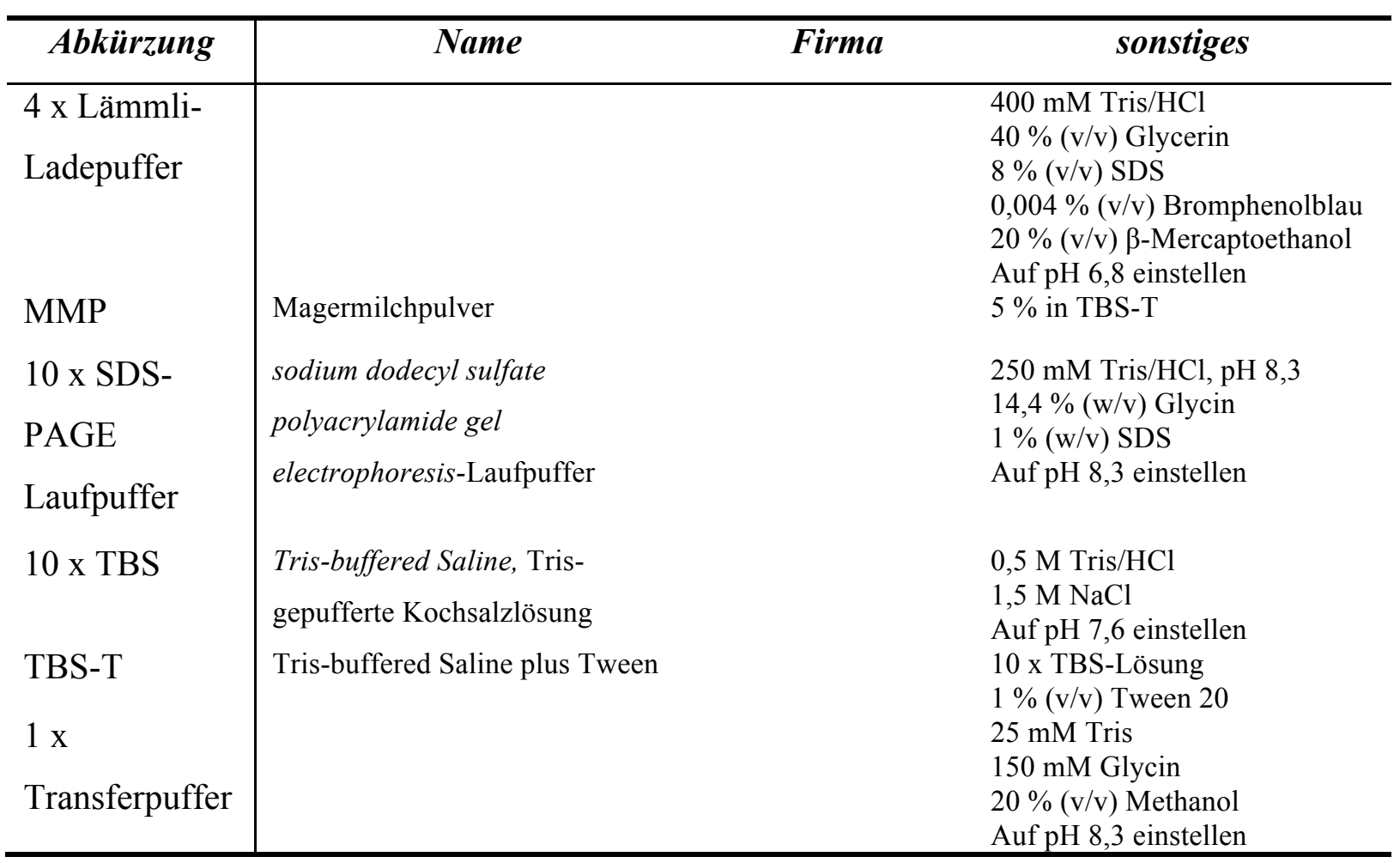




\subsubsection{Immunfluoreszenz}

\begin{tabular}{l|lll}
\hline \multicolumn{1}{c|}{ Abkürzung } & \multicolumn{1}{|c}{ Name } & Firma & sonstiges \\
\hline DAPI & 4',6' diamino-2' phenylindol & Sigma, München & $200 \mathrm{ng} / \mathrm{ml}$ in PBS \\
PFA & Paraformaldehyd & Sigma, München & $4 \%$ in PBS \\
TRITC- & Rhodamin-Phalloidin & Sigma, München & \\
Phalloidin & & & \\
Triton X-100 & Octylphenoxypolyethoxyethanol & Sigma, München & $0,02 \%$ in PBS/TBS \\
\hline
\end{tabular}

\subsubsection{4 qRT-PCR}

$10 \times$ PCR-Puffer:

Tris- $\mathrm{HCl} \mathrm{pH} 8,8$

$0,75 \mathrm{M}$

Ammoniumsulfat

$0,2 \mathrm{M}$

Tween-20

$0,1 \%(\mathrm{v} / \mathrm{v})$

\section{SYBR $^{\circledR}$-Green Master Mix:}

$10 \times$ PCR-Puffer $2,5 \mathrm{ml}$

$25 \mathrm{mM} \mathrm{MgCl}_{2}$

$3 \mathrm{ml}$

1:100 SYBR ${ }^{\circledR}$-Green (Roche, Mannheim)

20 mM dNTP-Mix

$5 \mathrm{U} / \mu 1$ Taq-Polymerase

$10 \%$ Triton X-100

$652 \mu 1$

$1 \mathrm{M}$ Trehalose

\section{PCR-Reaktionsmix:}

$\begin{array}{ll}\text { SYBR }^{\circledR} \text {-Green Master Mix } & 5,6 \mu l \\ \text { fw-Primer }(10 \mu \mathrm{M}) & 0,3 \mu \mathrm{l} \\ \text { rv-Primer }(10 \mu \mathrm{M}) & 0,3 \mu \mathrm{l} \\ \text { cDNA } 5 \mathrm{ng} / \mu \mathrm{l} & 2 \mu \mathrm{l} \\ \mathrm{H}_{2} \mathrm{O} & 1,8 \mu \mathrm{l}\end{array}$

\subsubsection{Enzyme}

Für den Restriktionsverdau wurden die Enzyme HindIII, BamHI, EcoRI, NotI, BgIII und der Puffer Blau der Firma Roche, Darmstadt verwendet. 


\subsubsection{Längenstandards}

\begin{tabular}{l|l}
\hline \multicolumn{1}{c|}{ Name } & \multicolumn{1}{c}{ Firma } \\
\hline $1 \mathrm{~kb}$ DNA-Ladder & NEB, Frankfurt a.M. \\
100 bp-DNA-Ladder & NEB, Frankfurt a.M. \\
Precision Plus Protein Dual Color & Biorad, München \\
Standards & \\
\hline
\end{tabular}

\subsubsection{Gebrauchsfertige Reaktionssysteme}

\begin{tabular}{|c|c|c|}
\hline Abkürzung & Name & Firma \\
\hline ECL prime $e^{\mathrm{TM}}$ & $\begin{array}{l}\text { Enhanced chemiluminescence } \\
\text { detection system prime }\end{array}$ & GE Healthcare, Solingen \\
\hline High Pure ${ }^{\mathrm{TM}}$ RNA Isolation & & Roche, Mannheim \\
\hline iScript $^{\mathrm{TM}} \mathrm{cDNA}$ Synthesis Kit & & Bio-Rad, München \\
\hline LOWRY-Proteinassay & & BioRad, München \\
\hline Nanofectin $^{\mathrm{TM}}$ & $\begin{array}{l}\text { Transfection Reagent, } \\
\text { Transfektionslösung }\end{array}$ & PAA, Cölbe \\
\hline EndoFree Plasmid Maxi Kit ${ }^{\circledR}$ & & Quiagen, Hilden \\
\hline
\end{tabular}

\subsubsection{Verbrauchsmaterialien}

$10 \mathrm{~cm}^{2}$-Zellkulturflaschen

$25 \mathrm{~cm}^{2}$-Zellkulturflaschen

2-Napf-Kammerobjektträger

6-Napf-Zellkulturschalen

24-Napf-Zellkulturschalen

48-Napf-Zellkulturschalen

96-Napf-Photometerplatten

Blotting Papier

Deckgläser $\varnothing 5 / 10 / 12$ mm

Deckgläser 25 x $60 \mathrm{~mm}$

Zentrifugenröhrchen $(15 / 50 \mathrm{ml})$

Glaspasteurpipetten

HybondTM-C Extra Nitrozellulose

Transfermembranen

Objektträger 76 x $26 \mathrm{~mm}$

Pipettenspitzen

Polykarbonatmembran (10 $\mu \mathrm{m}$ Poren $)$

Reaktionsgefäße $(0,5 / 1,5 / 2 \mathrm{ml})$
Sarstedt, Nümbrecht

Sarstedt, Nümbrecht

Nunc, Langenselbold

Nunc, Langenselbold

Becton Dickinson, Heidelberg

Becton Dickinson, Heidelberg

Sarstedt, Nümbrecht

Heinemann, Schwäbisch Gmünd

Thermo Scienific, Braunschweig

Roth, Karlsuhe

Sarstedt, Nümbrecht

Sarstedt, Nümbrecht

Amersham, Freiburg i. Breisgau

Thermo Scienific, Braunschweig

Sarstedt, Nümbrecht

Nucleopore, Pleasanton, CA, USA

Sarstedt, Nümbrecht 
Serologische Auslaufpipetten 5/10/25 ml

Zellschaber

\subsubsection{Geräte}

$\mathrm{CO}_{2}$-Brutschrank $C B 150$

Plattenphotometer Sunrise $e^{\mathrm{TM}}$

Konfokalmikroskop LSM 510

Lichtmikroskop Axiovert $200 \mathrm{M}$

Magnetrührer REO basic $C$

NanoDrop ${ }^{\mathrm{TM}}$ Spectrophotometer ND-1000

Sicherheitswerkbank UVF 6.12S

Thermomixer 5437

ThermoCycler T3000

Transilluminator-CCD-Kamera

UV-Transilluminator $T I 3$

Varioklav ${ }^{\circledR}$ Autoklaviergerät

Vortexer Genius $3^{\circledR}$

Wasserbad Köttermann

Wasservollentsalzungsanlage

Zählkammer Neubauer Improved

Zentrifuge $5415 \mathrm{C}$

Zentrifuge $1-15 \mathrm{~K}$

Zentrifuge Universal $30 \mathrm{RF}$

Zentrifuge Multifuge 3 L-R
Sarstedt, Nümbrecht

Sarstedt, Nümbrecht

Binder, Tuttlingen

Tecan, Männedorf, Schweiz

Zeiss, Göttingen

Zeiss, Göttingen

IAK Werk, Staufen

PeqLab, Erlangen

BDK, Sonnenbühl-Genkingen

Eppendorf, Hamburg

Biometra, Göttingen

Intas, Göttingen

Biometra, Göttingen

Thermo Scientific, Bonn

IKA Labortechnik, Staufen

Uetze, Hänigsen

Millipore, Schwalbach

LO Laboroptik, Friedrichsdorf

Eppendorf, Hamburg

Sigma, München

Hettich, Tuttlingen

Heraeus Thermo Scientific, Bonn

\subsection{Methoden}

\subsubsection{Allgemeine Zellkulturmethoden}

\subsubsection{Zellkultivierung}

Um eine Kontamination mit Bakterien und Pilzen zu vermeiden, wurden alle Schritte der Zellkultur, Ko-Kultur und Isolierung unter sterilen Bedingungen unter einer Zellkulturwerkbank durchgeführt. Folglich wurden alle verwendeten Materialien autoklaviert oder durch den Hersteller sterilisiert verpackt und so keimfrei verwendet.

Die Zelllinien MCF-7, SkBr3 und MDA-MB 231 und hTERT-HME1 wurden bei $37{ }^{\circ} \mathrm{C}$ einem $\mathrm{CO}_{2}$-Gehalt von $5 \%$ und einer Luftfeuchtigkeit von $90 \%$ inkubiert. Als Zellkulturmedium wurde für die Brustkrebszelllinien RPMI 1640 mit L-Glutamin, versehen 
mit $10 \%(\mathrm{v} / \mathrm{v})$ hitzein-aktiviertem fetalen Kälberserum (FCS) (beides der Firma Sigma, Deisenhofen), verwendet. Die Zelllinie hTERT-HME1 wurde ohne Serum in MECG-Medium kultiviert. Ein Wechsel des Kulturmediums erfolgte aller 2-3 Tage.

Die adhärent wachsenden Brustkrebszelllinien wurden zum Teilen (,,Splitten“), bei Konfluenz des Zellrasens oder zum Aussähen der Zellen für weitere Untersuchungen mittels Trypsin vom Boden des Zellkulturgefäßes gelöst. Um die Wirkung des Trypsins zu garantieren, wurde nach Absaugen des Mediumüberstands der Zellrasen mit phosphatgepufferter Salzlösung (PBS) ohne $\mathrm{Ca}^{2+}$ und $\mathrm{Mg}^{2+}$ gewaschen, um Reste dieser Kationen zu entfernen. Die Trypsin/ EDTA-Lösung (0,05 \% Trypsin, 0,02 \% EDTA (w/v) in PBS) (Biochrom, Berlin) wurde im Verhältnis 1:10 mit Milli-Q-Wasser vorverdünnt. Mit einem adäquaten Volumen Trypsin wurden die Zellen für 5-10 Minuten im Brutschrank bei $37^{\circ} \mathrm{C}$ inkubiert, um eine Aktivierung des Enzyms zu gewährleisten. Durch Zugabe von Zellkulturmedium +10 \% FCS wurde das Trypsin wieder inaktiviert und die gelösten Zellen konnten in ein neues, steriles Kulturgefäß überführt werden.

Bei den hTERT-HME1-Zellen erfolgte ein mechanisches Lösen der Zellen mit einem Zellschaber.

Je nach Größe des eingesetzten Zellkulturgefäßes wurde die Menge des Kulturmediums angepasst. Für eine kleine Zellkulturflasche $\left(10 \mathrm{~cm}^{2}\right)$ wurden $5 \mathrm{ml}$, für eine mittlere Zellkulturflasche $\left(25 \mathrm{~cm}^{2}\right) 10 \mathrm{ml}$ und in den Kammern der 2-Well-Chamberslides ${ }^{\mathrm{TM}}$ je $1 \mathrm{ml}$ Medium verwendet.

Zum Vergleich siehe hierzu unter anderem Hagemann et al. 2004, Pukrop et al. 2006 sowie Klemm et al. 2011.

\subsubsection{Zellzahlbestimmung}

Die Zellzahlbestimmung erfolgte mit Hilfe einer Neubauer-Zählkammer Improved nach Herstellerangaben. Hierbei wurden in 4 Quadraten der Kammer die Zellen eines definierten Volumens $\left(0,1 \mathrm{~mm}^{3}\right)$ ausgezählt. Anschließend wurden die Werte der Kammern arithmetisch gemittelt und unter Berücksichtigung eventueller Verdünnungsfaktoren die Zellzahl der Suspensionen je Volumen berechnet.

Um das Zählen zu erleichtern, konnten die Zellen in einem Eppendorf-Cup mit Tryptophanblau gefärbt werden. $10 \mu \mathrm{l}$ der Zellsuspension wurden hierfür mit $10 \mu 1$ Trypto-phanblau durch Auf- und Abpipettieren gemischt und $10 \mu 1$ der Suspension wurden zum Auszählen in der Zählkammer verwendet. Die ausgezählten Zellen wurden hier mit dem Faktor 2 
multipliziert.

\subsubsection{Einfrieren der Zellen (Kryokonservierung)}

Die Kryokonservierung erfolgte nach Standardverfahren: $45 \mathrm{ml} 10 \%$ FCS wurden mit $5 \mathrm{ml}$ DMSO zum Einfriermedium vermischt. Die Zellen wurden, wie beschrieben, gewaschen, abtrypsiniert und in das Kulturmedium aufgenommen. Nach einer Zentrifugation für 10 Minuten bei $1.000 \mathrm{rpm}$ wurde das Medium abgesaugt und das Pellet im Einfriermedium durch auf- und abpipettieren resuspendiert. Für bis zu $48 \mathrm{~h}$ wurden die Zellen in einer Einfrierbox mit Isopropanol bei $-80{ }^{\circ} \mathrm{C}$ gelagert und dann in einem Gefrierfach bei $-150{ }^{\circ} \mathrm{C}$ weggefroren.

\subsubsection{Plasmidherstellung}

\subsubsection{Transformation von kompetenten Bakterien}

Die Transformation der kompetenten Bakterien E. coli erfolgte nach Anweisungen des Herstellers und nach dem erstmals von Hanahan 1983 beschriebenen Hitzeschockprotokoll.

Ein $50 \mu \mathrm{l}$ Aliquot kompetenter, bei $-80{ }^{\circ} \mathrm{C}$ gelagerter E. coli-Bakterien (Top 10 Invitrogen) wurde für 10 Minuten auf Eis aufgetaut und mit $1 \mu$ Plasmid versetzt.

Nach 30 Minuten Inkubation bei $4{ }^{\circ} \mathrm{C}$ auf Eis wurde die Zellmembran durch einen einminütigen Hitzeschock in einem auf $42{ }^{\circ} \mathrm{C}$ vorgeheizten Wärmeblock für das Plasmid durchgängig gemacht.

Nach erneuter Inkubation der Suspension für 2 Minuten bei $4{ }^{\circ} \mathrm{C}$ wurden $250 \mu$ LB-Medium zugesetzt. Es folgte eine geschüttelte Inkubation für eine Stunde bei $37^{\circ} \mathrm{C}$.

Während dieser Vorbereitungen wurden LB-Agarplatten für die Bakterienanzucht entsprechend den Herstellerangaben gegossen. Hierfür wurden zum LB-Medium 1,5 \% (w/v) Agar zugefügt, erhitzt und autoklaviert. Nach dem Abkühlen dieser Lösung wurde unter sterilen Bedingungen, entsprechend der Antibiotikaresistenz der Plasmide, $1 \mu \mathrm{g}$ Ampicillin je ml Medium beigefügt. In die gewünschte Anzahl 21,5- $\mathrm{cm}^{2}$-Petrischalen wurden ca. $10 \mathrm{ml}$ der handwarmen Flüssigkeit gegossen. Nach dem Abkühlen der Agarplatten -am besten über Nacht- wurden diese, luftdicht verpackt bis zu ihrer Benutzung im Kühlraum $\left(4^{\circ} \mathrm{C}\right)$ gelagert. Zur Inkubation wurden pro Konstrukt je eine Platte mit $20 \mu 1$ und eine Platte mit $50 \mu 1$ bakterienhaltiger Suspension mit Hilfe einer steril gebogenen Pipettenspitze beimpft. Die Agarplatten wurden über Nacht im $37{ }^{\circ} \mathrm{C}$ Inkubator mit dem Boden nach oben verwahrt, um das Betropfen der Kulturen mit Kondenswasser zu vermeiden. Am folgenden Tag konnten 
Bakterienkolonien gepickt werden, welche das Plasmid mit seiner Resistenzkassette gegen Ampicillin erfolgreich aufgenommen hatten.

\subsubsection{Amplifikation von Plasmid-DNA}

Zur Amplifikation der transformierten Bakterien wurde in $4 \mathrm{ml}$ Ampicillin-haltigem LBMedium eine Starterkultur mit Zellen einer Kolonie der Agarplatten angelegt und mindestens $6 \mathrm{~h}$ geschüttelt bei $37^{\circ} \mathrm{C}$ inkubiert. Sicherheitshalber pickte ich mehrere Klone einer Kolonie zur Inkubation. Aus dieser Starterkultur wurde nun eine Hauptkultur gezüchtet. Hierfür wurden $2 \mathrm{ml}$ der Starterkultur in $200 \mathrm{ml}$ Antibiotika-haltigem Medium diesmal über Nacht geschüttelt bei $37^{\circ} \mathrm{C}$ inkubiert.

\subsubsection{Präparation der Plasmid-DNA}

Für die Präparation der Plasmid-DNA wurden zwei verschiedene Verfahren einesetzt:

\subsection{1-2-3 Mini-Präparation}

Puffer 1 (P1):

Tris- $\mathrm{HCl}(\mathrm{pH} 8)$

EDTA $10 \mathrm{mM}$

RNase A $\quad 100 \mu \mathrm{g} / \mathrm{ml}$

Puffer 2 (P2):

$\mathrm{NaOH} 200 \mathrm{mM}$

SDS $\quad 1 \%(\mathrm{w} / \mathrm{v})$

Puffer 3 (P3):

Natriumacetat $(\mathrm{pH} 5,5) \quad 3 \mathrm{M}$

Die Aufreinigung der Plasmid-DNA wurde vorerst nach dem modifizierten 1-2-3-Mini Präparationsschema nach Birnboim und Doly (1979) durchgeführt, um eine sichere Aussage über das Gelingen der Transformation der kompetenten Bakterien treffen zu können. Diese sogenannte „Dirty-Prep“-Methode (ein eher unreines Aufreinigungsverfahren), hat den Vorteil, dass sie kostengünstig und schnell für kleine Mengen Plasmid-DNA durchgeführt werden kann, um so alsbald eine Aussage über den Transformationserfolg treffen zu können.

Die über Nacht geschüttelt inkubierten Bakterienkulturen wurden bereitgestellt und von jeder Probe wurden $500 \mu 1$ abgenommen und im Kühlschrank verwahrt, um bei Transformationserfolg einen Glycerolstock (15\% v/v) anlegen zu können. 
Anschließend wurden die Kulturröhrchen bei Raumtemperatur und 4.600 xg für 10 Minuten abzentrifugiert. Nach Verwerfen des Überstands in eine Perform-haltige Lösung wurden die Pellets in je $250 \mu 1$ P1-Lösung mittels auf- und abpipettieren resuspendiert und dabei in Eppendorf-Cups überführt. Nach Zugabe von $250 \mu$ P2-Lösung und Mischen durch Invertieren wurden die Zellen bei Raumtemperatur für genau 5 Minuten inkubiert.

Anschließend wurden $250 \mu \mathrm{l}$ P3-Lösung hinzugegeben und wieder durch Invertieren gemischt. Darauf folgte eine Zentrifugation bei $4{ }^{\circ} \mathrm{C}$ und $16.000 \mathrm{xg}$ für 10 Minuten, woraufhin der die Plasmid-DNA enthaltende Überstand in ein neues Eppendorf-Cup überführt wurde. Nach Zugabe von 0,7 Volumen Isopropanol (entsprach in etwa $525 \mu 1$ ) und Mischen durch Invertieren wurden die Cups für 20 Minuten bei Raumtemperatur inkubiert.

Es folgte eine Zentrifugation bei $4{ }^{\circ} \mathrm{C}$ für 10 Minuten bei $16.000 \mathrm{xg}$, das Abpipettieren des Überstands und das Waschen der Pallets in $500 \mu 170$ \% EtOH, um das gesamte Isopropanol $\mathrm{zu}$ entfernen. Anschließend wurde ein weiteres Mal 10 Minuten lang bei $4{ }^{\circ} \mathrm{C}$ und $16.000 \mathrm{xg}$ zentrifugiert. Der Überstand wurde sehr gründlich entfernt und die Pallets im offenen Eppendorf-Cup bei Raumtemperatur getrocknet ( 10 Minuten).

Die Pellets wurden vorerst in $40 \mu \mathrm{H}_{2} \mathrm{O}$ gelöst, später wurden weitere $50 \mu \mathrm{l}$ Wasser hinzugefügt und die Röhrchen bei $37^{\circ} \mathrm{C}$ für 10 Minuten geschüttelt, um das Lösen zu erleichtern.

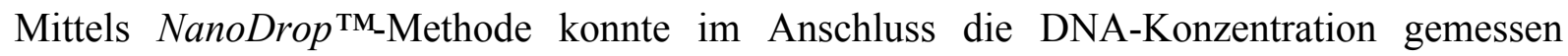
werden.

\subsection{Maxi-Präparation}

Die Präparation größerer Mengen, durch eine primär durchgeführte 1-2-3 Mini-Präparation gesicherter Plasmid-DNA, wurde mit dem EndoFree Plasmid Maxi Kit ${ }^{\circledR}$ von Qiagen nach Herstellerangaben durchgeführt.

Mit dem Kit können auf Basis des Anionen-Austauschs Plasmide mit einer Ausbeute von bis zu $500 \mu \mathrm{g}$ DNA aufgereinigt werden. Integriert ist in den Vorgang auch eine Endotoxinentfernung, was die Qualität der gewonnenen DNA sicher stellen soll.

Nach einer alkalischen Lyse mit Plasmidbindung an das Austauschharz wurden RNA, Proteine und Reste von niedermolekularen Verunreinigungen durch multiple Medium-SalzWaschungen entfernt. Das anschließende Lösen der Plasmid-DNA ist mittels hoher Salzkonzentrationen möglich. Anschließend wurde die DNA mit Isopropanol gefällt und aufgereinigt.

So besteht der Vorgang der DNA-Aufreinigung aus 5 Schritten: 1. Bakterienlyse; 2. Fitration 
des Lysats; 3. Binden der Plasmid-DNA; 4.Waschen und Elution; 5. Präzipitation und Isolierung der DNA.

Für 6 Stunden wurden 5ml LB-Amp-Medium (Konzentration 1:1.000), angeimpft mit transformierten E. coli-Bakterien aus dem Glycerolstock (vgl. Mini-Prep), bei $37{ }^{\circ} \mathrm{C}$ im Schüttelinkubator gelagert.

Da ich die Transformation der Bakterien mit mehreren verschiedenen Plasmiden durchgeführt habe, wurde die Plasmid-Isolation parallel für mehrere Konstrukte, wie in der durch den Hersteller herausgegebenen Anleitung detailliert beschrieben, durchgeführt.

\subsubsection{Bestimmung der DNA-Konzentration durch die NanoDrop ${ }^{\text {TM}}$-Methode}

Die Bestimmung der DNA-Konzentration der Plasmid-Suspensionen wurde nach Herstellerangaben, mittels des Spectrophotometer NanoDrop-1000 ${ }^{\text {TM }}$ der Firma PeqLab, Erlangen und der Software ND-1000 V3.1.0, durchgeführt.

Nach Herstellergebrauchsanweisung wurde das Gerät mit Hilfe eines $2 \mu 1$ Tropfen Wasser initialisiert und anschließend mit einem zweiten Tropfen Wasser (bzw. Lyse-Puffers) geeicht. Nun wurde je Probe ein $1 \mu 1$ großer Tropfen auf die Messstelle pipettiert, die Konzentration ermittelt und anschließend die Einsaugstelle und der Messarm gründlich mit einem Zellstofftuch gereinigt, um Kreuzkontaminationen zu vermeiden. Am Ende der Messungen wurde zur Kontrolle noch einmal das Eichwasser gemessen, es sollte bei korrektem Messen nach wie vor den Wert 0 ergeben. Die digitalen Daten konnten sowohl in Tabellenform (Format .xls) als auch grafisch (Format .pdf) zwischengespeichert und ausgewertet werden.

\subsubsection{Restriktionsverdau}

Der Restriktionsverdau wurde mittels Agarose-Gelelektrophorese ausgewertet. Deswegen wurde vor Ansetzen des Verdaus ein 1 \% Agarosegel aus HEEO Ultra Agarose (Roth, Karlsruhe), unter Berücksichtigung der Herstellerangaben, gegossen. Die gewünschte Agarosemenge wurde mit dem abgemessenen Volumen TAE-Puffer vermischt und vorsichtig im Mikrowellenherd in mehreren Schritten erhitzt. Um ein Überkochen zu verhindern und den Lösungsprozess besser verfolgen zu können, wurde der Erlenmeyerkolben mehrere Male aus der Mikrowelle genommen und vorsichtig geschwenkt. Sobald in der Lösung keine Schlieren mehr sichtbar waren, wurde das Erhitzen gestoppt und nach einem Abkühlen der Lösung auf circa $50{ }^{\circ} \mathrm{C}$ wurde eine Pipettenspitze (circa $\left.0,1 \%(\mathrm{v} / \mathrm{v})\right)$ SERVA DNA Stain ${ }^{\circledR}$ der Firma Serva, Heidelberg, wie durch den Hersteller beschrieben, hinzugefügt. 
Nach Bestimmung des Plasmidgehalts eines jeden Klons wurde mit Hilfe eines am Vortag entwickelten Schemas das $1 \mu \mathrm{g}$ Plasmid enthaltende Volumen der Suspensionen mit den entsprechenden Restriktionsenzymen (Roche), Puffer, gegebenenfalls BSA und $\mathrm{H}_{2} \mathrm{O}$ nach Herstellerangaben versetzt.

Nach Inkubation bei $37^{\circ} \mathrm{C}$ für eine Stunde im Wärmeblock wurden die $25 \mu 1$ Suspension mit je $6 \mu 16 x$ Loading-Buffer (Fermentas, St. Leon Rot) versehen, durch Auf- und Abpipettieren gut gemischt und zu je $15 \mu 1$ in die Taschen des vorbereiteten Agarose-Gels gefüllt. Hierbei ist $\mathrm{zu}$ beachten, dass je Plasmidsuspension eine neue Pipettenspitze verwendet wird, um Kontaminationen zu vermeiden.

Je nach erwarteter Fragmentgröße wurden Markersuspensionen der Firma NEB, Frankfurt a.M. in einer separaten Tasche aufgetragen, beispielsweise die 1kb DNA-Ladder oder die 100 bp-DNA-Ladder.

Nach Anlegen einer Spannung von 100 Volt für eine Stunde waren die Plasmide entsprechend ihrer Größe (bp) und Ladung im elektrischen Feld gewandert.

Hierbei gilt es zu beachten, dass ungeschnittene Plasmide auf dem Gel auch als breite Banden erscheinen können. So könnte man vermuten, dass die Restriktionsenzyme unspezifisch geschnitten hätten. Ursächlich dafür ist jedoch nur, dass die ungeschnittene, supercoiled Plasmid-DNA einen geringeren Widerstand besitzt, als die offene Form.

Mittels UV-Licht konnten die Banden auf einem UV-Transilluminator bei einer Wellenlänge von $302 \mathrm{~nm}$ dargestellt und abfotografiert werden. Dies und die Verarbeitung am PC erfolgte mittels charge-coupled device (CCD)-Kamera und mit Hilfe der dazugehörigen Software von Intas, Göttingen, Deutschland.

\section{0x TAE}

$\begin{array}{ll}\text { Tris } & 0,4 \mathrm{M} \\ \text { Essigsäure } & 0,2 \mathrm{M} \\ \text { EDTA (pH 8,5) } & 0,01 \mathrm{M}\end{array}$

\subsubsection{Transfektion}

\subsubsection{Transiente Transfektion}

Zur Transfektion der MCF-7-Zellen wurde die Transfektionsreagenz Nanofectin ${ }^{\mathrm{TM}}$ nach Herstellerangaben eingesetzt.

Mit der Transfektionsreagenz Nanofectin ${ }^{\mathrm{TM}}$ ist es möglich, Nanopartikel einheitlicher Größe 
$\mathrm{zu}$ erzeugen, die bevorzugt von der Zelle mittels Endozytose aufgenommen werden. Nanofectin $^{\mathrm{TM}}$ besteht hierfür aus zwei Komponenten, einem positiv geladenen Polymer, welches sich auf-grund seiner hohen DNA-Bindungskapazität in den zweiten Bestandteil, ein poröses Nano-Partikel, einlagert. Dieser Komplex schützt die gebundene DNA im Zytoplasma vor der Degradation durch Nukleasen. So kann der DNA-Nanopartikel-Komplex die Kernmembran durchdringen und in das Genom der Zielzelle, in meinen Versuchen die MCF-7-Zellen, integriert werden. Ein weiterer Vorteil der Transfektion mit Nanofectin ${ }^{\mathrm{TM}}$ ist, dass es sowohl für die transiente als auch -durch Selektionsdruck- für die stabile Transfektion geeignet ist. Hierbei ist es nicht toxisch und auch in Anwesenheit des Serums wirksam.

Die inkorporierte DNA wird transient transkribiert, das heißt, dass die MCF-7-Zellen nur vorübergehend die auf den Plasmiden kodierten Konstrukte exprimieren. Deswegen war meine Zielsetzung, die Zellen unter Selektionsdruck zur Aufnahme der Plasmide in das Genom, das heißt zur stabilen Transfektion, zu zwingen.

Die MCF-7-Zellen wurden über drei Tage hochgezüchtet und anschließend zunächst in 6Well-Zellkulturplatten in einer Dichte von $2-4 \times 10^{5}$ Zellen $/ \mathrm{ml}$ mit einem Mediumvolumen von 2-4 $\mathrm{ml}$ je Well ausgesät. Sie wurden dann für $24 \mathrm{~h}$ bei $37^{\circ} \mathrm{C}$ inkubiert.

Am nächsten Morgen war eine für die Transfektion ideale Konfluenz der adhärent wachsenden Zellen von circa $60 \%$ erreicht.

Pro Well wurden zu $3 \mu \mathrm{g}$ DNA, was bei meiner Vorverdünnung $3 \mu$ l Plasmid-Suspension entsprach, mit $100 \mu$ Diluent vermischt, vorsichtig mittels Vortexer gemischt (,vortexen“) und im Anschluss herunterzentrifugiert. In einem zweiten Röhrchen wurden 9,6 $\mu 1$ Nanofectin $^{\mathrm{TM}} \mathrm{zu} 100 \mu \mathrm{l}$ Diluent gegeben und ebenfalls vorsichtig gevortext und herunterzentrifugiert.

Die $100 \mu 1$ Nanofectin ${ }^{\mathrm{TM}}$-Lösung wurden dann zur $100 \mu \mathrm{l}$ DNA-Lösung gegeben. Es folgte nach kurzem Vortexen und Herunterzentrifugieren eine Inkubation der Lösungen bei Raumtemperatur für 15-30 Minuten.

Danach wurden die $200 \mu$ Nanofection/DNA-Suspension tröpfchenweise zum Serumenthaltenden Medium hinzugefügt, mittels behutsamem Schwenken wurde die Mixtur homogenisiert und gleichmäßig in den Zellkulturschalen verteilt.

Da sich die Transfektionsreagenz schädlich auf Wachstum und Vitalität der Zellen auswirkt, wurde nach 5 Stunden ein Mediumwechsel durchgeführt. Nach einer weiteren Inkubations- 
periode von mindestens 12 Stunden wurden die Zellen lichtmikroskopisch untersucht und eine Selektion mit den entsprechenden Antibiotika eingeleitet.

\subsubsection{Stabile Transfektion}

Im Anschluss an die oben beschriebene transiente Transfektion wurde, wie durch den Hersteller beschrieben, nach 24-48 Stunden das Medium gewechselt und das Antibiotikum Zeocin $^{\mathrm{TM}}$ bzw. Neomycin ${ }^{\mathrm{TM}}$ (G-418) in einer Konzentration von $100 \mu \mathrm{g} / \mathrm{ml}$ bzw. $750 \mu \mathrm{g} / \mathrm{ml}$ hinzugefügt. So wurde die Selektion der Zellen gestartet, da nur die Resistenzkassette enthaltenden Zellen weiterhin wachsen konnten. Aller zwei bis drei Tage wurde das Antibiotikum-enthaltende Medium gewechselt und die Zellen auf Viabilität und Zelldichte überprüft. Der Selektionsdruck wurde die gesamte Zeit der Kultivierung aufrechterhalten. Lediglich während der Versuche wurde Antibiotika-freies Medium verwendet.

Im Western Blot wurde überprüft, welche beiden polyklonen Kolonien das jeweilige Konstrukt am stärksten exprimierten. Diese wurden weiterhin in Kultur gehalten. Regelmäßig wurden Zellen entnommen und wie oben beschrieben bei $-150{ }^{\circ} \mathrm{C}$ zur Konservierung eingefroren.

\subsubsection{Proteinbiochemische Methoden}

\subsubsection{Herstellung von Zelllysaten für den Western Blot}

Die Mamma-Karzinom-Zellen der Zelllinien SkBr3, MDA-MB 231, hTERT-HME1 und die nativen, wie auch stabil transfizierten MCF-7-Zellen wurden für die anschließenden Experimente mittels RIPA-Puffer lysiert (vgl. hierzu unter anderem Menck et al. 2013).

Pro Zellreihe wurden hierfür in zwei 10-cm-Petri-Schalen je $2 \times 10^{6}$ Zellen ausgesät und über Nacht bei $37^{\circ} \mathrm{C}$ inkubiert.

Nach dem Entfernen des Mediums wurden die Zellen mit eiskaltem PBS gespült. Anschließend wurde der gesamte Überstand entfernt und die Zellen mit RIPA-Puffer zur Zelllyse bedeckt. Je Petrischale wurden $250 \mu$ l RIPA-Gebrauchslösung vorbereitet. Hierzu wurden auf Eis 222,5 $\mu 1$ der RIPA-1x Stocksolution, $25 \mu 1$ des Phosphatase-Inhibitors und 2,5 $\mu 1$ des Protease-Inhibitors verwendet.

Auf Eis wurden die Zellen mittels Zellschaber vom Boden der Zellkulturflaschen gelöst und in ein Eppendorf-Cup überführt. Nach kurzem Vortexen und Inkubation für 15 Minuten auf Eis, folgte eine Zentifugation bei $15.000 \mathrm{rpm}$ für 5 Minuten in einer ebenfalls auf $4{ }^{\circ} \mathrm{C}$ gekühlten Zentrifuge. Anschließend wurden der Überstand abgenommen und die Protein- 
konzentration bestimmt. Die Aliquots wurden zur Lagerung bei $-20{ }^{\circ} \mathrm{C}$ weggefroren.

\subsubsection{Zellauftrennung: Zytosol/Zellkerne/Membran}

Die Auftrennung der Zelllysate in die Bestandteile Zytosol und Kern erfolgte nach einem modifizierten Versuchsablauf nach Schreiber et al. 1989.

Bevor das erste Mal eine Zytosol- und Kernaufreinigung durchgeführt werden konnte, mussten Stocks nach folgender Zusammensetzung vorbereitet werden:

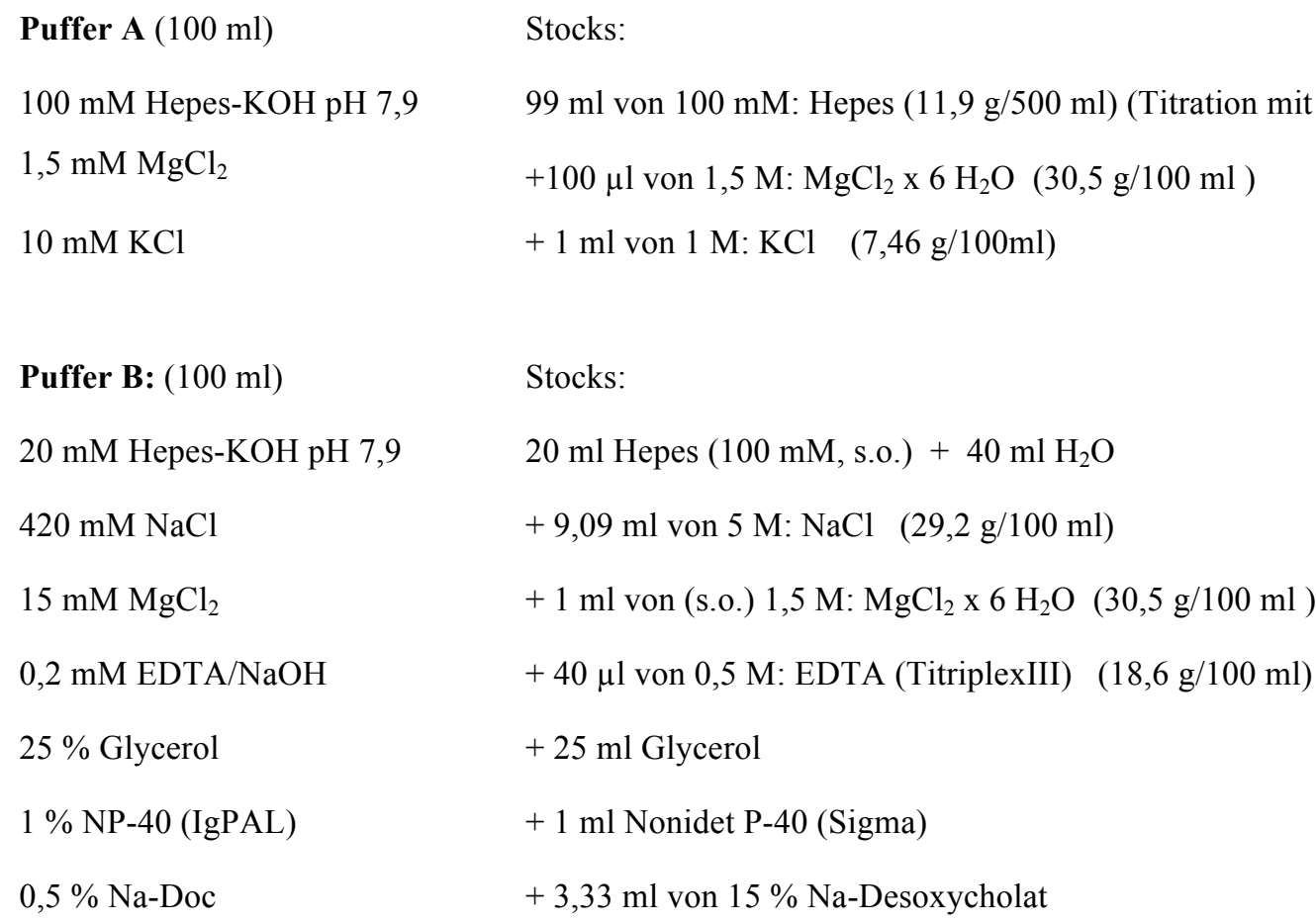

Vor jeder Aufreinigung wurde eine Gebrauchslösung für beide Puffer angesetzt. Diese setzte sich wie folgt zusammen:

\section{Gebrauchslösung:}

$1 \mathrm{ml} \quad$ Puffer A bzw. Puffer B

$5 \mu 1 \quad \operatorname{DTT}(=0,1 \mathrm{M})$

$10 \mu 1 \quad$ PMSF

$100 \mu 1 \quad$ Phospho-Stop (Tbl.)

$10 \mu 1 \quad$ Protease-Inhibitor-Cocktail 
Die Gebrauchslösungen beider Puffer, NP-40 und RIPA-Stocksolution wurden zur Vorbereitung auf Eis gestellt, eine Tischzentrifuge und ein Vortexer wurden im Kühlraum bei $4{ }^{\circ} \mathrm{C}$ vorgekühlt.

Über Nacht erfolgte die Anzucht der Zellen im Optimalmedium. In der Regel wurde eine Zellzahl von circa $1 \times 10^{7}$ Zellen für jede Zytosol-/Kernaufreinigung verwendet. Die Zellen wurden wie gewohnt gewaschen, abtrypsiniert, in Medium resuspendiert und bei $750 \mathrm{rpm}$ für 5 Minuten herunter zentrifugiert. Nachdem der Überstand verworfen worden war, wurden die Zellen in je $1 \mathrm{ml}$ PBS durch auf- und abpipettieren resuspendiert und gewaschen. Anschließend wurde die Suspension in ein Eppendorf-Cup überführt. Es folgte eine Zentrifugation bei $3.000 \mathrm{~g}$ für 10 Minuten. Erneut wurde der Überstand verworfen und das Pelett in $200 \mu 1$ Puffer A suspendiert.

Von nun an wurden alle weiteren Arbeitsschritte im Kühlraum bei $4{ }^{\circ} \mathrm{C}$ durchgeführt.

Durch eine Inkubation der Zellen von 10 Minuten auf Eis mit dem Puffer A zeigten sich alle Zellen im Mikroskop geschwollen und aufgequollen. Im Kühlraum folgte die Zugabe von 0,5 \% NP-40, i.d.R ein Volumen von $10 \mu$ l. Nach Zentrifugation über eine Minute bei 10.000 xg wurde der Überstand, welcher der Zytosolfraktion entspricht, in ein entsprechend beschriftetes Eppendorf-Cup überführt und bis zur Konzentrationsbestimmung auf Eis verwahrt.

Das verbleibende Pellet wurde in $50 \mu 1$ gekühlten Puffer B resuspendiert und die Suspension wurde für 30 Minuten, am Vortexer befestigt, geschüttelt inkubiert. Nach einer Zentrifugation von 5 Minuten bei 20.000 xg konnte die Kernfraktion im Überstand entnommen und ebenfalls in ein Cup überführt werden.

Zur Gewinnung der Membranfraktion konnte im Anschluss das Pellet in RIPA-Puffer resuspendiert werden. Nach einer kurzen Inkubation auf Eis und einer Zentrifugation (3.000 rpm für 5 min) konnte der die Membranen enthaltende Überstand entnommen werden.

Die Proteinkonzentrationen wurden im Anschluss wie unter 2.2.4.3 beschrieben bestimmt und die Lysate bis zum weiteren Gebrauch bei $-20{ }^{\circ} \mathrm{C}$ weggefroren.

\subsubsection{Proteinkonzentrationsbestimmung}

Die Konzentration der Proteine in den Zelllysaten wurde mittels Lowry-Assay (BioRad Dc Protein Assay) nach Angaben des Herstellers bestimmt.

Die Proteinbestimmung nach Lowry (1951) beruht auf zwei Reaktionsschritten: erstens, eine Biuretreaktion, in der ein blau-violetter Komplex zwischen Peptidbindungen und 
zweiwertigen Kupferionen in alkalischer Lösung gebildet wird; und zweitens, die Reduktion dieser Ionen zu einwertigen, wodurch eine gelbe Folin-Ciocalteu-Reagenz (Molybdän (VI)und Wolfram (VI)-Heteropolysäuren) zu Molybdänblau reduziert wird. Die Intensität des Farbumschlags korreliert linear mit der vorhandenen Proteinkonzentration und kann photometrisch bestimmt, anhand einer ebenfalls gemessenen Konzentratzionsstandardreihe quantifiziert, werden. Durch die zweite Farbreaktion ist die Methode nach Lowry deutlich enpfindlicher als die Biuret-Methode per se und es können niedrige Konzentrationen von bis zu 0,1-1 $\mu \mathrm{g}$ Protein pro Milliliter bestimmt werden.

Hierfür wurde zuerst eine BSA-Verdünnungsreihe $(0,25,125,250,500,750,1.000,1.500$ $\mu 1 / \mathrm{ml}$ ) angesetzt. Von jeder BSA-Verdünnung wurden $10 \mu 1$ in ein beschriftetes EppendorfCup vorgelegt. Für jede zu analysierende Probe wurden zur Verdünnung, je nach zu erwartender Proteinkonzentration, die Proben im Verhältnis 1:10 oder 1:5 mit Milli-Q-Wasser in einem Eppendorf-Cup vorverdünnt. Dabei war besondere Vorsicht geboten, damit die oftmals sehr geringen Mengen Proteinlösung nicht am Rand der Eppendorf-Cups hängen blieben und so nicht in die Proteinbestimmung eingeflossen wären. Gegebenenfalls konnte, um dies zu vermeiden, an dieser Stelle der Inhalt der Cups kurz mit einer Tischzentrifuge herunterzentrifugiert werden.

In alle Cups, BSA-Standard und Proben, wurden zu $50 \mu 1$ Lösung A', bestehend aus $49 \mu 1$ Lösung A und $1 \mu 1$ Lösung S, $400 \mu$ Lösung B zugegeben. Hierbei wurde, um den Einfluss eventueller Pipettierungenauigkeiten zu minimieren, ein Mastermix der Lösung A' entsprechend der Probenanzahl vorbereitet.

Von den Proben und den Kontrollen wurden 2x150 $\mu 1$ in die Wells einer 96er Platte überführt. Nach Inkubation für 15 Minuten bei Raumtemperatur wurde die Extinktion bei einer Wellenlänge von $700 \mathrm{~nm}$ gemessen. Die Werte der durchgeführten Doppelbestimmung wurden im Anschluss gemittelt.

Da die im Sunrise ${ }^{\mathrm{TM}}$ (Tecan, Männedorf, Schweiz) gemessene Absorption mit der Proteinkonzentrationen in den Suspensionen korreliert, konnten so, anhand der durch die BSAStandardreihe vorgegebenen Eichkurve, Rückschlüsse auf den Proteingehalt der Proben gezogen werden.

\subsubsection{Immunoblot}

Die Proteinlysate der Tumorzellen wurden mitttels Western Blot untersucht. Hierbei handelt es sich um eine Methode, mit welcher Proteingemische auf ein Protein einer bekannten Größe 
untersucht werden können. Die Proteine wurden zunächst mittels sodium dodecyl sulfate polyacrylamide gel electrophoresis (SDS-PAGE) nach Laemmli (1970) nach ihrem Molekulargewicht im Polyacrylamidgel aufgetrennt. In einem zweiten Schritt wurden die Proteine aus dem Gel auf eine Membran übertragen (to blot: abtupfen, beklecksen). In einem dritten und letzten Schritt wurden die Proteine mittels einer immunhistochemischen Reaktion nachgewiesen (vgl. hierzu beispielsweise Menck et al. 2013).

\subsubsection{Diskontinuierliche Proteinelektrophorese im SDS-Polyacrylamidgel}

Im hochmolekularen SDS-Polyacrylamidgen erfolgt durch Anlegen einer Spannung eine Auftrennung der Proteine nach ihrer Ladung und ihrem Molekulargewicht.

Durch die Verwendung von unterschiedlichen Acrylamidkonzentrationen in den Gelen können Proteine einer gewissen Größe besonders gut dargestellt werden. So wurden für die Untersuchungen auf DVL3 ein $7 \%$ Trenngel (30-120 kDa) und für die Untersuchungen auf Wnt5a und FLAG ein $10 \%$ Trenngel $(18-75 \mathrm{kDa})$ in durch Dichtungsgummies abgedichtete Biometra Glaskammern gegossen. Um eine klare Grenze zwischen Trenn- und Sammelgel zu gewährleisten, wurde das Gel während des Aushärtens mit $200 \mu 1$ Isoprapanol überschichtet. Anschließend wurde nach unten aufgeführter Zusammensetzung ein $5 \%$ Sammelgel gegossen. In das noch flüssige Gel wurde ein Kamm, mit einer der Taschen entsprechenden Zackenenzahl, zwischen den Glasplatten platziert.

Die Proteinlysate wurden wie folgt für die Elektrophorese vorbereitet:

Alle Proben außer Wnt5a wurden je nach gewünschtem Volumen und Proteingehalt mit destilliertem Wasser und vierfach Laemmli-Puffer (1/4 des Gesamtvolumens) vorbereitet. Nach kurzem Herunterzentrifugieren, um eine einheitliche Vermischung der Lösungen zu gewährleisten, wurden die Proteine fünf Minuten in einem Wärmeblock bei $95^{\circ} \mathrm{C}$ denaturiert. Durch die reduzierende Reagenz 2-Mercaptoethanol und das Erhitzen wurden, durch das Unterbrechen der Wasserstoffbrücken, Sekundär-, Tertiär- und Quartätstrukturen aufgelöst.

Da der verwendete Antikörper für die Detektion von Wnt5a nur natives Protein erkennt, wurde bei der Probenvorbereitung dieser Western Blots ein zweifach konzentrierter LaemmliPuffer verwendet, der die Reduktionsreagenz 2-Mercaptoethanol nicht enthielt. Des Weiteren fand kein Erhitzen der Probe statt.

Ein, in beiden Puffern enthaltenes, anionisches Detergenz bewirkte eine zum Proteingewicht proportionale Beladung mit negativer Ladung, sodass die Proteine nur entsprechend ihrer Größe und nicht entsprechend eventuell vorhandener Eigenladung zur Anode wandern. 
Nach der Probenvorbereitung wurde die Glaskammer in eine Mini-Proteingel-Kammer von Biometra eingebaut und oberhalb und unterhalb von den Elektrolyten des Elektrophoresepuffers umgeben. Durch das Anlegen einer Spannung wandern die negativ geladenen, linearisierten Proteine durch das SDS-Gel von der Kathode zur Anode. Da kleinere Proteine durch das mit einem Sieb vergleichbare Gel schneller wandern als größere, werden die Proteine ihrer Größe entsprechend aufgetrennt. Durch den Vergleich mit einem Größenmarker können auch nach dem Übertragen der Proteine auf eine Nitrozellulosemembran den Proteinbanden noch Größen zugeordnet werden.

Da die Zusammensetzungen von Trenn- und Sammelgel sich, wie unten beschrieben, unterscheiden, sind auch die Größe ihrer Poren und ihre pH-Werte unterschiedlich. Dies ist für die hier durchgeführte diskontinuierliche SDS-Gelelektrophorese von großer Bedeutung. Die Proteine wurden zunächst für circa 30 Minuten bei $90 \mathrm{~V}$ an der Grenze von Trenn- und Sammelgel aufkonzentriert. Anschließend folgte für ca. 90 Minuten bei $120 \mathrm{~V}$ die eigentliche Auftrennung der Proteine im Trenngel. Die Konzentration der Proteine ermöglicht eine genauere Auftrennung nach der Größe der Proteine und so eine Verringerung der eingesetzten Proteinmengen.

$7 \%$ Trenngel

10,2 ml Aqua dest.

4,6 ml $30 \%$ Acrylamid mit 0,8\%

Bisacrylamid

$5 \mathrm{ml}$ Trenngelpuffer (1,5 M, pH 8,8

+ SDS $10 \%$ )

$200 \mu 1 \quad 10 \%$ Ammoniumpersulfat (APS)

$20 \mu 1 \quad$ Tetramethylethylendiamin (TEMED)

\section{$10 \%$ Trenngel}

9,5 ml Aqua dest.

$5,3 \mathrm{ml} 30 \%$ Acrylamid mit $0,8 \%$

Bisacrylamid

$5 \mathrm{ml}$ Trenngelpuffer (1,5 M, pH 8,8

$+\operatorname{SDS} 10 \%$ )

$200 \mu 1 \quad 10 \%$ Ammoniumpersulfat (APS)

$20 \mu 1$ Tetramethylethylendiamin (TEMED)

\section{$5 \%$ Sammelgel (für $5 \mathrm{ml}$ )}

3,45 ml Aqua dest.

$0,83 \mathrm{ml} 30 \%$ Acrylamid mit 0,8\%

Bisacrylamid

0,63 ml Trenngelpuffer (1,0 M, pH 6,8

$+\operatorname{SDS} 10 \%$ )

$50 \mu 1 \quad 10 \%$ Ammoniumpersulfat (APS)

$5 \mu 1 \quad$ Tetramethylethylendiamin (TEMED) 


\subsubsection{Proteintransfer}

Im Anschluss an die Gelelektrophorese wurden die aufgetrennten Proteine durch die elektrophoretische Übertragung auf eine proteinbindende Nitrocellulosemembran, im sogenannten Western Blots ,,semi-dry“, dargestellt.

Prinzipiell können die Proteine aus dem Gel auf unterschiedliche Art und Weise auf eine Trägermembran übertragen werden, wie zum Beispiel auch über Diffusion oder Kapillarwirkung. In den Western Blots meiner Arbeit übertrug ich die Proteine meiner Gele mittels Elektophorese in einer dafür vorgesehenen Blotkammer auf eine Nitrozellulosemembran.

Der Aufbau der Apparatur erfolgte wie vom Hersteller beschrieben: pro Gel wurden sechs dicke Watman-Blottingpapiere und eine Nitrozellulose-Membran in Blotpuffer äquilibriert. Das Gel wurde vorsichtig aus der Glaskammer gelöst und ebenfalls kurz in den Blotpuffer gelegt. Die Elektroblotting-Kammer besteht aus einer die Anode enthaltenden Kammer und einem die Kathode enthaltenden Deckel. Zur Übertragung der negativen Proteine auf die Membran bietet sich also folgender Aufbau von unten (Anode) nach oben (Kathode) an: drei dicke Blotting-Papiere, darauf die Membran mit dem SDS-Gel, darauf drei weitere BlottingPapiere.

Mit einer Pipette wurde die Schichtung glatt gerollt und so eventuell störende Luftblasen entfernt. Vorsichtig wurde der Deckel mit der Kathode aufgesetzt und für 75 Minuten eine Spannung von 10 Volt angelegt.

Zur Überprüfung der Proteinübertragung und des einheitlichen Proteinauftrags wurde eine Färbung mit Ponceau-Rot durchgeführt. Bei Inkubation einer Membran mit mehreren Primärantikörpern wurde die Membran an dieser Stelle geschnitten.

\subsubsection{Immunfärbung}

Nach Entfärben mittels TBS mit 0,1\% Tween (TBS-T) wurden die Membranen zum Blocken überschüssiger Antikörperbindungsstellen in $5 \mathrm{ml}$ TBS-T mit (je nach Herstellerangaben bzw. Erfahrungswerten) $5 \%(\mathrm{w} / \mathrm{v})$ Rinderserumalbumin (bovine serum albumine, BSA) oder $5 \%$ (w/v) Magermilchpulver (MMP) 60 Minuten inkubiert. Im Anschluss wurden die Membranen mit dem gewünschten Primärantikörper in den Herstellerangaben entsprechenden Konzentrationen (i.d.R. 1:1.000) in TBS-T $(3 \mathrm{ml})$ bei $4{ }^{\circ} \mathrm{C}$ über Nacht inkubiert. Am nächtsten Tag wurde, nach dreimaligem Waschen für 5 Minuten in $5 \mathrm{ml}$ TBS-T, ein mit Meerrettich-Peroxidase (horseradish-peroxidase, HRP) gekoppelter anti-IgG-Sekundärantikörper spezifisch für den Ursprung des Primärantikörpers (rabbit, rat, mouse) auf die 
Membranen gegeben. Nach einer Inkubationszeit von 1 Stunde folgte ein weiterer Reinigungsschritt, wie oben bereits beschrieben, und die Entwicklung der Membranen mittels der Entwicklerlösung ECL prime Western Blotting Detection Reagents ${ }^{\mathrm{TM}}$ von GE Healthcare, Solingen.

Die Lösung enthält ein Acridin-basiertes Substrat, das durch das an den Sekundärantikörper gekoppelte Enzym umgesetzt wird und ein Chemifloureszenz- und Lumineszenzsignal entsendet. Zur Detektion des Signals wurde der Luminescent Image Analyzer LAS-400 von Fujifilm verwendet.

\subsubsection{Quantitative Echtzeit-Polymerase-Kettenreaktion (RT-qPCR)}

Die quantitative Echtzeit-Polymerase-Kettenreaktion (RT-qPCR) ist eine Vervielfältigungsmethode von Nukleinsäuren (Mullis et al. 1986). Sie beruht auf dem Prinzip der PolymeraseKettenreaktion, wird jedoch um Fluoreszenzmessungen nicht nur am Ende eines Laufes, sondern während jedes einzelnen Reaktionszyklus ergänzt (,Real Time“). Da das Fluoreszenzsignal proportional zum DNA-Gehalt der Probe zunimmt, kann eine Quantifizierung der DNA-Menge während der exponentiellen Phase der PCR, in der optimale Reaktionsbedingungen herrschen, durchgeführt werden.

So können Rückschlüsse auf die Menge vorhandener Boten-RNA (messenger- oder mRNA) einer Zelle gezogen werden und Informationen, wie oft ein Gen einer Zelle transkribiert und potentiell in ein Protein translatiert wird, gewonnen werden.

Wird im Folgenden von der Verwendung von Wasser gesprochen, so ist immer RNAse-freies Wasser gemeint, das eingesetzt wurde, um unspezifische Abbauprozesse der RNA zu vermeiden und so die Genauigkeit der quantitativen Messungen zu gewährleisten.

Die in dieser Arbeit dargestellten Ergebnisse wurden unter Verwendung des DNAmarkierenden Fluoreszenzfarbstoffs SYBR ${ }^{\circledR}$-Green gewonnen. Vgl. hierzu auch Rietkötter et al. 2013 sowie Menck et al. 2013.

\subsubsection{RNA-Isolation}

Die RNA-Isolation aus den transfizierten MCF-7 Zellen erfolgte mit dem High Pure RNA Isolation $\mathrm{Kit}^{\mathrm{TM}}$ von Roche (Mannheim) nach Herstellerangaben. Hierfür wurden am Tag vor der Isolation $1 \times 10^{6}$ Zellen in eine 10-cm-Petrischale ausgesät. Die adhärent wachsenden Zellen wurden mit warmem PBS gewaschen. Im Anschluss wurden $200 \mu 1$ PBS und $400 \mu 1$ Lysis-/Binding-Puffer zu den Zellen hinzugegeben und mit einem Zellschaber vom Boden der 
Platten gelöst. Die entstandene Zellsuspension wurde in ein 1,5-ml-Reaktionsgefäß überführt. Um die Zelllyse zu beschleunigen, wurden die Zellen kurz gevortext (circa $15 \mathrm{sec}$ ). Für jede Probe wurde eine im Kit mitgelieferte High Pure ${ }^{\mathrm{TM}}$ Filter-Säule in ein Collection Tube gegeben und die gesamte Suspension wurde, ohne den Filter zu berühren, auf die Säule aufgetragen. Die Säulen wurden bei $8.000 \mathrm{xg}$ für $15 \mathrm{sec}$ zentrifugiert. Nachdem der Durchfluss verworfen worden war, wurde die Sammelröhre wieder in die Säule gesteckt.

Für jede Probe wurden $90 \mu 1$ Inkubationspuffer und $10 \mu \mathrm{l}$ DNase I in ein 1,5-ml-Reaktionsgefäß vorgelegt und $100 \mu 1$ des Mastermixes auf jedes Tube aufgetragen.

Nach einer Inkubationszeit von 15 Minuten bei Raumtemperatur folgten mehrere Waschschritte mit denen vom Hersteller dafür vorgesehenen Waschpuffern (I+II).

Zuerst wurden $500 \mu \mathrm{l}$ Wash Buffer I auf jede Säule gegeben, die Tubes 15 Sekunden bei $8.000 \mathrm{xg}$ zentrifugiert, der Durchfluss verworfen und das Sammelröhrchen wieder unter die Säule gesteckt. Dieser Schritt wurde im Anschluss mit $500 \mu$ l Waschpuffer II wiederholt.

Daraufhin wurden $200 \mu$ Wash Buffer II auf die Säule gegeben und ein weiteres Mal, diesmal zwei Minuten bei maximaler Geschwindigkeit, zentrifugiert, um auch die letzten Reste des Waschpuffers zu entfernen. Die Säule wurde in ein frisches 1,5-ml-Reaktionsgefäß überführt und je Probe wurden $50 \mu$ l Elutionspuffer hinzugefügt. Nach einem weiteren Zentrifugationsschritt bei 8.000 xg für eine Minute konnte der die RNA enthaltende Überstand entnommen und die RNA-Konzentration mittels des NanoDrops $N D-1000^{\mathrm{TM}}$, wie oben bereits beschrieben, gemessen werden. Die beschrifteten Proben wurden bis zur weiteren Verwendung bei $-80{ }^{\circ} \mathrm{C}$ gelagert.

\subsubsection{Reverse Transkription}

Da für eine Polymerase-Kettenreaktion ein DNA-Strang zur Verfügung stehen muss, wurde die gewonnene RNA zunächst in ihre komplementäre DNA (cDNA) umgeschrieben. Diese besitzt, wie die dazugehörige messenger-RNA, keine Introns mehr.

Es wurde hierfür das $i S c r i p t^{\mathrm{TM}}$ System von BioRad nach Herstellerangaben verwendet. $1 \mu \mathrm{g}$ mRNA wird hierbei mit $5 \mu 1$ iScript ${ }^{\mathrm{TM}}$ Mastermix aus der Reversen Transkriptase und einem 5x Reaktionspuffer und RNAse-freiem Wasser versetzt, sodass ein Probenvolumen von $20 \mu 1$ erreicht wird.

In einem ThermoCycler T3000 (Biometra, Göttingen) wurde ein spezielles Programm entworfen, das die optimalen Reaktionstemperaturen für die verschiedenen Reaktionsphasen automatisch einstellen lies. 
So wurde das Reaktionsgemisch fünf Minuten bei $25^{\circ} \mathrm{C}$, 30 Minuten bei $42^{\circ} \mathrm{C}$, fünf Minuten bei $85^{\circ} \mathrm{C}$ inkubiert und im Anschluss auf $4{ }^{\circ} \mathrm{C}$ heruntergekühlt.

\subsubsection{Primerdesign und Primeraustestung}

Alle verwendeten qPCR-Primer wurden mit Hilfe der Software PerlPrimer entworfen (http://perlprimer.sourceforge.net) und wurden von IBA $\mathrm{GmbH}$, Göttingen nach diesen Vorgaben synthetisiert. Vor der Verwendung der Primer in Versuchen erfolgte eine Überprüfung der Effektivität in einem separaten qRT-Lauf anhand einer geeigneten Positivkontrolle.

Hierfür wurde mit Hilfe der Homepage http://www.genecards.org eine Zelllinie identifiziert, welche das gewünschte Gen stark exprimiert. Im Anschluss wurde, wie oben beschrieben, mit Hilfe des High Pure RNA Isolation Kit ${ }^{\mathrm{TM}} \mathrm{RNA}$ aus diesen Zellen isoliert, die Konzentration bestimmt und $1 \mu \mathrm{g}$ RNA mittels des iScript $c D N A$ synthesis kit ${ }^{\mathrm{TM}}$ von Bio-Rad nach Herstellerangaben in die komplementäre DNA transkribiert. Durch diesen Umschreibprozess erhiehlt man eine cDNA-Konzentration von $50 \mathrm{ng} / \mu \mathrm{l}$. Hieraus wurde nun eine Standardkonzentrationsreihe mit RNAse-freiem qRT-PCR Wasser angelegt. Es wurden folgende Konzentrationen benötigt: $25 \mathrm{ng}, 12,5 \mathrm{ng}, 3,125 \mathrm{ng}, 0,78125 \mathrm{ng}$ und 0,1953125 ng (1:4Verdünnungsreihe). Um Pipettierungenauigkeiten zu verringern, wurde jede Konzentration noch einmal 1:1 mit RNAse-freiem Wasser verdünnt und von jeder Konzentration $2 \mu 1$, anstatt $1 \mu 1$ später auf die qRT-Platte aufgetragen.

Für jedes zu testende Primerpaar, bestehend aus forward (fwd, vorwärts) und reverse (rev, rückwärts) Primern, und die No-template-control (Kontrolle ohne Vorlage, NTC) wurde ein sogenannter Mastermix von $8 \mu \mathrm{l}$ je Well angesetzt.

Die NTC ist ein Ansatz, in welchem anstatt der cDNA nur $\mathrm{H}_{2} \mathrm{O}$ pipettiert wurde. So sollte eine mögliche Verschmutzung der Lösungen und Geräte mit DNA ausgeschlossen werden.

Der Mastermix bestand für die Primer aus 5,6 $\mu 1$ 2x konzentriertem SYBR ${ }^{\circledR}$ Mix, 0,6 $\mu 15 \mu \mathrm{M}$ Primer-Arbeitslösung, das vorangesetzt wurde aus $90 \mu 1 \mathrm{H}_{2} \mathrm{O}$ und je $5 \mu \mathrm{fwd}$ - und rev-Primer (je $0,1 \mathrm{nmol} / \mu \mathrm{l}$ ) und 1,8 $\mu \mathrm{l}$ Wasser. In dem Mastermix für die No-primer-control (Kontrolle ohne Primer, NPC), das bedeutet den Primer-losen Kontrollansatz zum Ausschluss einer Verschmutzung der Proben und Lösungen mit anderen Startern, wurde die PrimerArbeitslösung durch $\mathrm{H}_{2} \mathrm{O}$ ersetzt, das heißt der NPC-Mastermix bestand aus 5,6 $\mu 1$ 2x konzentriertem SYBR ${ }^{\circledR}$ Mix und 2,4 $\mu 1$ Wasser.

Die Primer wurden für jede Konzentration in Triplikaten getestet. Im Vorfeld wurde die 
Plattenbelegung mit Hilfe einer Excel $^{\circledR}$-Datei geplant und gleichzeitig die belegten Wells und die benötigten Mastermix-Mengen für die gesamte Platte berechnet. So konnten die Volumina für den Versuch auf einmal angesetzt und der Pipettierfehler minimiert werden.

Nun wurden je Konzentration und Primer drei Wells mit $2 \mu 1$ cDNA und $8 \mu 1$ PrimerMastermix belegt.

Nach einer kurzen Zentrifugation bei $2.000 \mathrm{rpm}$ erfolgte die Durchführung der EchtzeitPolymerase-Kettenreaktion mittels des ABI Prism 7900 HT Sequence Detection System (Applied Biosystems, Darmstadt).

\section{PCR-Programm:}

1. $95^{\circ} \mathrm{C} \quad 12 \mathrm{~min} \quad$ Aktivierung der Taq-Polymerase

2. $95^{\circ} \mathrm{C} \quad 15 \mathrm{sec} \quad$ Denaturierung

3. $60^{\circ} \mathrm{C} \quad 1 \mathrm{~min} \quad$ Anlagerung (Annealing) und Elongation

40x Wiederholung von 2. und 3.

4. $95^{\circ} \mathrm{C} \quad 15 \mathrm{sec}$ und

$60-95{ }^{\circ} \mathrm{C} \quad 2{ }^{\circ} \mathrm{C} / \mathrm{min}$ zur Schmelzkurvenanalyse

Die Auswertung der Testergebnisse erfolgte mit Hilfe der Software SDS2.4 (Applied Biosystems, Darmstadt). Besonders wichtig war hierbei, die NPC und NTC auf Verunreinigungen gründlich zu überprüfen.

Das Programm berechnete nun die Ct (cycle threshold)-Werte, also den SchwellenwertZyklus, bei dem die Fluoreszens der markierten DNA erstmals signifikant über dem floureszierenden Hintergrund liegt. Außerdem die Werte der Slope (Steigung) und R2 (Triplikatgenauigkeit). Daraus ließ sich entsprechend folgender Formel die Effizienz der Primer berechnen:

$$
\text { Effizienz }=10^{(-1 / \text { Slope })}
$$

Eine negative Steigung von -3,32 entspricht hierbei in etwa einer Effizienz von 100 \%, R2 sollte möglichst nahe an 1,00 liegen. Eine optimale Effizienz besteht im Bereich zwischen 95 und $100 \%$. 


\subsubsection{4 qRT-PCR}

Die Durchführung der Echtzeit-Polymerase-Kettenreaktion erfolgte ähnlich der Primertestung.

Ein wichtiger Unterschied ist jedoch der Bezug der Ergebnisse auf sogenannte HousekeepingGene oder auch Haushaltsgene. Dies sind konstitutiv exprimierte Gene, die nicht reguliert in Zellen exprimiert werden. Oft sind dies Strukturmoleküle oder Enzyme, welche die wichtigen Stoffwechselprozese der Zelle koordinieren. Der Bezug der Zyklusschwellenwerte der Haushaltsgene auf die Ct-Werte der zu untersuchenden Gene (GOIs, genes of interest) ermöglicht eine Einschätzung der Größe und eventueller Schwankungen der mRNA/cDNA-Expression. Gleichzeitig ist eine gute Konstanz der Ct-Werte der Housekeeper ein weiteres Qualitätsmerkmal für die qRT-PCRs im Langzeitverlauf.

Die gewünschte RNA wurde isoliert, die Konzentrationen gemessen und in cDNA transkribiert. Die komplementäre DNA wurde im Anschluss von einer Konzentration von $50 \mathrm{ng} / \mu \mathrm{l}$ in $20 \mu \mathrm{l}$ durch Zugabe von $80 \mu \mathrm{l}$ Wasser auf eine Konzentration von $1 \mu \mathrm{g}$ in $100 \mu \mathrm{l}$ vorverdünnt. Eine Plattenbelegungsplanung erfolgte mit Hilfe einer Excel $^{\circledR}$-Tabelle.

Für jedes GOI, das heißt jedes untersuchte Gen und Primerpaar (auch die der gewählten Haushaltsgene) und die NTC wurde in dreifacher Menge, wie bereits erläutert, ein Mastermix angesetzt. Genauso wurde ein Mastermix für die NPC zusammengestellt.

Die komplementäre DNA wurde 1:1 mit RNAse-freiem Wasser verdünnt und $2 \mu 1$ wurden in jedes Well, nach Plattenbelegung vorgelegt. Ebenso für jeden Primer ein Triplikat NTC. Es folgte die Zugabe von $8 \mu 1$ Primermix bzw. NPC-Mix.

Der qRT-PCR-Lauf erfolgte, wie oben geschildert, nach einer kurzen Zentrifugation unter Standardbedingungen.

Die Auswertung erfolgte ebenfalls mit Hilfe der Software SDS2.4 $4^{\circledR}$ (Applied Biosystems, Darmstadt) und dem Tabellenkalkulierungsprogramm Excel $^{\circledR}$.

Anstelle einer Effizienzbestimmung erfolgte mit Hilfe der mittleren Ct-Werte der GOIs und House-Keeper die Berechnung der Differenz $(\Delta \mathrm{Ct})$ und in Bezug auf den Mittelwert der pcDNA-Kontrolle der $\Delta \Delta \mathrm{Ct}$. Hieraus lässt sich die relative Expression der mRNA in der jeweiligen Probe mittels folgender Formel berechnen:

$$
\begin{aligned}
& \text { Fold change }=2^{-\Delta \Delta C t}
\end{aligned}
$$

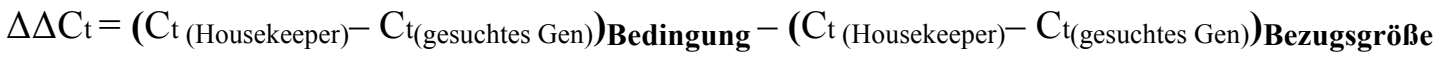


Jeder Versuch wurde mit drei (oder mehr) verschiedenen biologischen Replikaten durchgeführt. Im Anschluss wurde der Mittelwert berechnet.

Bei einer Signaldetektion nach einem qRT-PCR-Zyklus von 32 wurde, unter Berücksichtigung der Schmelzkurven, ein Vorhandensein von spezifischer mRNA nicht angenommen (nicht exprimiert $=$ n.e. $)$.

\subsubsection{Agarosegel-Elektrophorese}

Als weiterer Kontrollschritt wurde das PCR-Amplifikat in einem Agarosegel unter elektrischer Spannung entsprechend seiner Größe aufgetrennt und diese mit der erwarteten Größe verglichen (nach Sambrook et al. 1989).

Die PCR-Amplifikate (die ideale Menge sollte $1 \mu \mathrm{g}$ nicht überschreiten) wurden 5:1 in Probenpuffer gelöst.

Die wie unter 2.2.2.5 vorbereitete Gelkammer wurde in die Elektrophorese-Kammer eingesetzt und mit 1xTBS-Puffer bedeckt. Alle Proben und die 100 bp-Leiter wurden separat in die Taschen der Kammern pipettiert. Die Auftrennung erfolgte zunächst bei einer Spannung von 60 Volt für 15 min, im Anschluss für weitere 60 min bei 90 Volt.

Mit Hilfe eines UV-Transluminators erfolgte die Auswertung und Betrachtung der Gele bei $302 \mathrm{~nm}$. Die Ergebnisse wurden mittels einer CCD-Kamera dokumentiert und mit Hilfe der dazugehörigen Software (Intas, Göttingen, Deutschland) ausgewertet.

\subsubsection{Immunfluoreszenzfärbungen}

\subsubsection{Indirekte Einfach-Immunfluoreszenzfärbung}

Die stabil transfizierten Zellen wurden mittels Immunfluoreszenzfärbung auf ihren Gehalt und die Lokalisation verschiedener Proteine untersucht. Vgl. hierzu beispielsweise Pukrop et al. 2010 .

Um die Färbung durchführen zu können, wurden je 1x10 $0^{5}$ Zellen am Tag zuvor in das Well einer 24-Well-Platte auf $1 \mathrm{ml}$ vorgelegtes, 10 \% FCS haltiges RPMI-Medium gegeben. Auf diese Zellsuspension wurde vorsichtig ein rundes Deckgläschen gelegt. Pro Konstrukt wurden mindestens 2 Deckgläschen für die Färbung vorbreitet; zusätzlich wurde pro Konstrukt eine Negativkontrolle durchgeführt, um die Spezifität der verwendeten Antikörper zu überprüfen.

Nach einer Inkubationszeit von $24 \mathrm{~h}$ bei $37{ }^{\circ} \mathrm{C}$ und $5 \% \mathrm{CO}_{2}$ wurden alle belegten Wells zweibis dreimal vorsichtig mit je $1 \mathrm{ml}$ PBS gespült.

Die Fixierung erfolgte mit je 0,3 ml 4 \% PFA. Das PFA wurde hierfür 20 min bei Raum- 
temperatur auf die Wells gegeben. Nach dem Absaugen des PFAs mit einem Wasserstrahlsauger wurde erneut, wie oben beschrieben, mit PBS gespült.

Je Well wurden 0,3 ml PBS + 0,2 \% Triton-X zur Permeabilisierung der Membranen auf die Deckgläschen gegeben und für 10 Minuten bei Raumtemperatur inkubiert. Überschüssige Antikörperbindungsstellen wurden mit $0,3 \mathrm{ml} 1 \%$ BSA ( $1 \mathrm{~h}$, Raumtemperatur) blockiert. Es folgte die Inkubation mit dem Primärantikörper. Der jeweilige Antikörper, beispielweise Anti-FLAG (Sigma-Aldrich), wurde in der hierfür ausgetesteten Konzentration, hier 1:100, eingesetzt. $10 \mu \mathrm{l}$ der in PBS $+0,2 \%$ Triton-X $+1 \%$ BSA vorverdünnten Antikörperlösung wurden auf einen Parafilm gegeben und alle Deckgläschen bis auf die Negativkontrollen mit der zellbewachsenen Seite nach unten auf die Tropfen gegeben. Nach mindestens einer Stunde Inkubationszeit folgte ein weiterer Reinigungsschritt in der 24-Well-Platte.

Die Inkubation mit dem Sekundär-Antikörper erfolgte wie die oben beschriebene Inkubation mit dem Primär-Antikörper. Dafür wurde der entsprechende Sekundärantikörper, z.B. FITC Donkey anti-rabbit IgG Antikörper von BioLegend, in einer entsprechenden Konzentration (beispielsweise 1:500) verwendet.

Bevor eine Färbung der Zellkerne mit 4', 6' Diamino-2' Phenylindol (DAPI) durchgeführt wurde, wurde ein weiteres Mal gewaschen.

Alle Wells wurden für die Färbung in $300 \mu 1$ 1:1.000 mit PBS verdünnter Stocksolution (1 $\mathrm{mg} / \mathrm{ml}) 10 \mathrm{~min}$ im Dunkeln inkubiert.

Nach einem weiteren Reinigungsschritt wurden die Deckgläschen eingedeckt. Auf jeden beschrifteten Objektträger wurden drei Tropfen Mowiol-Gebrauchslösung gegeben. Die zwei gefärbten Deckgläschen und die Negativkontrolle wurden luftblasenfrei, mit der Zellseite nach unten, auf den Tropfen gelegt. Im Dunkeln trockneten die Objektträger über Nacht. Am nächsten Morgen wurden die Ränder mit Nagellack abgedichtet.

\subsubsection{Morphologie der Zellen im Konfrontationsassay}

Um den Vorgang der Tumorzellmigration als Bestandteil des Metastasierungsprozesses zu simulieren, wurde ein Konfrontationsassay in Chamberslides ${ }^{\mathrm{TM}}$ durchgeführt (Pukrop et al. 2010, Klemm et al. 2011, Rietkötter et al. 2013). Dieser auf Extrazellulärmatrix (extracellular matrix, ECM) basierte Versuchablauf wurde entwickelt, um Probleme und Ergebnisverfälschungen durch unphysiologische Oberflächen zu umgehen. Gleichzeitig ermöglicht er eine bessere Beobachtung und Beurteilung der Tumorzellmigration und erlaubt den Vergleich von zwei bis vier Krebszelllinien pro Kammer. 


\subsection{Aussaat der Zellen}

Um eine Art „Tumorplaque“ zu simulieren, wurden Tumorzellen dicht auf kleine, runde Deckgläschen ( $\mathrm{d}=5 \mathrm{~mm}$, Stärke Null) ausgesät und zum adherieren gebracht.

Eine mittlere Zellkulturflasche des zu untersuchenden Klons wurde, wie beschrieben, mit Trypsin/EDTA abtrypsiniert. Die in $10 \mathrm{ml}$ Medium $+10 \%$ FCS gut resuspendierten Zellen wurden in einer Neubauer-Zählkammer gezählt und je Deckgläschen wurden $2 \times 10^{5}$ Zellen ausgesät.

Hierfür wurden zuerst je Well $1 \mathrm{ml}$ Medium +10 \% FCS vorgelegt. Auf das Medium wurde nun die Zellsuspension gegeben und vorsichtig vermischt, ohne dass sich die Deckgläschen hoben oder umdrehten. Der Selektionsdruck wurde mit dem entsprechenden Antibiotikum weiterhin aufrechterhalten. Es folgte eine Inkubation der MCF-7 Brustkrebszellen für circa $72 \mathrm{~h}$ im Brutschrank bei $37^{\circ} \mathrm{C}$ und $5 \% \mathrm{CO}_{2}$.

\subsection{Kleben der Konfrontation im 2-Loch-Kammerobjektträger}

Je zwei der unterschiedlichen Konstrukte wurden einander in einem Zweikammer-Objektträger mit Abdeckung der Firma Lab-Tek ${ }^{\mathrm{TM}}$ gegenübergestellt. Der Vorteil dieser Methode ist, dass die Zellen direkt auf dem Objektträger wachsen können, auf dem sie später gefärbt werden. So ist kein Zelltransfer vor der Visualisierung nötig und es kommt zu keiner nachträglichen Beeinflussung des Versuchsergebnisses.

Die Kammern wurden vor Versuchsbeginn mit ECM beschichtet. Die erforderliche Menge tiefgefrorenes ECM-Gel wurde für circa 10 Minuten auf Eis aufgetaut und im Anschluss im Verhältnis 1:4 mit Serum-freiem RPMI 1640 Medium versetzt. Da sich die beiden Flüssigkeiten nur schwer suspendieren lassen, wurde gut hoch- und runter pipettiert. Die homogene, blasenfreie Masse wurde nun in die Kammer gegeben und wieder möglichst vollständig abgezogen, um eine einheitliche, hauchdünne Beschichtung des Objektträgers zu gewährleisten. Nach 10-15 Minuten bei Raumtemperatur war die ECM-Beschichtung getrocknet und es konnte mit dem Kleben der Konfrontation begonnen werden.

Zur Vorbereitung wurde eine spitze Pinzette in Alkohol desinfiziert, mit einem Feuerzeug abgeflammt und unter die Sterilbank gestellt. In ein 50-ml-Tube wurden circa 35 ml RPMI-Medium zum Abspülen der Deckgläschen gegeben.

Die benötigten Kammern der Objektträger wurden vorsichtig mit $1 \mathrm{ml} \mathrm{RPMI}+10 \%$ FCS und dem jeweiligen Selektionsantibiotikum geflutet. 
Die runden, mit den Krebszellen bewachsenen Deckgläschen wurden vorsichtig, eines nach dem anderen, mit der Pipette aus den 48-Well-Platten genommen und kurz in das Medium des $50 \mathrm{ml}$-Tubes getaucht, um tote und lose Zellen zu entfernen.

Dann wurden die Gläschen mit der Zellseite nach unten auf die ECM-Schicht des Oektträgers aufgebracht. Hierbei wurde darauf geachtet, dass kein Druck ausgeübt wird oder die Dckgläschen unnötig über den Objektträger abtreiben. Die Stelle, an der die Pinzettenspitze die Kante der Zellplaques berührt hatte, wurde in der Kammer nach außen hin orientiert platziert, da dort eventuell Zellen entfernt worden sein könnten. Das hätte das Ausbilden einer Lauffront beeinflussen können und so eine realistische Simulation der Tumorzellmigration verhindert. Insgesamt wurden vier Deckgläschen mit zwei verschiedenen Konstrukten in einer Kammer in einem Abstand von 2,5 mm einander gegenübergestellt. Ein beispielhafter Versuchsaufbau wird in Abbildung 2.2 gezeigt.

Über einen Zeitraum von mindestens drei Tagen wurden die Objektträger in einer sterilen Box im Inkubator der Zellkultur ohne Erschütterungen verwahrt, um ein Anwachsen der Zellen zu ermöglichen. Nach etwa dieser Zeit wachsen die MCF-7 Zellen langsam unter den Deckgläschen vor. Vorsichtig wurde ein Mediumwechsel mit einer Pipette vorgenommen und aller zwei bis drei Tage wiederholt. Nach etwa fünf bis zehn Tagen kann die Migrationssimulation gestoppt werden.

B

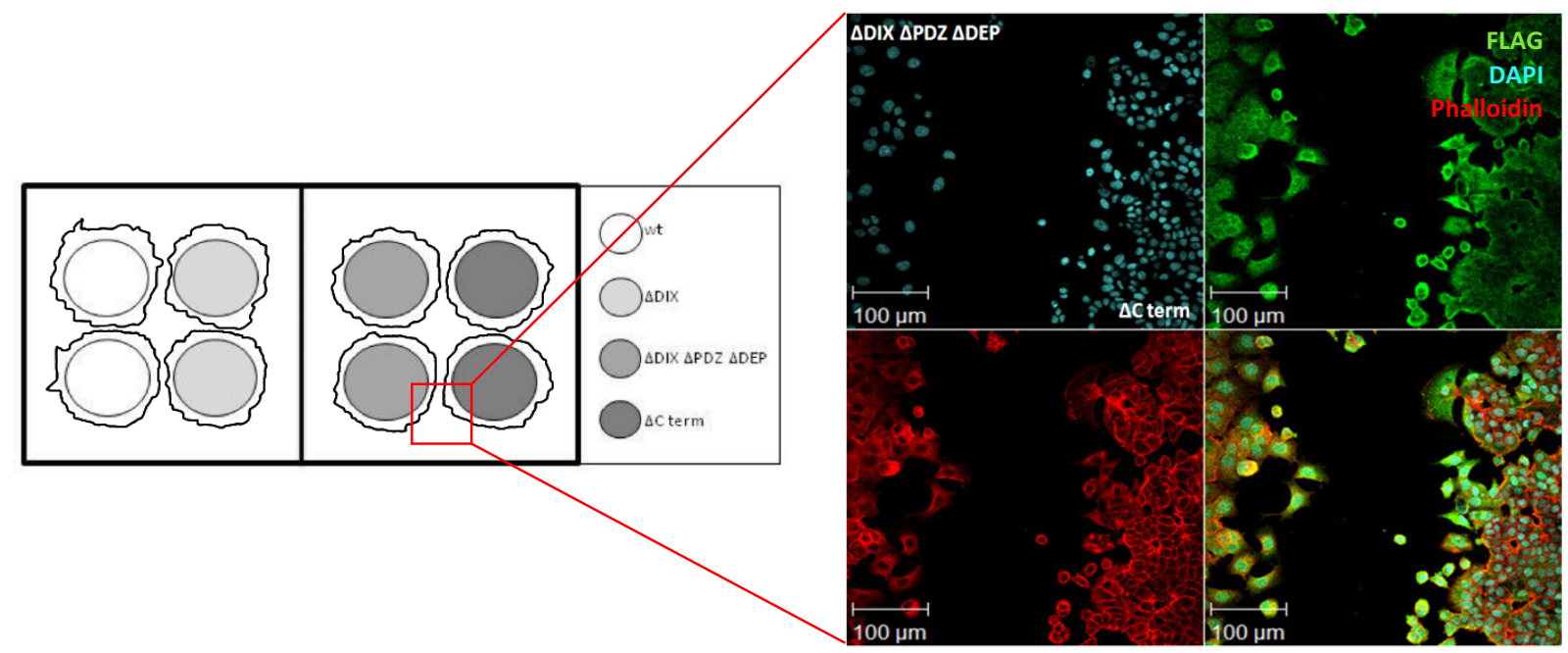

Abbildung 2.2 Beispielhafter Aufbau eines Konfrontationsassays im 2-Well-Chamberslide ${ }^{\mathrm{TM}}$. A: Schematische Darstellung des Objektträgers. Je Kammer konnte eine Versuchsbedingung mit zwei Zelllinien überprüft werden. B: Konfrontationsassay der Konstrukte DVL $\triangle$ DIX $\triangle$ PDZ $\triangle$ DEP und $\Delta \mathrm{C}$ term nach der Immunfluoreszenzfärbung. FITC-FLAG-Antikörper 1:100 (grün). Phalloidin (TRITC, rot). Kernfärbung: DAPI (blau). Merge (gelb). Die Auswertung der Färbungen erfolgte mit dem LSM 510 Konfokalmikroskop der Firma Zeiss, Göttingen. 


\subsection{Färbung}

In der Zellkulturbank wurde hierfür das Medium entfernt, alle Wells vorsichtig zweimal mit je $1 \mathrm{ml}$ PBS gespült und im Anschluss unter unsterilen Bedingungen am Arbeitsplatz mit 0,5 ml $4 \%$ PFA in PBS für 20 Minuten bei Raumtemperatur inkubiert.

Nach Absaugen und erneutem zweimaligem Spülen mit $1 \mathrm{ml}$ PBS je Well wurden die Zellen mit $0,5 \mathrm{ml}$ PBS $+0,2 \%$ Triton 10 Minuten ebenfalls bei Raumtemperatur fixiert. Das Blockieren unbelegter Antikörperbindestellen erfolgte mit $1 \mathrm{ml}$ unsterilem PBS $+0,2 \%$ Triton $+1 \%$ BSA für eine Stunde bei Raumtemperatur. Mindestens $300 \mu$ l Primär- und Sekundärantikörperlösung wurden für ein Well hergestellt und für je eine Stunde auf einem Schwenktisch im Dunkeln inkubiert. Zwischendurch erfolgte ein Waschschritt mit 3x $1 \mathrm{ml}$ PBS. Für eine Phalloidin- Färbung erfolgte nach einem weiteren Waschen eine erneute Inkubation mit $300 \mu$ Phalloidin-TRITC (1:200 in PBS $+0,2 \%$ Triton $+1 \%$ BSA) für eine Stunde bei Raumtemperatur im Dunkeln.

Zur Dapi-Kernfärbung wurde eine Stocksolution (1 mg/ml) 1:1.000 mit PBS + 0,2 \% Triton verdünnt und nach erneutem Waschen je $500 \mu 1$ für 10 min im Dunkeln inkubiert.

Nach einem letzten Reinigungsschritt wurde das PBS behutsam abgesaugt und die Objektträger eingedeckt. Die Kammerung wurde vorsichtig entfernt und die Reste des Klebers und der Dichtungsfolie mit einer Pinzette sorgfältig abgekratzt. Die Eindeckung erfolgte mit Mowiol, bzw. DAKO Fluorescent Mounting Medium ${ }^{\circledR}$ (DAKO, Hamburg) möglichst luftblasenfrei. Die Lagerung bis zur Mikroskopie erfolgte im Dunkeln bei Raumtemperatur. Vgl. hierzu Pukrop et al. 2010.

\subsubsection{Konfokalmikroskopie}

Die Immunfluoreszenzfärbungen wurden mit dem Laser-Scanning-Mikroskop LSM 510 von Carl Zeiss, Göttingen ausgewertet (Pukrop et al. 2010).

\subsubsection{Funktionelle Analysen}

\subsubsection{Viabilität im MTT-Assay}

Lebendige Zellen besitzen die Möglichkeit das Tetrazoliumsalzes 3-(4,5-Dimethylthiazol-2yl)-2,5-diphenytetrazoliumbromid (MTT) in ihren Mitochondrien durch das SuccinatTetrazolium-Reduktase-System in einen wasserunlöslichen Farbstoff umzuwandeln (Mosmann et al. 1983). Die Extinktionswerte dieses Farbstoffes verhalten sich somit proportional zur Stoffwechselaktivitat und Anzahl vitaler Zellen in einem definierten 
Volumen. Somit lässt sich dieser kalorimetrische Test zur Analyse der Vitalität einer definierten Zellzahl in einem definierten Volumen einsetzen.

Für diesen Versuch wurden je nach eingesetzter Zelllinie eine adäquate Zellzahl in der ihr entsprechend nötigen Menge Medium plus Selektionsantibiotikum in den Vertiefungen einer 24-Well-Platte ausgesät und für 48 bzw. 96 Stunden inkubiert.

Nach vorsichtiger Abnahme des Mediums mittels Pipette wurden $500 \mu 1$ Kulturmedium +10 $\%$ MTT $(5 \mathrm{mg} / \mathrm{ml})$ als MTT-Lösung auf die Zellen gegeben und für weitere 4 Stunden inkubiert. Nach erneutem Abpipettieren des Überstandes wurde Ameisensäure-haltiger MTTLysepuffer $(500 \mu 15 \%$ Ameisensäure $+63 \%$ Isopropanol $+32 \%$ DMSO) auf die Zellen gegeben und diese mittels Auf- und Abpipettieren gut suspendiert. Die Messung erfolgte in Triplikaten mit je $100 \mu \mathrm{l}$ der Suspension eines Ansatzes im Plattenphotometer der Firma Tecan in einer hierfür vorgesehenen 96-Well-Platte bei einer Wellenlänge von $540 \mathrm{~nm}$. Die Mittelwerte der Triplikatmessung wurden wiederum mit den anderen Werten des ursprünglichen Dreifachansatzes gemittelt und mit den Bezugsgrößen MCF-7 bzw. MCF-7 pcDNA verglichen. Der Bezug erfolgte auch auf die nativen MCF-7-Zellen, um eine verminderte Viabilität bereits durch Transfektion mit dem Leervektor auszuschließen.

\subsubsection{Wanderungsgeschwindigkeit im Migrationsassay}

Die Migrationsversuche erfolgten zu Beginn wie der Versuchsablauf der Konfrontationsassay. Die Zelllinien wurden wie unter 2.2.6.2.1 beschrieben ausgesät und in den Kammerobjektträgern nach Fragestellung angeordnet geklebt (vgl. Pukrop et al. 2010, Rietkötter et al. 2013). Nach etwa 4-7 Tagen wuchsen die Zellen unter den runden Deckgläschen hervor und es bildete sich eine sogenannte Migrationsfront, die aus einem Verband dicht und epithelial wachsender Zellen besteht. Wichtig ist zu beachten, dass sich gerade eben die ersten Zellen aus diesem Verband zu lösen beginnen und anfangen, in der Ebene zu migrieren. Zu diesem Zeitpunkt wurde mit Hilfe des Axiovert 200 M (Zeiss, Göttingen) eine erste Aufnahme an einer definierten Stelle der Deckgläschen von dieser Lauffront aufgenommen. Nach 96 Stunden wurden dieselben Stellen erneut aufgenommen und somit der Endpunkt der Migration dokumentiert.

Für die Auswertung wurde die gewachsene Fläche an drei verschiedenen Stellen des in Duplikaten durchgeführten Versuchs miteinander verglichen. Mittels der zum Mikroskop gehörenden Axiovision Rel. 4.6.3 (Zeiss, Göttingen) wurde in Start- und dazu gehörenden Stopaufnahmen eine Länge von $1 \mathrm{~mm}$ an der Deckgläschenkante abgemessen und senkrecht zu dieser Geraden die Länge der gewachsenen Fläche abgelesen. Frei Hand kann in diesem 
Programm die äußere Migrationsfront nachgefahren werden und es wird automatisch die Fläche der eingezeichneten Form berechnet. Nach Subtraktion des Startareals von der Endausdehnung wurden die Werte gemittelt. Im Anschluss konnten die Konstrukte miteinander verglichen werden. Zur besseren Übersichtlichkeit wurden die Ergebnisse auf das Kontrollkonstrukt MCF-7 pcDNA bezogen.

\subsubsection{Proliferation und Cell Index im $x$ CELLigence ${ }^{\circledR}$}

Zur Charakterisierung der Proliferationseigenschaften wurde das $x$ CELLigence RTCA DP ${ }^{\circledR}$ Gerät der Firma Roche (Mannheim) für Echtzeit Viabilitäts- und Proliferationsbestimmung unter Berücksichtigung der Herstellerangaben eingesetzt.

Das System misst die Impedanz der Zellen in speziell entworfenen Mikrotiter-Platten. Hierfür enthalten diese verflochtene Mikroelektroden aus Gold, sodass die Messung nicht-invasiv erfolgen kann. Da die Messung kontinuierlich erfolgt, ist es außerdem möglich, zwischen Störungen der Viabilität, Zellalterung, Zelltod und Zellzyklusarrest zu unterscheiden. Im Allgemeinen ist jedoch darauf hinzuweisen, dass die Messung der elektrischen Impedanz natürlich nicht allein die Proliferation der Zellen widerspiegelt, sondern auch beeinflusst wird durch Parameter wie Zellzahl, Viabilität, Morphologie und Adhäsionsgrad.

Die Skalierung erfolgt durch einen dimensionslosen Parameter, den Cell Index (CI). Er leitet sich von dem relativen Impedanzwechsel bezogen auf den Zellstatus ab. So ist der CI einer leeren Zellkammer oder bei nicht-adhärenten Zellen gleich null. Bei Zunahme der Zellzahl, Zellen gleicher Morphologie und gleichen physiologischen Konditionen nimmt der CI proportional zu. Hier repräsentiert die Zunahme des Cell Index folglich relativ spezifisch den Parameter der Proliferation

Je nach eingesetzter Zelllinie wurden $1 \times 10^{4}-8 \times 10^{5}$ Zellen pro Well auf einer $E$ Plate 16-LochPlatte der Firma Roche (Mannheim) ausgesät. Die Messungen wurden über einen Zeitraum von 72 Stunden durchgeführt. Siehe auch Rietkötter et al. 2013.

\subsubsection{Invasion in der Boyden-Kammer}

Die Fähigkeit der stabil transfizierten Zellen, in umliegendes Gewebe zu invadieren, wurde in einer modifizierten Boyden-Kammer untersucht. Dieses 1962 von Stephen Boyden erstmals an Leukozyten beschriebene Verfahren ermöglicht nicht nur das Untersuchen von Chemotaxis, sondern auch die aktive Migration verschiedener Zelllinien. Die Kammer besteht hierfür aus zwei Kompartimenten, die durch eine poröse ECM-beschichtete Polykarbonatmembran getrennt werden. Diese lässt zwar Flüssigkeiten frei diffundieren, die Zellen können 
diese Barriere jedoch nur durch aktive Migration mit proteolytischer Aktivität überwinden. Nach Ablauf eines vorher getesteten Inkubationszeitraums und gegebenenfalls nach Exposition mit zu testenden Substanzen werden die Zellen gezählt, welche von der einen in die andere Kammer und durch die Membran invadiert sind.

Die benutzten modifizierten Boyden-Kammern wurden extra für die Arbeitsgruppe in der Werkstatt der Universitätsklinik Göttingen aus Acryl hergestellt. Sie werden mehrmals verwendet und zwischen den einzelnen Versuchen autoklaviert. Die untere Kammerhälfte wurde mit $2 \%$ FCS-Medium befüllt, mit der ECM-beschichteten Membran steril und luftblasenfrei bedeckt und die obere Hälfte fest mit dem Unterbau verschraubt. Anschließend wurden die Wells der oberen Hälfte mit je $500 \mu 1$ Medium +10 \% FCS zur Äquilibrierung befüllt und 3060 Minuten im Zellkulturschrank inkubiert. Für die Invasionsversuche wurden je nach untersuchten Zelllinien, in der Regel jedoch $1 \times 10^{5}$ Tumorzellen, ausgesät und für 96 Stunden inkubiert, wobei jede Versuchsbedingung in Triplikaten durchgeführt wurde. Die Bezugsgröße war die MCF-7 Brustkrebszelle, die stabil mit dem Leervektor pcDNA 3.1 transfiziert worden war. Als Positivkontrolle wurde eine Reihe dieser Zelllinie mit rekombinantem Wnt5a (100 ng je ml Medium) stimuliert, das, wie durch Pukrop et al. 2006 beschrieben, zu einem signifikanten Anstieg der Invasivität führte.

Bei Verwendung des JNK-Inhibitors wurde zum Startzeitpunkt und nach 48 h je $5 \mu \mathrm{M}$ des Hemmstoffs zugesetzt.

Nach Ablauf der Migrationszeit wurden die Zellen mittels einer Pipette aus den unteren Wells abgenommen und die adhärierenden Zellen vorsichtig vom Boden abgeschabt. Die Zellsuspension wurde 5 Minuten bei $850 \mathrm{rpm}$ zentrifugiert, das Pellet in $1 \mathrm{ml}$ Medium anschließend gelöst. Die Zellzahlbestimmung erfolgte in der Neubauer-Kammer. Die MCF-7 pcDNA wurde als Bezugsgröße für die weiteren Konstrukte verwendet. Weitere Details zu dem hier beschriebenen Verfahren können unter anderem bei Hagemann et al. (2004) nachgelesen werden.

\subsubsection{Untersuchungen von zerebralen Metastasen}

\subsubsection{Immunhistochemie}

Die immunhistochemischen Färbungen der zerebralen Brustkrebsmetastasen auf DVL3 wurden durch die neuropathologische Abteilung der Universitätsklinik Göttingen (Arbeitskreis um Frau Prof. Dr. med. Christine Stadelmann) angefertigt. 


\subsubsection{Auszählung und Auswertung}

Die Auswertung der gefärbten Hirnschnitte erfolgte mit Hilfe des Axiovert $200 M$ (Zeiss, Göttingen) und der dazu gehörenden Software Axiovision Rel. 4.6.3.

In den Hirnmetastasenfärbungen von 31 Patientinnen wurden in je vier Gesichtsfeldern je 100 Zellen auf ihren zytoplasmatischen bzw. nukleären DVL3-Gehalt untersucht. Anschließend wurden die Patientengruppen anhand ihrer prozentualen Positivität kategorisiert (0 \%, 1-10 $\%, 11-25 \%,>25 \%)$.

Mit Hilfe der GraphPad Prism $5^{\circledR}$ Software (GraphPad Software, USA) wurde mittels Pearsons Rangkorrelationskoeffizienten eruiert, ob ein Zusammenhang zwischen dem Vorhandensein von nukleärem und zytoplasmatischem DVL3 bestand.

\subsubsection{Statistische Auswertung}

Die Daten aller Versuche $(n \geq 3)$ wurden gemittelt und wie angegeben mit der entsprechenden Standardabweichung bzw. dem Standardfehler dargestellt. Bei einer Irrtumswahrscheinlichkeit von $\mathrm{p}<0,05$ im Stundents $\mathrm{t}$-Test bezogen auf die jeweilige Kontrolle (zweiseitig offen, gepaart) wurde von einer statistischen Signifikanz (*) ausgegangen.

Die Rangkorrelation wurde nach Pearson berechnet.

Die Auswertung und Darstellung der Ergebnisse erfolgte mittels Windows-Tabellenprogramm Excel ${ }^{\circledR} 2008$ (Microsoft Corporation, USA) und der Software GraphPad Prism $5^{\circledR}$ (GraphPad Software, USA). 


\section{Ergebnisse}

\subsection{Charakterisierung der Brustkrebslinien hTERT-HME1, MCF-7, SkBr3 und MDA-MB 231}

Aus Vorergebnissen der Arbeitsgruppe war bekannt, dass die besonders maligne Zelllinie MDA-MB 231 viel Wnt5a und ROR1/2 exprimiert und die im Gegensatz dazu weniger maligne MCF-7 diese Parameter der nicht-kanonischen Signalwege nur gering ausbildet (Klemm et al. 2011). Folglich war von Interesse, ob der Vergleich der immortalisierten Mammaepithelzelllinie hTERT-HME1 mit den Mamma-Karzinomzelllinien MCF-7, MDAMB 231 und $\mathrm{SkBr} 3$ die Hypothese unterstützen würde, dass die Expression von nichtkanonischen Markern mit der Malignität der Zellen korreliert.

\subsubsection{Expressionsanalyse mittels qRT-PCR}

Messenger RNA-Level der drei DVL-Subtypen, von Wnt5a und den beiden RORs wurden mittels Echtzeit-Polymerase-Kettenreaktion bestimmt und der minimale bis maximale Wert der $\Delta$ Cts vergleichend aufgetragen (Abb. 3.1 A). Bei einer Signaldetektion nach einem qRTPCR-Zyklus von 32 wurde, unter Berücksichtigung der Schmelzkurven, ein Vorhandensein von spezifischer mRNA nicht angenommen.

Interessant war, dass keine mRNA von ROR2 in den kultivierten Zellen nachweisbar war; bei großzügigerer Wahl des Grenzwertes für die Zykluszahl, bis zu der eine Auswertung der PCR-Ergebnisse erfolgen durfte, auch nur allenfalls in sehr geringen Mengen. Außerdem fanden sich auch in der immortalisierten Zelllinie hTERT-HME1 hohe Werte von Wnt5a- und ROR1-mRNA.

Folglich gibt es keinen direkten linearen Zusammenhang singulärer Marker der $\beta$-Cateninunabhängigen Signalwege in der qRT-PCR mit der in der Literatur beschriebenen Malignität der Zellen.

\subsubsection{Proteinanalysen mittels Western Blot}

Um zu eruieren, ob eventuell auf Ebene der Proteine die Hypothese stützbar wäre, wurden Western Blot-Analysen durchgeführt.

Hierzu wurde vorerst das Gesamtlysat der Zellen auf DVL3, Wnt5a und $\beta$-Catenin untersucht. Auch hier wurden hohe Mengen Wnt5a in der hTERT-HME1 detektiert (Abb. 3.1 B).

Es eröffnete sich die Frage, ob die Bedeutung für die Malignität eventuell mit der Lokalisa- 
tion der Proteine zusammenhängt. Deswegen führte ich weitere Untersuchungen mit Zytosolund Kernfraktionen durch.

Es fiel auf, dass DVL3 in der hTERT-HME1 vor allem in der Kernfraktion zu finden war und in der malignen MDA-MB 231 im Zytosol überwog.

Eine Korrelation der Malignität der Zelllinien mit dem $\beta$-Catenin-Gehalt oder seiner Verteilung zwischen Zytoplasma und Kern konnte nicht festgestellt werden. Zum Vergleich siehe hierzu Abbildung 3.1 C. 


\section{A}

\section{mRNA-Expressionsmuster}

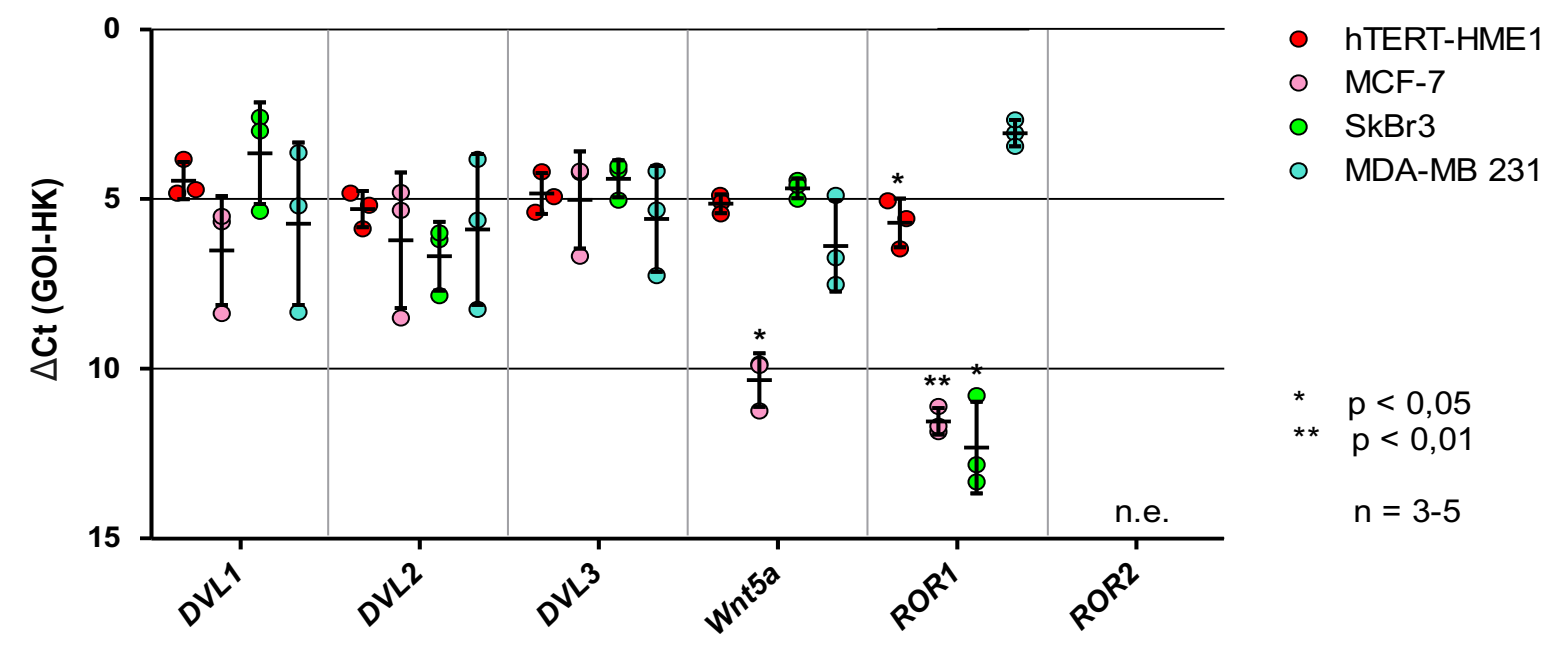

B

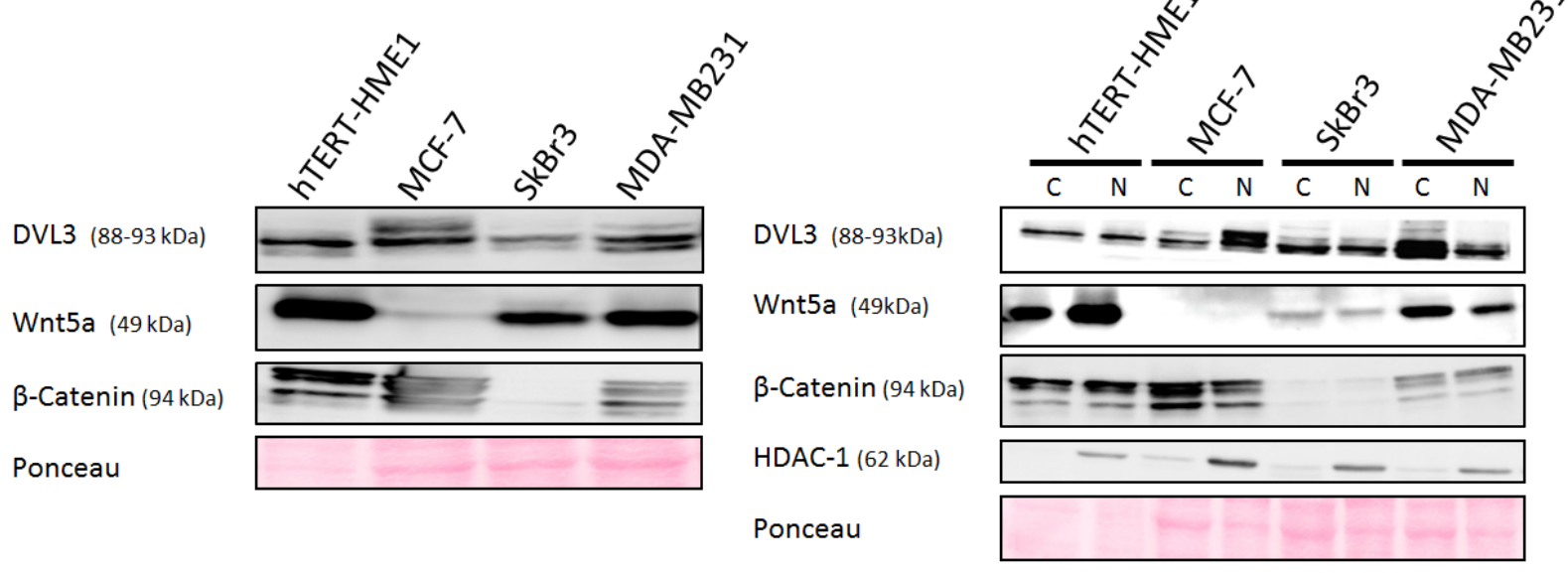

Abbildung 3.1 Untersuchung der Mammaepithelzelllinie hTERT-HME1 und der Brustkrebszelllinien MCF-7, SkBr3 und MDA-MB 231 in der Echtzeit-Polymerase-Kettenreaktion und im Western Blot. A: mRNA, qRT-PCR. Auf der x-Achse sind die untersuchten Gene, auf der y-Achse der $\Delta$ Ct-Wert (Gen von Interesse (GOI)) - Ct (Referenzgen (HK)) dargestellt. hTERT-HME1 (Rot), MCF-7 (Rosa), SkBr3 (Grün), MDA-MB 231 (Blau). Angegeben sind die Einzelwerte, der Mittelwert und die Standardabweichung. n.e. = nicht exprimiert. Bei einer Irrtumswahrscheinlichkeit von $\mathrm{p}<0,05$ im Stundents t-Test bezogen auf die auf die MDA-MB 231 (zweiseitig offen, gepaart) wurde von einer statistischen Signifikanz (*) ausgegangen. Western Blot-Analysen für die Proteine DVL3, Wnt5a und $\beta$-Catenin in den humanen Brustzelllinien. Gesamtlysat (B) und Zytosol-Kernaufreinigung (C). Zur Demonstration der Sauberkeit der Auftrennung wurde das rein nukleäre Protein Histone Deacerylase-1 (HDAC-1) sowie als Ladekontrolle Ponceau S dargestellt. C= Zytosol, N= Kern. 


\section{2 Überexpression von ROR2 in MCF-7}

Die Tatsache, dass ROR2 in den Hirnmetastasen der Brustkrebspatientinnen sehr hoch exprimiert wurde (Klemm et al. 2011), warf die Frage auf, welche Veränderungen diese Überexpression des ROR2-Rezeptors in den Zellen bewirkt. Folglich sollte ROR2 in den Östrogenrezeptor-positiven Adenokarzinomzellen MCF-7, die auch als luminal A klassifiziert werden, überexprimiert werden. Im Anschluss daran sollten sowohl Untersuchungen auf mRNA- und Proteinebene als auch funktionelle Analysen zu den typischen Malignitätskriterien wie Proliferation, Migration und Invasion folgen.

\subsubsection{Feststellung der Überexpression}

Nach der stabilen Transfektion der MCF-7 Zellen mit einem ROR2-Konstrukt in einem pcDNA-Vektor erfolgte zunächst der Nachweis der gelungenen Transfektion sowohl auf mRNA-Ebene in der Echtzeit-Polymerase-Kettenreaktion als auch auf Proteinebene im Western Blot und in der Immunofluoreszenz. 
A

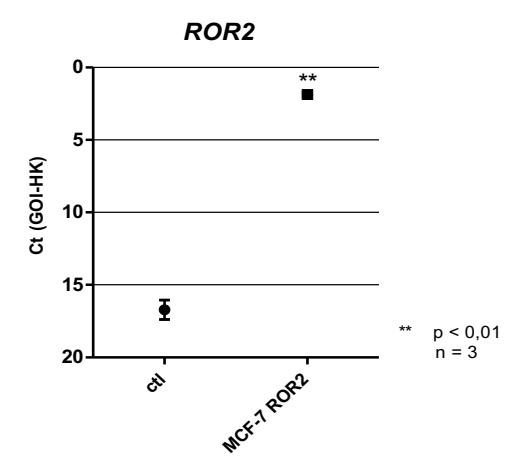

C

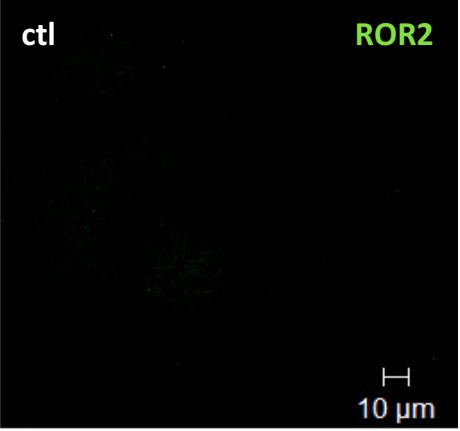

B

ROR2

(105 kDa)

Ponceau
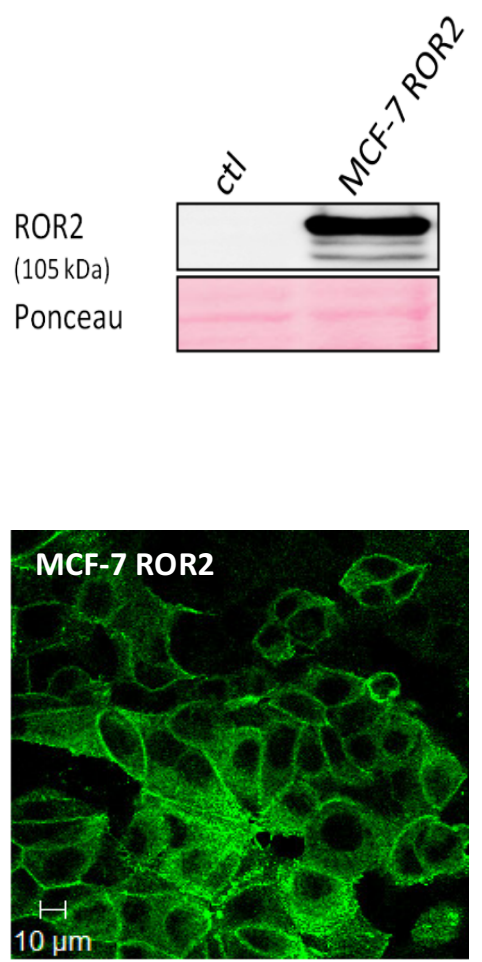

Abbildung 3.2 Feststellung der Überexpression von ROR2 in den stabil transfizierten MCF-7 Brustkrebszellen im Vergleich mit der Leervektorkontrolle. A: mRNA, qRT-PCR. Auf der x-Achse sind die Zelllinien, auf der y-Achse der ROR2- $\Delta$ Ct-Wert (Gen von Interesse (GOI)) - Ct (Referenzgen (HK)) dargestellt. Angegeben ist der Mittelwert und der Standardabweichung. Bei einer Irrtumswahrscheinlichkeit von $\mathrm{p}<0,05 \mathrm{im}$ Stundents t-Test bezogen auf die pcDNA-Kontrolle (zweiseitig offen, gepaart) wurde von einer statistischen Signifikanz (*) ausgegangen. B: Western Blot auf ROR2, Gesamtlysat. Als Ladekontrolle wurde Ponceau S dargestellt. C: Immunfluoreszenzfärbung. ROR2-Antikörper Serumüberstand 1:2 (FITC, grün).Die Auswertung der Färbungen erfolgte mit dem LSM 510 Konfokalmikroskop der Firma Zeiss, Göttingen. ctl = MCF-7 pcDNA.

\subsubsection{Charakterisierung der Zelllinie MCF-7 ROR2}

\subsubsection{Expressionsanalyse mittels qRT-PCR}

Zur Analyse der Zelllinie MCF-7 ROR2 wurden die mRNA-Level auf Marker der kanonischen und nicht-kanonischen Signalwege untersucht (Abb. 3.3.C). Durch die festgestellte morphologische Alteration der Zellen waren auch Indikatoren der epithelialmesenchymalen Transition von Interesse. 
3.2.2.1.1 Die Überexpression von ROR2 führt zu einem Anstieg des mRNA-Gehalts für ROR1 in der $q R T-P C R$

Durch die Überexpression von ROR2 kam es zu einer Erhöhung der mRNA-Level für ROR1, wobei darauf geachtet wurde, dass die Primer nur spezifische Produkte für die beiden Subtypen erkannten. Auf mRNA-Ebene wurde keine statistisch signifikante Veränderung der relativen Expression (bezogen auf die pcDNA-Kontrolle) für die drei DVL-Subtypen oder Wnt5a festgestellt. Wnt5b wurde nicht exprimiert.

\subsubsection{2 mRNA-Konzentrationen der EMT-Marker Vimentin und Snaill reduzierten sich in der qRT-PCR statistisch signifikant}

Bezüglich der EMT wurden Vimentin, Snail1, ZEB1 und ZEB2 untersucht. Es kam zu keiner veränderten Expression von ZEB1 und ZEB2, wobei letzteres nicht exprimiert wurde. Vimentin und Snaill sanken statistisch signifikant auf etwa die Hälfte der Kontrolle.

\subsubsection{Proteinanalysen mittels Western Blot}

Proteinlevel-Analysen wurden sowohl in Gesamtlysaten (vgl. hierzu Abb. 3.3.A) als auch nach Durchführung einer Kern-/Zytosolauftrennung (Abb. 3.3.B) im Immunoblot durchgeführt.

\subsection{Zunahme des Signals für DVL3 im Western Blot}

Initial wurde bei den Versuchen eine Anreicherung von DVL3 in den ROR2-überexprimierenden Zellen festgestellt. Dieses Ergebnis konnte jedoch im weiteren Verlauf nicht mehr konstant reproduziert werden, sodass es momentan weiterhin unklar bleibt, ob tatsächlich eine Regulation von DVL3 auf Proteinebene durch die Überexpression von ROR2 erfolgt. Dies müssen erneute Transfektionsexperimente zeigen.

\subsection{ROR2 hat allenfalls leichten inhibitorischen Einfluss auf die Aktivierung von $\beta$ - Catenin}

Ein deutlicher, konstanter Einfluss der ROR2-Überexpression auf $\beta$-Catenin oder aktiviertes, dephosphoryliertes $\beta$-Catenin $(\mathrm{ABC})$ wurde nicht detektiert. Allenfalls eine sehr leichte Inhibition von $\mathrm{ABC}$ in der zytosolischen Fraktion konnte im Vergleich mit der MCF-7 Kontrolle festgestellt werden.

Die Hochregulierung von ROR2 hat folglich keinen bis eventuell einen eher inhibierenden Einfluss auf den klassischerweise als kanonisch bezeichneten $\beta$-Catenin-abhängigen Signalweg. 


\subsection{ROR2-Überexpression führt zur Akkumulation von $p$-JNK und c-jun/p-c-jun}

Des Weiteren wurde eine vermehrte Phosphorylierung von JNK festgestellt. Dies wurde sowohl für die Kern- als auch Zytosolfraktion gezeigt.

Gleichzeitig konnten auch Anreicherungen von c-jun Gesamtprotein und phosphoryliertem cjun in der Auftrennung festgestellt werden.

A

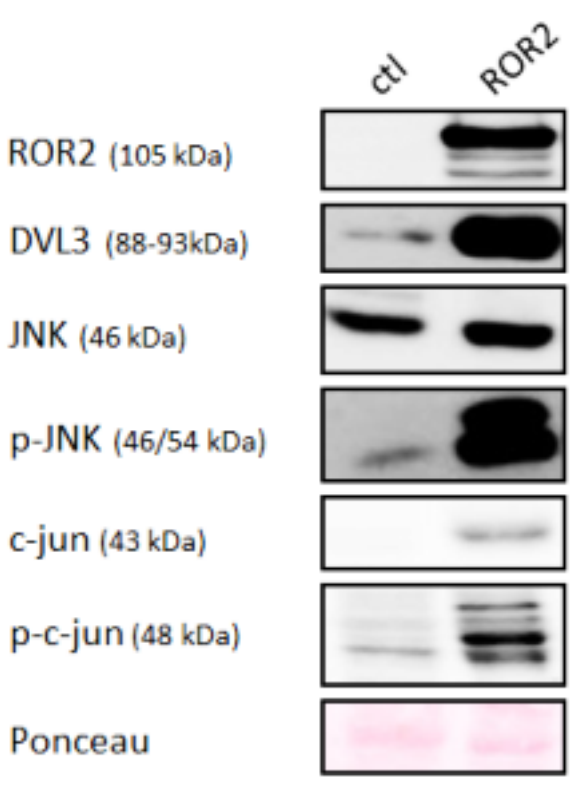

C

MCF7 ROR2
B

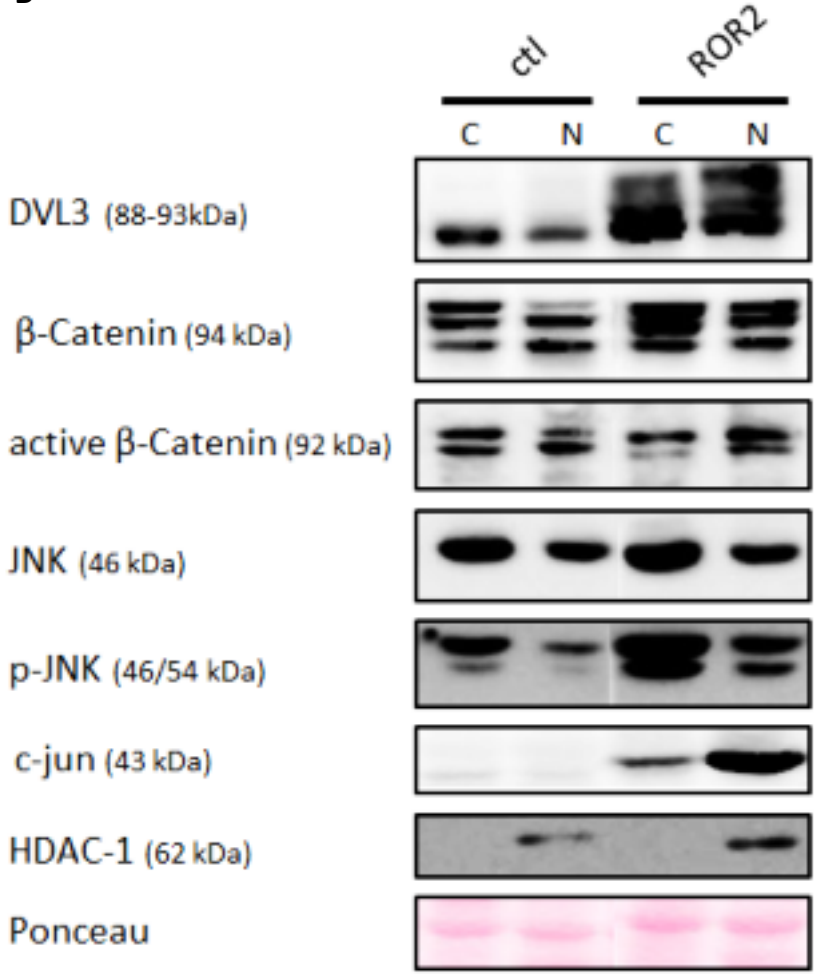

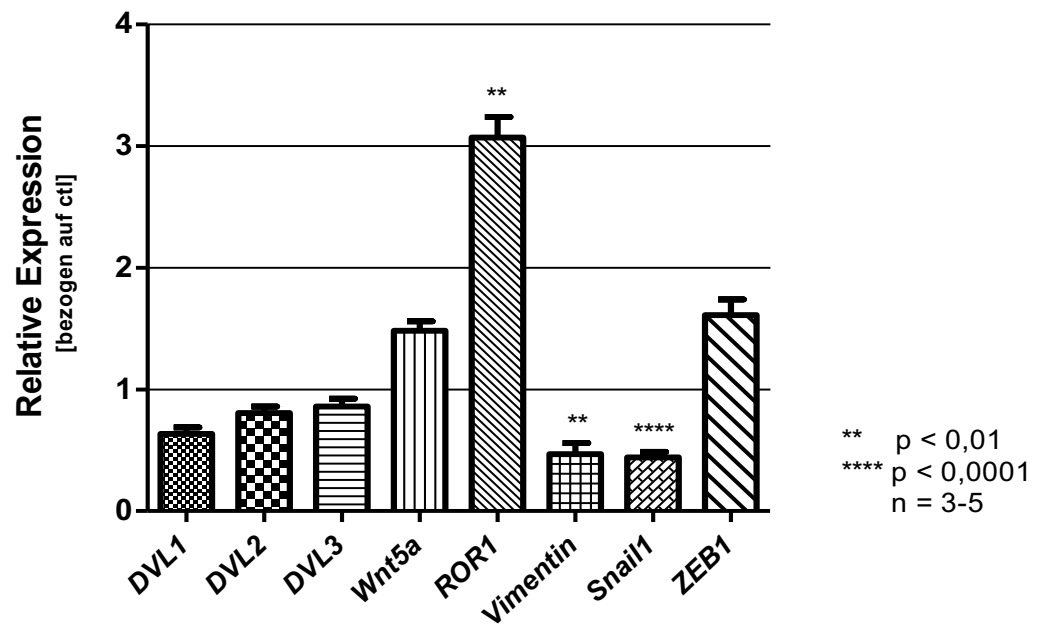


Abbildung 3.3 Untersuchung der Brustkrebszelllinien MCF-7 pcDNA und MCF-7 ROR2 im Western Blot und der qRT-PCR. Western Blot-Analysen für die Proteine ROR2, DVL3, JNK, p-JNK, c-jun, p-c-jun, $\beta$ Catenin und aktiviertes $\beta$-Catenin. A: Proteingesamtlysat. Der c-jun-Antikörper erfasst die Gesamtmenge des Proteins, der p-c-jun-Antikörper erfasst phosphoryliertes, unspezifisch jedoch auch unphosphoryliertes c-jun. Hier stellt die starke, schwarze Bande den p-c-jun-Gehalt dar. B: Auftrennung in Zytosol- und Kernfraktion. Zur Demonstration der Sauberkeit der Auftrennung wurde das rein nukleäre Protein Histone Deacerylase-1 (HDAC1) sowie als Ladekontrolle Ponceau $S$ dargestellt. $C=$ Zytosol, $N=$ Kern. C: mRNA, qRT-PCR. Auf der x-Achse sind die untersuchten Gene, auf der y-Achse die relative Expression, bezogen auf die MCF-7 pcDNA-Kontrolle (ctl), dargestellt. Angegeben ist die Standardabweichung. Bei einer Irrtumswahrscheinlichkeit von $\mathrm{p}<0,05$ im Stundents t-Test bezogen auf die pcDNA-Kontrolle (zweiseitig offen, gepaart) wurde von einer statistischen Signifikanz (*) ausgegangen. Housekeeper: HPRT und GNB2L1. Wnt5b und ZEB2 wurden nicht exprimiert und sind deswegen hier nicht dargestellt.

\subsubsection{Funktionelle Untersuchung der Zelllinie MCF-7 ROR2}

Es folgten Analysen zur Viabilität und Morphologie sowie zu den Malignitätskriterien der Zellproliferation, -migration und -invasion.

\subsubsection{Viabilität im MTT-Assay}

3.2.3.1.1 Die Viabilität der Zellen wird durch eine Überexpression von ROR2 nicht beeinflusst

Zunächst war von Interesse, ob die Zellen durch die stabile Transfektion und den permanenten Kontakt zum Selektionsantibiotikum Neomycin ${ }^{\mathrm{TM}}$ (G-418) eine Einschränkung oder Zunahme der Viabilität erfahren hatten. Die Untersuchung des Stoffwechsels einer definierten Zellzahl repräsentiert jene Viabilität im MTT-Assay. Es wurde weder in den mit dem Leervektor transfizierten MCF-7 (ctl) noch in den MCF-7 ROR2 Zellen eine signifikante Viabilitätsänderung bzw. Zunahme des Stoffwechsels durch eine vermehrte Proliferation der Zellen festgestellt (Abb. 3.4 B).

\subsubsection{Morphologie in der Immunfluoreszenz}

\subsection{Die Überexpression von ROR2 bewirkt morphologische Veränderungen der} Zellen

Um die in der Zellkultur bereits subjektiv festgestellte morphologische Umwandlung besser sichtbar zu machen, wurde eine Immunfluoreszenzfärbung der Zellen durchgeführt (Abb. 3.4 A). Prinzipell sind zwei verschiedene Gestaltschemata zu erkennen: Zellen im epithelialen Zellkontakt zeigen eine Zunahme des Zytoplasmas im Vergleich zur konstanten Kerngröße 
bzw. eine Abflachung der Zellen, wohingegen Einzelzellen dazu neigten, vermehrt Fortsätze zu bilden.

\subsubsection{Zellanalyse im $x$ CELLigence ${ }^{\circledR}$}

Zur Objektivierung der veränderten Morphologie wurden die Zellen mittels des $x$ CELLigence ${ }^{\circledR}$-Gerätes von Roche Applied Science analysiert. In Abbildung 3.4 C ist ein repräsentativer Einzelversuch dargestellt. Der Zellindex, also die elektrische Impendanz der ROR2 Zellen, zeigt im Vergleich zur pcDNA-Kontrolle keine signifikante Veränderung. Folglich unterscheiden sich die MCF-7 ROR2-Zellen bezüglich Viabilität nicht von der Leervektorkontrolle (vgl. auch die Ergebnisse des MTT-Assays unter 3.2.3.1).

\subsubsection{Invasion in der Boyden-Kammer}

\subsection{ROR2 steigert die Invasivität der Zellen signifikant}

Die Überexpression von ROR2 in MCF-7-Zellen führt zu einem signifikanten Anstieg der Invasivität durch Extrazellulärmatrix in der modifizierten Boyden-Kammer. Die bereits erläuterte, im Western Blot festgestellte vermehrte Phosphorylierung von JNK zu p-JNK (phospho-JNK) warf die Frage auf, ob die Zunahme der Invasion über den JNK-Signalweg zustande kommen könnte.

\subsection{Durch Inhibition von JNK wird der Invasivitätsanstieg unterbunden}

Durch die zweimalige Zugabe von $5 \mu \mathrm{M}$ JNK-Inhibitor im 96 h-Versuch blieb der bisher beobachtete Invasivitätsanstieg aus (Abb. 3.4 D).

Es ist folglich davon auszugehen, dass der Invasivitätsanstieg durch die ROR2-Überexpression über den $\beta$-Catenin-unabhängigen Signalweg infolge der Aktivierung von JNK verursacht wird.

\subsubsection{Migrationsassay}

Die Wanderung in der Ebene auf Extrazellulärmatrix wurde mit Hilfe des Migrationsassays untersucht. Es wurde keine signifikante Änderung der Migrationsgeschwindigkeit festgestellt (Abb. 3.4 E). Auffällig war jedoch die abweichende Gestalt der Zellen. Abb. 3.4 F zeigt die vermehrte Bildung von Fortsätzen bzw. Zytoplasmaausstülpungen auf Höhe der Lauffront. Ebenfalls scheint das Kern-Zytoplasma-Verhältnis zu Gunsten des Zytoplasmas verschoben. 


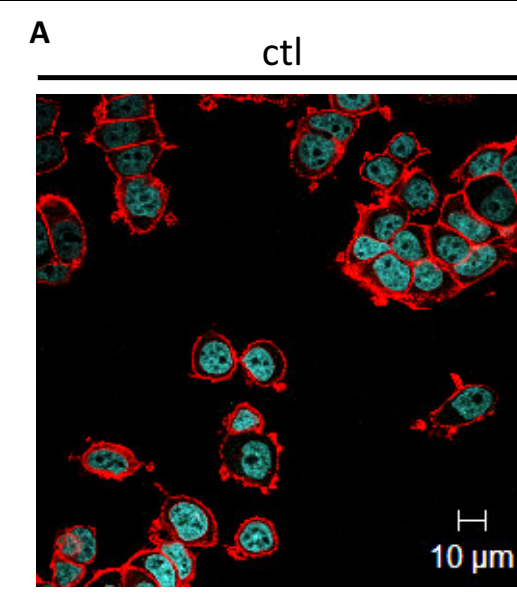

B

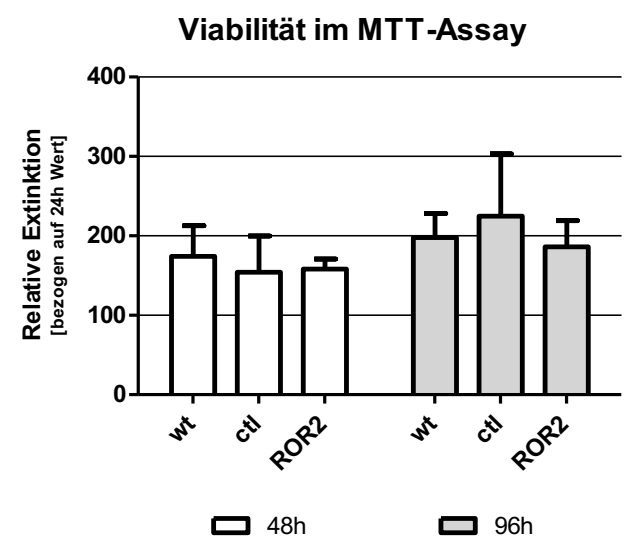

D

Invasivität

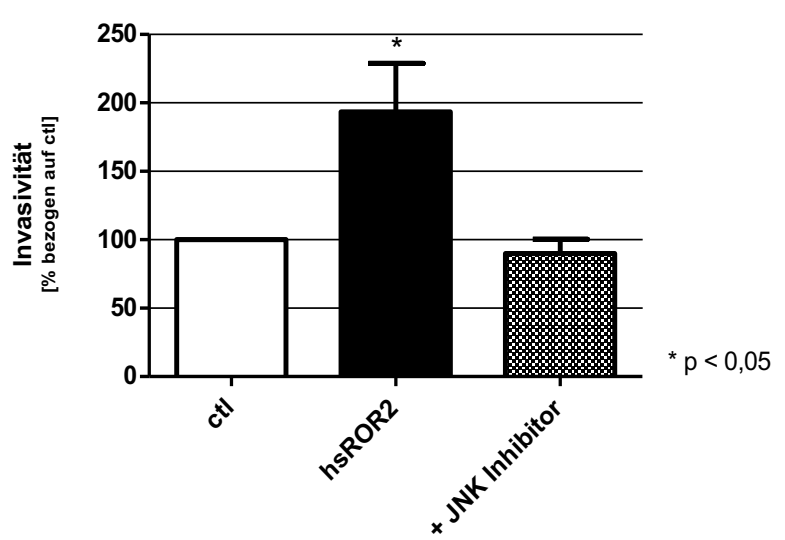

ROR2

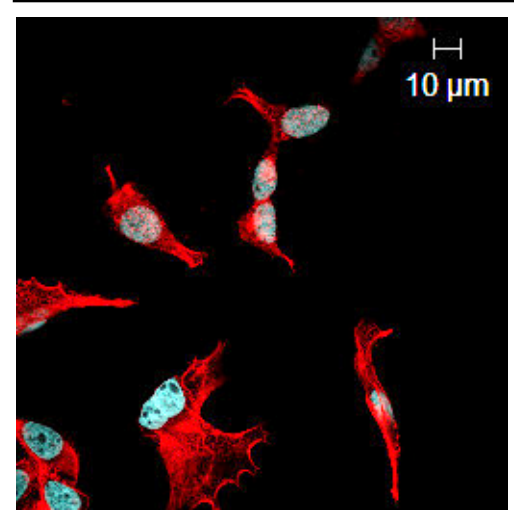

C

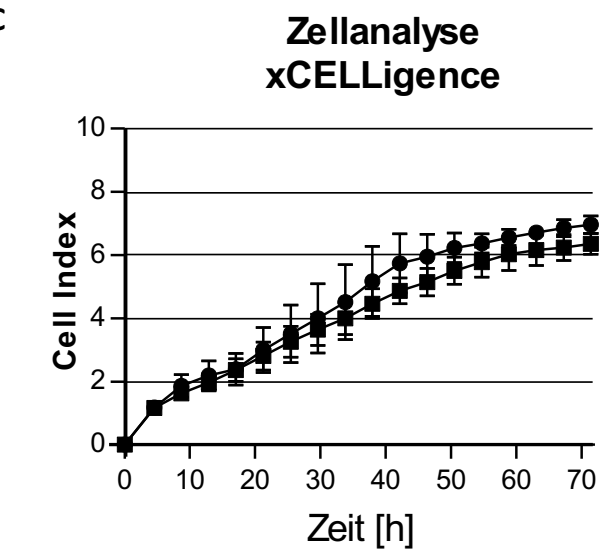

$\rightarrow \mathrm{ctl} \quad \rightarrow \quad \mathrm{pROR2}$

E

Migrationsassay

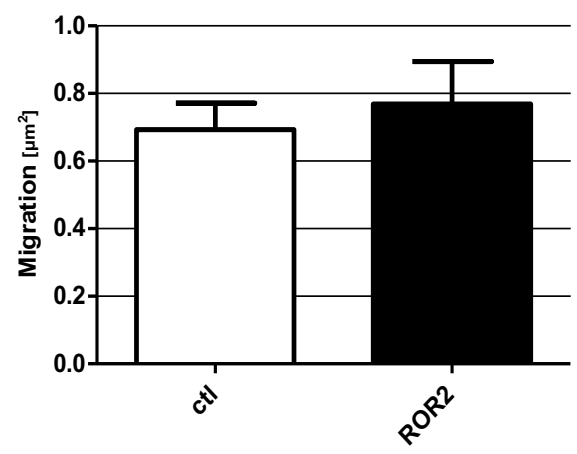

Zellanalyse xCELLigence

F

ctl

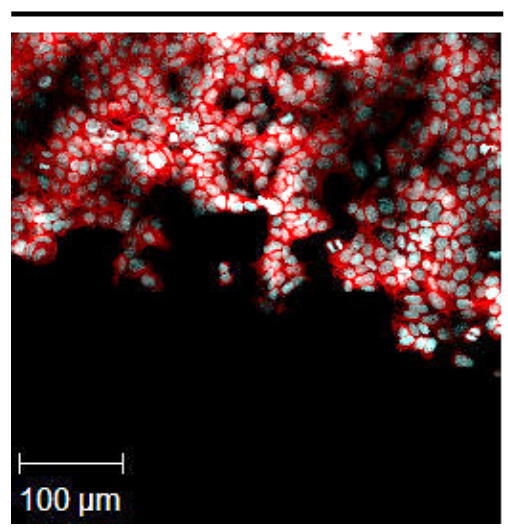

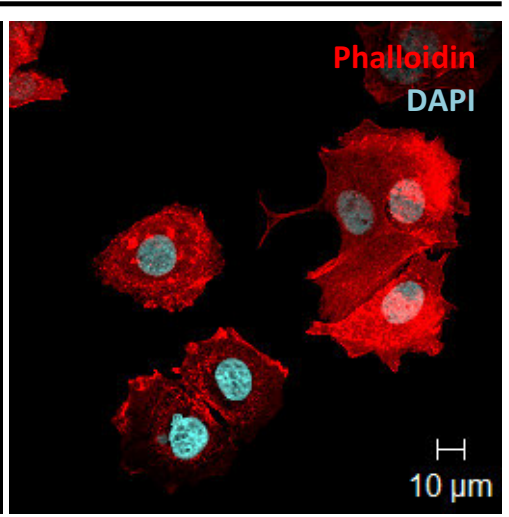

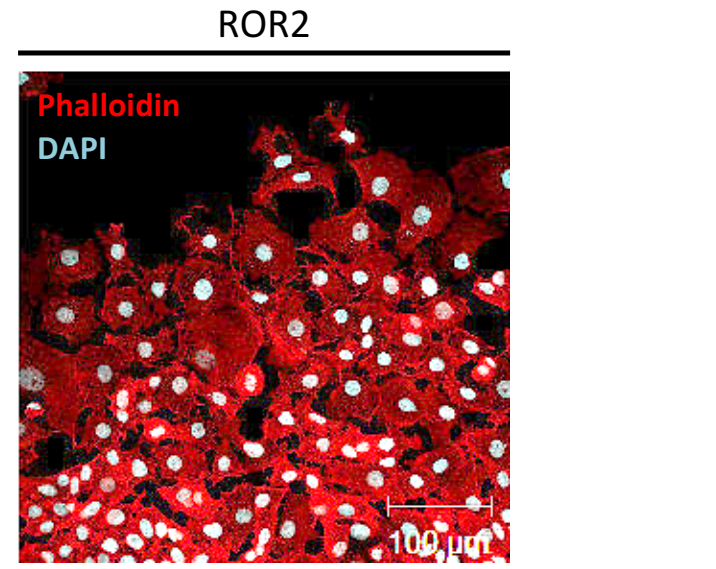


Abbildung 3.4 Funktionelle Untersuchungen der ROR2-überexprimierenden MCF-7 Brustkrebszellen. A: Vergleich der Zellform MCF-7 pcDNA (ctl) und MCF-7 ROR2. Einzelzellfärbung. Phalloidin (TRITC, rot). DAPI Kernfärbung (blau). B: Viabilität im MTT-Assaynach 48 und 96 Stunden. Auf der x-Achse sind die Zelllinien, auf der y-Achse die relative Extinktion in \% bezogen auf den jeweiligen $24 \mathrm{~h}-$ Wert angegeben. Mittelwert der drei Replikate \pm Standardabweichung. Wt $=$ MCF-7, ctl $=$ MCF-7 pcDNA. Bei einer Irrtumswahrscheinlichkeit von $\mathrm{p}<0,05$ im Stundents t-Test bezogen auf die MCF-7-Kontrolle (zweiseitig offen, gepaart) wurde von einer statistischen Signifikanz $(*)$ ausgegangen. C: Zellanalyse im $x$ CELLigence ${ }^{\circledR}$. Anzucht und kontinuierliche Beobachtung der Zellen für 72 Stunden. Auf der y-Achse ist der Zellindex als Marker der relativen Proliferation, auf der x-Achse die Zeit dargestellt.. Repräsentativer Einzelversuch. Ctl $=$ MCF-7 pcDNA. D: Invasivität in der Boyden-Kammer. Die Tumorzellen wurden in einer modifizierten BoydenKammer für 96 h kultiviert. Zum Startzeitpunkt und nach 48 h wurden in eine der Kammern je $5 \mu \mathrm{M} J N K-$ Inhibitor zugesetzt. Die Invasionsrate der ROR2-überexprimierenden Zellen wurde dabei auf die MCF-7 pcDNA Zellen (ctl) bezogen, diese wiederum auf $100 \%$ gesetzt. Dargestellt sind die Mittelwerte aus $\geq$ drei unabhängigen Experimenten \pm Standardfehler. E: Migrationsassay. ECM-basierter Migrationsassay für MCF-7 pcDNA (ctl) und MCF-7 ROR2. Dargestellt ist die ausgemessene Fläche $\left(\mu \mathrm{m}^{2}\right)$ nach $48 \mathrm{~h} \pm$ Standardabweichung. Bei einer Irrtumswahrscheinlichkeit von $\mathrm{p}<0,05$ im Stundents t-Test bezogen auf die pcDNA-Kontrolle (zweiseitig offen, gepaart) wurde in D un E von einer statistischen Signifikanz $(*)$ ausgegangen. F: Morphologie in der Migration: Immunfluoreszenzfärbung der Zellen MCF-7 pcDNA (ctl) und ROR2 im Migrationsassay. Phalloidin (TRITC, rot). DAPI Kernfärbung (blau). Die Auswertung der Färbungen erfolgte mit dem LSM 510 Konfokalmikroskop der Firma Zeiss, Göttingen.

\section{3 Überexpression von DVL3 wt und verschiedenen DVL3- Konstrukten in MCF-7-Brustkrebszellen}

Während die Aktivierung von JNK über ROR2 bereits in anderen Kontexten beschrieben wurde, galt dieser Signalweg immer als DVL-unabhängig. Folglich stellte sich die Frage, in wieweit DVL3 diesen Weg aktiviert.

Gleichzeitig wollte ich die Folgen dieser Stabilisierung oder vermehrten Proteinsynthese von denen der reinen ROR2-Überexpression unterscheiden können und mehr über die Eigenschaften von DVL3 als Schaltprotein der Wnt-Signalwege in Brustkrebszellen in Erfahrung bringen.

Hierzu transfizierte ich wiederum MCF-7 Zellen stabil, diesmal mit verschiedenen FLAGmarkierten DVL3 pcDNA-Konstrukten, die im Materialteil im Einzelnen dargestellt sind. 


\subsubsection{Nachweis der Überexpression}

Der Erfolg der Transfektion wurde mittels Western Blot auf FLAG und qRT-PCR auf DVL3 überprüft. Im Western Blot konnten spezifische Banden im Größenbereich der verschiedenen Konstrukte detektiert werden. Da die eingesetzten Primer im Bereich zwischen den Domänen DIX und PDZ angriffen, wurden die Konstrukte, denen dieser Bereich fehlte, nicht, beziehungsweise nur mangelhaft, erkannt. Aus Gründen der Übersichtlichkeit ist hier nur die Detektion der Wildtyp-Überexpression dargestellt (Abb. 3.5).

A

DVL3 wildtyp

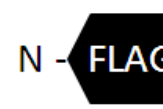

DVL3 $\triangle \mathrm{DIX}$

DVL3 $\triangle \mathrm{DIX} \triangle \mathrm{PDZ}$

DVL3 $\triangle \mathrm{DIX} \triangle \mathrm{PDZ} \triangle \mathrm{DEP}$

DVL3 $\triangle$ PDZADEP

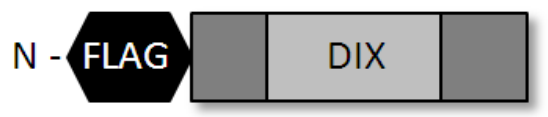

PDZ

DEP

N- FLAG

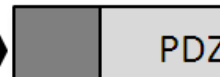

\begin{tabular}{|l|l|l|} 
PDZ & DEP \\
\hline
\end{tabular}

N-
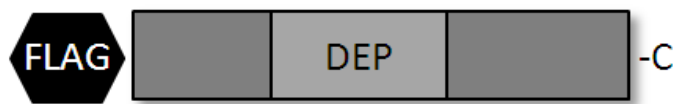

$\mathrm{N}-$ FLAG

DVL3 $\triangle$ PDZADEP

DVL3 $\triangle D E P$

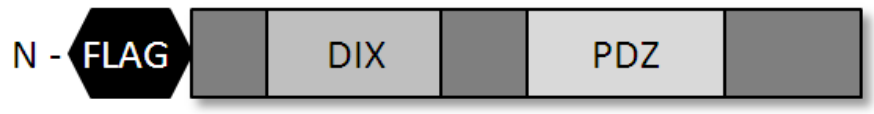

DVL3 $\Delta$ C-term
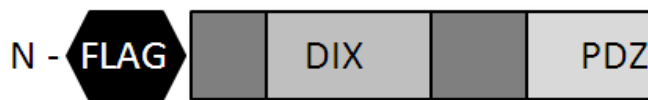

DEP

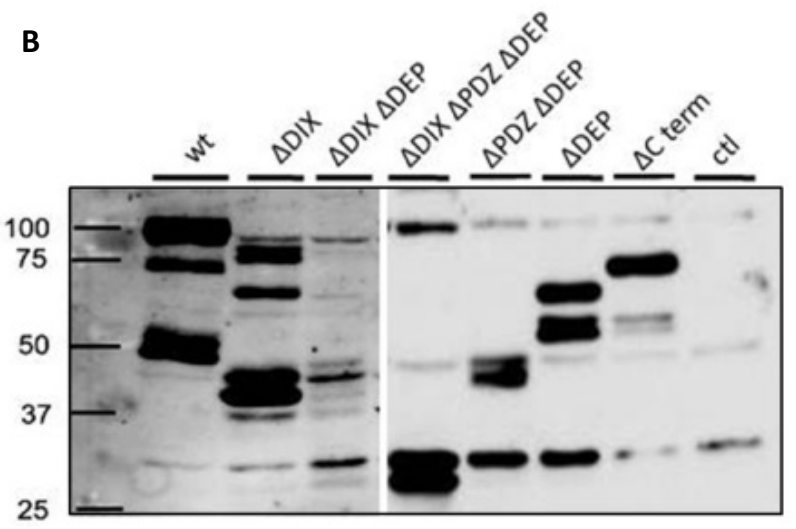

C

DVL3

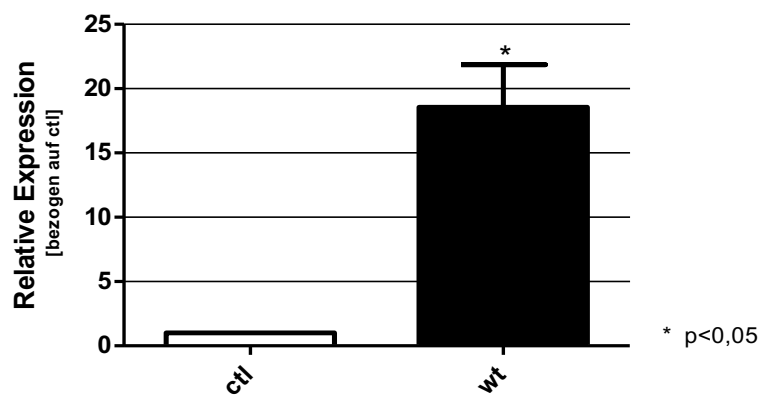

Abbildung 3.5 Überexpression der DVL3-Konstrukte in den stabil transfizierten MCF-7 Zellen. A:

Darstellung der verwendeten Konstrukte B: Nachweis der FLAG-markierten-Konstrukte im Western Blot. FLAG-Ak 1:6.000 in 5 \% MMP, ÜN. C: Nachweis des DVL3 wt-Konstrukts in der Echtzeit-PolymeraseKettenreaktion. Dargestellt ist der relative DVL3-mRNA-Gehalt der MCF-7 DVL3 wt-überexprimierenden Zellen bezogen auf die pcDNA-Leervektorkontrolle (ctl). Mittelwert von drei Experimenten \pm Standardabweichung. Bei einer Irrtumswahrscheinlichkeit von $\mathrm{p}<0,05$ im Stundents t-Test bezogen auf die pcDNA-Kontrolle (zweiseitig offen, gepaart) wurde von einer statistischen Signifikanz (*) ausgegangen. 


\subsubsection{Charakterisierung der stabil in MCF-7 transfizierten DVL3-Konstrukte}

\subsubsection{Expressionsanalyse mittels qRT-PCR}

Auch hier waren repräsentative Marker der Wnt-Signalkaskaden und EMT-Marker von Interesse. Alle Ergebnisse sind in Abb. 3.6 zusammengestellt.

\subsection{Das Konstrukt $\triangle D I X \triangle P D Z \triangle D E P$ führt zum Anstieg der mRNA für Wnt5a}

Interessanterweise konnte nach der stabilen Transfektion mit dem DVL3-Konstrukt, das nur aus dem c-terminalen Bereich DVLs besteht, ein vermehrter mRNA-Gehalt für Wnt5a in diesen Zellen bezogen auf die pcDNA Kontrolle festgestellt werden.

\subsection{DVL3-Überexpression führt zu einem Anstieg der ROR-mRNA in Abhängigkeit von den Domänen PDZ und DEP}

Die Überexpression von DVL3 wt führte zum Anstieg der mRNA für den Transmembranrezeptor ROR1. Dieser Effekt war in allen Knock-out-Konstrukten sichtbar, welche die als nicht-kanonisch geltenden Domänen PDZ und DEP noch besaßen.

\subsection{DVL3 wt-Überexpression führt zur verminderten $m R N A$-Expression von DVL2; DVL1 mRNA wird nicht beeinflusst}

Die Überexpression von DVL3 wt führt zu einer geringen, jedoch statistisch signifikanten, Regulation von DVL2-mRNA. Alle Domänen, auch der hochkonservierte c-terminale Bereich, scheinen hierfür von Bedeutung zu sein, da bereits das Fehlen dieses kleinen Abschnitts eine Reduktion von DVL2 verhindert. Es wurde kein Einfluss der Konstrukte auf DVL1 festgestellt.

\subsection{DVL3-Überexpression hat geringen Einfluss auf die hier untersuchten EMT- Marker}

Während keines der eingesetzten Konstrukte signifikante Veränderungen der mRNA-Level von ZEB1 oder Snail1 in Bezug auf die MCF-7-Kontrolle aufwies, konnte bei einigen Konstrukten eine statistisch signifikante Halbierung der Werte von Vimentin festgestellt werden. Inwieweit dies einen bedeutsamen Vorgang darstellt, konnte so jedoch nicht beurteilt werden.

Wnt5b, ROR2 und ZEB2 wurden nicht exprimiert und sind daher hier nicht aufgeführt. 

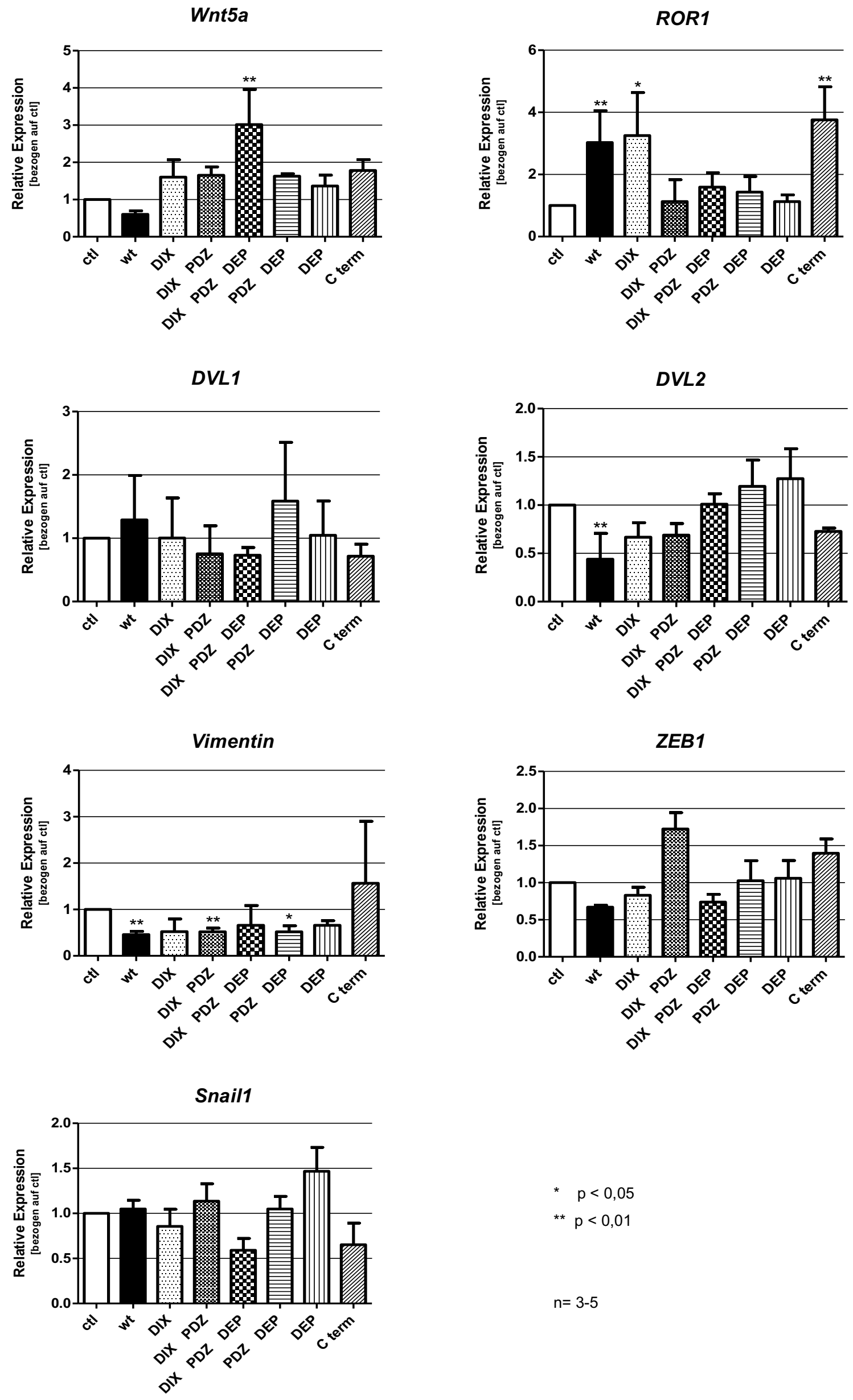

* $p<0,05$

** $p<0,01$

$n=3-5$ 
Abbildung 3.6 Untersuchung der mRNA-Expressionsmuster der mit DVL-Konstrukten stabil transfizierten Brustkrebszellen mittels qRT-PCR. Proteine des kanonischen und nicht-kanonischen WntSignalwege: Wnt5a, Wnt5b, DVL1 und 2, ROR1 und 2. Marker der epithelial-mesenchymalen Transition: Vimentin, ZEB1 und 2, Snail1. Auf der x-Achse sind die Zellen, auf der y-Achse die relative Genexpression bezogen auf die pcDNA-Kontrolle (ctl) aufgetragen. Angegeben ist der Mittelwert von $\geq 3$ Experimenten \pm Standardabweichung. Bei einer Irrtumswahrscheinlichkeit von $\mathrm{p}<0,05$ im Stundents $\mathrm{t}$-Test bezogen auf die pcDNA-Kontrolle (zweiseitig offen, gepaart) wurde von einer statistischen Signifikanz (*) ausgegangen. Housekeeper: HPRT und GNB2L1. Wnt5b, ROR2 und ZEB2 wurden nicht exprimiert und sind deswegen hier nicht dargestellt.

\subsubsection{Proteinanalysen mittels Western Blot}

\subsection{Die Überexpression von DVL3 wt führt zu keiner Akkumulation von $\beta$-Catenin}

Die Hochregulation des bisher eher für die $\beta$-Catenin-unabhängige Signaltransduktion zuständigen DVL3 wt hatte auch in diesem Kontext keinen Einfluss auf die Gesamtmenge oder Lokalisation von phosphoryliertem oder nicht-phosphoryliertem $\beta$-Catenin.

\subsection{Das Konstrukt DVL3 $\triangle D I X$ inhibiert die Akkumulation von $\beta$-Catenin in Zytosol- und Kernfraktion ohne Einfluss auf die $\beta$-Catenin-Gesamtproteinmenge}

Western Blot-Analysen zeigten Auswirkungen auf $\beta$-Catenin durch das Konstrukt DVL3 $\Delta$ DIX. Es reduzierte sowohl die zytosolischen als auch die nukleäre Proteinmenge von aktivem $\beta$-Catenin im Western Blot. Dabei hatte es jedoch keinen Einfluss auf die Proteinmenge oder Lokalisation des $\beta$-Catenin.

\subsection{Die Überexpression von DVL3 wt führt allenfalls zu einer diskreten Zunahme der Phosphorylierung von JNK}

Die Western Blot-Analysen zu p-JNK zeigten starke Schwankungen zwischen den einzelnen Versuchsläufen. Ein möglichst repräsentativer Einzelversuch ist in Abb. 3.7 dargestellt. Die Überexpression von DVL3 wt führt allenfalls zu einer diskreten Zunahme der Phosphorylierung von JNK im Vergleich zur pcDNA Kontrolle. 

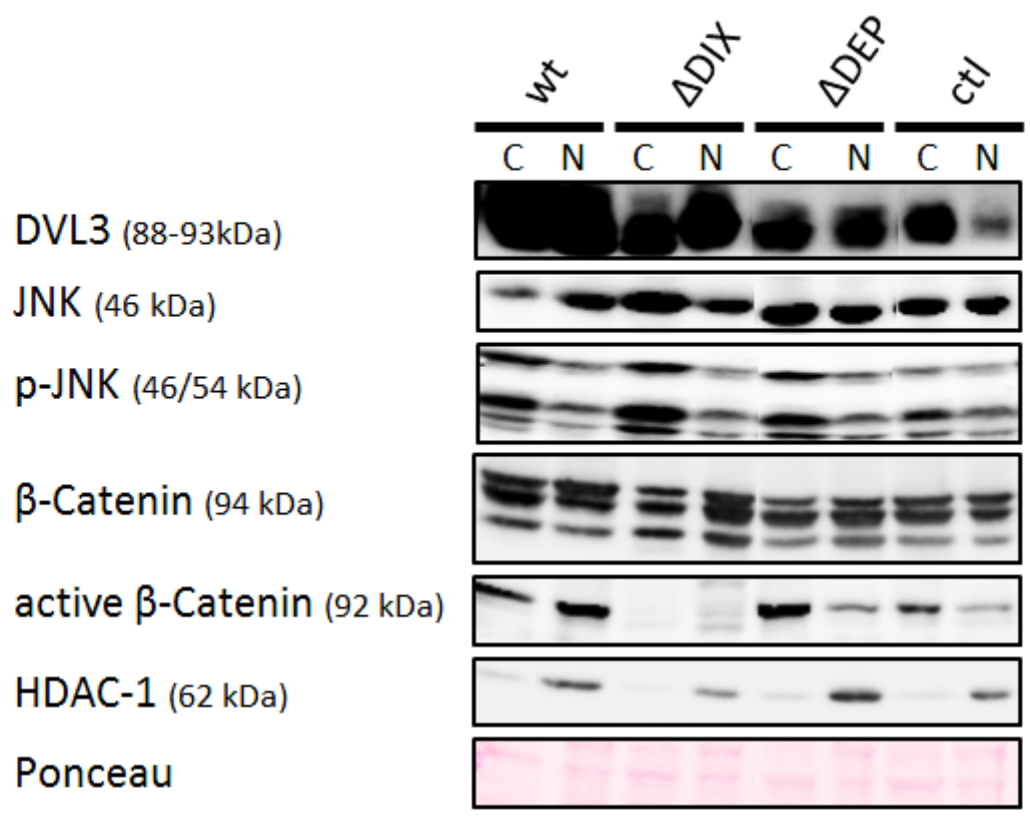

\begin{abstract}
Abbildung 3.7 Untersuchung der stabil transfizierten MCF-7-Zellen DVL3 wt, DVL3 $\triangle$ DIX, DVL3 $\triangle$ DEP und MCF-7 pcDNA (ctl) im Western Blot. Zytosol-/ Kernaufreinigung. Zur Demonstration der Sauberkeit der Auftrennung wurde das rein nukleäre Protein Histone Deacerylase-1 (HDAC-1) sowie als Ladekontrolle Ponceau $\mathrm{S}$ dargestellt. $\mathrm{C}=$ Zytosol, $\mathrm{N}=$ Kern.

Anmerkung: Der im oben dargestellten Blot auf DVL3 verwendete Antikörper detektiert endogenes DVL im hochkonservierten C-terminalen Bereich. Folglich werden auch die transduzierten Konstrukte DVL3 wt und DVL3 $\triangle$ DIX von diesem Antikörper erfasst, während in den Fraktionen der ctl und DVL3 $\triangle$ DEP nur das endogene DVL3 abgebildet wird.
\end{abstract}

\title{
3.3.3 Funktionelle Untersuchung der stabil in MCF-7 transfizierten DVL3-
}

\section{Konstrukte}

\subsubsection{Morphologie in der Immunfluoreszenz}

\subsection{Durch Überexpression der DVL3-Konstrukte kam es zu keiner in der Immunfluoreszenz sichtbaren morphologischen Veränderung der MCF-7-Zellen}

Die Überexpression der verschiedenen DVL3-Konstrukte bewirkte per se keine primär ersichtliche morphologische Veränderung der MCF-7-Zellen im Vergleich zur pcDNAKontrolle. Repräsentativ wurden einige Aufnahmen der stabil transfizierten Zellen mittels konfokaler Lasermikroskopie gemacht, ausgewählt und in Abb. 3.8 dargestellt.

Bereits in der Immunfluoreszensfärbung der Einzelzellen auf FLAG fiel auf, dass in einigen von ihnen Anreicherungen der Konstrukte in Form von Aggregaten, im Folgenden auch als 
„Dots“ oder „Konglomerate“ bezeichnet, stattfanden. Am deutlichsten war dies der Fall beim Konstrukt DVL3 $\triangle \mathrm{PDZ} \triangle \mathrm{DEP}$.

Des Weiteren zeigten einige Zellen Anreicherungen des FLAG-markierten DVL3-Proteins in Zellfortsätzen (s. Abb. 3.8 DVL3 $\Delta$ DIX 2. Bildreihe von oben).
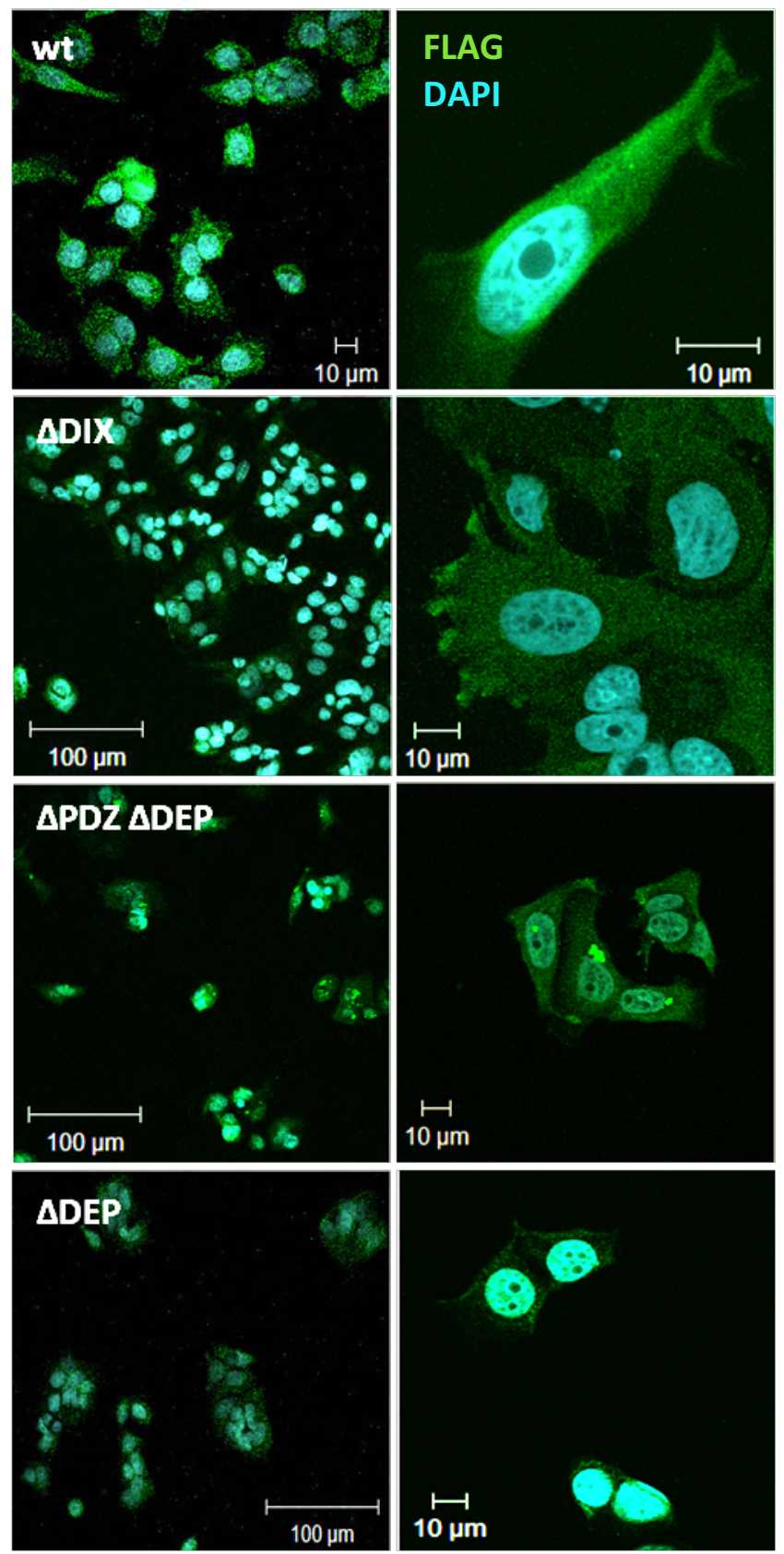

Abbildung 3.8 Untersuchung der stabil transfizierten MCF-7 Brustkrebszellen in der Immunfluoreszenz. Repräsentative Einzelzellfärbung der DVL3-Konstrukte DVL3 wt, DVL3 $\triangle$ DIX, DVL3 $\triangle$ PDZ $\triangle$ DEP, DVL3 $\triangle$ DEP. FLAG-Antikörper 1:100 (FITC, grün). Kernfärbung: DAPI (blau). Die Auswertung der Färbungen erfolgte mit dem LSM 510 Konfokalmikroskop der Firma Zeiss, Göttingen. 


\subsubsection{Viabilität im MTT-Assay}

\subsection{Die Viabilität der Zellen wird durch eine Überexpression der DVL3-Konstrukte nicht beeinflusst}

Bevor die Zellen für weitere Versuche eingesetzt wurden, erfolgten Viabilitätsanalysen mittels des MTT-Assays. Keines der eingesetzten Konstrukte bewirkte signifikante Veränderungen der Zellviabilität (Abb. 3.9 A).

\subsubsection{Zellanalyse im $x$ CELLigence ${ }^{\circledR}$}

\subsection{DVL3 wt zeigt einen verminderten Cell Index im xCELLigence ${ }^{\circledR}$-Zytometer}

Obwohl die Immunfluoreszenz keinen Einfluss auf die Morphologie der Zellen offenbarte, wurden sie anschließend zur Vollständigkeit ebenfalls im $x$ CELLigence ${ }^{\circledR}$-Zytometer untersucht. Hier fiel eine Abnahme des Zellindex der DVL3 wt-überexprimierenden MCF-7Zellen auf, während andere Konstrukte diesen nicht beeinflussten.

Da der CI von mehreren Parametern der Zellen beeinflusst wird, spricht dies entweder für eine verminderte Adhäsion oder morphologische Änderungen, die erst durch die höhere Präzision bzw. Sensitivität der Methode offengelegt werden konnten (Abb. 3.9 B).

A

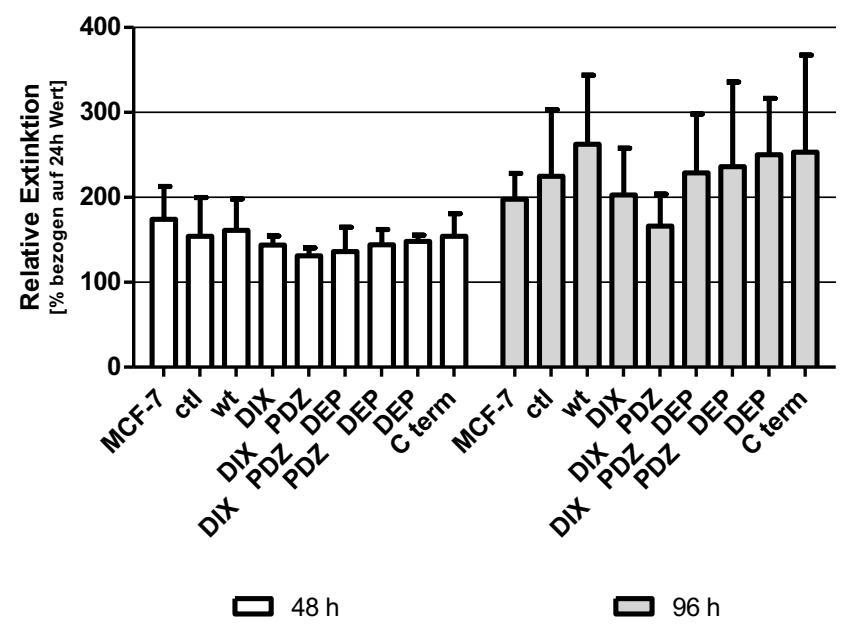

B

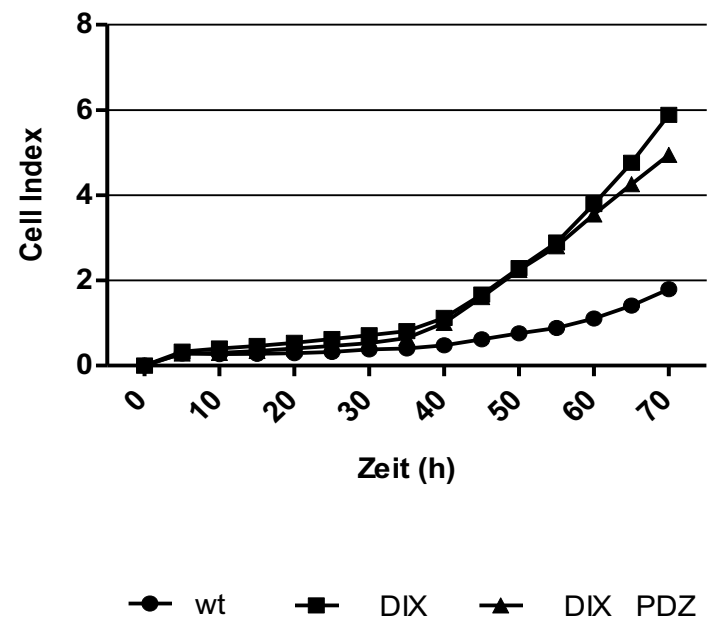

Abbildung 3.9 Funktionelle Untersuchungen der stabil transfizierten MCF-7 Brustkrebszellen. A: Viabilität im MTT-Assay nach 48 und 96 Stunden. Auf der x-Achse sind die Zelllinien, auf der y-Achse die relative Extinktion in \% bezogen auf den jeweiligen 24h-Wert angegeben. Mittelwert der drei Replikate \pm Standardabweichung. $\quad$ ctl $=$ MCF-7 pcDNA. Wt $=$ MCF-7 DVL3. Bei einer Irrtumswahrscheinlichkeit von $\mathrm{p}<0,05$ im Stundents t-Test bezogen auf die MCF-7-Kontrolle (zweiseitig offen, gepaart) wurde von einer statistischen Signifikanz $(*)$ ausgegangen. B: Zellanalyse im $x$ CELLigence ${ }^{\circledR}$. Anzucht und kontinuierliche Beobachtung der Zellen für 72 Stunden. Auf der y-Achse ist der Zellindex als Marker der relativen Proliferation, auf der x-Achse die Zeit dargestellt.. Repräsentativer Einzelversuch. wt = MCF-7 DVL3. 


\subsubsection{Migrationsassay}

3.3.3.4.1 DVL3 wt reduziert die Migrationsgeschwindigkeit der Zellen in der Ebene unabhängig vom hochkonservierten C-Terminus

Der Migrationsversuch auf einer ECM-beschichteten Petrischale zeigte eine verminderte Migration der DVL3 wt-überexprimierenden Zellen. Des Weiteren wies auch das Konstrukt, dem nur der c-terminale Bereich fehlte, eine geringere Migrationsgeschwindigkeit auf (Abb. $3.10 \mathrm{~A}+\mathrm{C})$.

\subsubsection{Invasion in der Boyden-Kammer}

\subsection{DVL3 steigert die Invasivität der Zellen in der Boyden-Kammer}

Untersuchungen in der modifizierten Boyden-Kammer zeigten eine pro-invasive Wirkung von DVL3 durch Extrazellulärmatrix. Sowohl DVL3 wt als auch die Konstrukte mit den verschiedenen Knock-out-Domänen steigerten die Invasion signifikant. Explizit war auch das Konstrukt DVL3 $\triangle$ DIX, das im Western Blot Reduktion des unphosphorylierten $\beta$-Catenin gezeigt hatte, pro-invasiv.

Interessanterweise wies das Konstrukt, dem die DEP-Domäne fehlte, als Einziges keine invasionsfördernde Wirkung auf. Während alle Zellen eine Invasivitätssteigerung auf mehr als $180 \%$ bezogen auf die pcDNA-Kontrolle bewirkten, blieb dies indifferent zur Referenz (Abb. 3.10 B). 
A

Migrationsassay

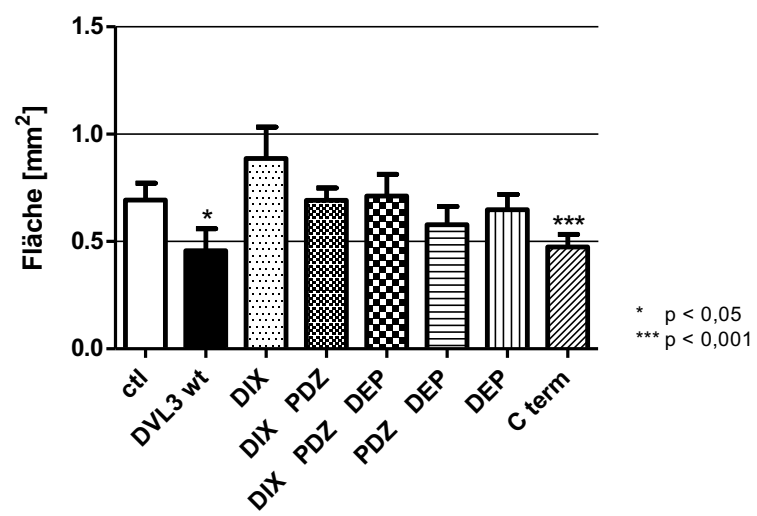

C

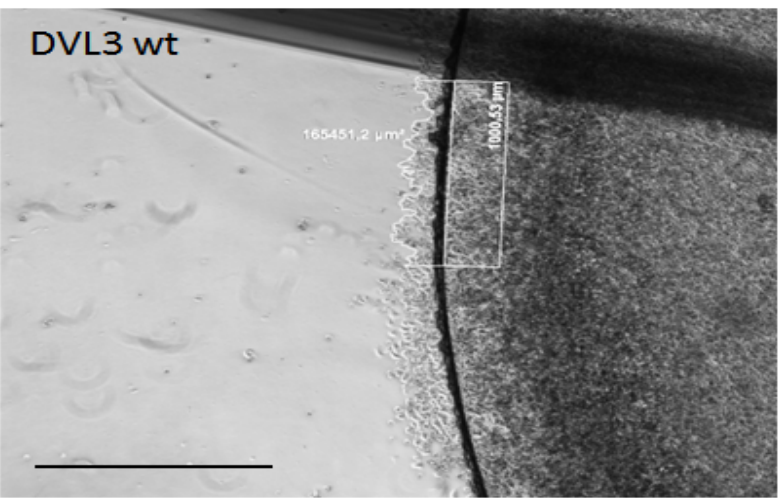

B

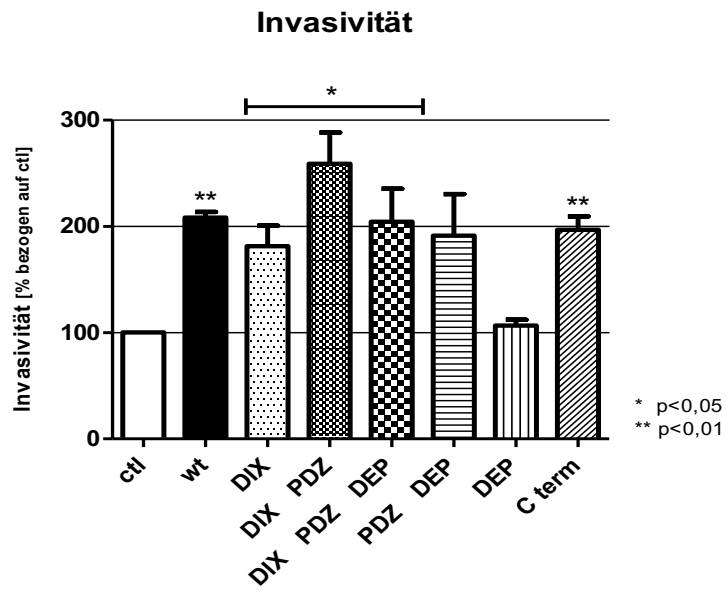

$+72 \mathrm{~h}$
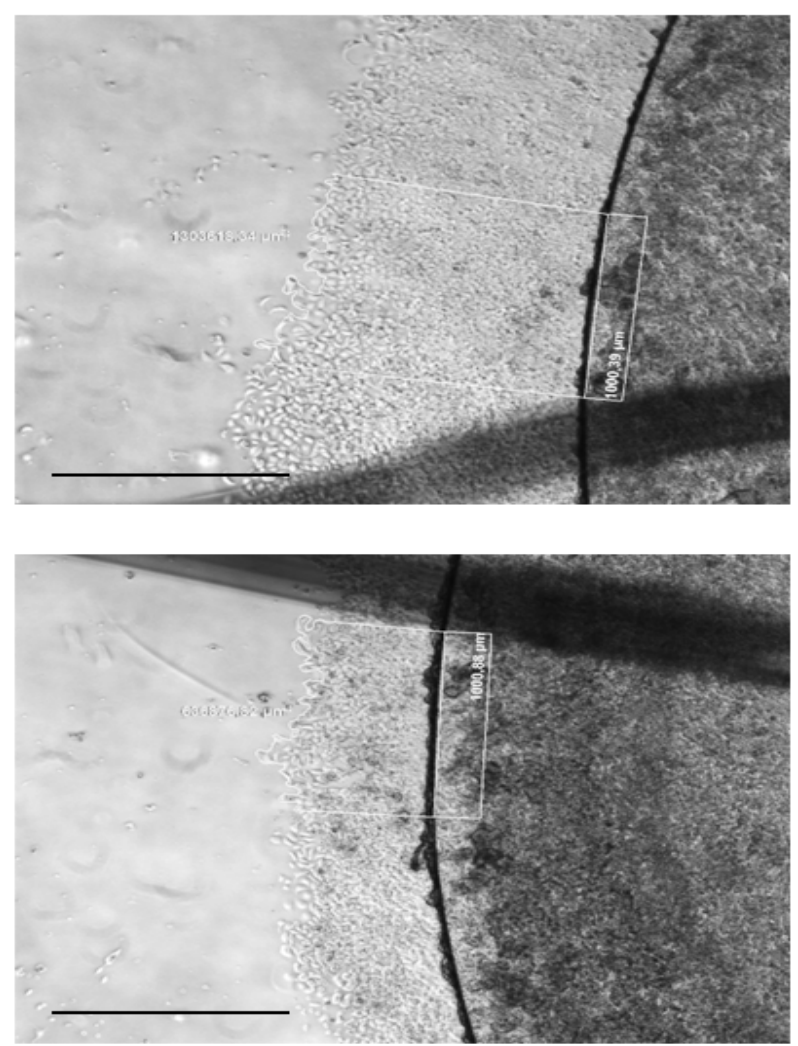

Abbildung 3.10 Funktionelle Untersuchungen der mit DVL-Konstrukten stabil transfizierten MCF-7

Brustkrebszellen. A: Auswertung des Migrationsassay. ECM-basierter Migrationsassay für MCF-7 pcDNA (ctl) und MCF-7 DVL3 (wt). Dargestellt ist die ausgemessene Fläche $\left(\mu \mathrm{m}^{2}\right)$ nach $48 \mathrm{~h} \pm$ Standardabweichung. B: Invasivität in der Boyden-Kammer. Die Tumorzellen wurden in einer modifizierten Boyden-Kammer für $96 \mathrm{~h}$ kultiviert. Die Invasionsrate der DVL3-Konstrukte-überexprimierenden Zellen wurde dabei auf die MCF-7 pcDNA Zellen (ctl) bezogen, diese wiederum auf $100 \%$ gesetzt. Dargestellt sind die Mittelwerte aus $\geq$ drei unabhängigen Experimenten \pm Standardfehler. Bei einer Irrtumswahrscheinlichkeit von $\mathrm{p}<0,05$ im Stundents tTest bezogen auf die pcDNA-Kontrolle (zweiseitig offen, gepaart) wurde in A und B von einer statistischen Signifikanz (*) ausgegangen. C: Repräsentative lichtmikroskopische Nativaufnahme des Migrationsassays. Die Versuchsauswertung erfolgte mit dem Lichtmikroskop Axiovert 200 M, Zeiss Göttingen und der dazu gehörigen Software Axiovision Rel. 4.6.3. Maßstabsbalken $=1 \mathrm{~mm}$. 


\subsubsection{Untersuchung intrazellulärer Aggregate}

Zur weiteren Untersuchung der in der Einzelzellfärbung auffälligen Aggregate der FLAGmarkierten-Konstrukte wurden weitere Immunfluoreszenzfärbungen während verschiedener Migrationsversuche durchgeführt.

3.3.4.1.1 DVL3 bildet dynamische Aggregate in Abhängigkeit vom Vorhandensein der DIXDomäne

Durch Auszählung der Zellen mit Dots je Gesichtsfeld konnte gezeigt werden, dass nur jene Konstrukte Aggregate bilden, die über eine intakte DIX-Domäne verfügen. Das Konstrukt, das wiederum nur aus dieser Domäne besteht, bildet die meisten Dots.

Die Untersuchungen der migrierenden Zellen des Konstrukts $\triangle \mathrm{PDZ} \triangle \mathrm{DEP}$ legten des Weiteren offen, dass sich im Bereich des epithelialen Zellverbandes, in dem die Zellen dicht aneinander liegen, deutlich mehr Dots nachweisen ließen, als in den migrierenden Zellen der Lauffront.

Interessanterweise reicherten diese Zellen Konstrukte in den zytoplasmatischen Ausläufern an. Zellen, welche sowohl Dots als auch zytoplasmatische Anreicherungen in den Fortsätzen zeigten, kamen praktisch nicht vor. Dies lässt Rückschlüsse auf eine dynamische Umverteilung der in den Aggregaten angereicherten Konstrukte zu (Abb. $3.11+3.12$ ). 
A

DVL3 $\triangle P D Z \triangle D E P$

$\alpha$ FLAG
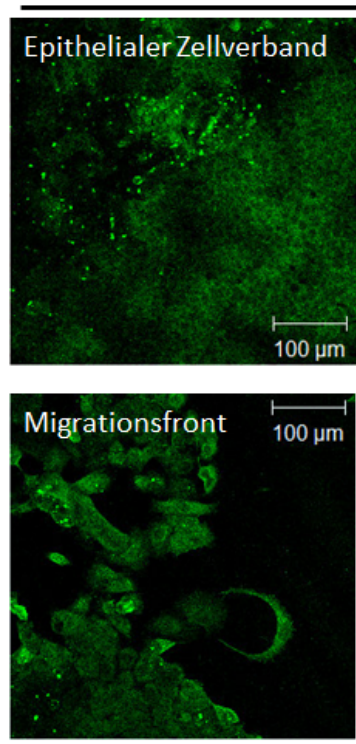
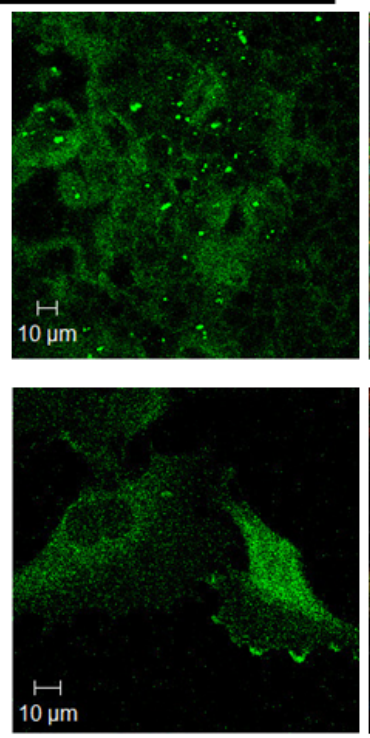

Merge
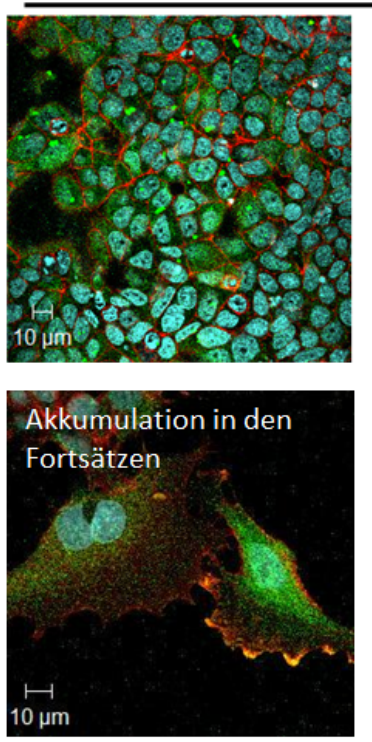
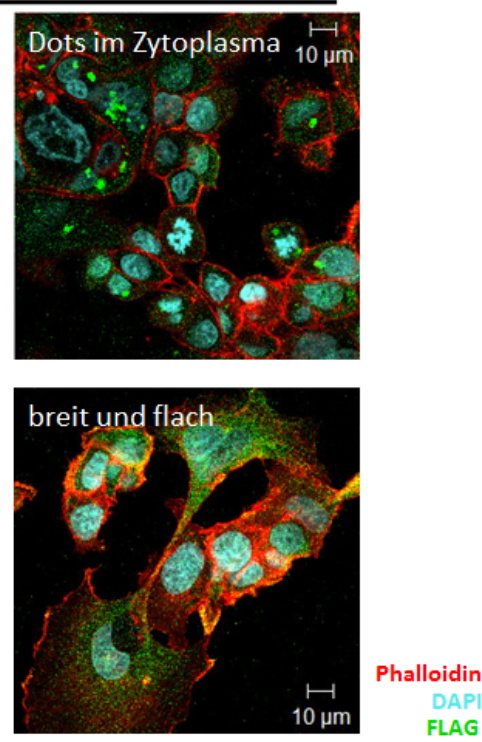

B

Epithelialer Zellverband
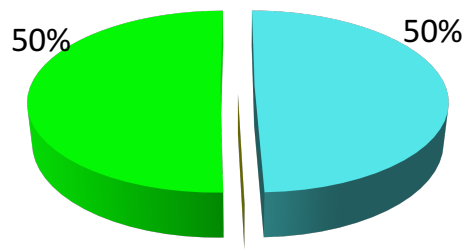

\section{Lauffront}

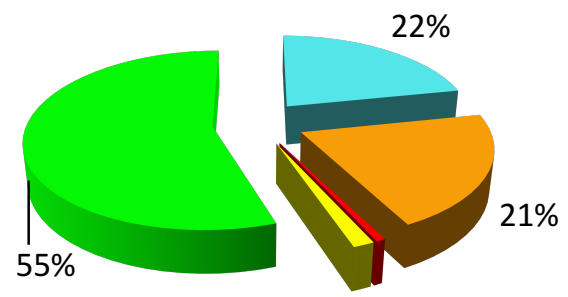

$1 \% 1 \%$
Dots im Zytoplasma

Akkumulation in den Zellfortsätzen

- Akkumulation in den Zellfortsätzen + Dots

breit und flach

- keine Auffälligkeiten

Abbildung 3.11 Auswertung des Migrationsassays DVL3 $\triangle$ PDZ $\triangle$ DEP. A: Beispiele für Zellen des epithelialen Zellverbands, der Migrationsfront, Zellen mit Akkumulation von DVL3 in den Fortsätzen, Dots im Zytoplasma und den breiten, flachen Phänotyp. FITC-FLAG-Antikörper 1:100 (grün). TRITC-Phalloidin (rot). Kernfärbung: DAPI (blau) Merge (gelb). B: Charakterisierung des Konstrukts DVL3 $\triangle$ PDZ $\triangle$ DEP. In 3 unabhängigen Versuchen wurden in je drei verschiedenen Gesichtsfeldern der Lauffront und des epithelialen Zellverbunds die Zellen den verschiedenen Kategorienzugeordnet und gezählt. Die Auswertung der Färbungen erfolgte mit dem LSM 510 Konfokalmikroskop der Firma Zeiss, Göttingen. 


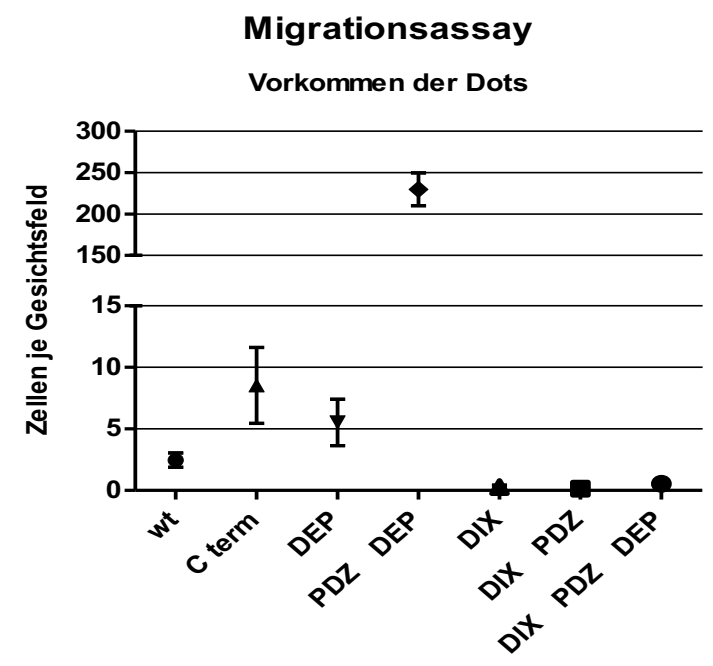

Abbildung 3.12 Auswertung der Migrationsassays der stabil transfizierten MCF-7 Zellen. Vorkommen der Dots in Abhängigkeit von der DIX-Domäne. In drei unabhängigen Versuchen wurden in je drei verschieden Gesichtsfeldern die Zellen gezählt, in denen DVL3-Aggregate vorhanden waren. Auf der y-Achse ist der Mittelwert der positiven Zellen je Geischtsfeld \pm Standardfehler, auf der x-Achse die verschiedenen Zellinien dargestellt Die Auswertung der Färbungen erfolgte mit dem LSM 510 Konfokalmikroskop der Firma Zeiss, Göttingen. Wt $=$ MCF-7 DVL3.

\subsection{DVL3 in zerebralen Mamma-Karzinommetastasen}

\subsubsection{Untersuchungen von Zytoplasma und Nukleus auf DVL3}

Nachdem die pro-invasive Wirkung einer DVL3-Überexpression in der MCF-7 Brustkrebszelllinie offengelegt werden konnte war von Interesse, inwieweit DVL3 auch in Metastasen von Brustkrebspatientinnen vermehrt exprimiert wurde, um so eine potentielle invivo-Bedeutung der in-vitro-Metastasierungsergebnisse abschätzen zu können.

31 zerebrale Metastasen von Brustkrebspatientinnen wurden immunhistochemisch gefärbt und auf ihre DVL3-Expression hin untersucht. Beispielhaft sind vier Hirnschnitte in 10x bzw. 40x Vergrößerung in Abb. 3.13 A-D dargestellt.

\subsubsection{Zytoplasmatisches DVL3 ist in einem Großteil der Hirnmetastasen nachweisbar}

Es fiel auf, dass die Mehrzahl der Metastasen zytoplasmatisch DVL3 aufwies. Nur eine von 31 Patientenproben zeigte kein zytoplasmatisches DVL3 (Abb. 3.13 A und Abb. 3.14). 


\subsubsection{Die Patientenproben unterscheiden sich sowohl in der Anzahl wie auch der} Intensität der Anfärbbarkeit des Zytoplasmas auf DVL3

Die Patientenproben wiesen DVL3 in einem unterschiedlich prozentualen Anteil, bezogen auf die untersuchte Gesamtzellzahl, (Abb. 3.14 B) und auch in unterschiedlicher Intensität (Abb. 3.14 D) auf.

\subsubsection{DVL3 ist nukleär nachweisbar, jedoch nicht in allen Proben gleichermaßen}

In einer deutlich geringeren Anzahl der Patientenproben war DVL3 auch im Kern anfärbbar (13 von 31), wobei auffiel, dass vor allem jene Zellen nukleär positiv für DVL3 waren, welche auch zytoplasmatisch zahlreich und von der Intensität her $* *$ bis $* * *$ positiv für das Protein waren.

\subsubsection{Korrelation von zytoplasmatischem und nukleärem DVL3-Gehalt}

Eine Korrelation zwischem dem Vorhandensein von nukleärem DVL3, bei gleichzeitigem Nachweis von zytoplasmatischem DVL3 wurde mit Hilfe von Pearsons Rangkorrelationskoeffizienten festgestellt: $r=0,59,95 \%$ Konfidenzintervall $[0,3-0,78], p=0,0004$. 


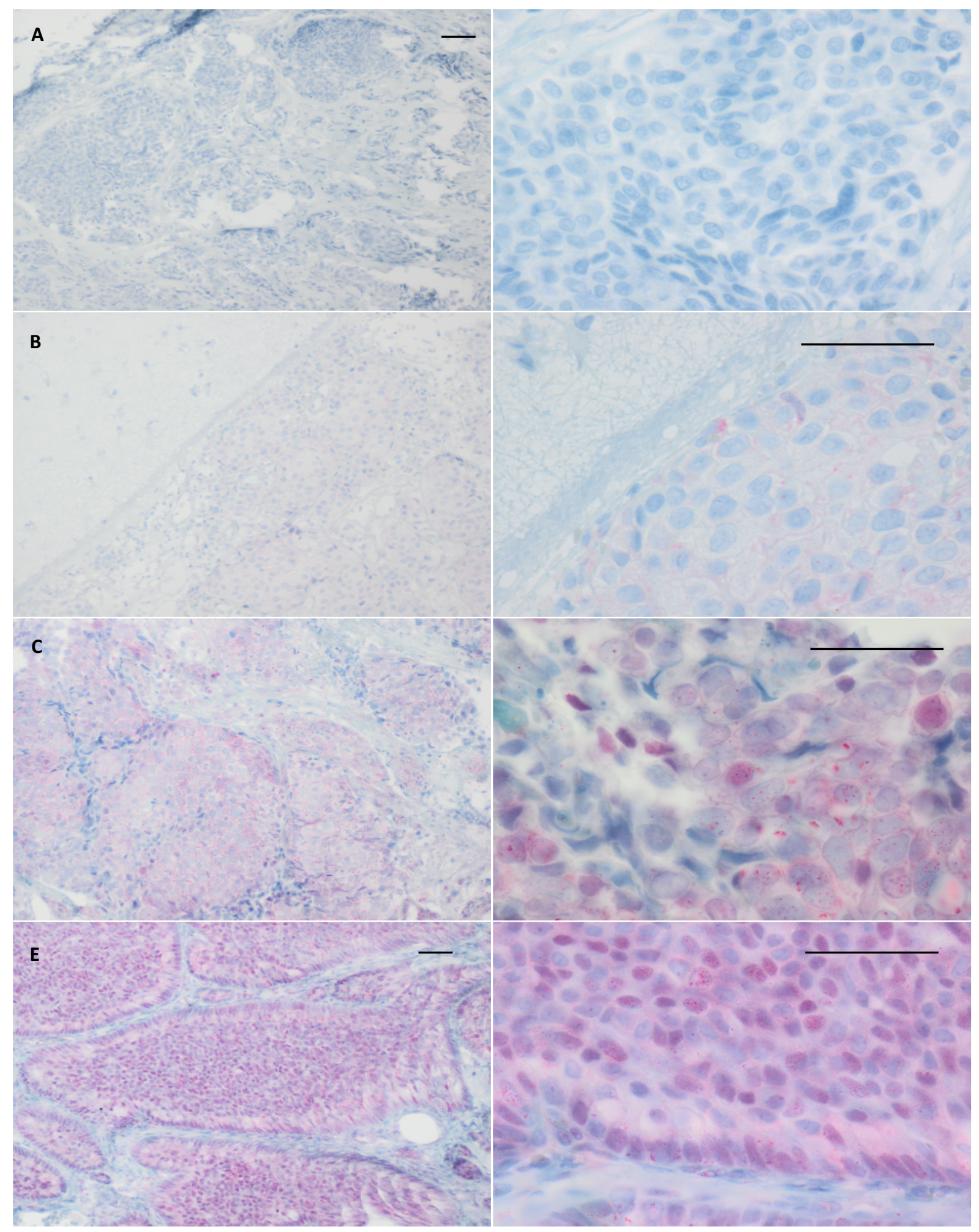

Abbildung 3.13 Beispielhafte Auswahl aus den mikroskopischen Aufnahmen der DVL3-

Hirnmetastasenfärbungen. A: Präparatbeispiel 1: Kerne $0 \%$, Zytoplasma $0 \%$, Intensität Zytoplasma 0 . B: Präparatbeispiel 2: Kerne 0 \%, Zytoplasma 11-25 \%, Intensität Zytoplasma *. C: Präparatbeispiel 3: Kerne >25 $\%$, Zytoplasma $>25 \%$, Intensität Zytoplasma **. D: Präparatbeispiel 4: Kerne $>25 \%$, Zytoplasma $>25 \%$, Intensität Zytoplasma ***. Die Versuchsauswertung erfolgte mit dem Lichtmikroskop Axiovert 200 M, Zeiss Göttingen und der dazu gehörigen Software Axiovision Rel. 4.6.3. Maßstabsbalken $=50 \mu \mathrm{m}$. 
A

\section{Hirnmetastasen DVL3}

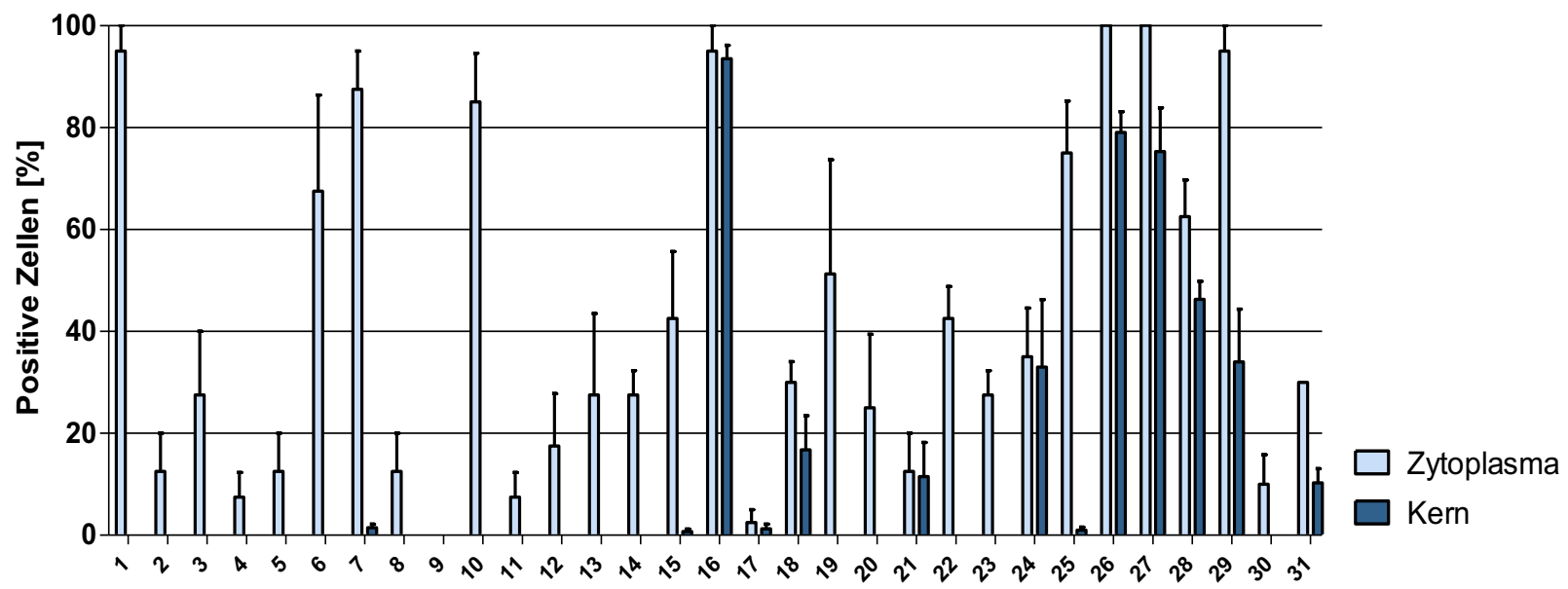

B

\section{Zytoplasmatisches DVL3}

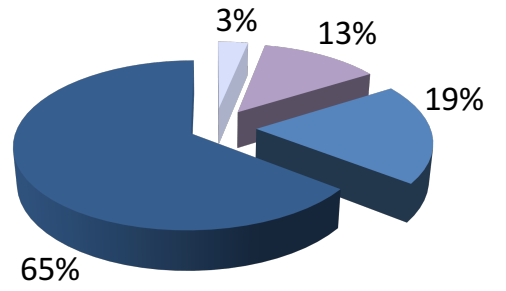

D

\section{Zytoplasmatisches DVL3} Intensität

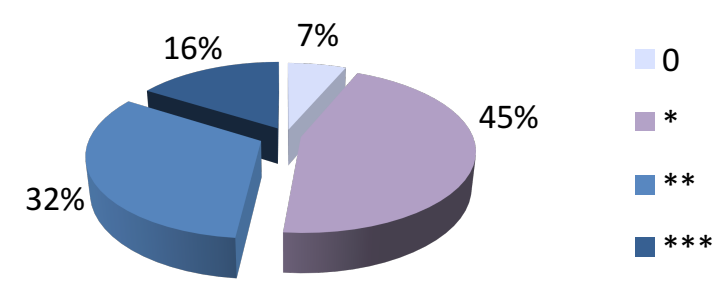

C

Nukleäres DVL3

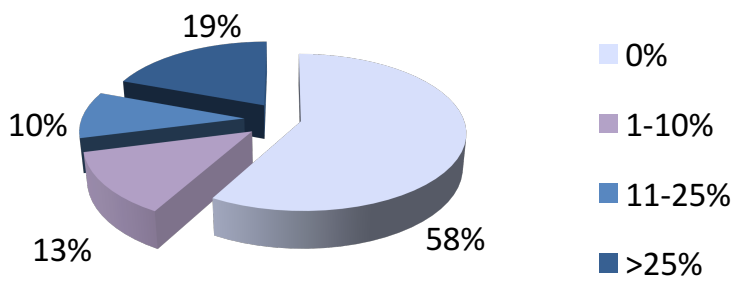

Abbildung 3.14 Auswertung der Hirnmetastasenfärbungen auf DVL3. Es wurden je Metastasenschnitt in vier verschiedenen Gesichtsfeldern je 100 Zellen gezählt und der Anteil an Zellen mit zytoplasmatisch bzw. nukleär lokalisiertem DVL3 bestimmt. Anschließend wurden Übergruppen gebildet (0\%, bis $30 \%$, bis $60 \%$, bis $100 \%$ ) und diese in der Abbildung aufgeführt. A: Übersicht über die Metastasenproben. Angegeben ist der Mittelwert mit SEM. B: Zytoplasmatisches DVL3. C: Nukleäres DVL3. D: Zytoplasmatisches DVL3 Intensität. Die Klassifizierung erfolgte in 4 Intensitätsgrade: keine Positivität, *, **, ***. Vgl. hierzu Abb. 3.13. Die Versuchsauswertung erfolgte mit dem Lichtmikroskop Axiovert 200 M, Zeiss Göttingen und der dazu gehörigen Software Axiovision Rel. 4.6.3. 


\section{Diskussion}

Die Aktivierung $\beta$-Catenin-abhängiger Wnt-Signalwege im Zuge von Karzinogenese und Metastasierung gilt im allgemeinen für verschiedene Tumorentitäten als anerkannter Prozess. Dass auch nicht-kanonische Kaskaden für spezifische Krebsarten von Bedeutung sind, geriet erst in den letzten Jahren zunehmend in den Fokus der Forschung. Zielsetzung meiner Arbeit war es, auf zellulärer Ebene den Einfluss verschiedener $\beta$-Catenin-unabhängiger Faktoren auf Malignitätskriterien wie Proliferation, Migration und Invasion zu eruieren.

Aufgrund der Vorergebnisse der Arbeitsgruppe (Klemm et al. 2011) und der ersten Ergebnisse meiner eigenen Arbeit konzentrierte ich mich hierbei auf den Rezeptor ROR und das Protein DVL.

In der Arbeit von Klemm et al. wurde im Vergleich der wenig invasiven MCF-7 und der deutlich invasiveren MDA-MB 231 eine Korrelation zwischen einem hohen Gehalt nichtkanonischer Marker (ROR1/2 und Wnt5a) und der Malignität aufgezeigt (Klemm et al. 2011). Ich wollte untersuchen, inwiefern auch weitere Zelllinien diesen Zusammenhang bekräftigten. Des Weiteren waren ROR1 und ROR2 in Hirnmetastasen von Brustkrebspatientinnen nachweisbar (Klemm et al. 2011). Auffällig war hierbei, dass ROR2-mRNA -weder in der MCF-7 noch in der MDA-MB 231- als Zellinien, die ursprünglich aus dem Gewebe eines Primarius gewonnen wurden, vor einer qRT-PCR-Zykluszahl von 32 nachweisbar war. Ich überexprimierte ROR2 in MCF-7 Zellen und untersuchte in-vitro-Veränderungen zwischen der Mutante und einer Leervektorkontrolle. So erhoffte ich, Rückschlüsse ziehen zu können auf Veränderungen, die eine Mamma-Karzinomzelle im Laufe der Metastasierung durchmachen könnte.

\subsection{Die Aussagekraft einzelner Spieler der Wnt-Signalwege über den Malignitätsgrad kultivierter Zelllinien}

Meine Untersuchungen zeigten weder auf der Proteinebene im Western Blot noch im mRNAGehalt in der Polymerase-Kettenreaktion eine direkte Korrelation verschiedener ausgewählter Marker mit der in der Literatur beschriebenen Malignität der Zelllinien in vivo.

Auffällig war jedoch, dass auch die neu untersuchten Zelllinien, die ursprünglich aus Primarien gewonnen wurden, kein ROR2 exprimierten.

Die fehlende Korrelation zwischen den Markern und der Malignität könnte selbstverständlich auf die Selektion und Limitierung der beobachteten Marker zurückzuführen sein. Hierfür 
könnte das Spektrum der ausgewählten Faktoren erweitert werden, beispielsweise um JNK bzw. p-JNK als nicht-kanonische Marker oder Wnt3a als Wnt mit Bezug auf $\beta$-Cateninabhängige Signalwege. So könnte eventuell eine nicht direkt ersichtliche Korrelation noch offengelegt werden.

Gleichzeitig ist der Versuch der Wertung dieses deskriptiven Experiments in einem zu großen Kontext methodisch zu hinterfragen. Zelllinien mit diesen Mitteln zu charakterisieren, ist sicherlich nicht uninteressant, gleichzeitig bieten diese Methoden jedoch wenig bis keine Chance, tatsächlich Rückschlüsse auf die Aktivität dieser Marker und das tatsächliche Verhalten der Zelllinien in vitro oder gar in vivo zu ziehen.

Überexpressions- bzw. Knock-out-Versuche zu einzelnen Spielern der Kaskaden würden zumindest mehr Möglichkeiten bieten, die Bedeutung dieser für Funktion und Malignität der Krebszellen zu eruieren. Deswegen wurde im Anschluss an meine Versuche vorerst der Rezeptor ROR2 in MCF-7 Zellen überexprimiert.

\subsection{ROR2 beeinflusst die Morphologie hin zu einem mesenchymalen Phänotyp}

Nachdem mittels MTT und $x$ CELLigence ${ }^{\circledR}$ eine verminderte Viabilität der Zellen ausgeschlossen wurde, führte ich Analysen zur Funktion und Morphologie der MCF-7 ROR2überexprimierenden Zellen durch.

Die Einzelzellen, aber auch die in meine Versuche eingebrachten Zellen zeigten -beispielsweise während der Migration- eine veränderte Morphologie. Zum einen wiesen die Einzelzellen vermehrt Zellfortsätze auf, andererseits erschienen sie phänotypisch eher mesenchymal. Die Kern-Zytoplasma-Relation der epithelial dicht stehenden Zellen wirkte zu Gunsten des Zytoplasmas verschoben. Im Gegensatz dazu zeigten die Untersuchungen mittels qRT-PCR jedoch eine verminderte Menge an mRNA für die klassischen EMT-Marker Vimentin und Snaill.

Auch Nishita und Kollegen zeigten 2006 in verschiedenen Zelllinien, unter anderem humanen Nierenzellen (human embryonic kidney (HEK) 293T) und MCF-7, dass die Überexpression von ROR2 eine vermehrte Bildung von Filopodien, das heißt von Scheinfüßchen, hervorrief. Diese Filopodienformation war unabhängig vom Vorhandensein Wnt5as, aber abhhängig vom Vorhandensein der Prolin-reichen Domäne (proline rich domain, PRD) ROR2s (Nishita et al. 2006). Hier, so zeigten Nishita et al., bindet das acting-binding Protein Filamin A, das 
essenziell ist für die ROR2-induzierte Filopodienbildung durch Aktinreorganisation (Nishita et al. 2006).

Embryonale Mausfibroblasten aus Wildtyp (ROR2 ${ }^{+/+}$) Mäusen zeigten in Nishitas Versuchen nach Exposition mit Wnt5a eine drastische Zunahme der Zellmigration im Vergleich zu Fibroblasten von ROR2-defizienten Mäusen $\left(\mathrm{ROR} 2^{-/}\right.$). Wnt3a steigerte in Versuchen mit beiden Fibroblastenarten gleichermaßen die Zellmigration, was sie zu dem Schluss führte, dass ROR2 für die speziell durch Wnt5a-induzierte Zellmigration von Bedeutung ist. Unterstützend zeigten sie, dass sowohl die PRD, aber auch die extrazelluläre, Cystein-reiche Domäne (CRD, Bindungsstelle von Wnt5a) vorhanden sein müssen (Nishita et al. 2006).

Die Unterdrückung von ROR2 oder Filamin A inhibierte sowohl die Bildung von Filopodien als auch die Wnt5a-induzierte Zellmigration (Nishita et al. 2006). Zusammenfassend stellten Nishita und Kollegen die These auf, dass ROR2 nicht nur für die Bildung der Scheinfüßchen verantwortlich ist, sondern essenziell für die Tumorzellmigration, die durch Wnt5a ausgelöst werden kann (Nishita et al. 2006).

Während über die Bedeutung von EMT und ROR2 im Mamma-Karzinom wenig bekannt ist (Analysen zur ROR2-abhängigen EMT in Tubuluszellen der Niere während der Entstehung von Nierenfibrose wurden beschrieben von Li et al. 2013), stellte der Arbeitskreis um Kipps ROR1 inzwischen ausführlich auch in diesem Kontext Untersuchungen an (Zhang et al. 2012, Cui et al. 2013).

Zang und Kollegen zeigten 2012 zum einen, dass ROR1 vor allem in metastasierenden Zelltypen exprimiert wurde. Klinische Analysen legten des Weiteren eine Assoziation mit kürzeren Metastasen-freien Intervallen der Patientinnen offen. Die Metastasierung fand hier vor allem in Lunge, Knochen und Hirn statt. Gleichzeitig fielen ihnen deutlich geringere Assoziationen mit der prognostisch günstigen Expression von Östrogen- und Progesteronrezeporen oder Her2 auf. Der Knock-out von ROR1 mittels shRNA zeigte in ihren Versuchen auf Proteinebene eine deutliche Abnahme mesenchymaler EMT-Marker, die Überexpression einen Anstieg dieser. Auch morphologische Alterationen konnten von Zhang et al. beobachtet werden. Verminderte Migration wurde in vitro, eine Abnahme der Metastasierung in einem in-vivo-Mausmodell beobachtet (Zhang et al. 2012).

Da die Überexpression von ROR2 in meinen Versuchen auf mRNA-Ebene auch zu einem Anstieg von ROR1 führte, könnten die beobachteten morphologischen Verändeungen statt auf ROR2 auch auf das ko-regulierte ROR1 zurückzuführen sein. Hierfür wäre interessant zu 
untersuchen, inwieweit dieser ROR1-mRNA-Anstieg auch auf Proteinebene umgesetzt zu sehen ist. Da mir die Etablierung eines im Western Blot gut einsetzbaren ROR1-Antikörpers während der Arbeiten zu dieser Promotion leider nicht gelang, war mir dies nicht möglich.

Gleichzeitig ist den Arbeiten von Zhang et al. (2012) nicht zu entnehmen, inwieweit durch den Einsatz von ROR1-shRNA evtl. auch ROR2 beeinflusst wurde. So könnte hier evenuell auch ROR2 ko-reguliert worden sein, ohne dass dies überprüft bzw. ausgeschlossen worden ist.

Da bisher wenig über die Bedeutung der beiden ROR-Subtypen bekannt ist, ist auch eine sich sehr weit überschneidende Funktionsweise ein möglicher Erklärungsansatz der ähnlichen Beobachtungen unserer Arbeitsgruppen, sodass eventuell sowohl ROR1 als auch ROR2 auf die Größen Morphologie, Migration und Invasion Einfluss nehmen.

Interessanterweise sind in der Veröffentlichung von Cui und Kollegen keine Untersuchung der EMT-Marker in der qRT-PCR aufgeführt.

Gleichzeitig könnte die fehlende Korrelation meiner qRT-PCR-Ergebnisse mit den morphologischen Beobachtungen wie folgt erklärt werden:

Während Vimentin $(p<0,01)$ auf $47 \%$ und Snaill $(p<0,0001)$ auf $44 \%$ der Konroll-mRNAWerte sinken $(n=6)$, spricht dies zum einen nicht automatisch für eine derartige Umsetzung auf Proteinebene, sei es durch Hemmung der Translation, alternatives Spleißen oder die Regulation des Transportes der mRNA aus dem Zellkern.

Des Weiteren kann es sich auch bei einer statistisch signifikanten Redukion des mRNAGehalts auf die Hälfte der Kontrolle um ein durch vorkommende Schwankungen der PCR herbeigeführtes Laborartefarkt handeln. So ist es in manchen Forschergruppen üblich, erst ab einer Reduktion auf ein Drittel der Kontrollmenge von einer tatsächlich in der Zelle vorhandenen und nicht nur statistisch signifikanten Reduktion auszugehen.

\subsection{Die Überexpression von ROR2 in Brustkrebszellen führt zu keiner Steigerung der Tumorzellmigration ohne Exposition mit exogenem Wnt5a}

ROR2 spielt in vielen Prozessen, in denen Zellmigration von Bedeutung ist, eine Rolle. CAM-1, das Ortholog von ROR2 in Caenorhabditis elegans beispielsweise, ist nachweislich beteiligt an Zellmigrationsprozessen, asymmetrischer Zellteilung und Axonextension während der Embryogenese (Forrester et al. 1999). So überraschte vorerst das Ergebnis des Migrationsassays, dass die ROR2-überexprimierenden MCF-7 Zellen keinen Unterschied im Vergleich mit der Leervektorkontrolle aufwiesen. 
Zurückkommend auf die bereits erwähnten Versuche von Nishita et al. von 2006 ist jedoch zu erwähnen, dass auch in ihren Versuchen eine gesteigerte Tumorzellmigration erst nach Exposition mit Wnt5a stattfand. Die alleinige Mehrexpression von ROR2 in den MEFs, aber auch in ROR2-überexprimierenden Mausfibroblastenzellen L Cells zeigte keinen Unterschied im Vergleich zur Kontrolle (Nishita et al. 2006). Mit Blick auf die Tatsache, dass ROR2 in Hirnmetastasen von Brustkrebspatientinnen exprimiert wurde, wäre folglich interessant, den Versuch unter Exposition mit Wnt5a zu wiederholen und zu eruieren, ob auch im Brustkrebs Wnt5a eine ROR2 vermittelte Tumorzellmigration induzieren kann.

Nishita und Kollegen zeigten ebenfalls einen Zusammenhang der Wnt5a-induzierten Zellmigration über ROR2 und DVL (Nishita et al. 2006). Nach Suppression der natürlich in $L$ Cells vorkommenden DVL-Subtypen 2 und 3 kam es trotz Überexpression von ROR2 und Exposition mit Wnt5a zu keiner Migrationszunahme. Die Zellen wiesen jedoch die bekannten ROR2 vermittelten Filopodien auf (Nishita et al. 2006). Ob und auf welche Weise DVLs die Wnt5a-ROR2 vermittelte Zellmigration beeinflussen blieb jedoch offen.

\subsection{Die Überexpression von ROR2 in Brustkrebszellen steigert die Invasivität unabhängig von $\beta$-Catenin über die Aktivierung von JNK und c- jun}

Western Blot-Analysen legten eine Akkumulation von p-JNK und p-c-jun im Zuge der ROR2-Überexpression offen, während die Aktivierung von $\beta$-Catenin eher inhibiert wurde. Dies, und die zum Teil deutlich detektierbare Anreicherung des, als für den $\beta$-Cateninunabhängigen Ast zuständig geltenden, DVL-Subtyps 3, sprechen eher für eine Aktivierung nicht-kanonischer Signalwege in den ROR2-überexprimierenden MCF-7.

Gleichzeitig zeigten die Zellen eine deutliche Zunahme der Invasivität in der modifizierten Boyden-Kammer, die wiederum durch Zugabe eines Inhibitors der c-Jun N-terminalen Kinase komplett inhibiert werden konnte. Dies bekräftigt nicht nur die Bedeutung der Kinase für die Mediation pro-invasiver Faktoren, sondern unterstützt ein weiteres Mal die Annahme, dass für die Tumorprogression und Metastasierung des Mammakarzinoms $\beta$-Catenin-abhängige Signalwege nicht von Bedeutung sind (Pukrop et al. 2006, Klemm et al. 2011, MacMillan 2014).

Sowohl eine Assoziation von ROR2 und JNK-Aktivität (Oishi et al. 2003, Yamanaka et al. 2002) als auch seine inhibitorischen Effekte auf die Aktivierung von $\beta$-Catenin (Mikels und 
Nusse 2006b) und die Mediation von Invasion und Metastasierung durch nicht-kanonische Signalwege (Katoh, 2005), beispielsweise in Nierenzellkarzinomzellen durch Induktion der Matrixmetalloprotease-2 (Wright at al. 2009), wurden in anderem Kontext von zahlreichen anderen Forschungsgruppen bereits beschrieben. Wnt5a, als eher nicht-kanonisch signalisierendes Wnt (Nishita et al. 2010a) und möglicher Ligand von ROR2 (Oishi et al. 2003, Nishita et al. 2006, Mikels und Nusse 2006a) bekräftigt noch einmal die wahrscheinliche Unabhängigkeit der gezeigten Effekte von $\beta$-Catenin.

\subsection{Die Überexpression von ROR2 führt zu einer Akkumulation von DVL3 in Zytosol und Kern}

Des Weiteren fiel in meinen Versuchen eine Signalzunahme von DVL3 im Western Blot auf, der mRNA-Gehalt hingegen blieb unbeeinflusst. Am ehesten ist dies auf eine Stabilisierung, z.B. durch Reduktion des Abbaus oder andere Faktoren zurückzuführen. Oder es findet eine vermehrte Phosphorylierung des vorhandenen DVL3-Proteins statt.

Nishita et al. zeigten 2010 (b) bereits eine Wnt5a-induzierte Zunahme an DVL2/3 Phosphorylierung über einen $\beta$-Catenin-unabhängigen, ROR2-abhängigen Signalweg in L-Fibroblastenzellen der Maus.

Die Exposition mit Wnt5a führte in den ROR2-überexprimierenden $L$ Cells nach zwei Stunden zu einer deutlichen Signalzunahme für DVL3, in geringerem Ausmaß auch für DVL2 im Western Blot (Nishita et al. 2010b). Sie beobachteten eine solche Signalzunahme auch nach Stimulation mit Wnt3a, allerdings unabhängig vom ROR2-Rezeptorstatus.

Eventuell sind die in unserer Arbeitsgruppe beobachteten Schwankungen des Western Blot Signals für DVL3 auf Schwankungen des Wnt5a-Gehalts während der Zellkultivierung zurückzuführen.

Bei Nishita et al. blieb 2010 (b) jedoch die Frage offen, ob DVL3 eine Folge der gesteigerten ROR2-Aktivität, also ein Endprodukt der Kaskade darstellt, oder auch als Ko-Ligand oder zytosolisches Schaltprotein des ROR-Signalwegs anzusehen ist und deswegen stabilisiert bzw. vermehrt phosphoryliert wird.

Bisher galt der Wnt5a-Signalweg über ROR2 immer als unabhängig von DVL3 (Schambony und Wedlich 2007, Liu et al. 2008).

Gegen die Annahme, DVL3 sei lediglich Produkt der gesteigerten c-jun Transkriptionsfaktoraktivität, spricht die Tatsache, dass kein Anstieg der mRNA von DVL3 in der qRT-PCR zu detektieren war. 
Um eine Bedeutung von DVL3 für die Signaltransduktion im Anschluss an den Transmembranrezeptor ROR2 annehmen zu können, müssten weitere Untersuchungen, die vorerst eine Assoziation der beiden Moleküle nachweisen, erfolgen. Dies könnte zum Beispiel mittels eines Immunpräzipitationsversuches untersucht werden. Gleichzeitig wäre die Darstellung der Phosphorylierung und damit auch der Aktivierung von DVL3 bedeutsam.

Des Weiteren war von Interesse, ob eine Überexpression von DVL3 im Umkehrschluss auch $\mathrm{zu}$ einer Aktivierung von JNK führen würde.

Western Blot-Analysen der DVL3 wt überxprimierenden MCF-7 zeigten allenfalls eine diskrete Zunahme von phosphorylierten JNK. Dies spräche für eine Bedeutung des DVL3 oberhalb von JNK, da eine Aktivierung auch unabhängig von ROR2 und extrazellulären Signalmolekülen stattfände. Gleichzeitig würde dieses Ergebnis jedoch eine Beeinflussung anderer Art, beispielsweise eine Ko-Kontrolle im Sinne eines circulus vitiosus, nicht sicher ausschließen.

Da Zhao et al. 2010 eine pro-invasive Wirkung von DVL3 beschrieben, die ich auch durch meine eigenen Versuche bestätigen konnte (s.u.), bleibt jedoch offen, ob es sich bei der von mir beobachteten Invasivitätssteigerung durch die ROR2-Überexpression um einen Effekt dieser, der Akkumulation von DVL3 oder einer Kombination der beiden handelt.

Für eine solche Unterscheidung würden in der Regel loss of function-Versuche angeschlossen werden, in denen man versucht, durch das Ausschalten eines Gens die beobachteten Effekte durch gegenteiliges Verhalten $\mathrm{zu}$ bestätigen. Da jedoch keine der beobachteten Brustkrebszelllinien ROR2 ausreichend exprimierte und ROR2 lediglich in den Metastasen nachweisbar war (vgl. Klemm et al. 2011), wäre dies im Kontext des Brustkrebses schwierig. Um dieses Problem zu umgehen, könnte man Versuche an anderen Zell- oder Gewebstypen durchführen, dies schränkte jedoch die Übertragbarkeit der Ergebnisse ein. Möglich wäre, in den bisher verwendeten MCF-7-Zellen zwar ROR2 überzuexprimieren, gleichzeitig aber DVL3 zu blockieren. Eventuell könnte man so zwischen den Auswirkungen von ROR2 und DVL3 diskriminieren.

\subsection{Auswirkung der DVL3-Überexpression auf die Aktivierung von $\beta$ - Catenin}

Die Überxpression von DVL3 führte in den Brustkrebszellen zu keinem signifikanten Anstieg von $\beta$-Catenin oder aktiviertem $\beta$-Catenin. 
Dies könnte zum einen damit erklärt werden, dass der eingesetzte DVL3-Subtyp eventuell nicht der für die Wnt-Signaltransduktion zu $\beta$-Catenin zuständige Untertyp ist (vgl. Zhao et al. 2010 in NSCLC). Um hier eine stärkere Signalzunahme erwarten zu können, müsste also der Versuch mit DVL1-Konstrukten (Zhao et al.) aber ggfs. auch DVL2 wiederholt werden. Eine weitere Erklärungsmöglichkeit wäre, dass in den Brustkrebszellen $\beta$-Catenin-Signaltransduktion per se eine untergeordnete Rolle spielen könnte und vermehrt der nichtkanonische Signalweg (fehl-) reguliert wird (Pukrop et al. 2006, Klemm et al. 2011). Die Überexpression eines Moleküls in einem nicht aktivierten Signalweg muss schließlich nicht automatisch zu dessen Aktivierung führen.

Interessanterweise ist das Konstrukt DVL3 $\Delta$ DIX in der Lage, aktives $\beta$-Catenin nicht nur auf den Gehalt der pcDNA-Kontrolle zurückzudrängen, sondern führt sogar eine Reduktion dessen herbei.

Ein Verlust der Fähigkeit, $\beta$-Catenin durch das Fehlen der DIX-Domäne zu stabilisieren, wurde für DVL1 bereits von Kishida et al. 1999 in COS-Fibroblastenzellen und für DVL2 durch Fan et al. 2004 in Neuroblastomzellen beschrieben. Dies hatte in diesem Kontext Auswirkungen auf die Neuritogenese und Zellmorphologie. Die angeführten Western Blots zeigten ebenfalls eine deutliche Abnahme des $\beta$-Catenin-Gehalts in den transfizierten Zellen. Allerdings verwendeten sie einen Antikörper für Gesamt- $\beta$-Catenin und keinen, der zwischen dephosphoryliertem, aktiviertem und inaktivem unterscheiden kann (Fan et al. 2004).

Durch meine Untersuchungen konnte gezeigt werden, dass das Konstrukt DVL3 $\triangle$ DIX die Fähigkeit zur Inhibition der Aktivierung von $\beta$-Catenin besitzt.

Bislang fehlten Erklärungsansätze, warum gerade dieses Konstrukt in der Lage war, $\beta$ Catenin zu inhibieren und andere Konstrukte, denen zusätzliche Domänen fehlten, nicht.

DIX gilt allgemein als für die Homo- und Heterodimerbildung von DVL nötige und Axinbindende Domäne (Kishida et al. 1999). Ein Knock-out dieses Bereiches sollte folglich die Möglichkeit, Axin zu binden, hemmen. Eine Signalweiterleitung zum $\beta$-CateninDestruktionskomplex sollte unterbunden sein und eine Phosphorylierung und Ubiquitin mediierte Proteolyse nicht mehr stattfinden.

PDZ hingegen wird die Funktion der Rezeptorbindung zugesagt (Cheyette et al. 2002, Wong et al. 2003).

Weiterhin besteht der entscheidende Unterschied zwischen den besagten Konstrukten in der Möglichkeit, an Fz zu binden. Die Bedeutung dieser Bindung für die Weiterleitung des Wnt- 
Signals an $\beta$-Catenin wird unter anderem von He (2004) beschrieben. Während das Konstrukt DVL3 $\Delta$ DIX $\triangle$ PDZ nicht in der Lage ist, an den Rezeptor zu binden, kann das im Vergleich zum endogenen DVL im Überfluss in der MCF-7-Zellen exprimierte Konstrukt $\triangle$ DIX immer wieder, über die vorhandene PDZ-Domäne, an den Rezeptor binden, die Weiterleitung des kanonischen Signalwegs jedoch nicht ausführen.

Da die Wahrscheinlichkeit, dass kompetentes, endogenes DVL an den Rezeptor bindet, viel geringer ist, als das exogen zugeführte, mutierte Produkt, wird der Signalweg de facto inhibiert. DVL3 $\triangle \mathrm{DIX} \triangle \mathrm{PDZ}$ kann nicht an den Rezeptor binden, also wird über endogenes DVL wie gewohnt $\beta$-Catenin aktiviert (zum Vergleich siehe Abb. 4.1).

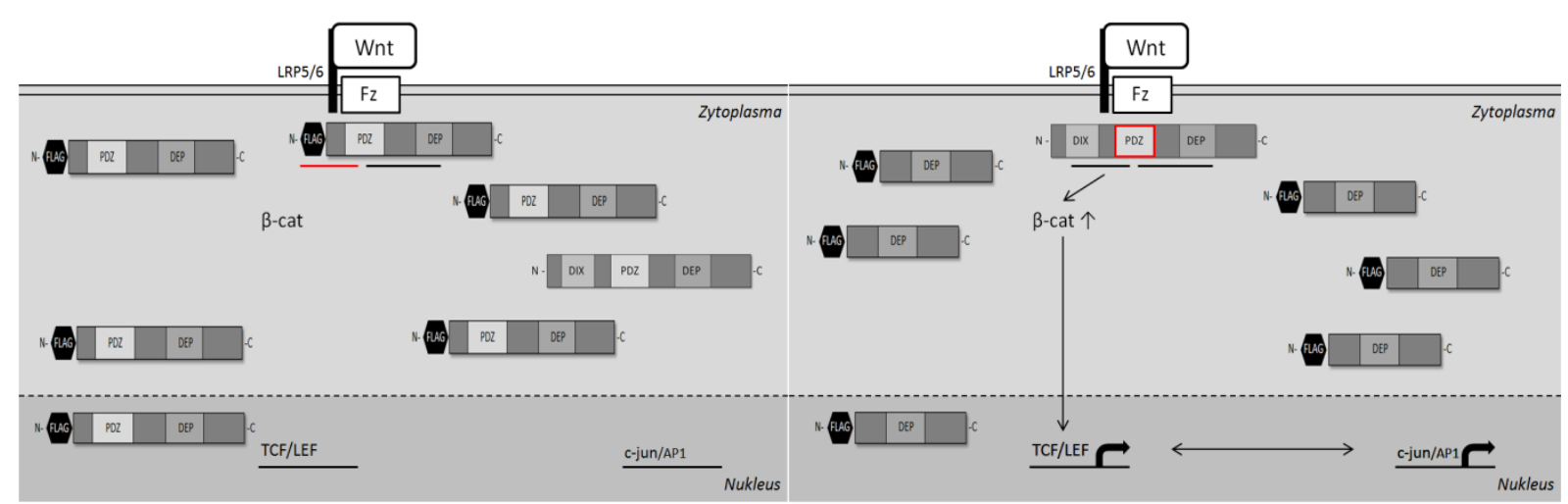

Abbildung 4.1 Theorie zur Funktionsweise der Konstrukte DVL3 $\Delta$ DIX und DVL3 $\Delta$ DIX $\Delta$ PDZ. A: Das überexprimierte Konstrukt DVL3 $\triangle$ DIX (graphisch gekenntzeichnet durch die FLAG-Markierung) ist durch das Fehlen der Axin-bindenen Domäne nicht in der Lage $\beta$-Catenin zu aktivieren. Dennoch kann es über die vorhandene PDZ-Domäne an Fz binden und somit den Rezeptor für endogenes DVL blockieren. So sinkt die im Western Blot detektierbare Menge an ABC unter den der pcDNA-Kontrolle. B: Das Konstrukt DVL3 $\triangle$ DIX $\triangle \mathrm{PDZ}$ auf der anderen Seite kann nicht an den Rezeptor binden. Dadurch bindet endogenes DVL3 an den Rezeptor und die detektierbare Menge ABC entspricht der Leervektor-Kontrolle.

\subsection{DVL3 steigert $\beta$-Catenin-unabhängig die Invasivität der Brustkrebszellen}

Die Überexpression von DVL3 führte zu einer Invasivitätssteigerung in vitro.

Dies geschah ohne Einflussnahme auf die nachgewiesene Menge aktiven $\beta$-Catenins. Auch das Konstrukt DVL3 $\triangle$ DIX, das die Aktivierung zu dephosphoryliertem $\beta$-Catenin blockierte, wirkte in den Zellen pro-invasiv. Folglich ist aktiviertes $\beta$-Catenin nicht relevant für die durch die DVL3-Überexpression herbeigeführte Invasivitätssteigerung der Brustkrebszellen. 
Zhao und Kollegen zeigten 2010 in nichtkleinzelligen Bronchialkarzinomen zum einen eine Aktivierung von p38 und JNK vor allem durch DVL3, während DVL1 vor allem die Transkriptionsfaktoren LEF/TCF aktivierte. Dies unterstützt die Annahme, dass dieser DVLSubyp tatsächlich vor allem den $\beta$-Catenin-unabhängigen Wnt-Signalweg reguliert.

Des Weiteren wiesen die von Zhao und Kollegen eigesetzten DVL3-überexprimierenden Zellen ebenfalls eine gesteigerte Invasivität auf, die sie mittels p38 und JNK-Inhibitoren unterbinden konnten.

Die Auswertung der Hirnmetastasen der Brustkrebspatientinnen zeigte deutliche Unterschiede in der Expression und Lokalisation von DVL3, jedoch fehlen im Moment noch die Analysen der klinischen Daten zu den jeweiligen Patientenproben. Es wäre sehr interessant herauszufinden, inwieweit diese unterschiedliche Expression bzw. Überexpression für die zerebrale Metastasierung von Bedeutung ist.

In bisher nicht veröffentlichten Untersuchungen unserer Arbeitsgruppe (Bleckmann et al.) konnte gezeigt werden, dass ein hoher Score aus c-jun, p-c-jun und DVL3 in Lebermetastasen eine Assoziation mit schlechten Überlebensraten aufwies. Eine Anreicherung $\beta$-Cateninabhängiger Faktoren ( $\beta$-Catenin, E-Cadherin, LEF-1) hatte jedoch keine prognostischen Auswirkungen auf die hepatische Metastasierung. Dies bekräftigt die Annahme, dass DVL3 im Prozess der Metastasierung eher eine prognostisch ungünstige Auswirkung auch bei Bustkrebspatientinnen haben könnte, indem es beispielsweise die Invasivität der Brustkrebszellen steigert. Eventuell ist dies auch bei anderen Karzinomen der Fall -hier fehlen allerdings valide, systematische Auswertungen.

\subsection{Die Überexpression von DVL3 inhibiert die Tumorzellmigration ohne Exposition mit exogenem Wnt5a}

Nachdem Nishita und Kollegen 2006 eine Bedeutung von DVL für die Wnt5a-induzierte Zellmigration über ROR2 vermutet haben, wollte ich eruieren, wie sich die DVL3-überexprimierenden Zellen im Migrationsassay verhalten würden.

Interessanterweise wiesen die Konstrukte DVL3 wt und DVL3 $\Delta \mathrm{C}$ eine Einschränkung der Migration in der Ebene auf. Ein Ergebnis, das vorerst im Widerspruch zu den invasivitätssteigernden Eigenschaften zu stehen schien.

Die Zellen migrierten gemeinsam im Zellverband (vgl. Abb. $3.10 \mathrm{C}$ ) und behielten ihre epitheliale Morphologie physikalisch und funktionell bei (vgl. Friedl und Gilmour 2009). 
Auch Vorergebnisse der Arbeitsgruppe ließen bereits die Schlussfolgerung zu, dass im Kollektiv wandernde Tumorzellen nicht unbedingt einen mesenchymalen Phänotyp annehmen müssen (Pukrop et al. 2010). Friedl und Gilmour betonten 2009 sogar die Bedeutung dieser suprazellulären Organisation für die Generierung von Fraktions- und Protrusionskräften im Rahmen der Migration. In Drosophila zeigten Llense und Martin-Blanco eine Bedeutung der JNK für Zell-Zell-Adhäsion und das kollektive Verhalten der Zellen: die Reduktion der JNK führte hier zur partiellen Dissoziation der Zellen der Lauffront, EMT ähnlich, und zum Verlust der koordinierten und gerichteten Zellmigration (Llense und Martin-Blanco 2008).

In meinen Versuchen zeigten sowohl die ROR2-überexprimierenden MCF-7 als auch die DVL3-überexprimierenden Zellen eher eine aktivierende Wirkung auf die JNK und beide wanderten im Kollektiv und nicht als Einzelzellen. Während der mesenchymalen Invasion ist jedoch ein Lösen der bestehenden Zellkontakte bedeutsam (vgl. Bacac und Stamenkovic 2008), beispielsweise, um im Rahmen der Intravasation in das Gefäßsystem einzudringen.

Lou et al. schlussfolgerten 2008 nach Studien zu EMT in einem Mausmodell, dass der Phänotyp nicht sicher das Metastasierungspotential einer Zelle, bestehend unter anderem aus den Faktoren Migration und Invasion, vorhersagen kann (Lou et al. 2008).

Folglich bedeutet eine gesteigerte Invasion nicht automatisch, dass Zellen auch schneller migrieren müssen und umgekehrt.

Gleichzeitig verdeutlicht das Ergebnis, dass es sich bei der gesteigerten Invasion durch die extrazelluläre Membran tatsächlich um einen, durch Substanzabbau und die Möglichkeit zum Lösen der bestehenden Zell-Zell-Verbindungen hervorgerufenen, Effekt handelt, und nicht um ein lediglich durch eine gesteigerte Mobilität der Zellen hervorgerufenes Artefakt.

Weitere Analysen der pro-invasiven, pro-migratorischen Konstruke, vergleichend mit den pro-invasiven, nicht-migrierenden Konstrukten, wären interessant durchzuführen. So könnte man eventuell Unterschiede in der Expression verschiedener Matrixmetalloproteasen (MMPs) oder Zelladhäsionsmoleküle in Erfahrung bringen und auch auf methodischer Ebene mehr über die Funktionsweise der beiden Versuche und die hierfür benötigten Voraussetzungen lernen.

Matsumoto et al. zeigten 2010, dass Wnt5a auch auf den Integrin-Signalweg wirkt und so Zellmigration und Adhäsion regulieren soll. Sie zeigten Wnt5a verstärkte, direkte Bindung von DVL an das adenomatous polyposis coli Genprodukt (APC), das auch bekannt ist als Mikrotubuli bindendes Protein. Wnt5a, Fz2 und Integrin $\beta 1$ waren kolokalisiert an der 
Lauffront von polarisierten, migrierenden Zellen anzutreffen. Dies bewirke die Assoziation von DVL und APC. Die hierdurch induzierte Stabilisierung der Mikrotubuli der Lauffront bewirke das Auflösen der fokalen Adhäsionsmoleküle und stimuliere so die Zellmigration. Die Versuche wurden, anders als in meinen nativen Versuchen, unter Stimulation mit Wnt5a durchgeführt (Matsumoto et al. 2010).

Auch Nishita und Kollegen zeigten, wie bereits geschildert, 2006 eine Bedeutung DVLs für die Wnt5a-induzierte Tumorzellmigration, allerdings in ROR2-überexprimierenden $L$ Cells. Der gleichzeitige Knock-out von beiden vorhandenen DVL-Subtypen (2 und 3) führte hier zu einer deutlichen Reduktion der Wnt5a vermittelten Migrationszunahme über ROR2 (Nishita et al. 2006). Genauere Theorien bezüglich einer möglichen Regulatorfunktion DVLs blieben jedoch aus.

Im Gegensatz dazu zeigten meine Ergebnisse in DVL3-überexprimierenden MCF-7 Zellen einen unveränderten Gehalt an DVL2 und Expression von zusätzlich DVL1 (vgl. Abb.3.1 A). Bei gleichzeitiger Abwesenheit von ROR2 war nicht nur ein Ausbleiben der bei Nishita und Kollegen (2006) scheinbar ersichtlichen pro-migratorischen Signale von DVL2/3 im Rahmen einer Überexpression von DVL3, sondern sogar eine Inhibition der Tumorzellmigration durch diese, unabhängig vom Vorhandensein des DVL3 C-Terminus, zu beobachten.

Dies könnte ein weiteres Mal die Bedeutung des Rezeptorstatus und ihrer Kofaktoren sowie der Zusammensetzung der intrazellulären Signalmoleküle für die Funktionsweise der Wntinduzierten Signalkaskaden hinweisen (vgl. Nishita et al. 2010a).

So wie auch MacMillan und Kollegen zeigten, dass Wnt5a über Fz und seine Ko-Rezeptoren ROR2/Ryk -abhängig vom Tumorstadium bzw. Zellkontext- promigratorische oder inhibitorische PCP-Signale vermitteln kann (MacMillan et al. 2014) und so die Zytoskelettreorganisation, essenziell für die Krebszellmigration, steuert.

\subsection{DVL3 bildet dynamische Aggregate in Abhängigkeit vom Vorhandensein der DIX-Domäne}

Die Tatsache, dass DVL3 intrazellulär Aggregate bildet, wurde bereits von verschiedenen Arbeitsgruppen sowohl für überexprimierende Zellen (Axelrod et al. 1998, Kishida et al. 1999, Rothbächer et al. 2000) als auch für endogenes Dishevelled in Drosophila, Caenorhabditis elegans, Xenopus und Mausembryonen (Yanagawa et al. 1995, Miller et al. 1999, Torres und Nelson 2000, Walston et al. 2004, Chang et al. 2005) beschrieben. 
Zum einen wird hier von punctae, also kleineren Pünktchen, gesprochen, auf der anderen Seite jedoch auch von größeren, supermolekularen Komplexen (2 Mega Da, Yokoyama et al. 2010). Diese, so wird vermutet, sollen nur größere Verbände der punctae darstellen (Yokoyama et al. 2012).

Die Theorien, auf welche Faktoren beide Komplexe zurückzufühen sind, gehen weit auseinander.

Eine Assoziation an vesikuläre, intrazytoplasmatische Membranen wurde von den meisten der beschreibenden Autoren auf Grund der Phospholipid-bindenden Eigenschaften der DIXDomäne lange vermutet. 2002 zeigten Capelluto et al. in CHO-Zellen tatsächlich die Bindung von DVL2 an Aktin-Stressfasern und vesikuläre Membranen in Abhängigkeit von der DIXDomäne. Schwarz-Romond et al. beschrieben 2005 bzw. 2007 dynamische DVL2-Aggregate, die ebenfalls abhängig vom Vorhandensein der DIX-Domäne anzutreffen sind.

Zum Teil noch unvollständige Vorarbeiten der Arbeitsgruppe wiesen vorerst jedoch auf einen Zusammenhang der Konglomerate mit dem Fehlen der DEP-Domäne hin. Dies wurde so auch durch Pan et al. 2004 für DVL1 und HEK 293-Zellen angenommen, da sie eine Membrantranslokation ohne Vorhandensein der DEP-Domäne ausschlossen.

Erst der vollständige Einsatz aller Konstrukte mit allen Knock-out-Domänen zeigte im Zuge der vorliegenden Arbeit eindeutig, dass nur jene Konstrukte Konglomerate bilden konnten, die eine DIX-Domäne besaßen. Das Konstrukt DVL3 $\triangle \mathrm{PDZ} \triangle \mathrm{DEP}$, das folglich nur aus der DIX-Domäne bestand, wies überdies signifikant mehr Aggregate au, als alle anderen Konstrukte, beinahe, als würde der Einfluss der DIX-Domäne hin zur supermolekularen Konfiguration überwiegen.

Da die DIX-Domäne nicht nur für Homo- und Heterodimerisierung von DVL bedeutsam ist, sondern auch mit der DIX-Domäne von Axin (hier zur Übersichtlichkeit als DAX-Domäne bezeichnet) assoziieren kann (Kishida et al. 1999, Fiedler et al. 2011) und gleichzeitig ähnliche Konglomerate auch für Axin beschrieben sind (Faux et al. 2008), wäre es durchaus interessant, weitere Untersuchungen durchzuführen, mit der Fragestellung, inwieweit es sich bei den in den Migrationsassays beobachteten Konglomeraten um Assoziationen von DVL und Axin handelt.

Während von Bryja et al. schon 2007 (a) eine Phosphorylierung von DVL2 durch die CK1 und Wnt5a-abhängig beschrieben wurde, die eine Umverteilung von DVL punctae hin zur 
Gleichmäßigkeit mit sich führte, publizierten Yokoyama et al. (2012) während der Durchführung der Versuche zu der vorliegenden Arbeit einen Artikel, in dem sie zusätzlich zu meinen Annahmen ähnliches zeigten: die Konstruktion von DVL3-basierten supermolekularen Komplexen fände durch Phosphorylierung und mittels Axin statt. Während die Mutation zur Unterbindung der Phosphorylierung durch eine Unterform der CK1 $(\delta)$ im Bereich zwischen der PDZ und der DEP-Domäne lokalisiert war, befand sich der Knock-out zur Unterbindung der Aggregate ebenfalls im Bereich der DIX-Domäne. Beide Bereiche waren hier, sowohl zur Signaltransduktion über TCF/LEF, also über Aktivierung von $\beta$-Catenin, als auch zur Bildung supermolekularer Aggregate nötig (Yokoyama et al. 2012).

Die Ergebnisse von Yokoyama et al. zur Bedeutung der DIX-Domäne stehen demzufolge im Einklang mit den Ergebnissen dieser Arbeit.

Die Notwendigkeit einer Phosphorylierung durch die CK $\delta$ zwischen PDZ und DEP lässt sich zwar nur schwer eruieren, da den Knock-out-Konstrukten sehr große Bereiche fehlen, also mehr, als nur die eigentliche Phosphorylierungsstelle. Jedoch ist auffällig, dass in den hier durchgeführten Versuchen, das Konstrukt dominante Aggregate bildet, welches über DIX verfügt, der Bereich zwischen PDZ und DEP jedoch fehlt (DVL3 $\triangle$ PDZ $\triangle \mathrm{DEP}$ ).

Da eine DIX-ähnliche Domäne des Weiteren auch für den Regulator des nicht-kanonischen Signalzweigs coiled-coiled-DIX1 (Ccd1) beschrieben ist (Wong et al. 2004), könnte die Analyse eines möglichen Zusammenhangs auch mit der Funktion und einer eventuellen Bindung von Ccd1 an DVL über die DIX Domäne erfolgen. Hier wäre unter anderem interessant, inwieweit eine, wie von Wong und Kollegen beschriebene, Blockade der JNK durch Ccd1 von den verschiedenen Konstrukten noch durchgeführt oder diese durch den Knock-out der verschiedenen Domänen auch unterbunden werden kann.

Nishita et al. vermuteten 2010 (b) nach Versuchen an L-Zellen, in denen sie DVL2-Aggregate aufzeigten, dass die DVL2-Polymerisierung durch einen ROR2/Fz7-Rezeptorkomplex Wnt5a-abhängig reguliert wird und über Rac1 eine Aktivierung von AP-1 induzierte. Sie detektierten Überexpressions-DVL2 puncta Bildung drei Minuten nach Stimulierung mit Wnt5a, diese hielt bis zu zwei Stunden an. Sie waren höchst mobil und translozierten an die Zellmembran, wo sie kolokalisiert mit exogen zugeführtem ROR2 anzutreffen waren (Nishita et al. 2010b).

Zellen mit einem exogen zugeführten DVL2-Konstrukt, mit Mutation in der DIX-Domäne, zeigten keine Polymerisation von DVL2, weder nach Stimulation mit Wnt5a noch nach 
Stimulation mit Wnt3a. Zellen mit exogem zugeführten DVL2, mit Mutation in der DEPDomäne, zeigten nach Stimulation mit Wnt5a reduzierte Polymerisation, wohingegen Wnt3a dazu weiterhin in der Lage war. Für die puncta Bildung und die folgende Aktivierung von AP-1 durch Wnt5a war folglich das Vorhandensein der DIX-Domäne und auch der DEPDomäne von Bedeutung (Nishita et al. 2010b).

Im Rahmen der oben genannten Untersuchungen versuchten Nishita et al. auch zu eruieren, ob DVL2 im Rahmen der Polymerisation eine Assoziation mit anderen Zellkomponenten eingehe. Sie untersuchten Markerproteine für Endozytose (Clathrin, AP2, EEA1 und Caveolin) und FM4-64, das membranöse, intrazelluläre Organelle der Endozytosekette markiert, und eine Assoziation an Mitochondrien, legten jedoch keine Bindung an solche offen (Nishita et al. 2010b).

Neben der Assoziation des exogenen DVL3 in Konglomeraten, fiel eine Überlagerung des TRITC-Phalloidin-Signals mit dem FITC-FLAG-Leuchten in den Fortsätzen der Zellen der Migrationsfront auf. Axelrod et al. beschrieben 1998 in Xenopus-Zellen eine Translokation des beobachteten Dsh von vesikulären Strukturen zur Plasmamembran als Antwort auf PCPSignale, wohingegen Wnt/ $\beta$-Catenin hierauf keine Auswirkungen zeigten. Auch Wu et al. (2004) zeigten einen Zusammenhang der Rekrutierung zur an der Spitze gelegenen Membran mit der Aktivierung des PCP-Astes, während $\beta$-Catenin basal und lateral dephosphoryliert wurde.

Im Jahr 2000 konnten Torres und Nelson die Kolokalisation von Dishevelled und den Zytoskelettbestandteil Aktin an sich entwickelnden Mausnieren nachweisen.

Folglich ist die Fähigkeit, DVLs an die Zellmembran, eventuell durch Assoziation mit Aktin, zu translozieren, als nicht unwahrscheinlich anzusehen. Nimmt man, durch die hier gezeigte Anreicherung in den Fortsätzen und dem Ergebnis von Axelrod et al. (1998), an, dass es sich auch bei dem hier dargestellten Switch um eine Aktivierung von PCP-Signalen handelt, so hebt dieses Ergebnis die Bedeutung von DVL3 und PCP im Kontext der Brustkrebsmigration in der Ebene ein weiteres Mal hervor.

Auch Matsumoto und Kollegen sahen im Rahmen der oben bereits erwähnten Untersuchungen (2010) zur Bedeutung von Wnt5a für die Tumorzelladhäsion und -migration über den Integrin-Signalweg eine Lokalisation von DVL an die apikale Membran der Lauffront, 
am ehesten durch Kolokalisation mit Fz. Kikuchi et al. sahen in ROR1/2 einen eventuellen Ko-Rezeptor für diesen Signalweg (Kikuchi et al. 2012). Nishita und Kollegen beschrieben 2006, wie bereits erläutert, neben der ROR2-abhängigen Bildung von Zellfortsätzen, die Assoziation von DVL an ROR2 und die Bedeutung des Proteins für die Tumorzellmigration.

Offen bleibt allerdings die Frage, warum auch bei dem Konstrukt, dem PDZ und DEP fehlen, der Lokalisationswechsel besonders gut zu beobachten ist, wo ihm doch beide Domänen, die zur Membranbindung fähig sein sollen, fehlen. Hierfür müssten weitere, spezialisiertere Untersuchungen zu den Proteineigenschaften DVLs durchgeführt werden -eventuell lassen sich so auch weitere Bereiche, die zur Membranbindung befähigt sind, identifizieren.

Eine tiefergehende Analyse der Bedeutung des beobachteten Shifts konnte bisher nicht erfolgen. Nishita et al. vermuteten 2010, dass die Wnt5a-induzierte Phosphorylierung von DVL eventuell die Polymerisierung DVLs im Sinne eines negativen Feedbacks hemmt und so Wnt5a/ROR2-Signale herunterreguliert (Nishita et al. 2010b). Hierzu ist jedoch separat anzuführen, dass kein Zusammenhang bestand zwischen der Fähigkeit, Dots zu bilden und den hier untersuchten Eigenschaften wie Invasion und Migration. Auch Zellen ohne Dots waren pro-invasiv, und das nicht-invasionsfördernde Konstrukt $\triangle \mathrm{DEP}$ konnte DVLAggregate bilden.

Interessanterweise jedoch war die Domäne, deren singulärer Knock-out eine Inhibition der Aktivierung von $\beta$-Catenin bewirkte, auch die Domäne, die zur Aggregatbildung nötig war. Die Bedeutung der Aggregate und des Shifts im Zusammenhang $\beta$-Catenin-abhängiger Signalkaskaden ist also anzunehmen. Eine Schlussfolgerung, die auch Nishita und Kollegen 2010 (b) zogen. Zum Vergleich siehe Abbildung 4.2. 


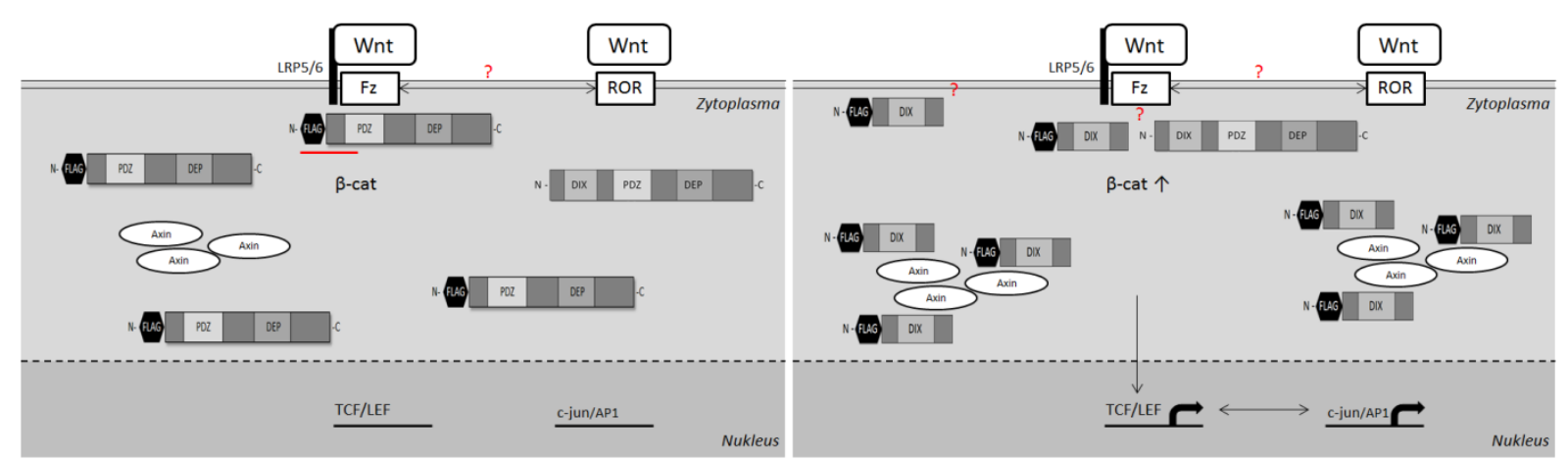

Abbildung 4.2 Theorien zur Entstehung und Bedeutung der dynamischen Aggregate. Das Vorhandensein der DIX-Domäne ist essenziell für das entstehen der Aggregate. Eine Assoziation mit der DIX-Domäne von Axin wurde unter anderem von Kishida et al. 1999 sowie von Fiedler et al. 2011 beschrieben. Das Konstrukt DVL3 $\triangle$ PDZ $\triangle$ DEP bildet zahlreiche Aggregate, des Weiteren ist ein deutlicher Shift des FLAG-markierten DVL3s an die apikale Plasmamembran und in die Fortsätze der Zellen zu beobachten. Über welchen Proteinbereich, beziehungsweise über Kolokalisation mit welchen Rezeptoren und Ko-Rezeptoren dies erfolgt, bleibt zunächst jedoch unklar (Zum Vergleich siehe unter anderem Matsumoto et al. 2010 sowie Kikuchi et al. 2012). Für Details siehe Text.

\subsection{Die Lokalisation der DVL3-Konstrukte in Zytoplasma und Nukleus}

Zur weiteren Analyse der Lokalisation der Konstrukte, und gegebenenfalls auch der Konglomerate, wurden Western Blot-Analysen auf das exogene DVL3 mittels FLAG-Antikörper und endogenes DVL3 durchgeführt. Die Ergebnisse lassen die Annahme zu, dass sich alle DVL3Konstrukte in beiden Kompartimenten, Kern und Zytoplasma, verteilen können.

Die Auswertung der Hirnmetastasenfärbungen zeigte, dass ein hoher Gehalt zytolasmatischen DVL3s mit dem Vorhandensein im Kern korrelierte. Dennoch gab es zytoplasmatisch stark positive Zellen, die nur wenig bis kein DVL3 im Kern aufwiesen. Zellen mit lediglich DVL3 im Kern, jedoch nicht im Zytoplasma, konnte ich nicht beobachten.

Auch in der Fachliteratur ist das Vorkommen von DVL im Kern häufig beschrieben worden (vgl. unter anderem Torres und Nelson 2000, Itoh et al. 2005). Berichte zu einer Kernlokalisation waren in diesen Jahren auch über die vormals ebenfalls als zytoplasmatisch beschriebenen Proteine APC, GSK3 und $\beta$-Trcp aufgekommen (vgl. Mac Donald et al. 2009). 
Offen blieben jedoch vorerst die Fragen nach der Bedeutung und Funktion dieser Proteine, vor allem DVLs im Kern.

Während die Tatsache, dass DVL in den Kern translozieren kann, für seine Funktionen im $\beta$ Catenin-Signalweg bedeutsam scheint (Habas und Dawid 2005), liegen keine Untersuchungen im Kontext der nicht-kanonischen Signalwege vor. Dass gerade jener DVL-Subtyp 3 im Kern nachweisbar ist, der vor allem nicht-kanonische Signale transduzieren soll, ist hierbei auffällig.

Darum interessierte mich, ob ich das Vorhandensein einer hierfür zuständigen Domäne mittels der hier eingesetzten Konstrukte nachweisen könnte. Gegebenenfalls wäre wiederum interessant zu erfahren, inwieweit eine fehlende Möglichkeit zur Kernlokalisation auch Auswirkungen auf die von $\beta$-Catenin-unabhängigen Signaläste hätte und ob von mir angenommene Funktionen DVLs im Kern (s. u.) hiervon beeinflusst werden würden.

Die Bedeutung eines Kernexportsignals (Nuclear Export Signal, NES) wie für humanes DVL3 zwischen Aminosäureposition 504 bis 506 (nach DEP am C-terminalen Bereich) von Itoh et al. 2005 oder einer Kernlokalisationssequenz (Nuclear Localization Export, NLS) an Position 329 bis 332 (am Ende der PDZ-Domäne) beschrieben, konnten durch meine Vesuche nicht nachgewiesen werden, da sich alle Knock-out-Konstrukte in beiden Kompartimenten anfärben ließen (Daten zum Teil nicht gezeigt).

Dies könnte jedoch mit der Vorstellung vereinbar sein, dass neben diesen beiden beschriebenen Sequenzen auch noch weitere bestehen, die in den Knock-out-Konstrukten nur dann ihre Funktion ausführen, wenn die sonst dafür zuständigen fehlen, oder dass DVL über andere Proteine im Komplex in den Kern transportiert wird.

Im Rahmen der Methodenkritik muss angemerkt werden, dass es in der Versuchsdurchführung der Zytosol-Kernaufreinigung zwar die HDAC-Kontrolle als allgemeinen Qualitätsstandard, speziell zur Messung einer Verunreinigung von Kernbestandteilen in der Zytosolfraktion, gibt, jedoch ein Parameter zur Darstellung einer Verunreinigung der Kernfraktion mit zytoplasmatischen oder membranösen Bestandteilen bisher nicht etabliert ist. Folglich sind alle Western Blot Ergebnisse mit Zytosol- und Kernfraktionen kritisch zu hinterfragen, da eine solche Verunreinigung nicht sicher ausgeschlossen werden konnte, selbst wenn eine korrekte Versuchsdurchführung nachgewiesen wurde.

In den im Anschluss durchgeführten Immunfluoreszenzfärbungen konnten jedoch alle DVL3Konstrukte sowohl im Zytoplasma als auch im Kern nachgewiesen werden. Auch die 
immunhistochemischen Färbungen der zerebralen Mamma-Karzinommetastasen wiesen DVL3 teilweise im Kern auf. Somit wurde die Kernlokalisation DVL3 mit zwei weiteren, unabhängigen Methoden nachgewiesen.

\subsection{Aufgaben von DVL abseits der Rezeptor-abhängigen Funktionen}

Dass DVL3 neben den bekannten Fz-abhängigen Aufgabenfeldern weitere Funktionen übernimmt bzw. übernehmen kann, wurde in meinen Versuchen mehrmals deutlich:

Zum einen waren DVL3-Fragmente, die weder über den Rezeptor wirken noch an Axin binden konnten, in der Lage, auf die mRNA-Menge der Zellen Einfluss zu nehmen. So bewirkte der isolierte C-Terminus beispielsweise einen Anstieg des Wnt5a-Gehalts in der Zelle.

Des Weiteren fiel im Rahmen der funktionellen Untersuchungen vor allem auf, dass auch Konstrukte die Invasivität der Zellen steigern konnten, die rein formal jedoch nicht in der Lage waren, an $\mathrm{Fz}$ zu binden.

Analysiert man diese beiden Auffälligkeiten, so weisen die Ergebnisse meiner Arbeit vorerst auf zwei weitere mögliche Funktionsweisen von DVL hin:

Zum einen scheint DVL transkriptionsregulierende Einflüsse unabhängig von $\mathrm{Fz}$ und $\beta$ Catenin $\mathrm{zu}$ haben. $\mathrm{Ob}$ es dies jedoch direkt, indirekt mit Einflussnahme auf einen vorhandenen weiteren Liganden oder durch Wirkung auf einen der Transkriptionsfaktoren bewirkt, bleibt bisher noch offen.

Des Weiteren schlussfolgerten Simons und Mlodzik 2008 aus den Ergebnissen mehrerer Abeitsgruppen und der Zusammenschau von Arbeiten an verschiedenen Spezies, dass DVL im Rahmen von PCP-Signalwegen auch am Membranstoffwechsel der Zellen beteiligt ist.

Hierbei ist unter anderem eine Wirkung über $\beta$-Arrestin beschrieben (Chen et al. 2003). Es soll die N-terminale Region von PDZ binden, wo sich eine CK1-Phosphorylierungsstelle befindet (Bryja et al. 2007a+b). PDZ war allerdings nicht die bedeutsame Domäne in den funktionellen Untersuchungen, sondern der Knock-out von DEP.

Neben $\beta$-Arrestin ist jedoch auch eine Beteiligung DVLs am Membrantransport in Synapsen durch eine bisher nicht genauer untersuchte Bindung/Domäne DVLs an Synaptotagmin (Syt) I (Kishida et al. 2007) beschrieben.

Mamidi et al. beschrieben 2012 eine Bedeutung DVLs für die Signalkaskaden über TGF $\beta$. Der Knock-out von DVL mittels siRNA führte zu einer signifikanten Abnahme der 
Luciferaseaktivität im Assay, war jedoch reversibel durch Zugabe von xDVL wt und xDVL $\Delta$ DIX. Interessanterweise wurden keine Angaben $\mathrm{zu}$ den Potentialen anderer Knock-outKonstrukte gemacht, sodass eine hierfür zuständige Domäne nicht identifiziert werden konnte. Dennoch legen die Ergebnisse von Mamidi und Kollegen nahe, dass DVL vielseitig in weitere Signalkaskaden involviert sein könnte.

Für mich ist dadurch denkbar, dass DVL über einen bisher nicht beschriebenen Mechanismus und eine bisher nicht beschriebene Bindungsstelle, eventuell mit direkter Abhängigkeit von seiner DEP-Domäne oder, durch die ihr mögliche stabilisierende, da Phospholipid-bindende Funktion (s.o.), auf den Membrantransport der Zellen Einfluss nimmt und so die, in meinen Versuchen im Rahmen der DVL3-Überexpression beobachteten, funktionellen Veränderungen, unabhängig von den bekannten Rezeptor-abhängigen Funktionsweisen, vermitteln kann.

\subsection{Signalwege über DVL und ROR2 -mehr gemeinsame Schnittmeng- en als bisher angenommen?}

Der $\beta$-Catenin-unabhängige Signalweg über ROR2 galt bisher als ebenfalls unabhängig von DVL (Schambony und Wedlich 2007, Liu et al. 2008). In dieser Arbeit konnte jedoch gezeigt werden, dass die Überexpression von ROR2 eine Zunahme des Western Blot-Signals für DVL3 bewirkt. Indirekt gibt es mehrere Hinweise, dass DVL an der Signaltransduktion über ROR2 beteiligt sein könnte. Gibt es darüber hinaus gemeinsame Schnittmengen dieser beiden Signalkaskaden?

Witte et al. zeigten in einer Publikation aus dem Jahr 2010 eine Bedeutung phosphorylierten DVLs für eine negative Regulatorfunktion durch ROR2 auf die Wnt-Signalwege. Die Versuche wurden zum Teil in humanen, embryonalen Nierenzellen, zum Teil in Fibroblastenähnlichen Zellen aus Affen durchgeführt.

Sie belegten, dass der phosphorylierte, hochkonservierte DVL C-Terminus an die ProlinSerin-Threonin-reiche Domäne von ROR2 binden kann und so eine kanonische Signalweitergabe unterbindet. Der DVL C-Terminus sei nötig und sogar ausreichend, in Anwesenheit von ROR2 die Kaskade zu inhibieren. Ihre Schlussfolgerung lautete, dass phosphoryliertes DVL einen negativen Feedbackmechanismus induziert und so andere WntSignalzweige ROR2-abhängig inhibiert.

Diese Veröffentlichung demonstriert eine mögliche Bedeutung der Anreicherung von DVL3 durch die ROR2-Überexpression. Vermehrte Expression von ROR2 führt zur Stabilisierung oder Phosphorylierung des DVL3s, da ihm in diesem Rezeptorkontext eine funktionelle 
Bedeutung zukommt. Die Tatsache, dass zu dem in der pcDNA-Kontrolle vorhandenen DVL3 weitere, in höherem kDa-Bereich sichtbare Proteinbanden entstehen, spricht dafür, dass es sich hier auch um eine Zunahme des von Witte und Kollegen beschriebenen phosphorylierten DVL3 handeln könnte.

Mehrere Ergebnisse meiner Arbeit weisen auf weitere Gemeinsamkeiten der RORabhängigen und DVL-abhängigen Wnt-Signalkaskaden hin. So führt die Überexpression von DVL3 wt beispielsweise zu einer Zunahme von mRNA von ROR1 - unabhängig vom Vorhandensein der als kanonisch geltenden DIX-Domäne oder des C-Terminus. Das Einbringen der bloßen C-terminalen Sequenz führte zum Anstieg der mRNA für Wnt5a, was die Bedeutung dieses Bereiches ein weiteres Mal unterstreicht.

$\mathrm{Zu}$ berücksichtigen ist jedoch, dass die Inhibition der kanonischen Signalkaskade durch den C-Terminus von DVL bei Witte et al. 2010 über ROR2 Bindung vermittelt wurde, einen Rezeptor über den weder die native MCF-7 noch die eingesetzten Mutanten verfügen. Interessant wäre folglich zu untersuchen, inwieweit DVL über seinen $\mathrm{C}$ terminalen Bereich auch in der Lage ist, beispielsweise an ROR1 zu binden, oder auf welche andere Weise es vermag, Einfluss auf die Genexpression zu nehmen.

Färbungen der Hirnmetastasensammlung auf ROR2 und das Überprüfen einer möglichen Korrelation des DVL3-Gehalts mit dem Vorhandensein von ROR2 in den Patientenproben sowie die ausstehende Auswertung der Patientendaten könnten mehr Information geben über das Zusammenspiel von DVL und ROR im Rahmen von Metastasierungsprozessen.

\subsection{Wnt-Signalwege als komplexes Netzwerk von Signalkaskaden}

Die qRT-PCR- und Western Blot-Versuche legten zahlreiche Verbindungen der verschiedenen Proteine der als kanonisch bzw. nicht-kanonisch klassifizierten Wnt-Signalwege offen (zum Vergleich siehe auch Abb. 4.3).

Methodenkritisch ist als erstes anzuführen, dass es sich hierbei lediglich um Überexpressionsversuche handelt, die in genetisch instabilen Krebszellen stattgefunden haben und bisher nicht mittels loss of function-Versuchen bestätigt worden sind. Dadurch könnten die entstandenen Veränderungen auch durch weitere Mutationen im Rahmen der genetischen Manipulation verursacht worden sein, und weniger spezifische Produkte veränderter Zellaktivität darstellen. Dennoch können die vorliegenden Ergebnisse einen Ansatz bieten, um Rückschlüsse auf verschiedene potentielle Prozesse in Krebszellen ziehen zu können. Getragen wird dies von 
der intrinsischen Kohärenz der Ergebnisse und Übereinstimmungen mit den Vorergebnissen anderer Arbeitsgruppen.

Solche Rückschlusse wären:

- DVL3 müssen, wie oben erläutert, andere Funktionen zukommen, abseits der Rezeptor-abhängigen.

- Mutationen in einzelnen Faktoren der Wnt-Signalwege führen schnell weitere Veränderungen mit sich, ein Vorgang, der im Rahmen der Tumorprogression in vivo durchaus stattfindet

- Eine Krebszelle, die DVL3 überexprimiert, ist in der Lage, ROR1 als Rezeptor hochzuregulieren, solange die Domänen PDZ und DEP erhalten sind. Hier nehmen also zwei $\beta$-Catenin-unabhängige Signalwege direkt aufeinander Einfluss.

- Gleichzeitig wird DVL2 herunterreguliert, wenn DVL3 im Überfluss vorhanden ist. Dies geht einher mit der Annahme von Lee et al. (2008), dass die drei DVL-Subtypen komplex kooperieren und sowohl spezifisch Funktionen übernehmen, zum Teil jedoch auch durch einander ersetzbar sind.

- Die Überexpression von ROR2 führt zum gleichzeitigen, spezifischen Anstieg der mRNA für ROR1 und zum Anstieg des Western Blot-Signals des als nicht-kanonisch geltenden DVL3s, während $\beta$-Catenin eher inhibiert wird.

Die klare Strukturierung der Wnt-induzierten Signalwege in kanonische und nicht-kanonische Zweige wurde in den vergangenen Jahren durch Bekanntwerden neuer Überschneidungen und synergistische wie auch antagonistische Modulationen zunehmend relativiert. So beschrieben beispielsweise Topol et al. 2003 eine Degradation von $\beta$-Catenin, unabhängig von GSK-3, durch Wnt5a. Nateri und Kollegen erkannten 2005 den positiven Effekt von PCP c-jun auf die Aktivität des bisher als kanonisch geltenden Transkriptionsfaktors TCF-4. Die modulatorischen Effekte von ROR2 auf $\beta$-Catenin wurden bereits beschrieben, und nach den Rezeptoranalysen von Grumolato et al. (2010) wird des Weiteren eine reziproke Hemmung von kanonischen und nicht-kanonischen Signalwegen an der Zelloberfläche angenommen, da beide Wnt-Untergruppen um den gemeinsamen (Ko-) Rezeptor Fzd konkurrieren sollen.

Alles in allem weisen die Ergebnisse auch meiner Arbeit darauf hin, dass es sich bei den Wntgesteuerten Signalwegen in Tumorzellen um ein hoch komplexes Netzwerk von Signalkaskaden und nicht um ein, wie lange Zeit angenommen, lineares System handelt, in dem ein spezifischer Ligand über spezifische Rezeptoren und Ko-Rezeptoren intrazellulär nur 
ein spezifisches Signal auslösen kann und sich kanonische von nicht-kanonischen Signalwegen immer klar abgrenzen lassen.Vielmehr handelt es sich um ein sensibles System, in dem zahlreiche Faktoren miteinander in Kontakt treten und geringe Alterationen bzw. Mutationen bereits zu vielseitigen funktionellen und morphologischen Veränderungen führen.

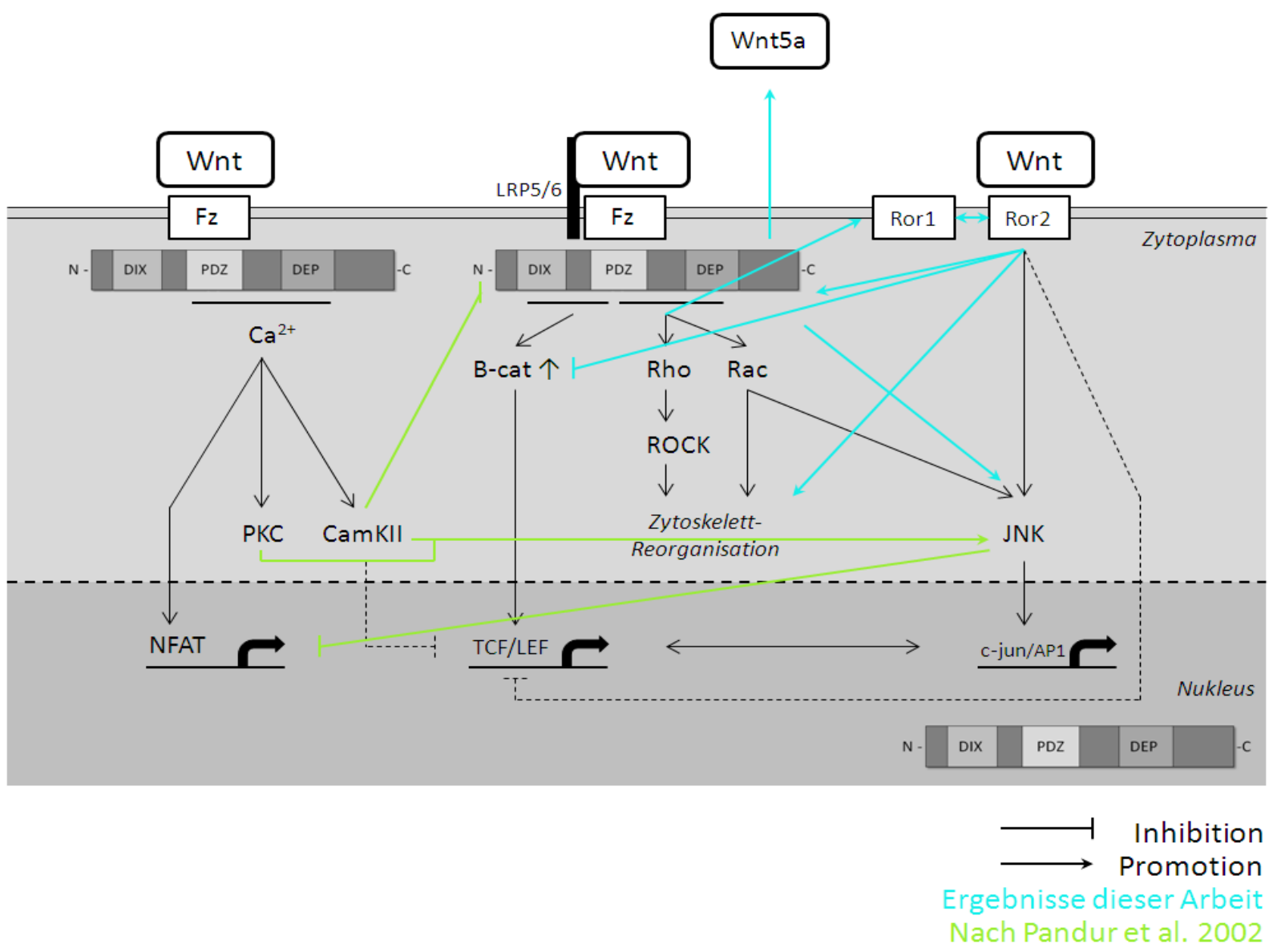

Abbildung 4.3 Wnt-Signalwege als komplexes Netzwerk von Signalkaskaden. Die Abbildung stellt eine Zusammenfassung der Verknüpfungen der verschiedenen Wnt-Signalkaskaden modifiziert nach Pandur et al. (2002) graphisch dar (grün). Zusätzlich zeigt die Abbildung die Erkenntnisse dieser Arbeit in blau. Für Details siehe Text.

\subsection{Bedeutung von EMT in Brustkrebs}

Die epithelial-mesenchymale Transition nimmt im Rahmen der Zellmigration und Invasion in der embryonalen Entwicklung eine zentrale Rolle ein. Gleichzeitig wird ihr immer wieder entscheidende Bedeutung in der gesteigerten Invasionsfähigkeit von Krebszellen im Rahmen der Tumormetastasierung zugesprochen (Thiery 2002, Yang und Weinberg 2008).

Regulatorfunktionen der EMT sind sowohl für den Wnt/ß-Catenin-Signalweg (Yang und Weinberg 2008) als auch für den PKC-Ast (Dissanayake et al. 2007) beschrieben. 
Folglich war von Interesse, inwieweit bei den hier durchgeführten Versuchen an Krebszellen dieser Prozess auch in der Brustkrebsentstehung und Metastasierung von Bedeutung sein könnte.

Sowohl die Überexpression von ROR2 als auch von DVL3 und seinen Konstrukten führte zu keiner Zunahme mesenchymaler Marker wie Vimentin oder EMT-Marker wie Snail1, ZEB1 oder 2 .

Folglich scheint die gesteigerte Invasivität im Mamma-Karzinom nicht, auf eine phänotypische Veränderung hin zu einem mesenchymalen Phänotyp zurückzuführen zu sein. Dieses Ergebnis ist im Einklang mit den Vorergebnissen von Klemm et al. und Rietkötter et al. (unpubliziert), die unabhängig voneinander keine Bedeutung von EMT in der Brustkrebspromotion feststellen konnten.

Auch Lou et al. schlussfolgerten 2008 nach Versuchen zu Brustkrebs an einem Mausmodell, dass EMT alleine für eine spontane Metastasierung nicht ausreicht.

$\mathrm{Ob}$ die geringfügige Abnahme des mesenchymalen Markers Vimentin als signifikant im Sinne einer mesenchymal-epithelialen Transition aufgefasst werden kann, ist mit diesen Versuchen nicht zu eruieren. Da es jedoch keine Korrelation der Abnahme dieser Marker mit der geringeren Migrationsfreudigkeit der Konstrukte DVL3 wt oder DVL3 $\Delta$ C-term gab, ist auch nicht davon auszugehen, dass EMT bzw. MET, für die DVL3-induzierte Migration von Zellen im Brustkrebs von Bedeutung ist.

\subsection{Ausblick}

\subsubsection{ROR2 als ein potentieller Angriffspunkt einer spezifizierten, personalisierten} Tumortherapie des Brustkrebs

Der Begriff der personalisierten oder auch individualisierten Medizin beschreibt ein medizinisches Konzept, nach welchem individuelle Risiken und persönliche Behandlungsmöglichkeiten und -chancen anhand von biologischen Markern abgeschätzt werden. Die personalisierte Therapie beinhaltet folglich therapeutische Strategien, die nach Bestimmung biologischer Merkmale (Pharmakogenomik, compagnion diagnostics) und mit Hilfe dieser durchgeführt wird. Eine solche zielgerichtete (engl. targeted) Therapie bedarf allerdings einer zellulären Proteinexpression, die möglichst spezifisch ist für Tumor-Gewebe, um maximale Effektivität bei minimalen Nebenwirkungen und so einen guten therapeutischen Effekt zu gewährleisten. 
Die Überexpression von ROR2 steigert in humanen Brustkrebszellen die Malignität der Krebszellen in vitro. Vor allem die Invasivität der Zellen wurde, am ehesten über JNK, beeinflusst.

Da ROR2 in Hirnmetastasen von Brustkrebspatientinnen angereichert nachgewiesen werden konnte (Klemm et al. 2011), in physiologischen, adulten Zellen jedoch nicht, könnte es sein, dass ROR2 eine mögliche Angriffsfläche für diese spezifizierte, personalisierte Tumortherapie, speziell zur Prävention der Metastasierung, darstellt. Da Loh und Kollegen zudem (vorerst jedoch ausschließlich in vitro) eine Resistenzentwicklung gegen selektive Östrogenrezeptormodulatoren (SERM) wie Tamoxifen durch ROR2 aufzeigten (2013), wäre es von großem Interesse die in vitro-Ergebnisse auf ihren Bestand in in-vivo-Versuchen zu überprüfen. Danach wäre es wünschenswert, die Rezeptoraktivität mittels small molecule inhibitors, also kleinen, inhibierenden Botenstoffen oder einer Antikörper-basierten Therapie zu blockieren. So könnte eventuell nicht nur die Metastasierung der Brustkrebszellen, sondern auch ihre Resistenzentwicklung gegen SERMs effektiv unterbunden werden. Leider gibt es Momentan weder spezifische Inhibitoren für ROR2, noch Antikörper, die mit einer ausreichenden Affinität binden (vgl. hierzu Rebagy et al. 2012).

\subsubsection{Die DEP-Domäne von DVL3 ist ein potentieller therapeutischer Angriffspunkt}

für Patientinnen mit Tumoren und Metastasen mit DVL3-Überexpression

Alle Überexpressionskonstrukte steigerten die Invasivität der MCF-7 Zellen in der BoydenKammer signifikant, außer das Konstrukt, dem isoliert die DEP-Domäne fehlte.

Die Bedeutung der DEP-Domäne wurde von verschiedenen Autoren in unterschiedlichem Kontext für sowohl $\beta$-Catenin-unabhängige als auch -abhängige Signalwege beschrieben.

Tauriello et al. beschrieben 2011 für DVL1 in HEK293T-Zellen und Maus L-Zellen die Bedeutung einer Interaktion der DVL1 DEP-Domäne und des C-Terminus mit Fzd, um ein Signal über $\beta$-Catenin transduzieren zu können. Auch Wang und Wang beschrieben 2012 eine Bedeutung dieser Domänen für die Translokation der IPMK (Inositol Polyphosphatase Multikinase) und kanonische Wnt-Signale.

Die Arbeitsguppen um Axelrod (1998) und Boutros (1998) zeigten, dass die Mutation der DEP-Domäne zu einer Beeinträchtigung des PCP-Signalwegs führt. Sie erklärten dies über die verminderte Fähigkeit des mutanten Konstrukts, an die Zellmembran zu binden. Auch Simons et al. zeigten 2009 eine Stabilisierung von Fz und Dsh über eine pH- und Ladungsabhängige Interaktion der DEP-Domäne mit Phospholipiden der Plasmamembran. 
Des Weiteren ist zu betonen, dass DVL im Bereich der DEP-Domäne über zahlreiche Phosphorylierungsseiten verfügt, die durch den Knock-out nicht mehr zur Verfügung stehen (vgl. Consonni et al. 2014).

Im Gegensatz dazu zeigten Zhang et al. im Jahr 2006 eine Bedeutung der DEP-Domäne für die Bindung des DVL-Antagonisten Dapper 1 (Dpr1). Dieser solle über DEP in humanen Zellen, jedoch über PDZ in Xenopus die Degradation, das heißt den Abbau von DVL2, vermitteln (Zhang et al. 2006). Ob das Ergebnis jedoch auch übertragbar ist auf andere DVLSubtypen und inwieweit durch eine Mutation der Domäne Dpr1 auch in menschlichen Zellen an andere Domänen binden kann, weitere Inhibitoren bzw. Promotoren in ihrer Wirkweise beeinflusst werden oder die Lokalisation DVLs hierfür eine Bedeutung hat, blieb bisher ungeklärt.

Folglich war von großem Interesse, ob sich für dieses Knock-out-Konstrukt auch eine direkte Inhibition eines dieser Pathways, ähnlich derer des DVL3 $\Delta$ DIX-Konstrukts, nachweisen lassen könnte.

Da bei dem hier in humanen Brustkrebszellen eingesetzten DVL3-Konstrukt keine Veränderung des Gehalts an $\beta$-Catenin oder aktiviertem $\beta$-Catenin nachgewiesen werden konnte, die Zellen jedoch trotzdem weniger invasiv waren, ist wiederum davon auszugehen, dass $\beta$-Catenin in diesem Kontext keine Bedeutung zukommt.

Versucht man die Hypothese der Hemmung von aktivem $\beta$-Catenin durch das Konstrukt $\Delta \mathrm{DIX}$ auch auf diesen Versuch zu übertragen, in der Annahme, dass die Membranbindung DVLs über PDZ suffizient erfolgen kann und DEP dabei lediglich stabilisierend wirkt, so könnte die fehlende Invasivitätssteigerung auch darüber erklärt werden, dass es zwar zur Bindung an den Rezeptor, jedoch nicht zur Weiterleiung eines adäquaten Signals, und damit zur Blockade $\beta$-Catenin-unabhängiger Signalwege, kommt und die Zellen deswegen nicht pro-invasiv sind.

Diese Theorie erklärt jedoch nicht, warum zum Teil auch Überexpressionskonstrukte eine Invasivitätssteigerung herbeiführen, die nach dem derzeitigen Stand der Forschung nicht an den Rezeptor binden können. Eine Theorie wäre, dass die durch die Überexpression von DVL3 vermittelte Invasivitätssteigerung nicht auf eine Bindung DVLs an einen Rezeptor angewiesen ist (s.o. zu möglichen weiteren Funktionen DVLs abseits der Rezeptorabhängigen), oder, dass weitere Bereiche DVLs eine solche Assoziation bewirken können. Hier ist, denke ich, eine gesonderte, detaillierte Beobachtung der einzelnen Konstrukte von Bedeutung, um das Potential der einzelnen Domänen im Rahmen der Tumorprogression und 
Metastasierung zu eruieren, um so das komplexe Netzwerk der verschiedenen Signalwegskomponenten besser zu verstehen. Potentiell können Mutationen in allen Bereichen DVLs in vivo stattfinden und so die Tumoreigenschaften und möglichen Angriffsflächen entscheidend verändern.

DEP als globuläre Domäne kommt auch in etwa zehn anderen Proteinen vor. Sie interagiert jeweils mit unterschiedlichen Partnern an der Membran, unter anderem mit Rezeptoren und Phospholipiden (vgl. Consonni et al. 2014). Oft ist hierfür das Vorhandensein einer spezifischen Sequenz oder die Exposition von bestimmten Aminosäuren für die adäquate Wirkweise von Bedeutung (Axelrod et al. 1998). Dies betont nochmals die Bedeutung des Sequenzkontextes für die Spezifität (Consonni et al. 2014). Das Vorhandensein zusätzlicher Domänen oder einer bestimmten dreidimensionalen Struktur, so Consonni et al., beeinflusst die Wirkweise des entsprechenden DEP beinhaltenden Proteins. Zusätzlich kommt es zu posttranslationalen Modifizierungen und Domän-Domän-Interaktionen, gezeigt zum Beispiel für DEP in PREX (Phosphatidylinositol 3,4,5-trisphosphate-dependent Rac exchanger 1 protein), einem Protein im Kontext der Regulation von Proliferation, Migration und Invasion unter anderem über Rac (Urano et al. 2008). Consonni et al. betonen noch einmal, dass DEP nicht nur ein Instrument zur Membranlokalisation darstellt, sondern die Gesamtfunktion des jeweiligen Proteins mitbeeinflusst, da hier verschiedene Regulationsmechanismen angreifen. Interessant ist auch, dass die jeweilige DEP-Domäne in ihrem Kontext spezifisch agiert, trotz der strukturellen Ähnlichkeiten in den verschiedenen Proteinen. Es wäre folglich interessant zu eruieren, ob DVL DEP nach Knock-out anderer Domänen eventuell in der Lage ist, auch in anormalem, potentiell DVL-unabhängigem Kontext zu wirken.

All dies könnte das unterschiedliche Verhalten der Knock-out-Konstrukte erklären.

Hervorzuheben ist jedoch an dieser Stelle, dasss die MCF-7 DVL3 $\triangle$ DEP-Zellen, trotz dieses per se gain of function-Versuchs, über keine gesteigerte Invasivität verfügen. Das heißt, dass in vivo ein potentieller Malignitätsgewinn von Tumorzellen durch eine Überexpression von DVL3 durch Blockade der DEP-Domäne verhindert werden könnte.

Dies ist besonders bemerkenswert, da den Spielern des PCP-Signalwegs immer wieder überlappende Funktionsweisen zugeschrieben wurden (vgl. Simons und Mlodzik, 2008).

Die MCF-7-Brustkrebslinie besitzt nach Versuchen von Schlange et al. (2007) neben DVL3 auch deutliche Proteinlevel von DVL1 und geringe Mengen an DVL2 im Western Blot. Auch in meiner Arbeit konnten in der qRT-PCR mRNA alle 3 Subtypen in der MCF-7- 
Brustkrebslinie nachgewiesen werden. Zwar war das überexprimierte DVL3 wt-Konstrukt in der Lage, DVL2-mRNA signifikant $\mathrm{zu}$ reduzieren (was prinzipiell eine Theorie der Funktionsübernahme unterstützen würde), jedoch war das Konstrukt $\triangle D E P$ oder ein anderes Knock-out-Konstrukt hierzu nicht in der Lage.

Die Ursache der fehlenden Invasivitätssteigerung des Konstrukts $\triangle D E P$ war durch die Versuche vorerst nicht zu eruieren.

Jedoch zeigen die Ergebnisse der Boyden-Kammer, dass (trotz der Komplexität der Signalkaskaden) eine Inhibition der Domäne für Patientinnen mit auch unterschiedlichen Mutationslokalisationen bzw. Expressionsmustern eine potentielle Therapieoption darstellen könnte.

Die Klassifizierung der Hirnmetastasen der Brustkrebspatientinnen zeigte eindeutige Unterschiede zwischen der Menge, aber auch der Verteilung von DVL3. Eine detaillierte Auswertung und Korrelation mit den Überlebensdaten der Patientinnen steht jedoch im Moment noch aus. Wie schon erwähnt, zeigen bisher noch unveröffentlichte Ergebnisse der Arbeitsgruppe (Bleckmann et al.) deutlich die klinische und auch prognostische Relevanz einer Überexpression von DVL3 in Lebermetastasen von Brustkrebspatientinnen. Es ist deswegen sehr erstrebenswert, weitere Versuche mit diesem Konstrukt, zum Beispiel im Tiermodell, durchzuführen, um so eine klinisch-therapeutische Relevanz der Hemmung dieser Domäne, beispielsweise mit einem gegen diese gerichteten smal molecule in Erfahrung zu bringen. Damit könnte man eventuell eine rasche Tumorprogression oder auch die gefürchtete Spätmetastasierung der Tumorzellen verlangsamen oder sogar komplett unterbinden.

\subsubsection{Die DIX-Domäne von DVL3 ist ein potentieller therapeutischer Angriffspunkt} in Tumoren, in denen eine Aktivierung von $\beta$-Catenin für die Tumorprogression von

\section{Bedeutung ist}

Da meine Versuche immer wieder die geringe Bedeutung der als kanonisch-bezeichneten Signalwege im Rahmen der Brustkrebsmetastasierung darstellen, handelte es sich bei dem Nachweis, dass das Fehlen der DIX-Domäne die Aktivierung von $\beta$-Catenin unterbindet, vorerst um ein Ergebnis, das von geringem Interesse war. Jedoch wäre ein Einsatz dieses Konstruktes in Krebszellen, in denen dieser Signalzweig für die Entwicklung verschiedener Malignitätskriterien bedeutsam ist, wie beispielsweise in der kolorektalen Karzinogenese (siehe unter anderem Wong et al. 2004), interessant. Dies könnte auch die DIX-Domäne als potentielles Target in der individualisierten Therapie dieser Tumoren offenlegen. 


\section{$5 \quad$ Zusammenfassung}

Mit den verbesserten Therapieoptionen des Brustkrebsprimarius steigt die Bedeutung, adäquate Wege zu finden, um auch die Fern- und Spätmetastasierung der Tumorzellen unterbinden zu können. Hierfür ist es notwendig, die Vorgänge um Tumorprogression und Metastasierung besser zu verstehen. Wnt-abhängige Signalkaskaden gelten seit langem als bedeutsam in diesem Kontext. Da Pukrop et al. 2006 den $\beta$-Catenin-abhängigen WntSignalwegen eine eher permissive Rolle in der Brustkrebsinvasion, dem PCP-Weg jedoch den aktiven Part zuweisen konnten, wollte ich in dieser Arbeit mehr über die Funktion und Bedeutung der einzelnen Wnt-Signale im Mamma-Karzinom und der Brustkrebsmetastasierung in Erfahrung bringen.

Die Untersuchungen der Brustkrebszelllinien, aber auch die Überexpressionsversuche mit ROR2 und den DVL3-Konstrukten, sowie die Analysen der zerebralen Metastasen der Brustkrebspatientinnen, demonstrieren die Komplexität der Wnt-abhängigen Signalwege. Wurde lange Zeit sehr klar zwischen „kanonischen“ und „nicht-kanonischen“ Signalwegen unterschieden, so wird zunehmend deutlich, dass eine so klare Diskriminierung, zumindest im Kontext der Krebsentstehung, nicht mehr möglich ist, da die einzelnen Spieler dieses Netzwerks sich gegenseitig stark - positiv wie auch negativ- regulieren. Eine Fehlregulation einzelner Faktoren kann zur Desintegration des gesamten Netzwerks führen.

Während im Zuge der Tumorprogression des kolorektalen Karzinoms offensichtlich eher $\beta$ Catenin fehlreguliert wird, weisen die im Kontext dieser Arbeit erhobenen Daten mehrfach darauf hin, dass $\beta$-Catenin in der Brustkrebsmetastasierung nur geringe Bedeutung zukommt. Dem gegenüber steht die hier offengelegte Aktivierung $\beta$-Catenin-unabhängiger Wege, mit Beteiligung von ROR2/JNK/c-jun und DVL nicht nur für eine morphologische Alteration der Zellen, sondern auch für die Ausprägung ihrer Fähigkeit zu Migration und Tumorzellinvasion.

Es gelang mir in dieser Arbeit, die Blockade von aktiviertem $\beta$-Catenin über die Hemmung der DIX-Domäne von DVL3 aufzuzeigen. Dies hatte zwar in diesem Kontext keine Bedeutung, könnte jedoch in der Tumorentstehung anderer Entitäten von großer Bedeutung sein.

Ich konnte zeigen, dass sowohl ROR2 als auch DVL3 Promotoren der Tumormetastasierung des Mamma-Karzinoms in vitro darstellen. Die Zusammenschau von klinisch-statistischen und experimentellen Vorergebnissen der Arbeitsgruppe und meinen Daten legt eine Übertragbarkeit der Ergebnisse auch auf die in-vivo-Verhältnisse nahe. 
Ich konnte folglich den Rezeptor ROR2 und die DEP-Domäne des Schaltproteins DVL als potentielle Angriffspunkte einer personalisierten, molekularen Brustkrebstherapie identifizieren. Die pharmakologische Entwicklung entsprechender Hemmstoffe und die Prüfung ihrer Wirksamkeit in vivo wäre ein wichtiger Praxisbezug.

Es fehlen aktuell Daten zur Funktion, Bedeutung und gegebenenfalls sich überschneidenden Aufgabenfeldern von ROR1 im Vergleich mit ROR2, genauso wie detaillierte Signalwegsanalysen von Wnt5b im Vergleich mit Wnt5a und detaillierte Untersuchungen zu den drei humanen DVL-Subtypen. Die Entwicklung und Etablierung leistungsstarker Antikörper für Forschung und Klinik ist vor allem für Wnt5b und ROR1 von hoher Bedeutung.

Die Tatsache, dass DVL3 in Hirnmetastasen von Brustkrebspatientinnen unterschiedlich stark und mit variierender Lokalisation ausgeprägt $\mathrm{zu}$ finden ist, wirft die Frage nach einer möglichen Korrelation mit verschiedenen Patientendaten wie dem rezidivfreiem Überleben, dem Vorhandensein von Lymphknoten- oder Fernmetastasen, dem Ansprechen auf verschiedene Therapiestrategien, wie beispielsweise auf den selektiven Östrogenrezeptormodulator Tamoxifen, und das Gesamtüberleben auf.

Während auf der einen Seite zunehmend mehr Detailwissen über die $\beta$-Catenin-unabhängigen Signalwege gesammelt wird, fehlt auf der anderen Seite oft die Zusammenschau der unterschiedlichen Ergebnisse im größeren Zusammenhang und die Übertragbarkeit in den klinischen Kontext. Die bessere Integration präklinischer Forschung und klinischer Entwicklung im Rahmen der translationalen Medizin hat folglich höchste Priorität. 


\section{$6 \quad$ Literaturverzeichnis}

Ahumada A, Slusarski DC, Liu X, Moon RT, Malbon CC, Wang HY (2002): Signaling of rat Frizzled-2 through phosphodiesterase and cyclic GMP. Science 298, 2006-2010

Angers S, Thorpe CJ, Biechele TL, Goldenberg SJ, Zheng N, MacCoss MJ, Moon RT (2006): The KLHL12-Cullin-3 ubiquitin ligase negatively regulates the Wnt- $\beta$-catenin pathway by targeting Dishevelled for degradation. Nature Cell Biology $\underline{8}, 348-357$

Asgharzadeh S, Pique-Regi R, Sposto R, Wang H, Yang Y, Shimada H, Matthay K, Buckley J, Ortega A, Seeger RC (2006): Prognostic significance of gene expression profiles of metastatic neuroblastomas lacking MYCN geneamplification. J Natl Cancer Inst $\underline{98}, 1193-$ 1203

Axelrod JD, Matsuno K, Artavanis-Tsakonas S, Perrimon N (1996): Interaction between Wingless and Notch signaling pathways mediated by dishevelled. Science $\underline{271}$, 1826-1832

Axelrod JD, Miller JR, Shulman JM, Moon RT, Perrimon N (1998): Differential recruitment of Dishevelled provides signaling specificity in the planar cell polarity and Wingless signaling pathways. Genes Dev 12 (16), 2610-22

Bacac M, Stamenkovic I (2008): Metastatic cancer cell. Annu Rev Pathol $\underline{3}$, 221-47

Backe J (2002): Brustkrebs beim Mann. Dtsch Arztebl 99 (17), A 1168

Baskar S, Kwong KY, Hofer T, Levy JM, Kennedy MG, Lee E, Staudt LM, Wilson WH, Wiestner A, Rader C (2008): Unique cell surface expression of receptortyrosinekinase ROR1 in humanB-cell chronic lymphocytic leukemia. Clin Cancer Res $\underline{14}$, 396-404

Bastock R, Strutt H, Strutt D (2003): Strabismus is asymmetrically localised and binds to Prickle and Dishevelled during Drosophila planar polarity patterning. Development 130, $3007-3014$

Bernhard EJ (2011): Interventions that induce modifications in the tumor microenvironment. Cancer Radiother 15 (5), 376-82

Birnboim HC, Doly J (1979): A rapid alkaline extraction procedure for screening recombinant plasmid DNA. Nucleic Acids Res $\underline{7}$ (6), 1513-23 
Bleckmann A, Siam L, Klemm F, Rietkötter E, Wegner C, Kramer F, Beissbarth T, Binder C, Stadelmann C, Pukrop T (2013): Nuclear LEF1/TCF4 correlate with poor prognosis but not with nuclear $\beta$-catenin in cerebral metastasis of lung adenocarcinomas.Clin Exp Metastasis $\underline{30}(4), 471-82$

Boutros M, Paricio N, Strutt DI, Mlodzik M (1998): Dishevelled activates JNK and discriminates between JNK pathways in planar polarity and wingless signaling. Cell $\underline{94}$ (1), 10918

Boyden SV (1962): The chemotactic effect of mixtures of antibody and antigen on polymorphonuclear leucocytes. J Exp Med 115, 453-66

Brabletz T, Jung A, Dag S, Hlubek F, Kirchner T (1999): $\beta$-catenin regulates the expression of the matrix metalloproteinase-7 in human colorectal cancer. Am J Pathol 155 , $1033-1038$

Bryja V, Schulte G, Rawal N, Grahn A, Arenas E (2007a): Wnt-5a induces Dishevelled phosphorylation and dopaminergic differentiation via a CK1-dependent mechanism. J Cell Sci $\underline{120}(4), 586-95$

Bryja V, Gradl D, Schambony A, Arenas E, Schulte G (2007b): Beta-arrestin is a necessary component of Wnt/beta-catenin signaling in vitro and in vivo. Proc Natl Acad Sci USA 17 $\underline{104}(16), 6690-5$

Cailleau R, Young R, Olivé M, Reeves WJ Jr (1974): Breast tumor cell lines from pleural effusions. J Natl Cancer Inst $\underline{53}$ (3), 661-74

Capelluto DG, Kutateladze TG, Habas R, Finkielstein CV, He X Overduin M (2002): The DIX domain targets dishevelled to actin stress fibres and vesicular membranes. Nature $\underline{419}$ (6908), 726-9

Chaffer CL, Weinberg RA (2011): A perspective on cancer cell metastasis. Science $\underline{331}$, $1559-1564$

Chang C, Chao C, Xia W, Yang J, Xiong Y, Li C, Yu W, Rehman SK, Hsu JL, Lee H et al. (2011): p53 regulates epithelial-mesenchymal transition (EMT) and stem cell properties through modulating miRNAs. Nat Cell Biol 13 (3), 317-323 
Chang W, Lloyd CE, Zarkower D (2005): DSH-2 regulates asymmetric cell division in the early C. elegans somatic gonad. Mech Dev $\underline{122}$ (6), 781-9

Chen W, Hu LA, Semenov MV, Yanagawa S, Kikuchi A, Lefkowitz RJ, Miller WE (2001): $\beta$-Arrestin1 modulates lymphoid enhancer factor transcriptional activity through interaction with phosphorylated dishevelled proteins. Proc Natl Acad Sci USA 98 (26), 14889-94

Chen W, ten Berge D, Brown J, Ahn S, Hu LA, Miller WE, Caron MG, Barak LS, Nusse R, Lefkowitz RJ (2003): Dishevelled 2 recruits beta-arrestin 2 to mediate Wnt5A-stimulated endocytosis of Frizzled 4. Science 301 (5638), 1391-4

Cheyette BN, Waxman JS, Miller JR, Takemaru K, Sheldahl LC, Khlebtsova N, Fox EP, Earnest T, Moon RT (2002): Dapper, a Dishevelled-associated antagonist of beta-catenin and JNK signaling, is required for notochord formation. Dev Cell $\underline{2}$ (4), 449-61

Chevallier B, Fumoleau P, Kerbrat P, Dieras V, Roche H, Krakowski I, Azli N, Bayssas M, Lentz MA, Van Glabbeke M (1995): Docetaxel is a major cytotoxic drug for the treatment of advanced breast cancer: a phase II trial of the Clinical Screening Cooperative Group of the European Organization for Research and Treatment of Cancer. J Clin Oncol 13 (2), 314-22

Choudhury A, Derkow K, Daneshmanesh AH, Mikaelsson E, Kiaii S, Kokhaei P, Osterborg A, Mellstedt H (2010): Silencing of ROR1 and FMOD with siRNA results in apoptosis of CLL cells. Br J Haematol 151, 327-335

Clevers H (2006): Wnt/ $\beta$-catenin signaling in development and disease. Cell 127, 469-480

Cong F, Schweizer L, Varmus H (2004): Wnt signals across the plasma membrane to activate the -catenin pathway by forming oligomers containing its receptors, Frizzled and LRP. Development 131, 5103-5115

Consonni SV, Maurice MM, Bos JL (2014): DEP domains: structurally similar but functionally different. Nat Rev Mol Cell Biol 15 (5), 357-62

Couso JP, Bishop SA, Martinez Arias A (1994): The wingless signalling pathway and the patterning of the wing margin in Drosophila. Development 120, 621-636 
Cui B, Widhopf GF II, Martinez JYD, Avery E, Zhang S, Chen L, Wu R, Wu CCN, Prussak C, Kipps TJ (2011) : Targeting of chronic lymphocytic leukemia B cells with a novel monoclonal antibody to ror1 blood. ASH Annual Meeting Abstracts $\underline{118}, 984$

Cui B, Zhang S, Chen L, Yu J, Widhopf GF 2nd, Fecteau JF, Rassenti LZ, Kipps TJ (2013): Targeting ROR1 Inhibits Epithelial-Mesenchymal Transition and Metastasis. Cancer Res $\underline{73}$ (12), 3649-60

Dissanayake SK, Wade M, Johnson CE, O'Connell MP, Leotlela PD, French AD, Shah KV, Hewitt KJ, Rosenthal DT, Indig FE (2007): The Wnt5A/protein kinase C pathway mediates motility in melanoma cells via the inhibition of metastasis suppressors and initiation of an epithelial to mesenchymal transition. J Biol Chem $\underline{282}$, 17259-71

Early Breast Cancer Trialists' Collaborative Group (EBCTCG), Peto R, Davies C, Godwin J, Gray R, Pan HC, Clarke M, Cutter D, Darby S, McGale P et al. (2012): Comparisons between different polychemotherapy regimens for early breast cancer: metaanalyses of long-term outcome among 100,000 women in 123 randomised trials. Lancet $\underline{379}$ (9814), 432-44

Edris B, Espinosa I, Mühlenberg T, Mikels A, Lee CH, Steigen SE, Zhu S, Montgomery KD, Lazar AJ, Lev D et al. (2012): ROR2 is a novel prognostic biomarker and a potential therapeutic target in leiomyosarcoma and gastrointestinal stromal tumour. J Pathol 227 (2), 223-33

Enomoto M, Hayakawa S, Itsukushima S, Ren DY, Matsuo M, Tamada K, Oneyama C, Okada M, Takumi T, Nishita M et al. (2009): Autonomous regulation of osteosarcoma cell invasiveness by Wnt5a/Ror2 signaling. Oncogene 28 (36), 3197-208

Fahmy OG, Fahmy M (1959): New mutant report. Dros Inf Serv $\underline{33}, 85$

Fan S, Ramirez SH, Garcia TM, Dewhurst S (2004): Dishevelled promotes neurite outgrowth in neuronal differentiating neuroblastoma 2A cells, via a DIX-domain dependent pathway. Brain Res Mol Brain Res 132 (1), 38-50

Faux MC, Coates JL, Catimel B, Cody S, Clayton AH, Layton MJ, Burgess AW (2008): Recruitment of adenomatous polyposis coli and beta-catenin to axin-puncta. Oncogene 27 (44), 5808-20 
Fidler IJ (1970): Metastasis: guantitative analysis of distribution and fate of tumor embolilabeled with 125 I-5-iodo-2'-deoxyuridine. J Natl Cancer Inst $\underline{45}$, 773-782

Fidler IJ (2002): The pathogenesis of cancer metastasis: the 'seed and soil' hypothesis revisited. Nat Rev Cancer $\underline{3}$ (6), 453-8

Fiedler M, Mendoza-Topaz C, Rutherford TJ, Mieszczanek J, Bienz M (2011): Dishevelled interacts with the DIX domain polymerization interface of Axin to interfere with its function in down-regulating $\beta$-catenin. Proc Natl Acad Sci USA 108 (5), 1937-42

Forrester WC1, Dell M, Perens E, Garriga G (1999): A C. elegans Ror receptor tyrosine kinase regulates cell motility and asymmetric cell division. Nature $\underline{400}$ (6747), 881-5

Friedl P, Gilmour D (2009): Collective cell migration in morphogenesis, regeneration and cancer. Nat Rev Mol Cell Biol 10, 445-457

Fukuda T, Chen L, Endo T, Tang L, Lu D, Castro JE, Widhopf GF 2nd, Rassenti LZ, Cantwell MJ, Prussak CE et al. (2008): Antisera induced by infusions of autologous AdCD154-leukemia B cells identify ROR1 as an oncofetal antigen and receptor for Wnt5a. Proc Natl Acad Sci USA 105, 3047-3052

Gan XQ, Wang JY, Xi Y, Wu ZL, Li YP, Li L (2008): Nuclear Dvl, c-Jun, beta-catenin, and TCF form a complex leading to stabilization of betacatenin-TCF interaction. J Cell Biol $\underline{180}, 1087-1100$

Gentile A, Lazzari L, Benvenuti S, Trusolino L, Comoglio PM (2011): Ror1 is a pseudokinase that is crucial for Met-driven tumorigenesis. Cancer Res $\underline{71}$, 3132-3141

Gloy J, Hikasa H, Sokol SY (2002): Frodo interacts with Dishevelled to transduce Wnt signals. Nat Cell Biol $\underline{4}, 351-357$

Goldhirsch A, Wood WC, Gelber RD, Coates AS, Thürlimann B, Senn HJ (2007): Progress and promise: highlights of the international expert consensus on the primary therapy of early breast cancer. Ann Oncol 18 (7), 1133-44

Goodrich LV (2008): The plane facts of PCP in the CNS. Neuron $\underline{60}$, 9-16 
Gordon MD, Nusse R (2006): Wnt signaling: multiple pathways, multiple receptors, and multiple transcription factors. J Biol Chem $\underline{281}$ (32), 22429-33

Gradl D, Kühl M, Wedlich D (1999): The Wnt/Wg signal transducer beta-catenin controls fibronectin expression. Mol Cell Biol $\underline{19}$, 5576-5587

Green JL, Kuntz SG, Sternberg PW (2008): Ror receptor tyrosine kinases: orphans no more. Trends Cell Biol $\underline{18}, 536-544$

Grigoryan T, Wend P, Klaus A, Birchmeier W (2008): Deciphering the function of canonical Wnt signals in development and disease: conditional loss- and gain-of-function mutations of beta-catenin in mice. Genes Dev 22 (17), 2308-41

Grumolato L, Liu G, Mong P, Mudbhary R, Biswas R, Arroyave R, Vijayakumar S, Economides AN, Aaronson SA (2010): Canonical and noncanonical Wnts use a common mechanism to activate completely unrelated coreceptors. Genes Dev $\underline{24}$ (22), 2517-30

Gupta GP, Massagué J (2006): Cancer metastasis: building a framework. Cell 127 (4), 67995

Habas R, Dawid IB (2005): Dishevelled and Wnt signaling: is the nucleus the final frontier? J Biol $\underline{4}(1), 2$

Habu M, Koyama H, Kishida M, Kamino M, Iijima M, Fuchigami T, Tokimura H, Ueda M, Tokudome M, Koriyama C et al. (2014): Ryk is essential for Wnt-5a-dependent invasiveness in human glioma. J Biochem $\underline{156}$ (1), 29-38

Hagemann T, Robinson SC, Schulz M, Trumper L, Balkwill FR, Binder C (2004): Enhanced invasiveness of breast cancer cell lines upon co-cultivation with macrophages is due to TNF-alpha dependent up-regulation of matrix metalloproteases. Carcinogenesis $\underline{25}$, $1543-1549$

Hagemann T, Wilson J, Kulbe H, Li NF, Leinster DA, Charles K, Klemm F, Pukrop T, Binder C, Balkwill FR (2005): Macrophages induce invasiveness of epithelial cancer cells via NF-kappa B and JNK. J Immunol 175 (2), 1197-205

Hanahan D (1983): Studies on transformation of Escherichia coli with plasmids. Journal of molecular biology $\underline{166}, 557-580$ 
Hanahan D, Weinberg RA (2000): The hallmarks of cancer. Cell 100, 57-70

Hanahan D, Weinberg RA (2011): Hallmarks of cancer: the next generation. Cell 144, 64674

He F, Xiong W, Yu X, Espinoza-Lewis R, Liu C, Gu S, Nishita M, Suzuki K, Yamada G, Minami Y et al. (2008): Wnt5a regulates directional cell migration and cell proliferation via Ror2-mediated noncanonical pathway in mammalian palate development. Development $\underline{135}$ (23), 3871-9

He TC, Sparks AB, Rago C, Hermeking H, Zawel L, da Costa LT, Morin PJ, Vogelstein B, Kinzler KW (1998): Identification of c-MYC as a target of the APC pathway. Science $\underline{281}, 1509-1512$

He X, Semenov M, Tamai K, Zeng X (2004): LDL receptor-related proteins 5 and 6 in Wnt/beta-catenin signaling: arrows point the way. Development 131 (8), 1663-77

Hino S, Kishida S, Michiue T, Fukui A, Sakamoto I, Takada S, Asashima M, Kikuchi A (2001): Inhibition of the Wnt signaling pathway by Idax, a novel Dvl-binding protein. Mol Cell Biol 21, 330-342

Hocevar BA, Mou F, Rennolds JL, Morris SM, Cooper JA, Howe PH (2003): Regulation of the Wnt signaling pathway by disabled-2 (Dab2). EMBO J 22 (12), 3084-94

Hsu W, Zeng L, Costantini F (1999): Identification of a domain of Axin that binds to the serine/threonine protein phosphatase $2 \mathrm{~A}$ and a self-binding domain. J Biol Chem 274 (6), $3439-45$

Inobe M, Katsube Ki, Miyagoe Y, Nabeshima Yi, Takeda S (1999): Identification of EPS8 as a Dvl1-associated molecule. Biochem Biophys Res Commun 266 (1), 216-21

Itoh K, Antipova A, Ratcliffe MJ, Sokol S (2000): Interaction of dishevelled and Xenopus axin-related protein is required for wnt signal transduction. Mol Cell Biol 20, 2228-2238

Itoh K, Brott BK, Bae GU, Ratcliffe MJ and Sokol SY (2005): Nuclear localization is required for Dishevelled function in Wnt/beta-catenin signaling. J Biol $\underline{4}$ (1), 3

Jenny A, Reynolds-Kenneally J, Das G, Burnett M, Mlodzik M (2005): Diego and Prickle 
regulate Frizzled planar cell polarity signalling by competing for Dishevelled binding. Nat Cell Biol ㅁ, 691-697

Jessen JR, Topczewski J, Bingham S, Sepich DS, Marlow F, Chandrasekhar A, SolnicaKrezel L (2002): Zebrafish trilobite identifies new roles for Strabismus in gastrulation and neuronal movements. Nat Cell Biol 4, 610-615

Jones C, Chen P (2007): Planar cell polarity signaling in vertebrates. Bioessays $\underline{29}$, 120-132

Joyce JA, Pollard JW (2009): Microenvironmental regulation of metastasis. Nature reviews Cancer $\underline{9}, 239-252$

Julius MA, Schelbert B, Hsu W, Fitzpatrick E, Jho E, Fagotto F, Costantini F, Kitajewski J (2000): Domains of axin and disheveled required for interaction and function in wnt signaling. Biochem Biophys Res Commun 276, 1162-1169

Jung H, Kim BG, Han WH, Lee JH, Cho JY, Park WS, Maurice MM, Han JK, Lee MJ, Finley D et al. (2013): Deubiquitination of dishevelled by Usp14 is required for Wnt signaling. Oncogenesis $\underline{2}, 64$

Kafka A, Bašić-Kinda S, Pećina-Šlaus N (2014): The cellular story of dishevelleds. Croat Med J $\underline{55}$ (5), 459-467

Kalluri R, Weinberg RA (2009): The basics of epithelial-mesenchymal transition. J Clin Invest $\underline{119}$ (6), 1420-1428

Kang Y, He W, Tulley S, Gupta GP, Serganova I, Chen CR, Manova-Todorova K, Blasberg R, Gerald WL, Massagué J (2005): Breast cancer bone metastasis mediated by the Smad tumor suppressor pathway. Proc Natl Acad Sci USA 102 (39), 13909-14

Kani S, Oishi I, Yamamoto H, Yoda A, Suzuki H, Nomachi A, Iozumi K, Nishita M, Kikuchi A, Takumi T et al. (2004): The receptor tyrosine kinase Ror2 associates with and is activated by casein kinase Iepsilon. J Biol Chem $\underline{279}$, 50102-50109

Katoh M (2005): Wnt/PCP signaling pathway and human cancer (review). Oncol Rep 14 (6), 1583-8

Khayat D, Antoine E (1997): Docetaxel in combination chemotherapy for metastatic breast 
cancer. Semin Oncol 24 (4 Suppl 13), S13-19 -S13-26

Kikuchi A, Yamamoto H, Sato A, Matsumoto S (2012): Wnt5a: its signalling, functions and implication in diseases. Acta Physiol (Oxf) 204 (1), 17-33

Kim MJ, Chia IV, Costantini F (2008): SUMOylation target sites at the C terminus protect Axin from ubiquitination and confer protein stability. FASEB J 22 (11), 3785-94

Kinoshita N, Iioka H, Miyakoshi A, Ueno N (2003): PKC delta is essential for Dishevelled function in a noncanonical Wnt pathway that regulates Xenopus convergent extension movements. Genes Dev $\underline{17}, 1663-1676$

Kishida S, Yamamoto H, Hino S, Ikeda S, Kishida M, Kikuchi A (1999): DIX domains of Dvl and axin are necessary for protein interactions and their ability to regulate beta-catenin stability. Mol Cell Biol $\underline{19}$ (6), 4414-22

Kishida S, Hamao K, Inoue M, Hasegawa M, Matsuura Y, Mikoshiba K, Fukuda M, Kikuchi A (2007): Dvl regulates endo- and exocytotic processes through binding to synaptotagmin. Genes Cells $\underline{12}$ (1), 49-61

Klemm F, Bleckmann A, Siam L, Chuang HN, Rietkötter E, Behme D, Schulz M, Schaffrinski M, Schindler S, Trümper L et al. (2011): $\beta$-catenin-independent Wnt signaling in basal-like breast cancer and brain metastasis. Carcinogenesis 32 (3), 434-42

Klingensmith J, Yang Y, Axelrod JD, Beier DR, Perrimon N, Sussman DJ (1996): Conservation of dishevelled structure and function between flies and mice: isolation and characterization of Dv12. Mech Dev $\underline{58}, 15-26$

Kobayashi M, Shibuya Y, Takeuchi J, Murata M, Suzuki H, Yokoo S, Umeda M, Minami Y, Komori T (2009): Ror2 expression in squamous cell carcinoma and epithelial dysplasia of the oral cavity. Oral Surg Oral Med Oral Pathol Oral Radiol Endod 107, 398-406

Kohn AD, Moon RT (2005): Wnt and calcium signaling: $\beta$-catenin-independent pathways. Cell Calcium $\underline{38}, 439-46$

Krasnow RE, Wong LL, Adler PN (1995): Dishevelled is a component of the frizzled signaling pathway in Drosophila. Development 121, 4095-4102 
Krebs in Deutschland 2009/2010. 9. Ausgabe. Robert Koch-Institut und die Gesellschaft der epidemiologischen Krebsregister in Deutschland e.V. (Hrsg.). Berlin 2013

Kuhl M, Sheldahl LC, Malbon CC, Moon RT (2000a): Ca2+/calmodulin-dependent protein kinase II is stimulated by Wnt and Frizzled homologs and promotes ventral cell fates in Xenopus. J Biol Chem 275, 12701-12711

Kuhl M, Sheldahl LC, Park M, Miller JR, Moon RT (2000b): The Wnt/Ca2+ pathway: a new vertebrate Wnt signaling pathway takes shape. Trends Genet 16, 279-283

Kurayoshi M, Oue N, Yamamoto H, Kishida M, Inoue A, Asahara T, Yasui W, Kikuchi A (2006): Expression of Wnt-5a is correlated with aggressiveness of gastric cancer by stimulating cell migration and invasion. Cancer Res $\underline{66}$, 10439-10448

Kwan HT, Chan DW, Cai PC, Mak CS, Yung MM, Leung TH, Wong OG, Cheung AN, Ngan HY (2013): AMPK activators suppress cervical cancer cell growth through inhibition of DVL3 mediated Wnt/ $\beta$-catenin signaling activity. PLoS One $\underline{8}(1), 53597$

Laemmli UK (1970): Cleavage of structural proteins during the assembly of the head of bacteriophage T4. Nature 227, 680-685

Langley RR, Fidler IJ (2011): The seed and soil hypothesis revisited-The role of tumorstroma interactions in metastasis to different organs. Int J Cancer 128, 2527-2535

Lee SE, Lim SD, Kang SY, Suh SB, Suh YL (2012): Prognostic Significance of ROR2 and Wnt5a Expression in Medulloblastoma. Brain Pathology 23, 445-453

Lee YN, Gao Y, Wang HY (2008): Differential mediation of the Wnt canonical pathway by mammalian Dishevelleds-1, -2, and -3. Cell Signal 20 (2), 443-52

Lee YT (1983): Breast carcinoma: pattern of metastasis at autopsy. J Surg Oncol 23, 175-180

Leek RD, Lewis CE, Whitehouse R, Greenall M, Clarke J, Harris AL (1996): Association of macrophage infiltration with angiogenesis and prognosis in invasive breast carcinoma. Cancer Res $\underline{56}$, 4625-4629

Li L, Yuan H, Weaver CD, Mao J, Farr GH 3rd, Sussman DJ, Jonkers J, Kimelman D, Wu D (1999): Axin and Frat1 interact with dvl and GSK, bridging Dvl to GSK in Wnt- 
mediated regulation of LEF-1. EMBO J 18 (15), 4233-40

Li X, Yamagata K, Nishita M, Endo M, Arfian N, Rikitake Y, Emoto N, Hirata K, Tanaka Y, Minami Y (2013): Activation of Wnt5a-Ror2 signaling associated with epithelialto-mesenchymal transition of tubular epithelial cells during renal fibrosis. Genes Cells $\underline{18}$ (7), 608-19

Liu Y, Rubin B, Bodine PV, Billiard J (2008): Wnt5a induces homodimerization and activation of Ror2 receptor tyrosine kinase. J Cell Biochem 105, 497-502

Llense F, Martín-Blanco E (2008): JNK signaling controls border cell cluster integrity and collective cell migration. Curr Biol 18 (7), 538-44

Logan CY, Nusse R (2004): The Wnt signaling pathway in development and disease. Annu Rev Cell Dev Biol 20, 781-810

Loh YN, Hedditch EL, Baker LA, Jary E, Ward RL, Ford CE (2013): The Wnt signalling pathway is upregulated in an in vitro model of acquired tamoxifen resistant breast cancer. BMC Cancer $\underline{13}, 174$

Lou Y, Preobrazhenska O, auf dem Keller U, Sutcliffe M, Barclay L, McDonald PC, Roskelley C, Overall CM, Dedhar S (2008): Epithelial-mesenchymal transition (EMT) is not sufficient for spontaneous murine breast cancer metastasis. Dev Dyn 237 (10), 2755-68

Lowry OH, Rosebrough NJ, Farr AL, Randall RJ (1951): Protein measurement with the Folin phenol reagent. J Biol Chem 193 (1), 265-75

Luo ZG, Wang Q, Zhou JZ, Wang J, Luo Z, Liu M, He X, Wynshaw-Boris A, Xiong W C, Lu B et al. (2002): Regulation of AChR clustering by Dishevelled interacting with MuSK and PAK1. Neuron $\underline{35}, 489-505$

Ma L, Wang HY (2006): Suppression of cyclic GMP-dependent protein kinase is essential to the Wnt/cGMP/Ca2+ pathway. J Biol Chem 281, 30990-31001

MacDonald BT, Tamai K, He X (2009): Wnt/beta-catenin signaling: components, mechanisms, and diseases. Dev Cell $\underline{17}$ (1), 9-26

MacMillan CD, Leong HS, Dales DW, Robertson AE, Lewis JD, Chambers AF, Tuck 
AB (2014): Stage of breast cancer progression influences cellular response to activation of the Wnt/planar cell polarity pathway. Sci Rep $\underline{4}, 6315$

Maeda K, Kobayashi Y, Udagawa N, Uehara S, Ishihara A, Mizoguchi T, Kikuchi Y, Takada I, Kato S, Kani S et al. (2012): Wnt5a-Ror2 signaling between osteoblastlineage cells and osteoclast precursors enhances osteoclastogenesis. Nat Med $\underline{18}, 405-12$

Mamidi A, Inui M, Manfrin A, Soligo S, Enzo E, Aragona M, Cordenonsi M, Wessely O, Dupont S, Piccolo S (2012): Signaling crosstalk between TGF $\beta$ and Dishevelled/Parlb. Cell Death Differ $\underline{19}$ (10), 1689-97

Mani SA, Guo W, Liao MJ, Eaton NE, Ayyanan A, Zhou AY, Brooks M, Reinhard F, Zhang, Shipitsin M et al. (2008): The Epithelial-Mesenchymal Transition Generates Cells with Properties of Stem Cells. Cell 133 (4), 704-715

Matsumoto S, Fumoto K, Okamoto T, Kaibuchi K, Kikuchi A (2010): Binding of APC and dishevelled mediates Wnt5a-regulated focal adhesion dynamics in migrating cells. EMBO J 29 (7), 1192-204

Medina A, Reintsch W, Steinbeisser H (2000): Xenopus frizzled 7 can act in canonical and non-canonical Wnt signaling pathways: implications on early patterning and morphogenesis. Mech Dev $\underline{92}, 227-237$

Menck K, Klemm F, Gross JC, Pukrop T, Wenzel D, Binder C (2013): Induction and transport of Wnt 5a during macrophage-induced malignant invasion is mediated by two types of extracellular vesicles. Oncotarget $\underline{4}$ (11), 2057-66

Micalizzi Ds, Farabaugh SM, Ford HL (2010): Epithelial-Mesenchymal Transition in Cancer: Parallels between Normal Development and Tumor Progression. J Mammary Gland Biol Neoplasia $\underline{15}, 117-134$

Mikels AJ, Nusse R (2006a): Wnts as ligands: processing, secretion and reception. Oncogene $\underline{25}, 7461-7468$

Mikels AJ, Nusse R (2006b): Purified Wnt5a protein activates or inhibits beta-catenin-TCF signaling depending on receptor context. PLoS Biol $\underline{4}, 570-582$ 
Mikels A, Minami Y, Nusse R (2009): Ror2 receptor requires tyrosine kinase activity to mediate Wnt5A signaling. J Biol Chem 284, 30167-30176

Miller JR, Rowning BA, Larabell CA, Yang-Snyder JA, Bates RL, Moon RT (1999): Establishment of the dorsal-ventral axis in Xenopus embryos coincides with the dorsal enrichment of dishevelled that is dependent on cortical rotation. J Cell Biol 146 (2), 427-37

Miyakoshi A, Ueno N, Kinoshita N (2004): Rho guanine nucleotide exchange factor xNET1 implicated in gastrulation movements during Xenopus development. Differentiation 72, 48-55

Moriguchi T, Kawachi K, Kamakura S, Masuyama N, Yamanaka H, Matsumoto K, Kikuchi A, Nishida E (1999): Distinct domains of mouse dishevelled are responsible for the c-Jun N-terminal kinase/stress-activated protein kinase activation and the axis formation in vertebrates. J Biol Chem 274, 30957-30962

Morioka K, Tanikawa C, Ochi K, Daigo Y, Katagiri T, Kawano H, Kawaguchi H, Myoui A, Yoshikawa H, Naka N et al. (2009): Orphanreceptor tyrosine kinase ROR2 as a potential therapeutic target for osteosarcoma. Cancer Sci 100, 1227-1233

Mosmann T (1983): Rapid colorimetric assay for cellular growth and survival: application to proliferation and cytotoxicity assays. J Immunol Methods $\underline{65}$ (1-2), 55-63

Mullis K, Faloona F, Scharf S, Saiki R, Horn G, Erlich H (1986): Specific enzymatic amplification of DNA in vitro: the polymerase chain reaction. Cold Spring Harbor symposia on quantitative biology $\underline{51,263-273}$

Nateri AS, Spencer-Dene B, Behrens A (2005): Interaction of phosphorylated c-Jun with TCF4 regulates intestinal cancer development. Nature 437, 281-285

Nikolaou K, Sarris M, Talianidis I (2013): Molecular pathways: the complex roles of inflammation pathways in the development and treatment of liver cancer. Clin Cancer Res 19 (11), 2810-6

Nishita M, Yoo SK, Nomachi A, Kani S, Sougawa N, Ohta Y, Takada S, Kikuchi A, Minami Y (2006): Filopodia formation mediated by receptor tyrosine kinase Ror2 is required for Wnt5a-induced cell migration. J Cell Biol 175 (4), 555-62 
Nishita M, Enomoto M, Yamagata K, Minami Y (2010a): Cell/tissue-tropic functions of Wnt5a signaling in normal and cancer cells. Trends Cell Biol 20, 346-354

Nishita M, Itsukushima S, Nomachi A, Endo M, Wang Z, Inaba D, Qiao S, Takada S, Kikuchi A, Minami Y (2010b): Ror2/Frizzled complex mediates Wnt5a-induced AP-1 activation by regulating Dishevelled polymerization. Mol Cell Biol 30 (14), 3610-9

Nomachi A, Nishita M, Inaba D, Enomoto M, Hamasaki M, Minami Y (2008): Receptor tyrosine kinase Ror2 mediates Wnt5a-induced polarized cell migration by activating c-Jun Nterminal kinase via actin-binding protein filamin A. J Biol Chem $\underline{283}$ (41), 27973-81

Noordermeer J, Klingensmith J, Perrimon N, Nusse R (1994): dishevelled and armadillo act in the wingless signalling pathway in Drosophila. Nature $\underline{367}, 80-83$

Nubler-Jung K (1987): Insect epidermis: disturbance of supracellular tissue polarity does not prevent the expression of cell polarity. Dev Genes Evol 196, 286-9

Nusse R (2005): Wnt signaling in disease and development. Cell Res $\underline{15}, 28-32$

Nüsslein-Volhard C, Wieschaus E (1980): Mutations affecting segment number and polarity in Drosophila. Nature 287, 795-801

O'Connell MP, Fiori JL, Xu M, Carter AD, Frank BP, Camilli TC, French AD, Dissanayake SK, Indig FE, Bernier M et al. (2010): The orphan tyrosine kinase receptor, ROR2, mediates Wnt5A signaling in metastatic melanoma. Oncogene 29, 34-44

Oishi I, Suzuki H, Onishi N, Takada R, Kani S, Ohkawara B, Koshida I, Suzuki K, Yamada G, Schwabe GC et al. (2003): The receptor tyrosine kinase Ror2 is involved in noncanonical Wnt5a/JNK signalling pathway. Genes Cells $\underline{8}$ (7), 645-54

Oshita A, Kishida S, Kobayashi H, Michiue T, Asahara T, Asashima M, Kikuchi A (2003): Identification and characterization of a novel Dvl-binding protein that suppresses Wnt signalling pathway. Genes Cells $\underline{8}, 1005-1017$

Ossipova O, Dhawan S, Sokol S, Green JB (2005): Distinct PAR-1 proteins function in different branches of Wnt signaling during vertebrate development. Dev Cell $\underline{8}, 829-841$

Paget S (1889): The distribution of secondary growths in cancer of the breast. Lancet $\underline{1}, 571$ - 
Pan WJ, Pang SZ, Huang T, Guo HY, Wu D and Li L (2004): Characterization of function of three domains in dishevelled-1: DEP domain is responsible for membrane translocation of dishevelled-1. Cell Res 14 (4), 324-30

Pandur P, Maurus D, Kühl M (2002): Increasingly complex: new players enter the Wnt signaling network. Bioessays $\underline{24}(10), 881-4$

Park M, Moon RT (2002): The planar cell-polarity gene stbm regulates cell behaviour and cell fate in vertebrate embryos. Nat Cell Biol $\underline{4}, 20-25$

Peinado H, Olmeda D, Cano A (2007): Snail, Zeb and bHLH factors in tumour progression: an alliance against the epithelial phenotype? Nat Rev Cancer $\underline{7}$ (6), 415-428

Perrimon N, Mahowald AP (1987): Multiple functions of segment polarity genes in Drosophila. Dev Biol 119, 587-600

Peters JM, McKay RM, McKay JP, Graff JM (1999): Casein kinase I transduces Wnt signals. Nature $\underline{401}, 345-350$

Pizzuti A, Amati F, Calabrese G, Mari A, Colosimo A, Silani V, Giardino L, Ratti A, Penso D, Calza L (1996): cDNA characterization and chromosomal mapping of two human homologues of the Drosophila dishevelled polarity gene. Hum Mol Genet $\underline{5}$, 953-958

Pukrop T, Binder C (2008): The complex pathways of Wnt 5a in cancer progression. J Mol Med $\underline{86}(3), 259-66$

Pukrop T, Klemm F, Hagemann T, Gradl D, Schulz M, Siemes S, Trumper L, Binder C (2006): Wnt 5a signaling is critical for macrophage-induced invasion of breast cancer cell lines. Proc Natl Acad Sci USA 103 (14), 5454-9

Pukrop T, Dehghani F, Chuang HN, Lohaus R, Bayanga K, Heermann S, Regen T, Van Rossum D, Klemm F, Schulz M et al. (2010): Microglia promote colonization of brain tissue by breast cancer cells in a Wnt-dependent way. Glia $\underline{58}$ (12), 1477-89

Rabbani H, Ostadkarampour M, Danesh Manesh AH, Basiri A, Jeddi-Tehrani M, Forouzesh F (2010): Expression of ROR1 in patients with renal cancer -a potential 
diagnostic marker. Iran Biomed J 14, 77-82

Ratcliffe MJ, Itoh K, Sokol SY (2000): A positive role for the PP2A catalytic subunit in Wnt signal transduction. J Biol Chem $\underline{275}, 35680-35683$

Rebagay G, Yan S, Liu C, Cheung NK (2012): ROR1 and ROR2 in Human Malignancies: Potentials for Targeted Therapy. Front Oncol 2, 34

Reddy UR, Phatak S, Pleasure D (1996): Human neural tissues express a truncated Ror1 receptor tyrosine kinase, lacking both extracellular and transmembrane domains. Oncogene $\underline{13}(7), 1555-9$

Rietkötter E, Menck K, Bleckmann A, Farhat K, Schaffrinski M, Schulz M, Hanisch UK, Binder C, Pukrop T (2013): Zoledronic acid inhibits macrophage/microglia-assisted breast cancer cell invasion Oncotarget $\underline{4}(9), 1449-60$

Riggleman B, Schedl P, Wieschaus E (1990): Spatial expression of the Drosophila segment polarity gene armadillo is posttranscriptionally regulated by wingless. Cell $\underline{63}, 549-560$

Rijsewijk F, Schuermann M, Wagenaar E, Parren P, Weigel D, Nusse R (1987): The Drosophila homolog of the mouse mammary oncogene int-1 is identical to the segment polarity gene wingless. Cell $\underline{50}(4), 649-57$

Rothbächer U, Laurent M N, Blitz I L, Watabe T, Marsh JL, Cho KW (1995): Functional conservation of the Wnt signaling pathway revealed by ectopic expression of Drosophila dishevelled in Xenopus. Dev Biol 170, 717-721

Rothbächer U, Laurent MN, Deardorff MA, Klein PS, Cho KW, Fraser SE (2000): Dishevelled phosphorylation, subcellular localization and multimerization regulate its role in early embryogenesis. EMBO J 19 (5), 1010-22

Rousset R, Mack JA, Wharton KA Jr, Axelrod JD, Cadigan KM, Fish MP, Nusse R, Scott M P (2001): Naked cuticle targets dishevelled to antagonize Wnt signal transduction. Genes Dev 15, 658-671

Rual JF, Venkatesan K, Hao T, Hirozane-Kishikawa T, Dricot A, Li N, Berriz GF, Gibbons FD, Dreze M, Ayivi-Guedehoussou N et al. (2005): Towards a proteome-scale map of the human protein-protein interaction network. Nature $\underline{437}$ (7062), 1173-8 
Sakanaka C, Leong P, Xu L, Harrison SD, Williams LT (1999): Casein kinase iepsilon in the wnt pathway: regulation of -catenin function. Proc Natl Acad Sci USA $\underline{96}, 12548-12552$

Sambrook J, Fritsch EF, Maniatis T: Molecular Cloning.; in: A labratory manual. 2. Auflage; Cold Spring Harbor Laboratory Press, Cold Spring Harbor, New York, 1989

Savagner P (2001): Leaving the neighborhood: molecular mechanisms involved during epithelial-mesenchymal transition. Bioessays $\underline{23}$ (10), 912-23

Schambony A, Wedlich D (2007): Wnt-5A/Ror2 regulate expression of XPAPC through an alternative noncanonical signaling pathway. Dev Cell. 12 (5), 779-92

Schlange T, Matsuda Y, Lienhard S, Huber A, Hynes NE (2007): Autocrine Wnt signaling contributes to breast cancer cell proliferation via the canonical Wnt pathway and EGFR transactivation. Breast Cancer Res $\underline{9}$ (5), R63

Schlessinger J (2000): Cell signaling by receptor tyrosine kinases. Cell 103, 211-225

Schreiber E, Matthias P, Müller MM, Schaffner W (1989): Rapid detection of octamer binding proteins with 'mini-extracts', prepared from a small number of cells. Nucleic Acids Res 17 (15), 6419

Schulte G, Bryja V (2007): The Frizzled family of unconventional G-protein-coupled receptors. Trends Pharmacol Sci $\underline{28}$ (10), 518-25

Schwabe GC, Tinschert S, Buschow C, Meinecke P, Wolff G, Gillessen-Kaesbach G, Oldridge M, Wilkie AO, Kömec R, Mundlos S (2000): Distinct mutations in the receptor tyrosine kinase gene ROR2 cause brachydactyly type B. Am J Hum Genet 67, 822-31

Schwarz-Romond T, Merrifield C, Nichols BJ, Bienz M (2005): The Wnt signalling effector Dishevelled forms dynamic protein assemblies rather than stable associations with cytoplasmic vesicles. J Cell Sci 118, 5269-77

Schwarz-Romond T, Fiedler M, Shibata N, Butler PJ, Kikuchi A, Higuchi Y, Bienz M (2007): The DIX domain of Dishevelled confers Wnt signaling by dynamic polymerization. Nat Struct Mol Biol 14, 484-492

Seifert JR, Mlodzik M (2007): Frizzled/PCP signalling: a conserved mechanism regulating 
cell polarity and directed motility. Nat Rev Genet $\underline{8}, 126-138$

Semenov MV, Snyder M (1997): Human dishevelled genes constitute a DHR-containing multigene family. Genomics $\underline{42}, 302-310$

Semenov MV, Habas R, Macdonald BT, He X (2007): SnapShot: Noncanonical Wnt Signaling Pathways. Cell $\underline{131}, 1378$

Shabani M, Asgarian-Omran H, Vossough P, Sharifian RA, Faranoush M, Ghragozlou S, Khoshnoodi J, Roohi A, Jeddi-Tehrani M, Mellstedt H et al. (2008): Expression profile of orphan receptor tyrosine kinase (ROR1) andWilms' tumor gene 1 (WT1) in different subsets of B-cell acute lymphoblastic leukemia. Leuk Lymphoma 49, 1360-1367

Sheldahl LC, Park M, Malbon CC, Moon RT (1999): Protein kinase C is differentially stimulated by Wnt and Frizzled homologs in a G-protein-dependent manner. Curr Biol $\underline{9}, 695$ 698

Sheldahl LC, Slusarski DC, Pandur P, Miller JR, Kuhl M, Moon RT (2003): Dishevelled activates Ca2+ flux, PKC, and CamKII in vertebrate embryos. J Cell Biol 161, 769-777

Siegfried E, Wilder E L, Perrimon N (1994): Components of wingless signalling in Drosophila. Nature $\underline{367}, 76-80$

Simons M, Mlodzik M (2008): Planar cell polarity signaling: from fly development to human disease. Annu Rev Genet 42, 517-40

Simons M, Gault WJ, Gotthardt D, Rohatgi R, Klein TJ, Shao Y, Lee HJ, Wu AL, Fang Y, Satlin LM et al. (2009): Electrochemical cues regulate assembly of the Frizzled/Dishevelled complex at the plasma membrane during planar epithelial polarization. Nat Cell Biol 11 (3), 286-94

Slusarski DC, Pelegri F (2007): Calcium signaling in vertebrate embryonic patterning and morphogenesis. Dev Biol 307, 1-13

Slusarski DC, Corces VG, Moon RT (1997a): Interaction of Wnt and a Frizzled homologue triggers G-protein-linked phosphatidylinositol signalling. Nature $\underline{390}$, 410-413 
Slusarski DC, Yang-Snyder J, Busa WB, Moon RT (1997b): Modulation of embryonic intracellular $\mathrm{Ca}^{2+}$ signaling by Wnt-5A. Dev Biol $\underline{182}, 114-120$

Sokol SY, Klingensmith J, Perrimon N, Itoh K (1995): Dorsalizing and neuralizing properties of Xdsh, a maternally expressed Xenopus homolog of dishevelled. Development $\underline{121}$, $1637-1647$

Soule HD, Vazguez J, Long A, Albert S, Brennan M (1973): A human cell line from a pleural effusion derived from a breast carcinoma. J Natl Cancer Inst 51 (5), 1409-16

Stacker SA, Baldwin ME, Achen MG (2002): The role of tumor lymphangiogenesis in metastatic spread. Faseb J 16, 922-934

Stasinopoulos I, Penet MF, Chen Z, Kakkad S, Glunde K, Bhujwalla ZM (2011): Exploiting the tumor microenvironment for theranostic imaging. NMR Biomed 24 (6), 636-47

Strovel ET, Wu D, Sussman DJ (2000): Protein phosphatase 2C dephosphorylates axin and activates LEF-1-dependent transcription. J Biol Chem 275, 2399-2403

Sun TQ, Lu B, Feng JJ, Reinhard C, Jan YN, Fantl WJ, Williams LT (2001): PAR-1 is a Dishevelled-associated kinase and a positive regulator of Wnt signalling. Nat Cell Biol $\underline{3}$, 628-636

Sussman DJ, Klingensmith J, Salinas P, Adams PS, Nusse R, Perrimon N (1994): Isolation and characterization of a mouse homolog of the Drosophila segment polarity gene dishevelled. Dev Biol 166, 73-86

Tanaka M, Kamo T, Ota S, Sugimura H (2003): Association of Dishevelled with Eph tyrosine kinase receptor and ephrin mediates cell repulsion. EMBO J 22, 847-858

Tauriello DV, Jordens I, Kirchner K, Slootstra JW, Kruitwagen T, Bouwman BA, Noutsou M, Rüdiger SG, Schwamborn K, Schambony A, et al. (2012): Wnt/ $\beta$-catenin signaling requires interaction of the Dishevelled DEP domain and $\mathrm{C}$ terminus with a discontinuous motif in Frizzled. Proc Natl Acad Sci USA, 109 (14): E812-20

Theisen H, Purcell J, Bennett M, Kansagara D, Syed A, Marsh J L (1994): Dishevelled is required during wingless signaling to establish both cell polarity and cell identity. Development $\underline{120}, 347-360$ 
Thiery JP (2002): Epithelial-mesenchymal transitions in tumour progression. Nature reviews Cancer $2,442-454$

Thiery JP, Sleeman JP (2006): Complex networks orchestrate epithelial-mesenchymal transitions. Nature Reviews Molecular Cell Biology $\underline{7}, 131-142$

Thiery JP, Acloque H, Huang YJR, Nieto MA (2009): Epithelial-Mesenchymal Transitions in Development and Disease. Cell 139 (5), 871-890

Topol L, Jiang X, Choi H, Garrett-Beal L, Carolan PJ, Yang Y (2003): Wnt-5a inhibits the canonical Wnt pathway by promoting GSK-3-independent beta-catenin degradation. J Cell Biol 162, 899-908

Torres MA, Nelson WJ (2000): Colocalization and redistribution of dishevelled and actin during Wnt-induced mesenchymal morphogenesis. J Cell Biol 149 (7), 1433-42

Tree DR, Shulman JM, Rousset R, Scott MP, Gubb D, Axelrod JD (2002): Prickle mediates feedback amplification to generate asymmetric planar cell polarity signaling. Cell $\underline{109}$, $371-381$

Trempe GL (1976): Human breast cancer in culture. Recent Results Cancer Res. 57, 33-41

Tsang M, Lijam N, Yang Y, Beier DR, Wynshaw-Boris A, Sussman D J (1996): Isolation and characterization of mouse dishevelled-3. Dev Dyn 207, 253-262

Urano D, Nakata A, Mizuno N, Tago K, Itoh H (2008): Domain-domain interaction of PRex 1 is essential for the activation and inhibition by $G$ protein betagamma subunits and PKA. Cell Signal 20, 1545-1554

van Bokhoven H, Celli J, Kayserili H, van Beusekom E, Balci S, Brussel W, Skovby F, Kerr B, Percin EF, Akarsu N et al. (2000): Mutation of the gene encoding the ROR2 tyrosine kinase causes autosomal recessive Robinow syndrome. Nat Genet 25, 423-426

Veeman MT, Axelrod JD, Moon RT (2003): A second canon. Functions and mechanisms of beta-catenin-independent Wnt signaling. Dev Cell $\underline{5}, 367-377$

Wallingford JB, Habas R (2005) The developmental biology of Dishevelled: an enigmatic protein governing cell fate and cell polarity. Development 132, 4421-4436 
Walston T, Tuskey C, Edgar L, Hawkins N, Ellis G, Bowerman B, Wood W, Hardin J (2004): Multiple Wnt signaling pathways converge to orient the mitotic spindle in early $\mathrm{C}$. elegans embryos. Dev Cell 7 (6), 831-41

Wang Y (2009): Wnt/Planar cell polarity signaling: A new paradigm for cancer therapy. Mol Cancer Ther 8, 2103-2109

Wang Y, Wang HY (2012): Dvl3 translocates IPMK to the cell membrane in response to Wnt. Cell Signal 24 (12), 2389-95

Warner DR, Pisano MM, Roberts EA, Greene RM (2003): Identification of three novel Smad binding proteins involved in cell polarity. FEBS Lett 539 (1-3), 167-73

Weber GF (2008): Molecular mechanisms of metastasis. Cancer Lett 270 (2), 181-90

Weber U, Paricio N, Mlodzik M (2000): Jun mediates Frizzled-induced R3/R4 cell fate distinction and planar polarity determination in the Drosophila eye. Development 127, 36193629

Weeraratna AT, Jiang Y, Hostetter G, Rosenblatt K, Duray P, Bittner M, Trent JM (2002): Wnt5a signaling directly affects cell motility and invasion of metastatic melanoma. Cancer Cell $\underline{1}$ (3), 279-88

Westermarck J und Kahari VM (1999): Regulation of matrix metalloproteinase expression in tumor invasion. FASEB J 13 (8), 781-92

Wharton KA Jr, Zimmermann G, Rousset R, Scott MP (2001): Vertebrate proteins related to Drosophila Naked Cuticle bind Dishevelled and antagonize Wnt signaling. Dev Biol 234, 93-106

Willert K, Brink M, Wodarz A, Varmus H, Nusse R (1997): Casein kinase 2 associates with and phosphorylates dishevelled. EMBO J $\underline{16}$, 3089-3096

Winter CG, Wang B, Ballew A, Royou A, Karess R, Axelrod JD, Luo L (2001): Drosophila Rho-associated kinase (Drok) links Frizzled-mediated planar cell polarity signaling to the actin cytoskeleton. Cell $\underline{105}, 81-91$

Witte F, Bernatik O, Kirchner K, Masek J, Mahl A, Krejci P, Mundlos S, Schambony A, 
Bryja V, Stricker S (2010): Negative regulation of Wnt signaling mediated by CK1phosphorylated Dishevelled via Ror2. FASEB J 24 (7), 2417-26

Wolff T, Rubin GM (1998): Strabismus, a novel gene that regulates tissue polarity and cell fate decisions in Drosophila. Development 125, 1149-1159

Wong CK, Luo W, Deng Y, Zou H, Ye Z, Lin SC (2004): The DIX domain protein coiledcoil-DIX1 inhibits c-Jun Nterminal kinase activation by Axin and dishevelled through distinct mechanisms. J Biol Chem 279, 39366-39373

Wong HC, Mao J, Nguyen JT, Srinivas S, Zhang W, Liu B, Li L, Wu D and Zheng J (2000): Structural basis of the recognition of the dishevelled DEP domain in the Wnt signaling pathway. Nat Struct Biol $\underline{7}$ (12), 1178-84

Wong HC, Bourdelas A, Krauss A, Lee HJ, Shao Y, Wu D, Mlodzik M, Shi DL and Zheng J (2003): Direct binding of the PDZ domain of Dishevelled to a conserved internal sequence in the C-terminal region of Frizzled. Mol Cell $\underline{12}$ (5), 1251-60

Wong SC, Lo ES, Lee KC, Chan JK, Hsiao WL (2004): Prognostic and diagnostic significance of beta-catenin nuclear immunostaining in colorectal cancer. Clin Cancer Res $\underline{10}$, $1401-8$

Wright TM, Brannon AR, Gordan JD, Mikels AJ, Mitchell C, Chen S, Espinosa I, Van De Rijn M, Pruthi R, Wallen E et al. (2009): Ror2, a developmentally regulated kinase, promotes tumor growth potential in renal cell carcinoma. Oncogene 28, 2513-2523

Wu J, Klein TJ, Mlodzik M (2004): Subcellular localization of frizzled receptors, mediated by their cytoplasmic tails, regulates signaling pathway specificity. PLoS Biol $\underline{2}$ (7), e158

Yamagata K, Li X, Ikegaki S, Oneyama C, Okada M, Nishita M, Minami Y (2012):

Dissection of Wnt5a-Ror2 signaling leading to matrix metalloproteinase (MMP-13) expression. J Biol Chem 287 (2), 1588-99

Yamamoto H, Yoo SK, Nishita M, Kikuchi A and Minami Y (2007): Wnt5a modulates glycogen synthase kinase 3 to induce phosphorylation of receptor tyrosine kinase Ror2. Genes Cells 12 (11), 1215-23 
Yamamoto S, Nishimura O, Misaki K, Nishita M, Minami, Y, Yonemura S, Tarui H, Sasaki H (2008): Cthrc1 selectively activates the planar cell polarity pathway of Wnt signaling by stabilizing the Wnt-receptor complex. Dev Cell 15, 23-36

Yamanaka H, Moriguchi T, Masuyama N, Kusakabe M, Hanafusa H, Takada R, Takada S, Nishida E (2002): JNK functions in the non-canonical Wnt pathway to regulate convergent extension movements in vertebrates. EMBO Rep $\underline{3}$ (1), 69-75

Yanagawa S, van Leeuwen F, Wodarz A, Klingensmith J, Nusse R (1995): The dishevelled protein is modified by wingless signaling in Drosophila. Genes Dev $\underline{9}, 1087-97$

Yang J, Weinberg RA (2008): Epithelial-mesenchymal transition: at the crossroads of development and tumor metastasis. Dev Cell 14, 818-829

Yang J, Wu J, Tan C, Klein PS (2003): PP2A:B56epsilon is required for Wnt/ -catenin signaling during embryonic development. Development 130, 5569-5578

Yokoyama N, Golebiewska U, Wang HY, Malbon CC (2010): Wnt-dependent assembly of supermolecular Dishevelled-3-based complexes. J Cell Sci 123 (21), 3693-702

Yokoyama N, Markova NG, Wang HY, Malbon CC (2012): Assembly of Dishevelled 3based supermolecular complexes via phosphorylation and Axin. J Mol Signal , 8

Yost C, Farr GH 3rd, Pierce SB, Ferkey DM, Chen MM, Kimelman D (1998): GBP, an inhibitor of GSK-3, is implicated in Xenopus development and oncogenesis. Cell $\underline{93}$, 10311041

Zeng L, Fagotto F, Zhang T, Hsu W, Vasicek TJ, Perry WL 3rd, Lee JJ, Tilghman SM, Gumbiner BM, Costantini F (1997): The mouse Fused locus encodes Axin, an inhibitor of the Wnt signaling pathway that regulates embryonic axis formation. Cell $\underline{90}, 181-192$

Zhang L, Gao X, Wen J, Ning Y, Chen YG (2006): Dapper 1 antagonizes Wnt signaling by promoting dishevelled degradation. J Biol Chem 281, 8607-12

Zhang S, Chen L, Cui B, Chuang HY, Yu J, Wang-Rodriguez J, Tang L, Chen G, Basak GW, Kipps TJ (2012): ROR1 is expressed in human breast cancer and associated with enhanced tumor-cell growth. PLoS One $\underline{7}$ (3), e31127 
Zhao Y, Yang ZQ, Wang Y, Miao Y, Liu Y, Dai SD, Han Y, Wang EH (2010):

Dishevelled-1 and dishevelled-3 affect cell invasion mainly through canonical and noncanonical Wnt pathway, respectively, and associate with poor prognosis in nonsmall cell lung cancer. Mol Carcinog $\underline{49}$ (8), 760-70

\section{Internet-Quellen:}

Gendatenbank des National Center for Biotechnology Information (NCBI): http://www.ncbi.nlm.nih.gov/gene, 28.07.2013, bzw. 01.10.2014 (wie im Text angegeben). 


\section{$7 \quad$ Anhang}

\subsection{Abkürzungsverzeichnis}

\begin{tabular}{|c|c|}
\hline $\mathrm{ABC}$ & aktiviertes $\beta$-Catenin \\
\hline APS & Ammoniumpersulfat \\
\hline APC & Adenomatosis Polyposis Coli, Tumor Suppressor \\
\hline BLAST & Basic Local Alignment Search Tool \\
\hline BSA & bovines Serumalbumin \\
\hline $\mathrm{Ca}^{2+}$ & Kalzium \\
\hline $\mathrm{CaM}$ & Calmodulin \\
\hline CamKII & Ca2+/calmodulin-dependent protein kinase II \\
\hline cDNA & komplementäre DNA \\
\hline cGMP & zyklisches Guanosinmonophosphat \\
\hline $\mathrm{CI}$ & Zellindex, Cell Index \\
\hline c-jun & Jun-Onkogen \\
\hline $\mathrm{CK}$ & Casein-Kinase \\
\hline ctl & Kontrolle, control \\
\hline DAPI & 4‘,6-Diamidino-2-phenylindol \\
\hline DEP & Dishevelled/EGL-10/Pleckstrin protein \\
\hline DIX & Dishevelled-Axin-Domäne \\
\hline DMSO & Dimethylsulfidoxid \\
\hline DNA & Desoxyribonukleinsäure, desoxyribonucleic acid \\
\hline DVL & Dishevelled \\
\hline E.Coli & Escherichia coli \\
\hline ECL & verstärkte Chemilumineszenz, enhanced chemiluminescence \\
\hline ECM & extrazelluläre Matrix, extracellular matrix \\
\hline EDTA & Ethylendiamintetraacetat \\
\hline EGF & Epidermaler Wachstumsfaktor, epithelial growth factor \\
\hline EGFR & EGF-Rezptor, epithelial growth factor receptor \\
\hline EMT & Epithelial-mesenchymale Transition \\
\hline ER & Östrogenrezeptor \\
\hline FCS & fetales Kälberserum, fetal calf serum \\
\hline
\end{tabular}


FITC

fwd

$\mathrm{Fz}$

GSK

HBS

Her2

HEPES

HRP

IP3

JNK

LB

LPS

MCF-7

MMP

MTT

NES

NLS

PA

SDS-PAGE

PBS

PCP

PCR

PDZ

PFA

PIP2

PKC

rev

RNA

ROC

RT

SDS
Fluoresceinisothiocyanat

vorwärts, forward

Frizzled

Glykogensynthase-Kinase

HEPES-gepufferte Salzlösung, HEPES buffered saline

humaner, epithelialer Wachstumsfaktor-Rezeptor 2, human epidermal

growth factor receptor 2

2-(4-(2-Hydroxyethyl)-1-piperazinyl)-ethansulfonsäure

Meerrettichperoxidase, horseradish peroxidase

Inositol-1,4,5-trisphosphat

C-jun-N-terminale-Kinase

Luria-Bertani

Lipopolysaccharid

humane Mamma-Karzinomzelllinie der Michigan Cancer Foundation

Matrixmetalloproteinase

3-(4,5-Dimethylthiazol-2-yl)-2,5-diphenytetrazoliumbromid

Kernexportsignal, nuclear export signal

Kernlokalisationssignal, nuclear localisation signal

Polyacrylamid

Sodiumdodecylsulfat-Polyacrylamid-Gelelektrophorese

Phosphat-gepufferte Salzlösung, phosphate buffered saline

planare Zellpolarität, planar cell polarity

Polymerase-Kettenreaktion, polymerase chain reaction

post synaptic density Protein 95/ Discs large Septate junction Protein aus

Drosophila melanogaster/ Zonula occludentes-1 Tight junction Protein

Paraformaldehyd

Phosphatidylinositol-4,5-bisphosphat

Proteinkinase $\mathrm{C}$

rückwärts, reverse

Ribonukleinsäure, ribonucleic acid

Rho-assoziierte-Kinase

Reverse Transkription

Natriumdodecylsulfat, sodium dodecyl sulfate 
TBS-T

TEMED

TNF- $\alpha$

Tris

TRITC

UV

VEGF

wg

WHO

Wnt

wt

$\mathrm{xDsh}$

Maßeinheiten:

$\%(\mathrm{v} / \mathrm{v})$

$\%(\mathrm{w} / \mathrm{v})$

bp

rpm

V
Tris-gepufferte Kochsalzlösung (Tris-buffered saline) mit Tween 20

Tetramethylethylendiamin

Tumornekrosefaktor- $\alpha$

Tris(hydroxymethyl)-aminomethan

Tetramethylisothiocyanat

ultraviolett

Gefäßendothelwachstumsfaktor, vascular endothelial growth factor

Wingless

World Health Organization

Wingless type MMTV integration site

Wildtyp

Xenopus Dishevelled

Volumenprozent (Volumen/Volumen)

Massenprozent (Gewicht/Volumen, weight/volume)

Basenpaare

Umdrehungen pro Minute, rounds per minute

Volt 


\subsection{Abbildungsverzeichnis}

Abbildung 1.1 Übersicht über die Wnt-induzierten Signalwege und ihre Abhängigkeit von DVL und seinen Domänen. 7

Abbildung 1.2 $\beta$-Catenin-abhängiger Signalweg in Anwesenheit von Wnt............................ 8

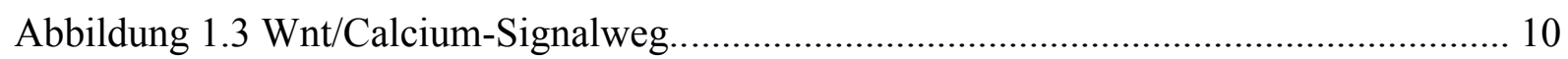

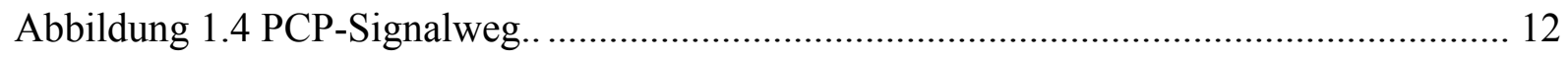

Abbildung 1.5 $\beta$-Catenin-unabhängige Signalwege über ROR........................................... 14

Abbildung 1.6 Hochkonservierte Domänen von DVL und ihre Funktionen in den Wnt-

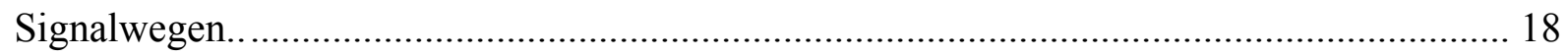

Abbildung 2.1 Übersicht über die verwendeten DVL3-Konstrukte...................................... 24

Abbildung 2.2 Beispielhafter Aufbau eines Konfrontationsassays im 2-Well-Chamberslide ${ }^{\mathrm{TM}}$..

Abbildung 3.1 Untersuchung der Mammaepithelzellinie hTERT-HME1 und der Brustkrebszellinien MCF-7, SkBr3 und MDA-MB 231 in der Echtzeit-PolymeraseKettenreaktion und im Western Blot..

Abbildung 3.2 Feststellung der Überexpression von ROR2 in den stabil transfizierten MCF-7 Brustkrebszellen im Vergleich mit der Leervektorkontrolle.

Abbildung 3.3 Untersuchung der Brustkrebszelllinien MCF-7 pcDNA und MCF-7 ROR2 im Western Blot und der qRT-PCR..

Abbildung 3.4 Funktionelle Untersuchungen der ROR2-überexprimierenden MCF-7 Brustkrebszellen.

Abbildung 3.5 Überexpression der DVL3-Konstrukte in den stabil transfizierten MCF-7 Zellen..

Abbildung 3.6 Untersuchung der mRNA-Expressionsmuster der mit DVL-Konstrukten stabil transfizierten Brustkrebszellen mittels qRT-PCR

Abbildung 3.7 Untersuchung der stabil transfizierten MCF-7-Zellen DVL3 wt, DVL3 $\triangle$ DIX, DVL3 $\triangle$ DEP und MCF-7 pcDNA (ctl) im Western Blot..

Abbildung 3.8 Untersuchung der mit DVL-Konstrukten stabil transfizierten MCF-7 Brustkrebszellen in der Immunfluoreszenz..

Abbildung 3.9 Funktionelle Untersuchungen der stabil transfizierten MCF-7 Brustkrebszellen......

Abbildung 3.10 Funktionelle Untersuchungen der stabil transfizierten MCF-7

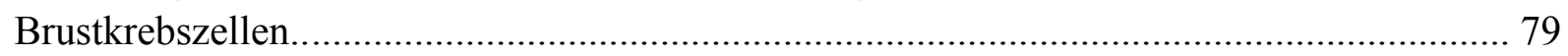

Abbildung 3.11 Auswertung des Migrationsassays DVL3 $\triangle$ PDZ $\triangle$ DEP............................. 81

Abbildung 3.12 Auswertung der Migrationsassays der stabil transfizierten MCF-7 Zellen... 82 
Abbildung 3.13 Beispielhafte Auswahl aus den mikroskopischen Aufnahmen der DVL3Hirnmetastasenfärbungen. 84

Abbildung 3.14 Auswertung der Hirnmetastasenfärbungen auf DVL3. 85

Abbildung 4.1 Theorie zur Funktionsweise der Konstrukte DVL3 $\triangle$ DIX und DVL3 $\Delta$ DIX $\triangle \mathrm{PDZ}$. 94

Abbildung 4.2 Theorien zur Entstehung und Bedeutung der dynamischen Aggregate. 102

Abbildung 4.3 Wnt-Signalwege als komplexes Netzwerk von Signalkaskaden. 108

\subsection{Tabellenverzeichnis}

Tabelle 1 Charakterisierung der Tyrosinkinase-ähnlichen Rezeptoren ROR1 und ROR2 ..... 15

Tabelle 2 Bindungspartner von Dsh. 19 


\section{Publikationen}

Ergebnisse der vorliegenden Promotion präsentierte ich auf dem Wnt Symposium: Stem Cells, Development and Disease in Heidelberg, 2013 in Form eines Posters mit dem Titel „Signaling and functional analysis of ROR overexpression in the luminal A cell line MCF-7“ (Schubert A, Klemm F, Binder C, Pukrop T).

Im April 2016 werden Ergebnisse im Rahmen des Manuskripts „ $\beta$-catenin-independent Wnt signaling and Ki67 in contrast to the estrogen receptor status are prognostic and associated with poor prognosis in breast cancer liver metastases" (Bleckmann A, Conradi LC, Menck K, Schmick NA, Schubert A, Rietkötter E, Arackal J, Middel P, Schambony A, Liersch T, et al.) im Journal Clinical \& Experimental Metastasis (33 (4), 309-323) publiziert. 


\section{Danksagung}

Prof. Dr. med. Tobias Pukrop Vielen Dank, dass du mir dieses spannende und weit gefasste Thema anvertraut, mir so viel Raum gelassen hast, selbst planend und gestalterisch tätig zu werden und die Selbstständigkeit, die dies gefördert hat. Danken möchte ich dir auch für all die Unterstützung, die du mir über den eigentlichen Rahmen dieser Doktorarbeit hinaus hast zukommen lassen. Die Einblicke in wissenschaftliches Arbeiten, Arzt- und Mensch-Sein, die ich so erhalten konnte, haben mich sehr geprägt.

Prof. Dr. med. Claudia Binder Danke für die zahlreichen wissenschaftlichen Diskussionen, Anregungen und Verbesserungsvorschläge. Durch dich habe ich gelernt, immer wieder die eigenen Ergebnisse kritisch zu hinterfragen, jedoch im entscheidenden Moment auch in der Lage zu sein, eigene Ansichten vor anderen zu verteidigen.

Dr. med. Christina Dicke und Dr. med. Florian Klemm Herzlichen Dank euch beiden für den guten Start in die Doktorarbeit. Ohne euch wäre dies nicht so unkompliziert gelungen. Dr. med. Annalen Bleckman Danke dir, für deine Hilfe mit der Statistik und die Möglichkeit, einen Teil dieser Promotion in deine klinischen Untersuchungen einzubringen.

Besonderer Dank gilt auch dem Rest des Laborteams für mannigfaltige Unterstützung über die Jahre. 


\section{Lebenslauf}

Am 02. Dezember 1988 wurde ich als Tochter von Jens Daniel und Barabara Theresia Schubert, geborene Thamm, in Dresden geboren.

Von 1999 bis 2008 besuchte ich das St. Benno-Gymnasium in Dresden. Das Schuljahr 2005/06 durfte ich als Stipendiatin des Parlamentarischen Patenschaftsprogramms des Deutschen Bundestags in Fort Worth/Dallas, Tx, USA verbringen.

Ich schloss die gymnasiale Oberstufe im Jahr 2008 mit der Allgemeinen Hochschulreife (Durchschnitt 1,1) ab.

Im folgenden Herbst nahm ich das Studium der Humanmedizin an der Georg AugustUniversität in Göttingen auf. Den ersten Abschnitt der ärztlichen Prüfung absolvierte ich im Sommer 2010 mit der Gesamtnote ,gut““ $(2,0)$.

Im Wintersemester 2011/12 wurde ich in die Deutsche Studierendenförderung durch die Konrad-Adenauer-Stiftung aufgenommen.

Den schriftlichen Teil des zweiten Staatsexamens bestand ich im Frühjahr 2014 mit der Note „gut“ (2,0), im Mai 2015 die mündlich-praktische Prüfung mit „sehr gut“( $(1,0)$.

Die Arbeiten zur vorliegenden Promotion begann ich in der Arbeitsgruppe um Prof. Dr. Tobias Pukrop und Prof. Dr. Claudia Binder im Herbst 2011, wobei ich im Wintersemester 2011/12 hierfür ein Forschungssemester nahm.

Für die bis dahin erlangten Zwischenergebnisse und zur Förderung weiterer experimenteller Arbeiten erhielt ich im Frühjahr 2012 das Stipendium „Gö4Med“ der Universitätsmedizin Göttingen.

Seit Oktober 2015 arbeite ich in der Klinik für Hämatologie und Medizinische Onkologie der Universitätsmedizin Göttingen als Assistenzärztin. 